Aus der Abteilung Humangenetik

(Prof. Dr. med. Dr. h.c. W. Engel)

im Zentrum Hygiene und Humangenetik

der Medizinischen Fakultät der Universität Göttingen

\title{
Funktionelle Analyse des keimzellspezifischen Gens ADAM 27
}

\section{INAUGURAL-DISSERTATION}

zur Erlangung des Doktorgrades

der Medizinischen Fakultät der Georg-August-Universität zu Göttingen

vorgelegt von

Christian Baldauf

aus

Schmalkalden

Göttingen 2010 
Dekan: Prof. Dr. med. C. Frömmel

I. Berichterstatter: Prof. Dr. rer. nat. K. Nayernia II. Berichterstatter/in:

III. Berichterstatter/in:

Tag der mündlichen Prüfung: 


\section{Inhaltsverzeichnis}

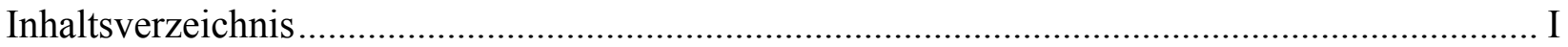

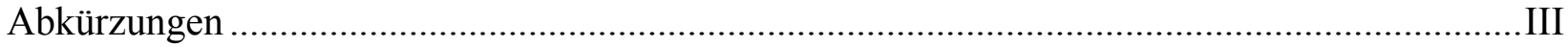

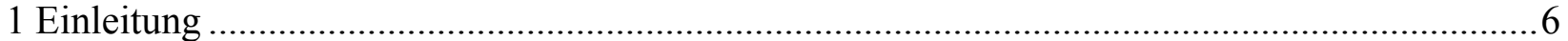

1.1 $A D A M$ (A Disintegrin and Metalloproteinase)-Gen- und Proteinfamilie ..............................6

1.2 Phänotypen verschiedener $A D A M$-Knockout-Mäuse...........................................................

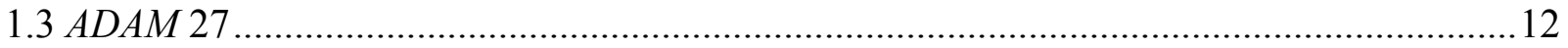

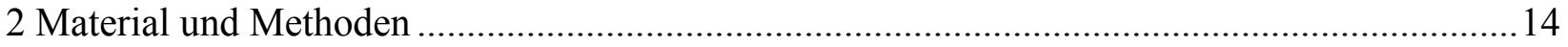

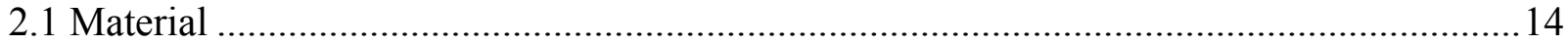

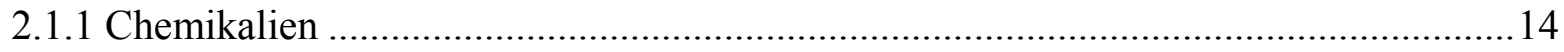

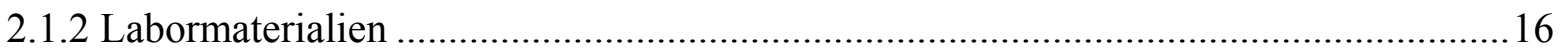

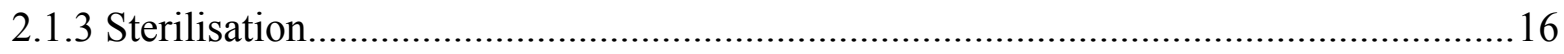

2.1.4 Puffer und Stammlösungen ............................................................................... 16

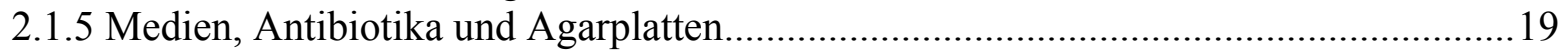

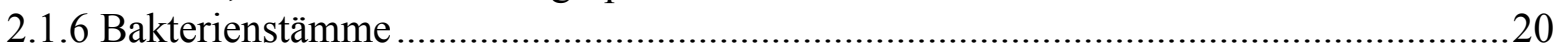

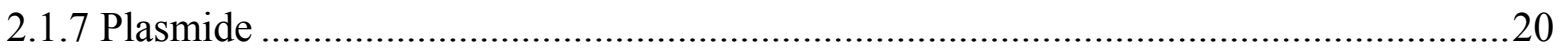

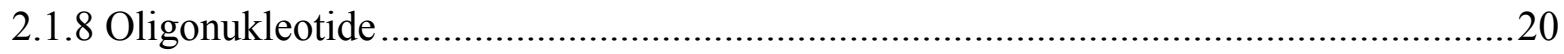

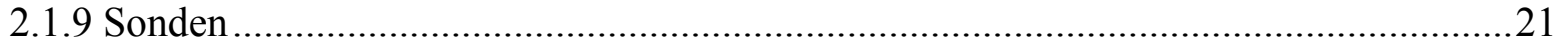

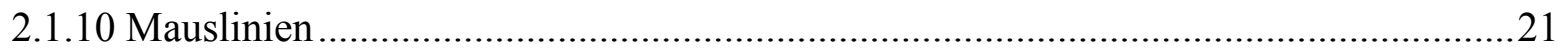

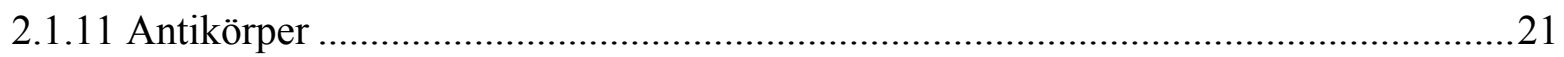

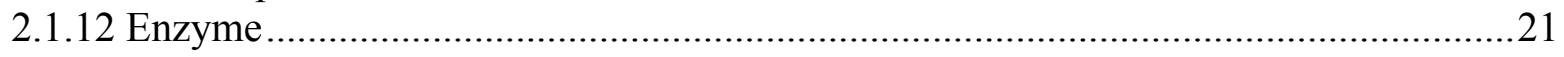

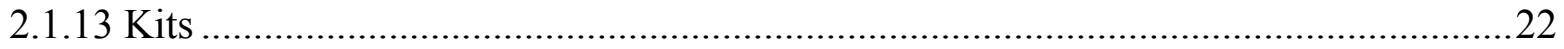

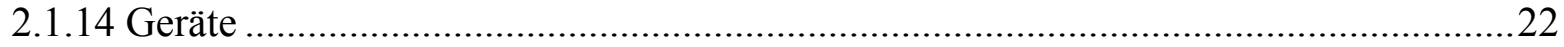

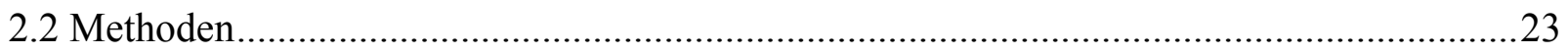

2.2.1 Isolierung genomischer DNA aus Mausschwanzbiopsien ..........................................23

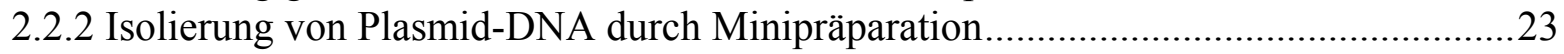

2.2.3 Isolierung von Gesamt-RNA aus Gewebe ……….................................................2

2.2.4 Konzentrationsbestimmung von Nukleinsäuren .....................................................24

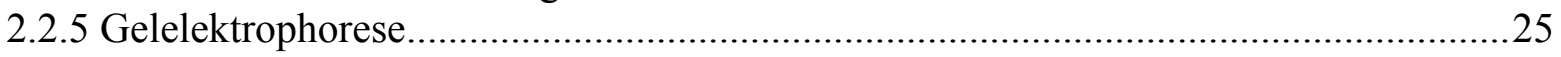

2.2.6 Isolierung und Aufreinigung von DNA-Fragmenten aus Agarosegelen mittels QIAquick Gel Extraction Kit .....................................................................................2.

2.2.7 Spaltung von Plasmid-DNA mit Restriktionsendonukleasen .....................................26

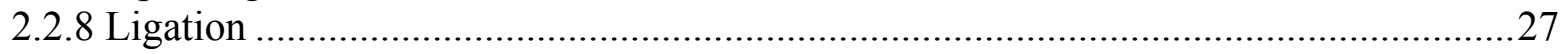

2.2.9 Plasmidtransformation in kompetente Escherichia-coli-Zellen...................................2.

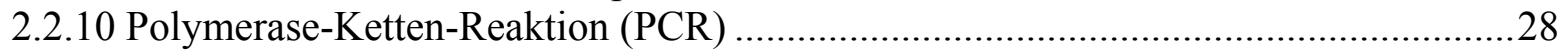

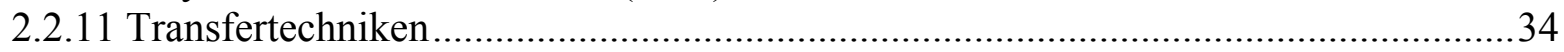

2.2.12 Radioaktive Markierung von DNA-Fragmenten und Hybridisierung .........................34

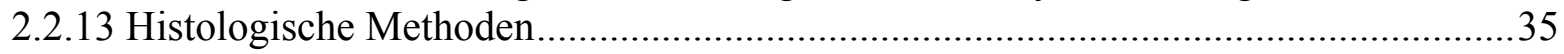

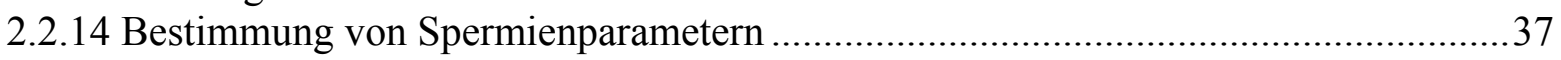

2.2.15 Versuch zur Spermien-Oozyten-Bindung (Bindungsassay) ........................................40

2.2.16 Computeranalyse .............................................................................................. 41

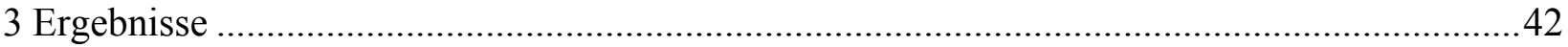

3.1 Einführung zum Ergebnissteil ADAM 27 ………………...........................................42

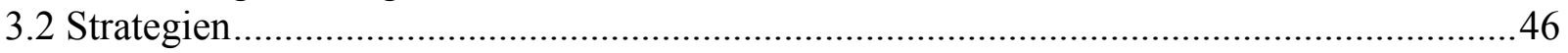

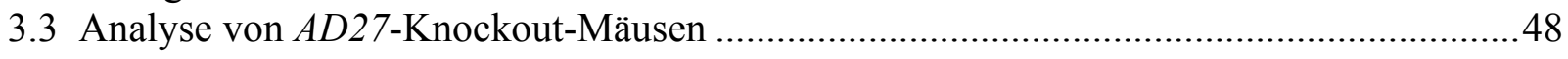




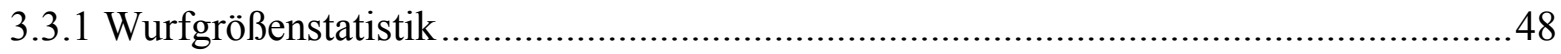

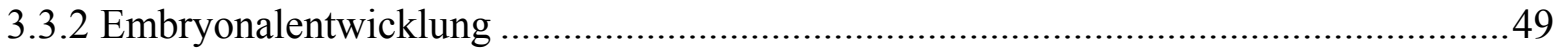

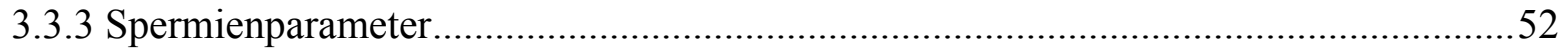

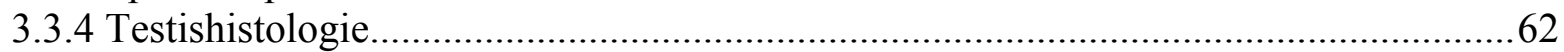

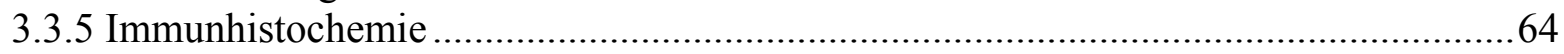

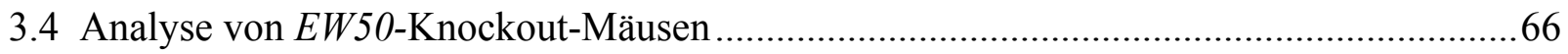

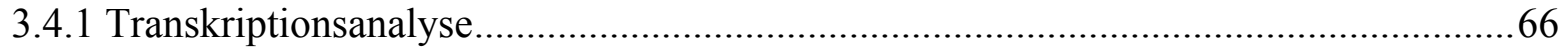

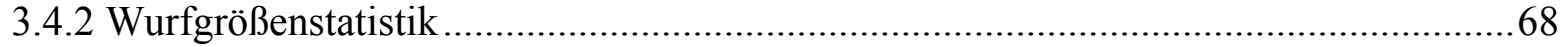

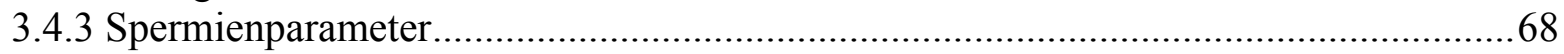

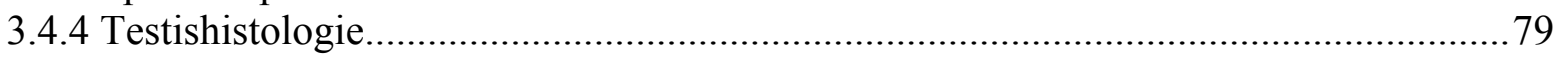

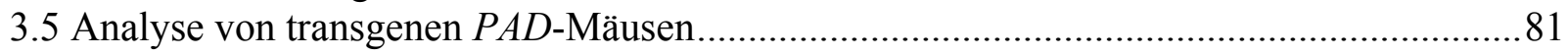

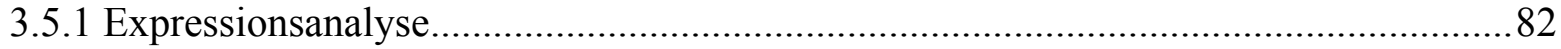

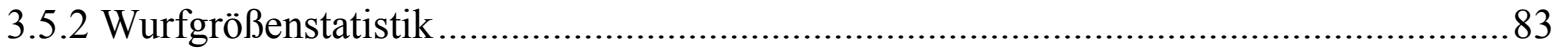

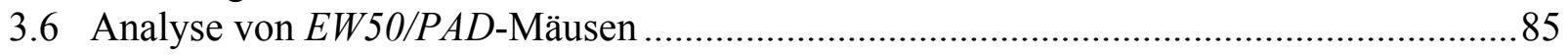

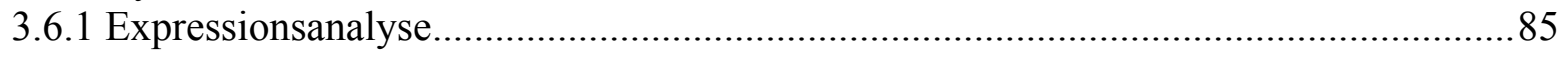

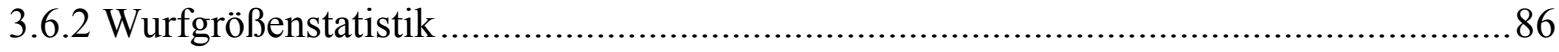

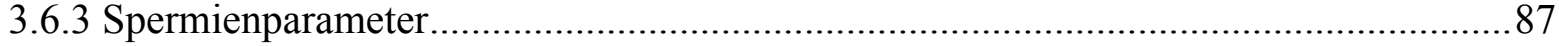

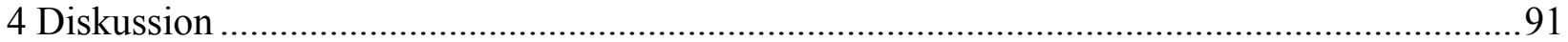

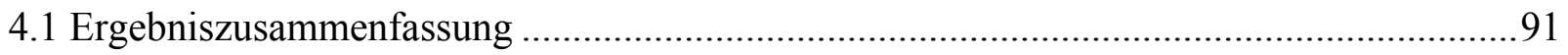

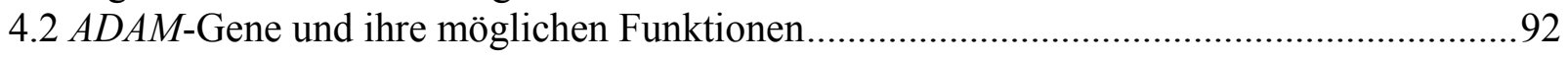

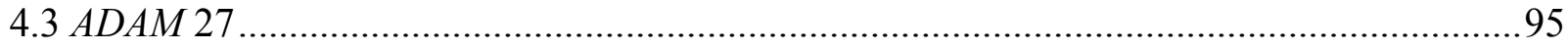

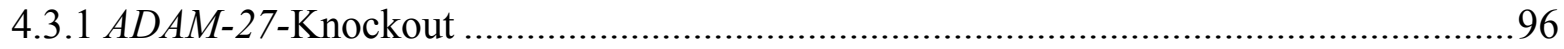

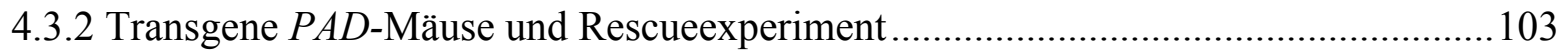

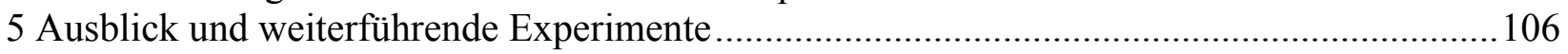

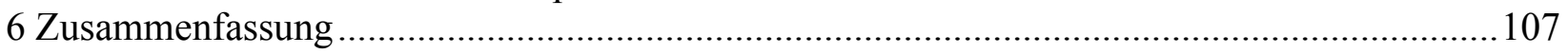

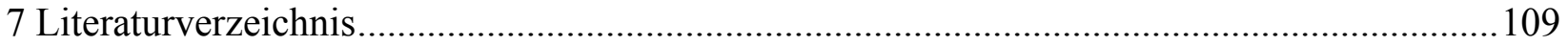




\section{Abkürzungen}

Abb.

ATP

BLAST

bp

bzw.

${ }^{\circ} \mathrm{C}$

ca.

cDNA

CTP

d

d.h.

dATP

$\mathrm{dCTP}$

DEPC

dGTP

DMSO

DNA

dNTPs

DTT

dTTP

E. coli

EDTA

et al.

$\mathrm{EtBr}$

g

$\mathrm{x} g$

$\mathrm{h}$

Hrsg.

IPTG

$\mathrm{kb}$
Abbildung

Adenosintriphosphat

„basic local alignment search tool“

Basenpaare

beziehungsweise

Grad Celsius

circa

komplementäre DNA

Cytidin-5'-triphosphat

Tag

das heißt

Desoxyadenosintriphosphat

Desoxycytidintriphosphat

Diethylpyrocarbonat

Desoxyguanosintriphosphat

Dimethylsulfoxid

Desoxyribonukleinsäure

Desoxynukleotidtriphosphate

Dithiothreitol

Desoxythymidintriphosphat

Escherichia coli

Ethylendiamintetraessigsäure

et alii

Ethidiumbromid

Gramm

Erdbeschleunigung

Stunde

Herausgeber

Isopropyl- $\beta$-thiogalactopyranosid

Kilobasenpaare 


\begin{tabular}{|c|c|}
\hline $\mathrm{kDa}$ & kilo Dalton \\
\hline 1 & Liter \\
\hline LB & Luria-Bertani \\
\hline M & Molarität \\
\hline $\mathrm{m}-$ & mili- $\left(1 \times 10^{-3}\right)$ \\
\hline$\mu-$ & mikro- $\left(1 \times 10^{-6}\right)$ \\
\hline $\mathrm{mb}$ & Megabasen \\
\hline $\min$ & Minute \\
\hline MOPS & 3-(N-Morpholino)-Propansulfonsäure \\
\hline mRNA & messenger Ribonukleinsäure \\
\hline $\mathrm{n}-$ & nano- $\left(1 \times 10^{-9}\right)$ \\
\hline o. g. & oben genannt \\
\hline PAGE & Polyacrylamid-Gelelektrophorese \\
\hline PBS & Phosphatgepufferte Salzlösung \\
\hline p.c. & post conceptionem \\
\hline PCI & Phenol/Chloroform/Isoamylalkohol (25:24:1) \\
\hline PCR & „Polymerase chain reaction“ \\
\hline RNA & Ribonukleinsäure \\
\hline RNase & Ribonuklease \\
\hline RT & Raumtemperatur \\
\hline $\mathrm{s}$ & Sekunde \\
\hline S (IUB Ambiguity Code) & Guanin, Cytosin \\
\hline $\mathrm{S}$. & Seite \\
\hline s. & siehe \\
\hline SDS & Natriumdodecylsulfat \\
\hline $\mathrm{SSC}$ & „standard saline citrat“ (-Puffer) \\
\hline SSPE & „standard saline phosphate EDTA“(-Puffer) \\
\hline TBE & Tris-Borat-EDTA (-Puffer) \\
\hline $\mathrm{TE}$ & Tris-EDTA (-Puffer) \\
\hline Tris & Tris-hydroxymethyl-aminomethan \\
\hline $\mathrm{U}$ & Unit (Einheit der Enzymaktivität) \\
\hline u. a. & unter anderem \\
\hline
\end{tabular}


UTR

V (IUB Ambiguity code)

$\mathrm{V}$

vgl.

$\mathrm{v} / \mathrm{v}$

Vol.

$\mathrm{w} / \mathrm{v}$

$\mathrm{X}$-Gal

z.B. untranslated region

Guanin, Cytosin, Adenin

Volt

vergleiche

Volumen pro Volumen

Volumen

Gewicht pro Volumen

5-Brom-4-Chlor-3-Indolyl- $\beta$-Galactosid

zum Beispiel

\section{Code der Nukleinsäuren}

$\begin{array}{ll}\text { A } & \text { Adenin } \\ \text { T } & \text { Thymin } \\ \text { G } & \text { Guanin } \\ \text { C } & \text { Cytosin } \\ \text { U } & \text { Uracil }\end{array}$

Code der Aminosäuren
A (Ala) Alanin
M (Met) Methionin
$\mathrm{C}$ (Cys) Cystein
$\mathrm{N}$ (Asp) Asparagin
D (Asn) Asparaginsäure
P (Pro) Prolin
E (Gln) Glutaminsäure
Q (Glu) Glutamin
F (Phe) Phenylalanin
R (Arg) Arginin
G (Gly) Glycin
S (Ser) Serin
$\mathrm{H}$ (His) Histidin
$\mathrm{T}$ (Thr) Threonin
I (Ile) Isoleucin
V (Val) Valin
K (Lys) Lysin
W (Trp) Tryptophan
L (Leu) Leucin
Y (Tyr) Tyrosin 


\section{Einleitung}

\subsection{ADAM (A Disintegrin and Metalloproteinase)-Gen- und Proteinfamilie}

Die $A D A M$-Genfamilie ist eine heterogene Gruppe von Genen mit typischer Domänenstruktur, bestehend aus Prodomäne (P), Metalloproteasedomäne (M) (eine katalytische Domäne mit einem Zinkbindungsmotiv), Disintegrindomäne (D), Cystein-reicher Domäne (C), EGF (epidermal growth factor)- ähnlicher Domäne (E), Transmembrandomäne (TM) und einem Zytoplasmaschwanz (Ct) (Abb. 1.1). Aus diesem typischen Aufbau leitet sich der Name dieser

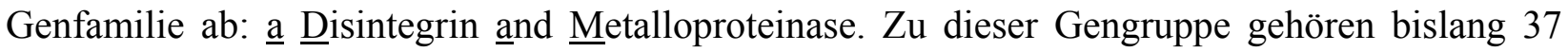
Gene (Stein et al., 2005), welche in einer großen Zahl von Organismen, reichend von Schizosaccharomyces pombe bis zum Menschen, zu finden sind. Nicht vorhanden sind sie jedoch z.B. in E. coli und Pflanzen.

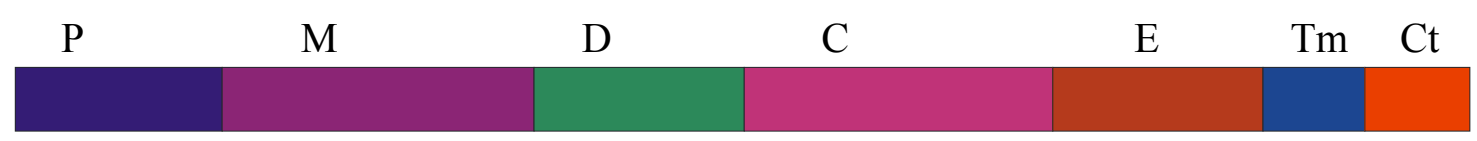

Prodomäne Metalloprotease Disintegrin cysteinreiche EGF-ähnliche Transmembran Zytoplasmaschwanz Abb. 1.1: Typische Domänenstruktur der ADAM-Proteine. Funktionen der einzelnen Domänen: die ProDomäne (P) unterbindet die Proteaseaktivität; die Metalloprotease (M) hat Proteaseaktivität; Disintegrindomäne (D) für Adhäsion; die cysteinreiche Domäne (C) hat auch Adhäsionsaktivität; die EGFähnliche Domäne (E) stimuliert Membranfusion; Transmembrandomäne (Tm) zur Verankerung in der Zellmembran. Der Zytoplasmaschwanz kann phosphoryliert werden und reguliert andere ADAM-Aktivitäten.

Die ADAMs weisen eine strukturelle Ähnlichkeit $\mathrm{zu}$ den SVMPs (snake venom metalloproteinases) auf. Die SVMPS binden mit ihrer Disintegrindomäne kompetitiv an ein Thrombozytenintegrin und hemmen so die Blutgerinnung. Auf Grund der Strukturähnlichkeit wird für die ADAM-Proteine, analog $\mathrm{zu}$ den SVMPS, sowohl Protease als auch Zelladhäsionsfunktion angenommen (Jia et al., 1996). Um als aktive Metalloproteinase zu fungieren, ist jedoch im aktiven Zentrum ein Zinkbindungsmotiv nötig, welches bei ca. einem 
Drittel der $A D A M s$ fehlt. Somit ist für dieses Drittel lediglich die Funktion als Adhäsionspartner zu erwarten (Abb. 1.2).

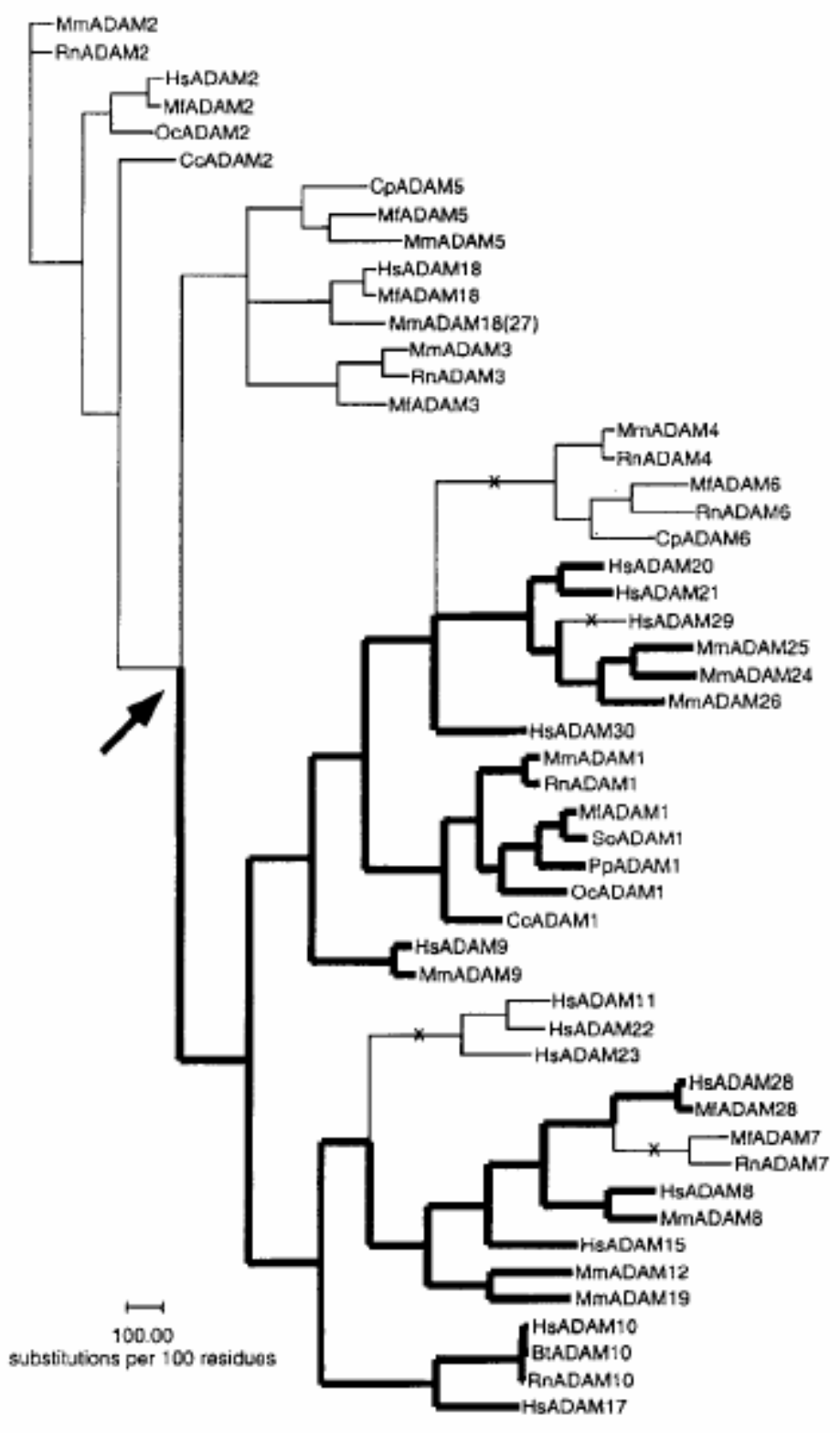

Abb. 1.2: Stammbaum der ADAM-Genfamilie bei Säugetieren nach Bolcun-Filas, 2003, S. 5. Fettgedruckte Zweige markieren ADAM-Gene mit Zink-Bindungsmotiv und Proteaseaktivität. Abkürzungen: Mm, Mus musculus; Rn, Rattus norvegicus; Hs, Homo sapiens; Mf, Macaca fascicularis; Oc, Oryctolagus cuniculus; Cc Cavia cobaya; Cp, Cavia porcellus; So, Saguinus oedipus; Pp Pongo pygmaeus; Bt, Bos taurus. 


\section{Einleitung}

Manche der $A D A M$-Gene werden ubiquitär exprimiert, wie z.B. $A D A M$ 9, $A D A M$ 10, $A D A M 15$ und $A D A M 17$ mit eventuellen pleiotropen Effekten, so z.B. beschrieben für ADAM 15 und 17 (Bohm et al., 1999; McCulloch et al., 2000; Bosse et al., 2000; Al-Fakhri et al., 2003; Shi et al., 2003; Moro et al., 2003; ). Viele andere dieser Gene zeigen jedoch eine gewebespezifische Expression, wobei die größte Gruppe ( 1, 2, 3, 5, 6, 16, 18, 20, 21, 24, 25, 26, 27, 29, 30, und 34) spezifisch oder zumindest vorrangig im Hoden exprimiert wird und somit wahrscheinlich in die Prozesse von Spermatogenese und oder Fertilisation eingebunden ist.

Die am besten untersuchten Gene der hodenspezifischen Gruppe sind ADAM 1(Fertilin $\alpha$ ) und, ADAM 2 (Fertilin $\beta$ ), welche zusammen das Heterodimer Fertilin bilden, sowie ADAM 3 (Cyritestin). In der Maus wurden 2 Isoformen von ADAM 1 identifiziert (Nishimura et al., 2002), wobei $A D A M$ la nur intrazellulär im endoplasmatischen Retikulum (ER) der Spermatiden lokalisiert ist, während sich $A D A M 1 b$ im ER von Spermatiden und auf der Oberfläche von ausgereiften Spermien im Nebenhodenschwanz befindet (Kim E et al., 2003).

Eine Übersicht über die jeweiligen Gene mit chromosomaler Lokalisation, Gen- und Transkriptgröße, sowie auch subzellulärer Lokalisation der Proteine bei der Maus wird in Abbildung 1.3 gegeben. 


\begin{tabular}{|c|c|c|c|c|c|}
\hline $\mathrm{Parameter}_{\text {Gen }}^{\text {Gen }}$ & $A D A M 27$ & $\begin{array}{l}\text { ADAM la } \\
(\text { Fertilin } \alpha)\end{array}$ & $A D A M 1 b$ & $\begin{array}{l}\text { ADAM } 2 \\
(\text { Fertilin } \beta)\end{array}$ & $\begin{array}{l}\text { ADAM } 3 \\
\text { (Cyritestin) }\end{array}$ \\
\hline $\begin{array}{l}\text { Chromosomale } \\
\text { Lokalisation }\end{array}$ & $\begin{array}{l}\text { Chromosom } \\
8 \mathrm{qA} 2\end{array}$ & $\begin{array}{l}\text { Chromosom } \\
5 \mathrm{~F}\end{array}$ & $\begin{array}{l}\text { Chromosom } \\
5 \mathrm{~F}\end{array}$ & $\begin{array}{l}\text { Chromosom } \\
\text { 14D1 }\end{array}$ & $\begin{array}{l}\text { Chromosom } \\
8 \mathrm{qA} 2\end{array}$ \\
\hline Gengröße & $\begin{array}{l}\text { total } 72,5 \mathrm{~kb}, \\
20 \text { Exons }\end{array}$ & $\begin{array}{l}\text { total 3,0 kb, } \\
1 \text { Exon }\end{array}$ & $\begin{array}{l}\text { total } 2,8 \mathrm{~kb}, \\
1 \text { Exon }\end{array}$ & $\begin{array}{l}\text { total } 50 \mathrm{~kb} \text {, } \\
21 \text { Exos }\end{array}$ & $\begin{array}{l}\text { total } 48,5 \mathrm{~kb} \text {, } \\
22 \text { Exons }\end{array}$ \\
\hline Transkriptgröße & $2,37 \mathrm{~kb}$ & $3,0 \mathrm{~kb}$ & $2,8 \mathrm{~kb}$ & $2,5 \mathrm{~kb}$ & $2,7 \mathrm{~kb}$ \\
\hline Expression & hodenspezifisch & hodenspezifisch & hodenspezifisch & hodenspezifisch & hodenspezifisch \\
\hline $\begin{array}{l}\text { Subzelluläre } \\
\text { Lokalisation }\end{array}$ & $\begin{array}{l}\text { Golgi-Apparat/ } \\
\text { Akrosom von } \\
\text { runden und } \\
\text { elongierten } \\
\text { Spermatiden; } \\
\text { kein } \\
\text { Vorkommen an } \\
\text { der } \\
\text { Zelloberfläche } \\
\text { bei reifen } \\
\text { Spermien, } \\
\text { genaue } \\
\text { Lokalisation hier } \\
\text { noch unbekannt }\end{array}$ & $\begin{array}{l}\text { Intrazellulär im } \\
\text { ER von } \\
\text { Spermatiden; } \\
\text { komplexiert mit } \\
A D A M 2\end{array}$ & $\begin{array}{l}\text { Intrazellulär im } \\
\text { ER von } \\
\text { Spermatiden; } \\
\text { Zelloberfläche } \\
\text { von reifen } \\
\text { Spermien; } \\
\text { komplexiert mit } \\
A D A M 2\end{array}$ & $\begin{array}{l}\text { Intrazellulär im } \\
\text { ER von } \\
\text { Spermatiden; } \\
\text { Zelloberfläche } \\
\text { von reifen } \\
\text { Spermien; } \\
\text { komplexiert mit } \\
\text { ADAM la+b, } \\
\text { Cyritestin }\end{array}$ & $\begin{array}{l}\text { Zelloberfläche } \\
\text { von Spermatiden } \\
\text { und reifen } \\
\text { Spermien, hier } \\
\text { auch komplexiert } \\
\text { mit } A D A M 2\end{array}$ \\
\hline
\end{tabular}

Abb. 1.3: Übersicht über Lokalisation, Größe und Expression der ADAM-Gene 1a, 1b, 2, 3, 27.

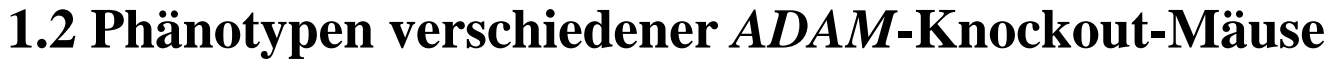

Oftmals wird die Funktion eines Gens untersucht, indem man es ausschaltet und die Auswirkungen auf den Phänotyp des bereffenden Organismus beobachtet. Für eine Reihe von Genen der $A D A M$-Familie existieren solche Knockout-Modelle in Mäusen, wobei hier im einzelnen auf die Gene $A D A M 1 a, 1 b, 2$ und 3 eingegangen werden soll. Gemeinsam ist diesen Genen die spezifische Expression im Hoden und, daß eine Ausschaltung eines dieser Gene in einer Sub- respektive Infertilität der jeweiligen männlichen Mäuse resultiert. Weitere 
Gemeinsamkeit ist, daß diese Gene in einem direkten und komplexen Verhältnis zueinander stehen, welches dazu führt, daß beim Ausschalten des einen Gens die Menge eines anderen ebenfalls vermindert ist.

Zum Beispiel sind Knockout-Mäuse für $A D A M$ la nahezu infertil, was darauf beruht, daß $A D A M-1 a^{-/-}$-Spermien nicht durch den Uterus in den Ovidukt gelangen. Im Weiteren durchdringen diese Spermien in vitro nicht die Kumuluszellen und zeigen eine verminderte Bindung an die Zona pellucida (Nishimura et al., 2004). Untersuchungen zeigten weiterhin, daß Cyritestin in reifen Spermien von $A D A M-1 a$-Knockout-Mäusen deutlich vermindert ist, während es in den Spermatiden dieser Tiere in normaler Konzentration vorhanden ist. Dies impliziert die Funktion von $A D A M 1 a$, respektive des Fertilin-Komplexes in Transportvorgänge von z.B. Cyritestin an die Spermiumoberfläche während der Spermatogenese und Spermiogenese (Nishimura et al., 2004).

Interessanterweise zeigen Knockout-Mäuse für $A D A M 1 b$ eine normale Fertilität, obwohl diese Isoform von $A D A M 1$ ebenfalls mit $A D A M 2$ als Fertilin-Komplex vorliegt und sich an der Zelloberfläche von Spermatiden und reifen Spermien befindet. Spermien dieser Tiere zeigen eine normale Migration vom Uterus in den Ovidukt, wie auch eine normale Bindung an die Zona pellucida von Oozyten. Weitere Untersuchungen zeigten, daß lediglich $A D A M 2$ in reifen Spermien von $A D A M-1 b^{-/-}$-Mäusen erniedrigt ist, wobei die Konzentration von $A D A M 2$ in den Spermatiden dieser Tiere normal ist (Kim E et al., 2006). Daß sich $A D A M 2$ in verminderter Menge in reifen Spermien findet, steht zumindest in Einklang mit der Tatsache, daß diese zwei Proteine als Fertilin-Komplex in reifen Spermien vorliegen und somit die Ausschaltung des einen Gens in diesem Zusammenhang auch das andere Gen beeinflusst. Interessant ist nur, daß sich die verringerte Menge von $A D A M 2$ nicht auf die Fertilität der Mäuse auswirkt, da Knockout-Mäuse für $A D A M 2$ ebenfalls infertil sind, wobei deren Phänotyp denen der $A D A M$-1 $a$-Mäuse ähnelt. Spermien dieser Tiere migrieren ebenfalls nicht in den Ovidukt und zeigen eine stark eingeschränkte Bindungsfähigkeit an die Zona pellucida (Cho et al., 1998). Des Weiteren fand sich, daß reife $A D A M-2^{-/}$-Spermien einen kompletten Verlust von $A D A M 3$ und $A D A M 1 b$ zeigen, während sich in Spermatiden normale Mengen von $A D A M 3$ finden. Die Konzentration von $A D A M 1 b$ findet sich auch in $A D A M-2^{-/-}$-Spermatiden vermindert (Nishimura et al., 2004). Dies findet sich in Übereinstimmung mit der Hypothese, daß der ADAM-1a/ADAM-2-FertilinKomplex zum einen essentiell für den Transport von z.B. ADAM 3 an die Zelloberfläche im Rahmen der Spermiogenese ist, und daß $A D A M 3$ ein Schlüsselelement im Rahmen der 


\section{Einleitung}

Spermien-Oozyteninteraktion darstellt. Gemeinsam ist den Knockout-Spermien von ADAM-1aund $A D A M$-2-Mäusen, daß sich kein $A D A M 3$ an deren Zelloberfläche findet. Daß ADAM 3 eine evidente Rolle bei der Anlagerung von Spermien an die Zona pellucida spielt, zeigte der Versuch mit $A D A M-3^{-/}$-Tieren. Diese waren infertil und deren Spermien waren nicht in der Lage, an die Zona pellucida zu binden (Shamsadin et al. 1999). Andere Spermienparameter, wie Morphologie, Migration in den Ovidukt oder Bindung an das Oolem, waren nicht beeinträchtigt. Ebenso zeigte sich, bis auf $A D A M 2$, welches nur zu 75\% der Wildtypkonzentration vorlag, bislang kein anderes Protein in geringerer Konzentration in diesen Knockout-Tieren (Nishimura et al., 2007). Neuere Erkenntnisse zeigen, daß sich $A D A M 3$ zusammen mit $A D A M 2$ als weiterer Komplex auf reifen Spermien findet (Nishimura et al., 2007). Eine Auflistung der Gene, der jeweiligen Phänotypen bei Knockout-Modellen, wie auch eine Auflistung der Autoren gibt Abbildung 1.4. 
Einleitung

\begin{tabular}{|c|c|c|c|c|}
\hline Gen & $\begin{array}{l}\text { ADAM 1a } \\
(\text { Fertilin } \alpha)\end{array}$ & $\begin{array}{l}A D A M 2 \\
(\text { Fertilin } \beta)\end{array}$ & $\begin{array}{l}\text { ADAM } 3 \\
\text { (Cyritestin) }\end{array}$ & ADAM $1 b \quad($ Fertilin $\alpha)$ \\
\hline Knockout & Komplettes Gen & Komplettes Gen & Komplettes Gen & Komplettes Gen \\
\hline Phänotyp & $\begin{array}{l}\text { Spermien können } \\
\text { nicht in den } \\
\text { Ovidukt } \\
\text { transportiert } \\
\text { werden, } \\
\text { durchdringen } \\
\text { nicht die } \\
\text { Cumuluszellen, } \\
\text { verminderte } \\
\text { Bindung an die } \\
\text { Zona pellucida. } \\
\text { Cyritestin ist } \\
\text { reduziert in reifen } \\
\text { Spermien }\end{array}$ & $\begin{array}{l}\text { Spermien zeigen } \\
\text { Defekte beim } \\
\text { Passieren des Uterus, } \\
\text { bei der Anlagerung } \\
\text { an die Zona } \\
\text { pellucida, bei der } \\
\text { Anlagerung/Ver- } \\
\text { schmelzung mit der } \\
\text { Oozytenmembran, } \\
\text { Cyritestin in reifen } \\
\text { Spermien komplett } \\
\text { verschwunden, } \\
\text { ebenso } A D A M 1 b . \\
\text { Dieses ist auch in } \\
\text { Spermatiden nicht } \\
\text { vorhanden }\end{array}$ & $\begin{array}{l}\text { Spermien können } \\
\text { nicht an die Zona } \\
\text { pellucida binden, } \\
\text { Konzentration von } \\
A D A M 2 \text { in reifen } \\
\text { Spermien leicht } \\
\text { vermindert }\end{array}$ & $\begin{array}{l}\text { Mäuse sind fertil, } \\
\text { Konzentration von } \\
A D A M 2 \text { in reifen } \\
\text { Spermien stark } \\
\text { vermindert }\end{array}$ \\
\hline Autor & $\begin{array}{l}\text { Nishimura et al., } \\
2004\end{array}$ & $\begin{array}{l}\text { Cho et al., } 1998 \\
\text { Nishimura et al., } \\
2004\end{array}$ & $\begin{array}{l}\text { Shamsadin et al., } \\
1999 \\
\text { Nishimura et al., } 2007\end{array}$ & Kim E et al., 2006 \\
\hline
\end{tabular}

Abb. 1.4: Übersicht über die ADAM-Gene 1a, 1b, 2, 3 mit Angaben über Knockout-Modell, deren Phänotyp und jeweiligem Autor.

\subsection{ADAM 27}

In diesem komplexen Zusammenspiel der $A D A M$-Gene während Spermato-/Spermiogenese und Befruchtung, scheint $A D A M 27$ ein weiteres, potentiell in diese Vorgänge involviertes Gen zu sein. Es gehört, ebenso wie $A D A M 2$ und 3, zu der Gruppe der $A D A M$-Gene ohne Proteinaseaktivität. Es zeigt den typischen Domänenaufbau der $A D A M$-Gene. Erstmals wurde es 1999 beschrieben (Zhu et al., 1999) und wird nur im Hoden exprimiert (Zhu et al., 1999). Aufgrund der Ergebnisse der Experimente mit Cyritestin und Fertilin sollte eine funktionelle 


\section{Einleitung}

Analyse von $A D A M 27$ mittels gezielter Ausschaltung dieses Gens durchgeführt werden, wobei unter anderem die Rolle von $A D A M 27$ als Membranprotein von speziellem Interesse war. Hierfür wurden zwei Knockout-Konstrukte entwickelt, wobei bei einem das komplette Gen ausgeschaltet wurde und bei dem anderen nur die Transmembrandomäne. Weiterhin sollte untersucht werden, wie sich die Überexpression von $A D A M 27$ auswirkt, so daß ein transgenes Mausmodell etabliert wurde. Diese Modelle lagen bei Studienbeginn bereits vor. 


\section{Material und Methoden}

\subsection{Material}

\subsubsection{Chemikalien}

\begin{tabular}{ll} 
Agar & Roth, Karlsruhe \\
Agarose & Invitrogen, Karlsruhe \\
Ampicillin & Sigma, Deisenhofen \\
Ampuwa & Fresenius, Bad Homburg \\
Choloroform & Merck, Darmstadt \\
Coomassie G-250 & Sigma, Deisenhofen \\
Vectashield (DAPI) & Vector, Burlingame \\
Diethylpyrocarbonat (DEPC) & Sigma, Deisenhofen \\
DNA-Marker & Invitrogen, Karlsruhe \\
dNTPs (100 mM) & Invitrogen, Karlsruhe \\
Eisessig & Merck, Darmstadt \\
Ethanol & Baker, Deventer, NL \\
Ethidiumbromid & Roth, Karlsruhe \\
Ficoll 400 & Applichem, Darmstadt \\
Formaldehyd & Merck, Darmstadt \\
Formamide & Sigma, Deisenhofen \\
D-Fruktose & Merck, Darmstadt \\
Galactose & Sigma, Deisenhofen \\
Glutaraldehyd & Sigma, Deisenhofen \\
HCl & Roth, Karlsruhe \\
Ionophore A23187 & Calbiochem, Bad Soden \\
IPTG & Biomol, Hamburg \\
Isopropanol & Merck, Darmstadt \\
IVF-Medium & Merlin \\
\hline
\end{tabular}


Material und Methoden

$\mathrm{KCl}$

M 2-Medium

M 16-Medium

$\mathrm{MgCl}_{2}$

MOPS

Na-Acetat

$\mathrm{Na}-\mathrm{Citrat}$

$\mathrm{NaCl}$

$\mathrm{NaOH}$

Orange $\mathrm{G}$

Pepton

PBS

Picrinsäure

Proteinase K

Radioaktive Substanzen:

$\left[\gamma_{32} \mathrm{P}\right]-\mathrm{ATP}\left[\alpha_{32} \mathrm{P}\right]-\mathrm{dCTP}$

Rediprimetм II

RNA-Größenstandard

RNA-Reagenz

RNAse away

Lachsspermien DNA

SDS

Tris

Tri-Natriumcitrat-Dihydrat

X-Gal
Merck, Darmstadt

Medicult, Berlin

Medicult, Berlin

Merck, Darmstadt

Applichem, Darmstadt

Merck, Darmstadt

Merck, Darmstadt

Merck, Darmstadt

Merck, Darmstadt

Sigma, Deisenhofen

Roth, Karlsruhe

Invitrogen, Karlsruhe

Fluka, Neu Ulm

Applichem, Darmstadt

Amersham, Braunschweig

Amersham, Braunschweig

Invitrogen, Karlsruhe

Biomol, Hamburg

Biomol, Hamburg

Sigma, Deisenhofen

Serva, Heidelberg

Sigma, Deisenhofen

Merck, Darmstadt

Biomol, Hamburg

Chemikalien die nicht aufgeführt wurden, wurden entweder von Merck, Darmstadt oder Roth, Karlsruhe bezogen. 
Material und Methoden

\subsubsection{Labormaterialien}

Whatman blotting Papier

(GB 002, GB 003 and GB 004)

Einmalfilter Minisart NMI

Filterpapier 0858

Hybond C

Petrischalen

Pipettenspitzen

Reaktionsgefäße

Röntgenfilme

Superfrost Objektträger

White-colored 384-well plates
Schleicher and Schüll, Dassel

Sartorius, Göttingen

Schleicher and Schüll, Dassel

Amersham, Braunschweig

Greiner, Nürtingen

Eppendorf, Hamburg

Eppendorf, Hamburg

Amersham, Braunschweig

Menzel, Gläser

ABgene, Hamburg

\subsubsection{Sterilisation}

Die Sterilisation von Lösungen erfolgte für $20 \mathrm{~min}$ bei $120{ }^{\circ} \mathrm{C}$ und $10^{5}$ Pascal im Dampfdruckautoklaven (Webeco, Bad Schwartau) oder bei hitzeempfindlichen Lösungen durch Sterilfiltration (Porengröße: 0,2 $\mu \mathrm{m}$ ). Gebrauchswaren wurden entweder autoklaviert oder ü. N. bei $180{ }^{\circ} \mathrm{C}$ hitzesterilisiert.

\subsubsection{Puffer und Stammlösungen}

Die Lösungen für den routinemäßigen Laborbetrieb wurden nach Sambrook et al. (1989) angesetzt. Die Chemikalien wurden den Erfordernissen entsprechend in deionisiertem Wasser $\left(\mathrm{dH}_{2} \mathrm{O}\right)$, in vollentsalztem Wasser (Millipore) oder Ampuwa gelöst. Je nach Bedarf wurden die Lösungen autoklaviert, sterilfiltriert, frisch angesetzt, aliquotiert und bei $-20{ }^{\circ} \mathrm{C}$ oder bei $4{ }^{\circ} \mathrm{C}$ aufbewahrt. Für Versuche mit RNA wurden die Chemikalien in mit 0,1\% DEPC behandeltem und autoklaviertem Wasser gelöst. 
Material und Methoden

$5 x$ TBE

Stopmix

DEPC- $\mathrm{H}_{2} \mathrm{O}$

dNTP-Mix

Lysepuffer

Lachsspermien-DNA

20x SSC

Waschlösung I

Waschlösung II
$450 \mathrm{mM}$ Tris

450 mM Borsäure

20 mM EDTA (pH 8)

$15 \%$ Ficoll 400

$200 \mathrm{mM}$ EDTA

$0,1 \%$ Orange $\mathrm{G}$

$0,1 \%(\mathrm{v} / \mathrm{v})$ Diethylpyrocarbonat

Inkubation für 24 Stunden unter Rühren

und anschließend autoklavieren

$10 \mathrm{mM}$ dTTP

$10 \mathrm{mM}$ dATP

$10 \mathrm{mM}$ dGTP

$10 \mathrm{mM}$ dCTP

$100 \mathrm{mM} \mathrm{NaCl}$

$100 \mathrm{mM}$ Tris/HCl $(\mathrm{pH} \mathrm{8,0)}$

$0,5 \%$ SDS

$100 \mathrm{mM}$ EDTA

$5 \mathrm{mg} / \mathrm{ml}$ (Scherung durch Sonifikation)

$3 \mathrm{M} \mathrm{NaCl}$

0,3 M Tri-Natriumcitrat ( $\mathrm{pH} 7,0$ )

$2 \times \mathrm{SSC}$

$0,1 \%$ SDS

$0,2 \times \mathrm{SSC}$ 
Material und Methoden

Bouin'sche Lösung

15 x Volumen von Picrinsäure (in $\mathrm{H}_{2} \mathrm{O}$ )

5 x Volumen Formaldehyd

$1 \mathrm{x}$ Volumen Eisessig

Ligationspuffer (10x)

$600 \mathrm{mM}$ Tris/HCl $(\mathrm{pH} 7.5)$

$80 \mathrm{mM} \mathrm{MgCl}$

$100 \mathrm{mM}$ DTT

10x MOPS Puffer

41,8 $\mathrm{ml}$ MOPS

16,6 ml 3 M Natriumcitrat

$20 \mathrm{ml} \mathrm{0,5}$ M EDTA

in 1 Liter DEPC Wasser

auf $\mathrm{pH}$ 6,75 einstellen

TE Puffer

$10 \mathrm{mM}$ Tris/ $\mathrm{HCl}(\mathrm{pH} 8.0)$

$1 \mathrm{mM}$ EDTA

EM-Fixierlösung

1\% Paraformaldehyd

3\% Glutaraldehyd

in $0,1 \mathrm{M}$ Cacodylatpuffer $\mathrm{pH} 7,4$

EM-Spüllösung

0,1 M Cacodylatpuffer $\mathrm{pH}$ 7,4

0,1 M Saccharose 


\subsubsection{Medien, Antibiotika und Agarplatten}

\subsubsection{Bakterienmedien}

LB (Luria-Bertani)-Medium (pH 7,5)

$$
\begin{aligned}
& 1 \% \text { Pepton } \\
& 0,5 \% \text { Hefeextrakt } \\
& 1 \% \mathrm{NaCl} \\
& 1 \% \text { Pepton } \\
& 0,5 \% \mathrm{Hefeextrakt} \\
& 1 \% \mathrm{NaCl} \\
& 1,5 \% \mathrm{Agar}
\end{aligned}
$$

LB-Agar

SOC-Medium

$$
\text { Invitrogen, Karlsruhe }
$$

Das LB-Medium wurde mit bidestilliertem Wasser angesetzt, autoklaviert und bei $4{ }^{\circ} \mathrm{C}$ aufbewahrt.

\subsubsection{Antibiotika}

Von dem Antibiotikum Ampicillin wurde eine Stammlösung angesetzt, die steril filtriert und bei $20{ }^{\circ} \mathrm{C}$ gelagert wurde. Das Antibiotikum wurde erst nach dem Autoklavieren und Abkühlen des LB-Mediums auf $55^{\circ} \mathrm{C}$ zugegeben.

$\begin{array}{llc}\text { Stammlösung } & \text { gelöst in } & \text { Endkonzentration } \\ \text { Ampicillin } & 50 \mathrm{mg} / \mathrm{ml} \mathrm{H}_{2} \mathrm{O} & 100 \mu \mathrm{g} / \mathrm{ml}\end{array}$

\subsubsection{Ampicillin-IPTG/X-Gal-Platten}

Zur Herstellung von X-Gal-Platten (Blau-Weiß-Selektion) wurde dem LB-Agar $\left(55^{\circ} \mathrm{C}\right)$ Ampicillin (Endkonzentration: $100 \mu \mathrm{g} / \mathrm{ml}$ ) zugegeben und in Petrischalen gegossen. Die Platten 
wurden bei $4{ }^{\circ} \mathrm{C}$ gelagert. Die X-Gal- und IPTG-Stammlösungen wurden vor Gebrauch direkt auf der Oberfläche der Platten ausgestrichen.

$\begin{array}{lll}\text { Stammlösung } & \text { gelöst in } & \text { eingesetzte Menge pro Platte } \\ \text { X-Gal } 2 \% & \text { Dimethylformamid } & 70 \mu 1 \text { Stammlösung } \\ \text { IPTG } 100 \mathrm{mM} & \mathrm{H}_{2} \mathrm{O} & 30 \mu 1 \text { Stammlösung }\end{array}$

\subsubsection{Bakterienstämme}

E. coli $\mathrm{DH} 5 \alpha \quad$ Invitrogen, Karlsruhe

\subsubsection{Plasmide}

pGEM-T Easy Promega, Mannheim

\subsubsection{Oligonukleotide}

Die verwendeten Oligonukleotide wurden von der Firma Qiagen, Hilden synthetisiert. Die Oligonukleotide wurden mit Ampuwa auf eine Konzentration von $100 \mu \mathrm{M}(100 \mathrm{pmol} / \mu \mathrm{l})$ eingestellt und als Stock bei $-20^{\circ} \mathrm{C}$ gelagert.

$\begin{array}{ll}\text { ATG27FP } & \text { 5' AAG TGC AAG AAG CTC AGC CGA 3' } \\ \text { ATG27RP } & \text { 5' CCT GAG CTG GTA GTT CAG AAC 3' } \\ \text { NEO RI } & \text { 5' AGG AGC AAG GTG AGA TGA CAG 3' } \\ \text { PGK - 2seq/FP } & \text { 5' CAG CCC CTC AAC AGC AAG TT 3' } \\ \text { AD275'seq/RP } & \text { 5' CGT GGC TCT ATC TTC TGT GG 3', } \\ \text { Cyr5'seq/RP } & \text { 5' CGT CTT TGC CTG CAG CGA TC 3', } \\ \text { GAPDH-FP } & \text { 5' CAT CAC CAT CTT CCA GGA GC 3', }\end{array}$


GAPDH-RP

AD18-FP

AD18-RP
5' ATG ACC TTG CCC ACA GCC TT 3'

5' CAT TGA CGG GAA GCC CTA CTC 3'

5' CAT TAT GCA TGG AGC GCT GGG 3'

\subsubsection{Sonden}

Human-Elongation-Factor-2-cDNA

$\beta$-actin-cDNA

Adam 27

EGFP
Hanes et al., 1992

Clontech, Palo Alto

hergestellt in der vorliegenden Studie

Dev, 2006

\subsubsection{Mauslinien}

Für die Versuche wurden Mäuse der Linien C57BL/6J, 129/SV und FVB verwendet. Alle Linien waren bei Versuchsbeginn bereits im Institutstierstall vorhanden.

\subsubsection{Antikörper}

anti-Maus ppADAM27 polyklonal gegen ADAM27-Peptid, hergestellt in Kaninchen anti-Maus fpADAM27 polyklonal gegen ADAM27-Fusionsprotein, hergestellt in Kaninchen

\subsubsection{Enzyme}

RNase - Inhibitor

Superscript-II

Platimum Taq polymerase

T4 DNA ligase
Invitrogen, Karlsruhe

Invitrogen, Karlsruhe

Invitrogen, Karlsruhe

Promega, Mannheim 
T4 RNA ligase

Restriktionsenzyme

Proteinase $\mathrm{K}$

Hyaluronidase
Invitrogen, Karlsruhe

Invitrogen, Karlsruhe

Sigma, Deisenhofen

Invitrogen, Karlsruhe

\subsubsection{Kits}

Plasmid Mini Kit

QIAquick Gel Extraction Kit

Rediprimeтм II Random Prime

Labeling System

Sequencing Ready Reaction Kit

DYEnamic ET-Terminator mix
Qiagen, Hilden

Qiagen, Hilden

Amersham Pharmacia, Braunschweig

Amersham Pharmacia, Braunschweig

\subsubsection{Geräte}

ABI PRISM 377 DNA Sequencer

ABI 3100 Genetic Analyzer

Mikroskop BX60

Mikroskop Stemi SV 11

GeneAmp PCR System 9600

Microtiterplate-Photometer

Molecular Imager FX

Spectrophotometer Ultraspec 3000

SpeedVac concentrator SVC $100 \mathrm{H}$

Thermomixer 5436

Turboblotter ${ }^{\mathrm{TM}}$

Video - Dokumentationssystem

Röntgenfilmentwickler Curix 60
Applied Biosystem, Darmstadt

Applied Biosystem, Darmstadt

Olympus, Planegg

Zeiss, Oberkochen

Perkin Elmer, Rodgau

BioRad, München

BioRad, München

Amersham Pharmacia, Braunschweig

Schütt Labortechnik, Göttingen

Eppendorf, Hamburg

Schleicher \& Schüll, Dassel

Herolab, Heidelberg

Agfa, Köln 
Autoklav

Neubauerzählkammer

CASA (Computer Assisted Semen Analysis)-

System (CEROS Version 10)
Webeco, Bad Schwartau

Schütt Labortechnik, Göttingen

Hamilton Thorne Research, Beverly

\subsection{Methoden}

\subsubsection{Isolierung genomischer DNA aus Mausschwanzbiopsien}

Lysepuffer: $\quad 50 \mathrm{mM}$ Tris / $\mathrm{HCl}(\mathrm{pH} \mathrm{8,0)}$

$100 \mathrm{mM}$ EDTA

$0,5 \% \mathrm{SDS}$

Hochmolekulare genomische DNA wurde modifiziert nach Laird et al. (1991) isoliert. Dazu wurde ca. $1 \mathrm{~cm}$ des Mausschwanzes in $700 \mu 1$ Lyse-Puffer (w/v) zusammen mit $35 \mu 1$ Proteinase K $(10 \mu \mathrm{g} / \mu \mathrm{l})$ unter Schütteln im Thermomixer bei $55^{\circ} \mathrm{C}$ ü. N. inkubiert. Nach einer Phenol/Chloroform-Extraktion wurde die DNA mit 2 Volumen absolutem Ethanol präzipitiert und anschließend mit $500 \mu 170$ \%igem Ethanol gewaschen. Die genomische DNA wurde in 100-200 $\mu 1$ Ampuwa gelöst und bei $4^{\circ} \mathrm{C}$ gelagert.

\subsubsection{Isolierung von Plasmid-DNA durch Minipräparation}

Die Isolierung von Plasmid-DNA im analytischen Maßstab (Minipräparation) wurde mit den Lösungen des QIAGEN Plasmid Kits (QIAGEN, Hilden) mittels alkalischer Lyse (Birnboim und Doly, 1979; Birnboim, 1983) aus $5 \mathrm{ml}$ LB-Übernachtkulturen mit entsprechendem plasmidkodiertem Antibiotikum durchgeführt, wobei auf die Reinigung über Anionenaustauschersäulen verzichtet wurde. Die Qualität dieser DNA ist hinreichend gut, um sie in Sequenzierungsreaktionen, in Restriktionen und für die Insert-Isolierung einzusetzen. 


\subsubsection{Isolierung von Gesamt-RNA aus Gewebe}

Gesamt-RNA für Northern-Blot-Analysen wurde aus unterschiedlichen Geweben der Maus isoliert. Da RNA besonders anfällig gegen Abbau durch RNasen endogener und exogener Herkunft ist, wurden alle Lösungen ü. N. mit 0,1 \% DEPC inkubiert und autoklaviert, um die sich eventuell in Lösung befindlichen Enzyme zu neutralisieren. Glaswaren wurden weitestgehend vermieden oder ü. N. bei $180^{\circ} \mathrm{C}$ erhitzt. Um eine RNase-Kontamination aus exogener Quelle zu vermeiden, wurden alle Glasgeräte und Einmal-Plastikartikel nur mit Handschuhen berührt. Zusätzlich wurden die Gelkammern mit RNAse away (Biomol, Hamburg) gereinigt. Die Arbeitsschritte wurden nach Möglichkeit auf Eis oder im Kühlraum durchgeführt.

Die Organe für die RNA-Präparation wurden sofort nach dem Entnehmen in einem geeigneten Reaktionsgefäß, in flüssigem Stickstoff schockgefroren. Die Isolierung der RNA wurde mit dem „Trizol total RNA Isolation Reagent“ der Firma Invitrogen, Karlsruhe durchgeführt und basiert auf der Methode von Chomczynski und Sacchi (1987). Bis zu $100 \mathrm{mg}$ Gewebe wurden mit $1 \mathrm{ml}$ „Total RNA Isolation Reagent“ versetzt, mit einem Dispergierwerkzeug (Ultraturrax T 25, Schütt Labortechnik, Göttingen) homogenisiert und zur vollständigen Dissoziation der Nukleoproteinkomplexe 5 min auf Eis inkubiert. Nach Zugabe von $200 \mu$ Chloroform wurde die Suspension gevortext und erneut $5 \mathrm{~min}$ auf Eis inkubiert. Durch Zentrifugation für $10 \mathrm{~min}$ bei 8000x g und $4^{\circ} \mathrm{C}$ wurden die Phasen getrennt. Die obere wäßrige Phase wurde in ein neues Reaktionsgefäß überführt und die RNA durch Zugabe von 1 Volumen Isopropanol für 10 min auf Eis präzipitiert. Durch Zentrifugieren für $10 \mathrm{~min}$ bei $8000 \mathrm{x}$ g und $4{ }^{\circ} \mathrm{C}$ sedimentiert, einmal in $75 \%$ Ethanol gewaschen, abzentrifugiert und die Pellets bei $65{ }^{\circ} \mathrm{C}$ getrocknet und in $50-100 \mu 1$ DEPC-Wasser gelöst. Bis zur weiteren Verwendung wurde die RNA bei $-80^{\circ} \mathrm{C}$ gelagert.

\subsubsection{Konzentrationsbestimmung von Nukleinsäuren}

Die Konzentrationsbestimmung von Nukleinsäuren erfolgte photometrisch durch Bestimmung der Lichtabsorption bei $260 \mathrm{~nm}$ in einem Spektralphotometer (Ultrospec ${ }^{\circledR} 3000$ pro, Amersham Pharmacia, Braunschweig). Die Nukleinsäure-Konzentration wurde nach folgender Formel errechnet: 


$$
\begin{array}{rl}
c=\left(O D_{260}-O D_{320}\right) * \varepsilon * f & f=\text { Verdünnungsfaktor } \\
\varepsilon=50 \mu g / \mu l \quad(D N A) \\
\varepsilon=40 \mu g / \mu l \quad(R N A)
\end{array}
$$

\subsubsection{Gelelektrophorese}

\subsubsection{Horizontale Agarosegelelektrophorese}

Die horizontale Gelelektrophorese wurde hauptsächlich bei Testgelen und Gelen für Insertisolierungen eingesetzt. Je nach Größe der zu trennenden Fragmente wurden $1-2 \%$ ige Gele in 0,5x TBE-Puffer benutzt. Den Gelen wurde Ethidiumbromid in einer Endkonzentration von $10 \mathrm{mg} / \mathrm{ml}$ zugesetzt und anschließend in eine horizontale Gelkammer gegossen. Die Größenbestimmung der DNA - Fragmente erfolgte durch den Vergleich mit dem $1 \mathrm{~kb}$ ladder (Gibco/BRL).

Zur Sichtbarmachung der Lauffront wurde den DNA - Proben vor dem Lauf 20\% Stop-Mix hinzugefügt .

\subsubsection{Denaturierende Agarose-Gelelektrophorese}

(Hodge, 1994)

$$
\begin{array}{ll}
\text { Laufpuffer: } & 1 \times \text { MOPS } \\
\text { RNA-Probenpuffer: } & \begin{array}{l}
60 \% \text { Formamid } \\
25 \% \text { Formaldehyd } \\
15 \% 10 \times \text { Mops-Puffer }
\end{array} \\
& 92,6 \% \text { Stopmix } \\
& 7,4 \% \text { Ethidiumbromid }(w / v)
\end{array}
$$


Zur Herstellung eines denaturierenden Agarosegels (1\%) wurden 2 g Agarose und 20 ml 10x MOPS - Puffer zusammen mit 148 ml DEPC-Wasser aufgekocht. Nach dem Abkühlen bis auf $60{ }^{\circ} \mathrm{C}$ wurden 33,2 ml Formaldehyd zugegeben und das Gel in eine Gelkammer gegossen. Das denaturierende Agarosegel wurde zum Transfer von gelelektrophoretisch aufgetrennter RNA im Northern - Blot (Sambrook et al., 1989) auf einer Nylonmembran benutzt.

Die RNA-Proben (15-30 $\mu \mathrm{g}$ Gesamt - RNA) und $4 \mu$ l RNA-Längenstandard (4 $\mu \mathrm{g})$ wurden in der Vakuum-Zentrifuge oder durch Zugabe von DEPC-Wasser auf ein Volumen von $6 \mu 1$ gebracht, mit $12 \mu \mathrm{l}$ frisch zubereitetem Proben-Puffer vermischt, für $10 \mathrm{~min}$ bei $65^{\circ} \mathrm{C}$ denaturiert und anschließend für 5 min auf Eis gestellt, um eine Renaturierung zu vermeiden. Vor dem Auftragen wurden die Proben mit $6 \mu$ RNA-Ladepuffer versetzt und in die Geltaschen pipettiert. Die Elektrophorese erfolgte in 1 x MOPS-Puffer für 8-10 h bei konstanter Spannung von max. 60 V im Kühlraum bei $4^{\circ} \mathrm{C}$.

\subsubsection{Isolierung und Aufreinigung von DNA-Fragmenten aus Agarosegelen mittels QIAquick Gel Extraction Kit}

Diese Methode ist geeignet, um DNA-Fragmente von 70 b bis zu $10 \mathrm{~kb}$ Länge aus Agarosegelen $\mathrm{zu}$ isolieren und aufzureinigen, wobei bis $\mathrm{zu} 400 \mathrm{mg}$ Agarose pro Reaktionsgefäß eingesetzt werden kann. Das Prinzip dieses Verfahrens beruht auf der selektiven Bindung zwischen DNA und der speziell strukturierten Silicagelmembran im Zentrifugenröhrchen. Das gewünschte DNAFragment wurde anleitungsgemäß isoliert.

\subsubsection{Spaltung von Plasmid-DNA mit Restriktionsendonukleasen}

Standardmäßig wurden $10 \mathrm{U}$ Enzym pro $1 \mu \mathrm{g}$ DNA über 1-2 h bei der Optimumstemperatur des verwendeten Enzyms eingesetzt. Zur „Insert“-Isolierung wurden entsprechend $10 \mu \mathrm{g}$ PlasmidDNA mit $100 \mathrm{U}$ Enzym $(10 \mathrm{U} / \mu \mathrm{l})$ in Reaktionsansätzen von 100-200 $\mu$ l eingesetzt. Doppelrestriktionen wurden in kompatiblen Puffern des Herstellers oder nacheinander nach Hitzeinaktivierung $\left(15 \mathrm{~min}, 65^{\circ} \mathrm{C}\right)$ oder Phenol/Chloroform-Extraktion und EtOH-Fällung 
durchgeführt. Die Vollständigkeit der Spaltung wurde in einer Agarose-Gelelektrophorese überprüft. Die Restriktionsenzyme wurden vor Durchführung weiterer enzymatischer Modifikationen hitzeinaktiviert $\left(15 \mathrm{~min}, 65^{\circ} \mathrm{C}\right.$ ) oder bei hitzeresistenten Restriktionsenzymen über Phenol/Chloroform-Extraktion und EtOH-Fällung entfernt.

\subsubsection{Ligation}

Für die Ligasereaktion wurden 50 ng restriktionsenzymatisch linearisierte Insert-DNA und der entsprechende restriktionsenzymatisch vorbehandelte Vektor in einem molaren Verhältnis von 3:1 zusammen mit dem vom Hersteller mitgelieferten Ligase-Puffer und 0,1 x Volumen T4Ligase in einem $10 \mu 1$ Reaktionsansatz gemischt und ü. N. bei $16{ }^{\circ} \mathrm{C}$ ligiert.

Zur Klonierung von PCR-Produkten wurde das pGEM $^{\circledR}$-T-Easy Vektorsystem (Promega, Mannheim) benutzt. Dieses System enthält linearisierten pGEM $^{\circledR}$-T-Easy-Vektor mit einfachen 3'-T-Überhängen, die kompatibel zu den 3'-A-Überhängen von PCR-Produkten sind, welche von den meisten thermostabilen DNA-Polymerasen (Taq- und Tth-Polymerasen) aufgrund terminaler Transferaseaktivität bei der Elongation angehängt werden (Clark, 1988).

Folgender Reaktionsansatz wurde verwendet:

50 ng pGEM-T Easy Vector

PCR Produkt (Verhältnis Vektor : Insert 1:3)

$1 \mu 1$ T4 DNA Ligase 10x Puffer

$1 \mu 1$ T4 DNA Ligase

Gesamtvolumen: $10 \mu 1$

Inkubation über Nacht bei $4^{\circ} \mathrm{C}$

\subsubsection{Plasmidtransformation in kompetente Escherichia-coli-Zellen}

(Sambrook et al., 1989)

$50 \mu \mathrm{l}$ kompetente E. coli-DH5 $\alpha$-Zellen (Invitrogen, Karlsruhe) wurden auf Eis aufgetaut und nach Zugabe von $5 \mu$ des Ligationsansatzes den Herstellerangaben folgend 30 min auf Eis 
inkubiert. Nach „Hitzeschock“ bei $37^{\circ} \mathrm{C}$ für $20 \mathrm{~s}$ wurden die Zellen 2 min auf Eis inkubiert und nach Zugabe von $950 \mu \mathrm{l}$ SOC-Medium (Invitrogen, Karlsruhe) $1 \mathrm{~h}$ bei $37{ }^{\circ} \mathrm{C}$ inkubiert. Je $100 \mu \mathrm{l}$ der homogenen Zellsuspension wurden zur Kontrolle auf Selektionsplatten (z.B. OjaAgarplatten) ausplattiert und ü. N. bei $37^{\circ} \mathrm{C}$ im Brutschrank inkubiert.

\subsubsection{Polymerase-Ketten-Reaktion (PCR)}

Die PCR-Technik ist eine enzymatische Methode für die in-vitro-Amplifikation spezifischer DNA-Fragmente (Saiki et al., 1988). Die Spezifität dieser Amplifikation basiert auf zwei Oligonukleotidprimern, die das zu amplifizierende DNA-Segment flankieren und nach einer Hitzedenaturierung an den komplementären Strängen binden. Die hitzestabile DNA-Polymerase (Taq-Polymerase) des Archaebakteriums Thermus aquaticus (Chien et al., 1976) synthetisiert die DNA entlang der Region zwischen den Primern. Durch sich wiederholende Zyklen von Denaturierung der DNA-Stränge, Anlagerung der Primer (,Annealing“) und DNA-Synthese „Elongation“" wird eine exponentielle Vermehrung des jeweiligen DNA-Fragments erreicht. Durch den Einsatz der hitzestabilen Taq-Polymerase wird die Automatisierung der PCR in Thermocyclern ermöglicht.

Generell enthält der PCR-Reaktionsansatz folgende Substanzen:

10 ng DNA

$1 \mu 1$ forward primer (10pmol)

$1 \mu 1$ reverse primer (10pmol)

$1 \mu 1$ 10mM dNTPs

$5 \mu 1$ 10x PCR buffer

$1.5 \mu 150 \mathrm{mM} \mathrm{MgCl}_{2}$

$1 \mu 1$ Taq DNA Polymerase (5U/ $\mu \mathrm{l})$

auf $25 \mu 1 \mathrm{H}_{2} \mathrm{O}$ 
Der Reaktionsansatz wurde in einem $200 \mu 1$ PCR-Cup zusammenpipettiert und in einen Thermocycler gestellt. Ein Standard-PCR-Programm ist im Folgenden dargestellt:

Initiale Denaturation $\quad 95^{\circ} \mathrm{C} \quad 5 \mathrm{~min}$

Elongation $\quad 95^{\circ} \mathrm{C} \quad 30$ sek (Denaturieren)

30-35 Zyklen $\quad 58^{\circ} \mathrm{C} \quad 45$ sek (Annlagerung)

$72^{\circ} \mathrm{C} \quad 1-2$ min (Verlängerung)

Finale Verlängerung $\quad 72^{\circ} \mathrm{C} \quad 10 \mathrm{~min}$

\subsubsection{Genotypisierung von genetisch veränderten Mäusen mittels PCR}

Die Genotypen aller Mäuse mit verändertem Erbmaterial (Knockout und Transgene), wurden mittels PCR bestimmt.

DNA wurde zur Analyse aus Mausschwanzbiopsaten, wie oben beschrieben, isoliert und jeweils 0,5-1 $\mu \mathrm{g}$ zu den jeweiligen Reaktionsansätzen hinzupipettiert. Diese sind nachfolgend aufgelistet.

EW 50: $\quad 17.9 \mu 1 \mathrm{H}_{2} \mathrm{O}$

$3 \mu 1$ Puffer (10x, Invitrogen, Karlsruhe)

$1 \mu 1 \mathrm{MgCl}_{2} \quad 50 \mathrm{mM}$

$0,3 \mu 1 \mathrm{dNTP} \quad 10 \mathrm{mM}$

$0,5 \mu \mathrm{l}$ ATG27RP $(10 \mathrm{pmol} / \mu \mathrm{l})$

$0,5 \mu 1$ ATG27FP $(10 \mathrm{pmol} / \mu \mathrm{l})$

$0,5 \mu \mathrm{l}$ NEO RI $(10 \mathrm{pmol} / \mu \mathrm{l})$

0,3 $\mu 1$ Platinum Taq (5 U/ $\mu 1$, Invitrogen, Karlsruhe)

$1 \mu 1$ DNA $\quad(300-500 \mathrm{ng})$ 


$$
\begin{aligned}
& \text { PAD: } \quad 19,5 \mu 1 \mathrm{H}_{2} \mathrm{O} \\
& \text { 2,5 } \mu \text { l Puffer (10x) } \\
& 0,75 \mu \mathrm{l} \mathrm{MgCl} 2 \quad 50 \mathrm{mM} \\
& 0,5 \mu \mathrm{ldNTP} \quad 10 \mathrm{mM} \\
& 0,5 \mu 1 \text { PGK-2seqFP }(10 \mathrm{pmol} / \mu \mathrm{l}) \\
& 0,5 \mu \mathrm{AD} 5 \text { 'seqRP }(10 \mathrm{pmol} / \mu \mathrm{l}) \\
& 0,25 \mu 1 \text { Platinum Taq (5 U/ } \mu \text { l, Invitrogen, Karlsruhe) } \\
& 0,5 \mu 1 \text { DNA (300-500 ng) } \\
& \text { PCY: } \quad 19,5 \mu 1 \mathrm{H}_{2} \mathrm{O} \\
& \text { 2,5 } \mu 1 \text { Puffer (10x) } \\
& 0,75 \mu 1 \mathrm{MgCl}_{2} \quad 50 \mathrm{mM} \\
& 0,5 \mu \mathrm{ldNTP} \quad 10 \mathrm{mM} \\
& 0,5 \mu 1 \text { PGK-2seqFP } \quad(10 \mathrm{pmol} / \mu \mathrm{l}) \\
& 0,5 \mu \mathrm{l} \mathrm{Cyr} 5 \text { 'seqRP } \quad(10 \mathrm{pmol} / \mu \mathrm{l}) \\
& 0,25 \mu 1 \text { Platinum Taq (5 U/ } \mu \text { l, Invitrogen, Karlsruhe) } \\
& 0,5 \mu 1 \text { DNA (300-500 ng) }
\end{aligned}
$$

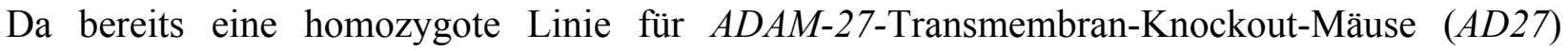
etabliert war, wurde auf eine Genotypisierung der Nachkommen dieser Linie verzichtet.

\subsubsection{Genotypisierung transgener Mauslinien mittels quantitativer Real-Time-PCR}

Aussagen über Zahl und Integration von Genkopien, sowie die Differenzierung zwischen homo und heterozygoten Mäusen wurde durch die Quantifizierung der einzelnen Amplikons relativ zu einem Referenzamplikon mittels quantitativer Real-Time-PCR ermöglicht (Boehm et al., 2004). Zur Detektion wurde der SYBR-Green I-Farbstoff (Abb. 2.1) verwendet, welcher im „2 x QuantiTect SYBR Green PCR Master Mix“ (Qiagen, Hilden) enthalten ist. Er bindet alle doppelsträngigen DNA-Moleküle und emittiert während des Bindungsvorgangs ein Fluoreszenzsignal. 


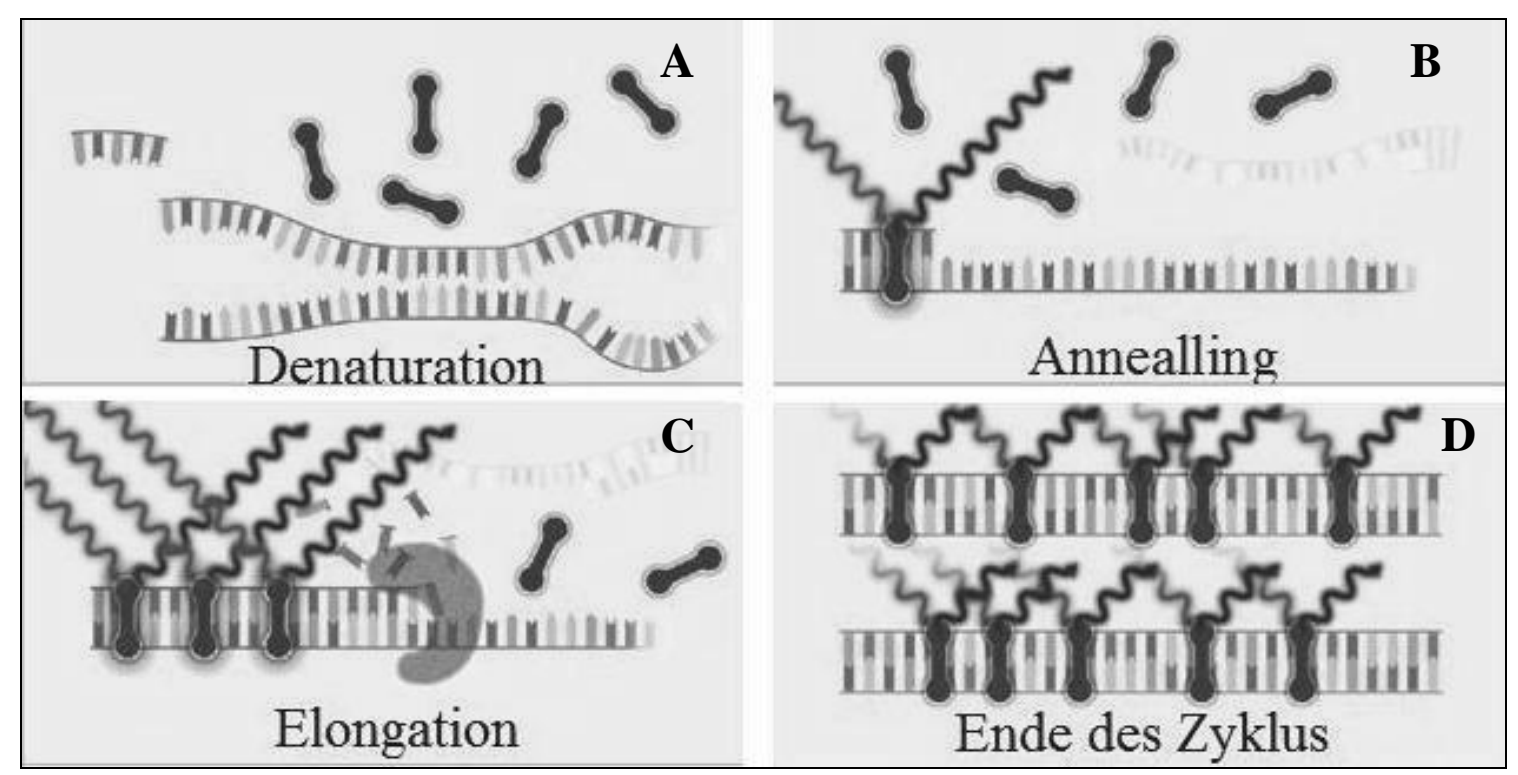

Abb. 2.1 Wirkungsweise des SYBR-Green-I-Farbstoffs (Zuther, 2004, S 41). Beim Denaturierungsschritt (A) ist es für den SYBR-Green I-Farbstoffs unmöglich, sich an die DNA anzulagern, da die DNA einzelsträngig ist. Beim Annealingvorgang (B) lagern sich die Primer an die einzelsträngige DNA an und bilden somit kurze, doppelsträngige Bereiche. An ihnen können wenige SYBR-Green-I-Farbstoff-Moleküle binden. Je weiter die Elongation (C) voranschreitet, desto länger wird der doppelsträngige Bereich, und um so mehr SYBR-GreenI-Farbstoffmoleküle können sich anlagern und Fluoreszenz emittieren (D).

Eine 384-Proben-Hochdurchsatz-Analyse wurde mit dem „ABI Prism 7900 Sequence Detection System“ durchgeführt. Dieses System arbeitet mit einem Temperatur-Cycler und einem Laser, der die Fluoreszenz-Emission der Proben anregt, welche mittels einer ladungsempfindlichen Vorrichtung gemessen wird. Die Daten wurden mit Hilfe der Sequenz-DetektionssystemSoftware (SDS Version 2.1, PE Applied Biosystems) quantifiziert, exportiert und in Excel (Microsoft) ausgewertet. Die Reaktions-Ansätze enthielten 0,25 nM eines jeden Oligonukleotids und $5 \mu 12 \times$ QuantiTect $^{\mathrm{TM}}$ SYBR $^{\circledR}$ Green PCR Master Mix (Qiagen, Hilden). Jedem Ansatz wurden schließlich entweder Verdünnungen der Kontroll-DNA eines bekannt heterozygoten Tieres der F1 - Generation in einer Endkonzentration von 2,5 ng/ $\mu 1,1,25 \mathrm{ng} / \mu 1,0,625 \mathrm{ng} / \mu 1$ und $0,3125 \mathrm{ng} / \mu 1$ oder Proben-DNA von zu untersuchenden Mäusen in einer Endkonzentration von $2,5 \mathrm{ng} / \mu 1$ zugegeben. Alle Primer wurden unter identischen Bedingungen amplifiziert.

Um das Auftreten von unspezifischen Produkten auszuschließen, wurde nach Abschluß der Amplifikation routinemäßig eine Schmelzkurvenanalyse durchgeführt. 
$50{ }^{\circ} \mathrm{C}$

$95^{\circ} \mathrm{C}$

$94{ }^{\circ} \mathrm{C}$

$60{ }^{\circ} \mathrm{C}$ (optimal)

$72{ }^{\circ} \mathrm{C}$

$94{ }^{\circ} \mathrm{C}$

$60{ }^{\circ} \mathrm{C}$

$60{ }^{\circ} \mathrm{C}-95{ }^{\circ} \mathrm{C}$
2 min

$15 \mathrm{~min}$

$\left.\begin{array}{l}15 \mathrm{sec} \\ 30 \mathrm{sec} \\ 1 \mathrm{~min}\end{array}\right\}$

$30 \mathrm{sec}$

$30 \mathrm{sec}$

$2{ }^{\circ} \mathrm{C} / \mathrm{min}$
Vordenaturierung

Denaturierung

40 Zyklen

Annealing

Elongation

Die Kontroll-DNA wurde zur Erstellung einer Standard-Kurve genutzt. Die Anzahl an Zyklen, bei der die Menge des amplifizierten Zielbereichs einen bestimmten Schwellenwert erreicht, ist der sog. Wert $\mathrm{C}_{\mathrm{t}}$. Dieser $\mathrm{C}_{\mathrm{t}}$-Wert korreliert mit der Anzahl der Kopien zum Startpunkt. Eine höhere oder niedrigere Start-Kopiezahl resultiert in einem signifikant früheren oder späteren Anstieg der Fluoreszenz-Emission (Abb. 2.2).
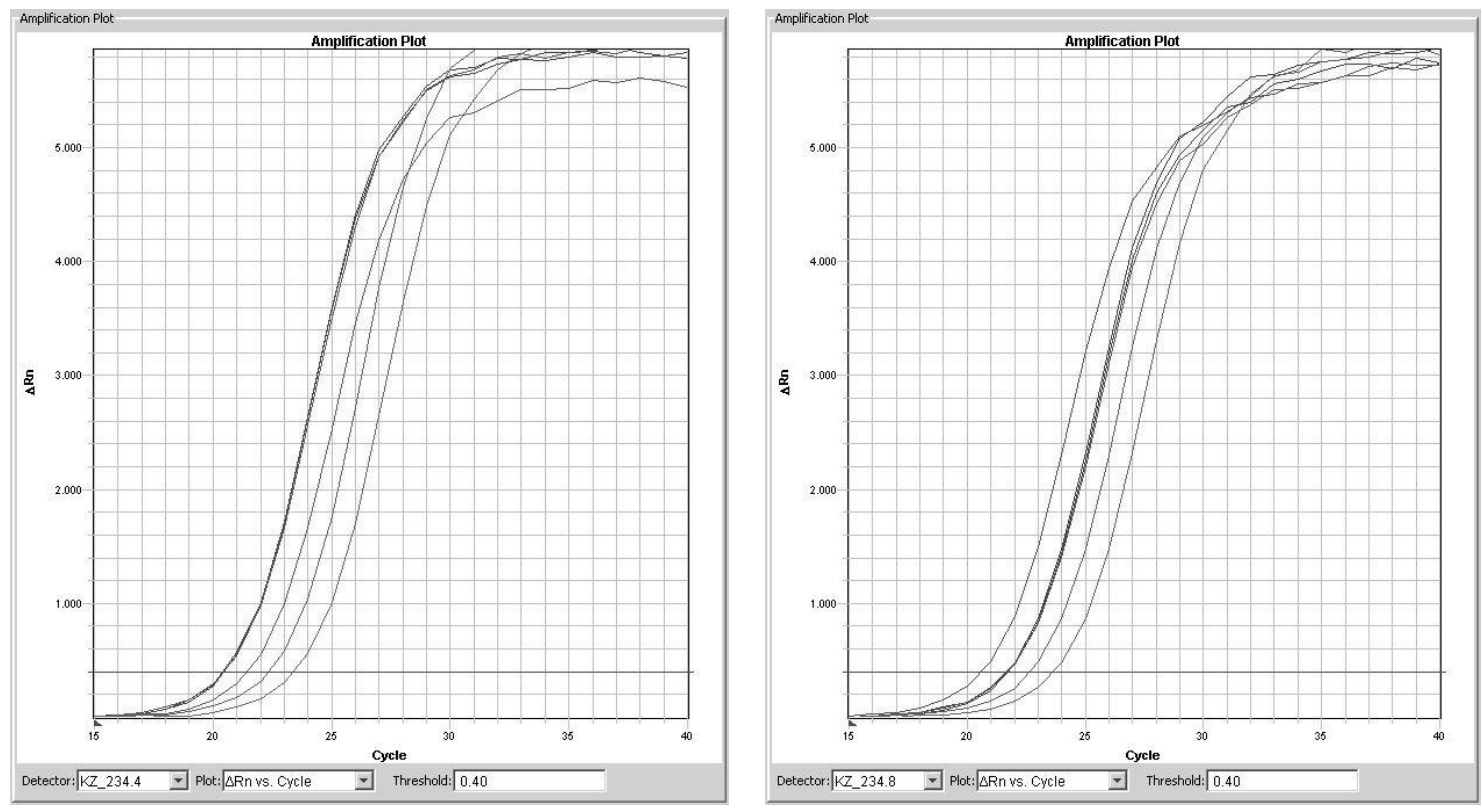

Abb. 2.2 Lineare Darstellung der Standardkurven mit Konzentrationen (Zuther, 2004, S 43): 5,0 ng/pl, 2,5

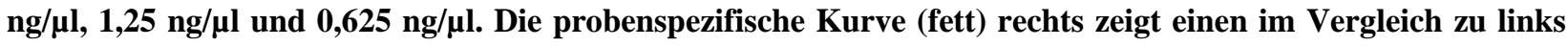
signifikant späteren Anstieg und damit eine (in diesem Fall) um die Hälfte verminderte Konzentration an. 
Die absolute Quantifizierung des Zielamplikons in unbekannten Proben wird ermöglicht durch die Messung des $\mathrm{C}_{\mathrm{t}}$-Wertes und durch lineare Interpolation in der entsprechenden halblogarithmischen Darstellung $\left(\mathrm{c}_{\mathrm{t}} / \log \left(\mathrm{c}_{0}\right)\right)$.

Die absoluten Daten wurden exportiert, in Excel importiert und gegen ein disomes ReferenzAmplikon durch Berechnung des Verhältnisses $\mathbf{c}_{\text {Testamplikon }} / \mathfrak{c}_{\text {Referenzamplikon }}$ normalisiert. Durch diese Methode wird die Menge und die Qualität genomischer DNA für jede Probe normalisiert (Boehm et al., 2004).

Ein Verhältnis $\mathrm{c}_{\text {Testamplikon }} / \mathrm{c}_{\text {Referenzamplikon }}$ von 1.0 zeigt einen balancierten oder normalen, diploiden Karyotyp an, ein Verhältnis von 0,5 oder 1,5 identifiziert monosome oder trisome Bereiche.

\subsubsection{RT-PCR}

Die Methode der RT-PCR (Reverse Transkriptase Polymerase-Ketten-Reaktion) basiert auf der Umschreibung von mRNA in cDNA durch das Enzym Reverse Transkriptase. Durch die RTPCR können kleinste Transkriptmengen im Gewebe detektiert werden und der so erzeugte cDNA-Strang in einer anschließenden PCR mit Hilfe von sequenzspezifischen Primern amplifiziert werden. Die RT-PCR wurde mit Hilfe des SUPERSCRIPT ${ }^{\mathrm{TM}}-$ Kits von Invitrogen (Karlsruhe) durchgeführt.

Für die Erststrang-Synthese (First Strand Synthesis) wurden 1-5 $\mu \mathrm{g}$ RNA zusammen mit $1 \mu \mathrm{l}$ OligodT Primer $(10 \mathrm{pmol} / \mathrm{ml})$ angesetzt und mit Ampuwa auf ein Gesamtvolumen von $12 \mu \mathrm{l}$ aufgefüllt. Die RNA im Reaktionsgemisch wurde zunächst bei $70{ }^{\circ} \mathrm{C} 10$ min denaturiert und kurz auf Eis gelegt. Nach kurzem Zentrifugieren wurden folgende Substanzen hinzugefügt:

$4 \mu 15 x$ First strand buffer

$2 \mu 10.1$ M DTT

$1 \mu 110 \mathrm{mM}$ dNTPs

Der Ansatz wurde mit der Pipette gut gemixt und 2 min bei $42{ }^{\circ} \mathrm{C}$ inkubiert. Anschließend wurde $1 \mu 1$ SUPERSCRIPT-Enzym (Invitrogen, Karlsruhe) hinzugefügt und das Ganze weitere $50 \mathrm{~min}$ bei $42{ }^{\circ} \mathrm{C}$ inkubiert. Es folgten 15 min bei $70{ }^{\circ} \mathrm{C}$ zur Inaktivierung des Enzyms. 
Die Einzelstrangsynthese war damit vollzogen. Die Intaktheit der cDNA wurde mittels PCR, analog der unter 2.2.9 beschriebenen Methode, überprüft. Als Primer wurden GAPDH-FP und GAPDH-RP für das Haushaltsgen Glycerinaldehyd-3-phosphat-Dehydrogenase verwendet. Als Annealingtemperatur wurde dafür $55^{\circ} \mathrm{C}$ gewählt.

\subsubsection{Transfertechniken}

\section{Northern Blot}

Als Northern Blot wird der Transfer von RNA auf nukleinsäurebindende Membranen bezeichnet. Hierbei wird die RNA in denaturierenden Agarosegelen aufgetrennt (2.2.5.2), nach der Elektrophorese photographiert und ohne Vorbehandlung durch ein modifiziertes KapillarblottingVerfahren mit einem Turbo-Blotter ${ }^{\mathrm{TM}}$ (Schleicher \& Schüll, Dassel) auf eine Nitrozellulosemembran übertragen. Nach dem Transfer der RNA aus dem Gel auf den Nitrozellulosefilter wurde der Filter 30 min bei RT getrocknet und die RNA durch 2 h Inkubation bei $80^{\circ} \mathrm{C}$ auf dem Filter fixiert.

\subsubsection{Radioaktive Markierung von DNA-Fragmenten und Hybridisierung}

(Denhardt, 1966; Feinberg and Vogelstein, 1989)

Für Hybridisierungsexperimente wurden DNA-Fragmente radioaktiv markiert. Hierfür wurde das Rediprime $^{\mathrm{TM}}$ II Random Prime Labeling System (Amersham Pharmacia, Braunschweig) verwendet. Pro Reaktion wurden 25 - 50 ng Sonden-DNA eingesetzt, welche in einem Gesamtvolumen von $45 \mu 1$ durch 10 minütiges Kochen in Wasser denaturiert und anschließend für 5 min auf Eis gelegt wurde. Nach Pipettieren der denaturierten Probe in ein Rediprime ${ }^{\mathrm{TM}}$ IIRandom-Prime-Labeling-System-Gefäß und Zugabe von $4 \mu \mathrm{l}[\alpha-32 \mathrm{P}] \mathrm{dCTP}(3000 \mathrm{Ci} / \mathrm{mmol})$ wurde der Ansatz für $1 \mathrm{~h}$ bei $37^{\circ} \mathrm{C}$ inkubiert. Nicht inkorporierte $[\alpha-32 \mathrm{P}] \mathrm{dCTP}$ 's wurden mittels Microspin Columns (Amersham Pharmacia, Braunschweig) entfernt. 
Der Filter wurde in ein mit 2x SSC gefülltes Hybridisierungsgefäß überführt und luftblasenfrei an die Innenseite des Gefäßes angelegt, wobei die RNA/DNA-behaftete Seite nach innen zeigte. Zur Verminderung unspezifischer Bindungen der Sonde wurden $10 \mathrm{ml}$ bei $65^{\circ} \mathrm{C}$ vorgewärmter „Rapid-hyb buffer“ sowie $300 \mu \mathrm{l}$ denaturierte Lachsspermien-DNA zugegeben. Die Membran wurde für mindestens $4 \mathrm{~h}$ bei $65^{\circ} \mathrm{C}$ prähybridisiert. Anschließend wurde die denaturierte und radioaktiv markierte Sonde (s.o.) hinzugefügt und ü. N. bei $65^{\circ} \mathrm{C}$ inkubiert. Nach der Hybridisierung wurde die Membran in $2 \times \mathrm{SSC}$ bei $65^{\circ} \mathrm{C} 2 \times 15 \mathrm{~min}$ im Wasserbad geschwenkt und anschließend in Waschlösung I und II solange gewaschen, bis die Hintergrundaktivität ausreichend gesenkt war.

Die Membran wurde getrocknet, eingeschweißt und mit einem Röntgenfilm in eine Autoradiographiekassette eingelegt. Der Film wurde dann bei $-80{ }^{\circ} \mathrm{C}$ je nach Aktivität bis zu 1 Woche exponiert und anschließend entwickelt.

\title{
2.2.13 Histologische Methoden
}

\subsubsection{Fixierung und Paraffineinbettung von Mausgewebe}

\author{
Bouin'sche Lösung $\quad 15$ x Volumen von Picrinsäure (in $\mathrm{H}_{2} \mathrm{O}$ ) \\ $5 \mathrm{x}$ Volumen Formaldehyd \\ $1 \times$ Volumen Eisessig
}

Um Alterationen der zellulären Strukturen zu verhindern, wurde das präparierte Gewebe für mindestens $24 \mathrm{~h}$ in Bouin'scher Lösung bei RT fixiert. Da Gewebe, welches in Paraffin eingebettet werden soll, wasserfrei sein sollte, wurde dieses in einer aufsteigenden Alkoholreihe dehydriert, anschließend wurde der Alkohol durch Isopropanol entfernt und dieses letztlich durch Xylol ersetzt. Dieses stellt sich wie folgt dar:

$\begin{array}{ll}1 \times 70 \% \mathrm{EtOH} & 15 \mathrm{~min}-\mathrm{üN} \\ 3 \times 80 \% \mathrm{EtOH} & 20 \mathrm{~min} \\ 4 \times 90 \% \mathrm{EtOH} & 30 \mathrm{~min}\end{array}$




$\begin{array}{ll}4 \times 96 \% \mathrm{EtOH} & 30 \mathrm{~min} \\ 5 \times 100 \% \mathrm{EtOH} & 20 \mathrm{~min} \\ \text { Isopropanol } & \text { üN } \\ 75: 25 \text { Isopropanol/Xylol } & 30 \mathrm{~min}-1 \mathrm{~h} \\ 50: 50 \text { Isopropanol/Xylol } & 30 \mathrm{~min}-1 \mathrm{~h} \\ 25: 75 \text { Isopropanol/Xylol } & 30 \mathrm{~min}-1 \mathrm{~h} \\ \text { Xylol } & \text { üN }\end{array}$

Im Anschluß wurde das Gewebe 2 × $3 \mathrm{~h}$ und 1 x ü. N. in Paraplast bei $60{ }^{\circ} \mathrm{C}$ inkubiert, bevor dieses mit flüssigem Paraffin in Blöcke gegossen wurde.

\subsubsection{Paraffinschnitte}

Um histologische Schnitte zu machen, wurden die Paraffinblöcke mit dem darin eingebettetem Gewebe in ein Mikrotom gespannt (Hn 40 Ing., Nut hole, Germany). Die Schnittdicke betrug 4 $5 \mu \mathrm{m}$. Die so erhaltenen Schnitte wurden, um sich auszubreiten, in $40{ }^{\circ} \mathrm{C}$ warmes Wasser gelegt und kurz darauf auf Objektträger aufgebracht. Um überschüssiges Wachs zu entfernen, wurden diese nach dem Trocknen bei RT für $2 \mathrm{~h}$ bei $80^{\circ} \mathrm{C}$ inkubiert und bei RT gelagert.

\subsubsection{Hämatoxylin-Eosin (HE)-Färbung}

Zur lichtmikroskopischen Darstellung von Zellkernen und Zytoplasma wurden die angefertigten Schnitte bzw. Ausstriche mittels HE-Färbung gefärbt. Hierzu wurden die Objektträger 3x für je 3 min in Xylol inkubiert, anschließend erfolgte die Inkubation in einer absteigenden Alkoholreihe für je 2 min. Es fanden folgende EtOH-Konzentrationen Verwendung: 100\%, 96\%, 90\%, 80\%, $70 \%, 50 \%$.

Vor dem Färben für 15 min in Hämatoxilin und nach dem anschließenden Bläuen für 10 min unter fließendem Wasser wurden die Objektträger für je $2 \mathrm{~min}$ in $\mathrm{dH}_{2} \mathrm{O}$ gewässert. Anschließend erfolgte die Färbung für 3 min in Eosin 0,1\% und erneutem 2 minütigem Spülen in $\mathrm{dH}_{2} \mathrm{O}$. 
Abschließend wurden die Schritte der Alkoholreihe und des Spülens in Xylol in umgekehrter Reihenfolge wie oben beschrieben durchgeführt, die Schnitte bei Raumtemperatur getrocknet und anchließend mit Eukitt (Fluka, Neu Ulm) eingedeckelt.

\subsubsection{Indirekte Immunohistochemie-Färbung von Testisschnitten}

Das zu untersuchende Gewebe wurde wie unter 2.2.11.1 beschrieben fixiert, geschnitten und auf Objektträger gebracht. Die Schnitte wurden entparaffiniert und in einer absteigenden Alkoholreihe, wie in 2.2.11.3 beschrieben, bewässert. Die nachfolgende Behandlung gestaltete sich folgendermaßen: Nach dreimaliger Inkubation für je $3 \mathrm{~min}$ in PBS wurde der Primärantikörper in Verdünnung 1:200 aufgebracht und bei $4^{\circ} \mathrm{C}$ ü. N. inkubiert. Danach wurde mit PBS 3x 3 min gespült und der Sekundärantikörper aufgebracht, Verdünnung 1:500 bei Raumtemperatur für 45-60 min. Abschließend erfolgte eine erneute Spülung mit PBS, 3x 3 min und das Eindecken mit Vectashield (DAPI).

\subsubsection{Elektronenmikroskopie}

Um Gewebeschnitte elektronenmikroskopisch beurteilen zu können, wurde das jeweilige Gewebe in der EM-Fixierlösung für ca. 8-12h, jedoch max. $16 \mathrm{~h}$ bei $4^{\circ} \mathrm{C}$ fixiert. Danach wurden die Präparate in der EM-Spüllösung gespült und in dieser zur EM-Begutachtung versandt. Die Begutachtung erfolgte in einem Labor außer Haus.

\subsubsection{Bestimmung von Spermienparametern}

\subsubsection{Spermienzahl in Nebenhodenschwanz, Uterus und Ovidukt}

Der Nebenhodenschwanz wurde unter aseptischen Bedingungen entfernt und in $500 \mu 1 \mathrm{M} 2-$ Medium eingebracht. Die Spermien wurden ausgedrückt und vor dem Zählen 40fach in PBS 
verdünnt. $10 \mu \mathrm{l}$ der Suspension wurden in die Neubauer - Zählkammer pipettiert und 8 Felder, wobei jedes Zählfeld eine Fläche von $0.0025 \mathrm{~mm}^{2}$ hat, unter dem Mikroskop (Olympus BX60) mit 20facher Vergrößerung ausgezählt.

Die Gesamtspermienzahl wurde nach folgender Formel berechnet:

Gesamtzahl $=$ durchschnittliche Spermienzahl $\times 10 \times 40 \times 500$

Zur Bestimmung der Spermienzahl in Uterus und Ovidukt wurden weibliche Wildtypmäuse mit genetisch veränderten Männchen verpaart. Von Vaginalpfropf-positiven Weibchen wurden die Uteri und Ovidukte entfernt und die sich darin befindenden Spermien ausgedrückt und gezählt.

\subsubsection{Spermienmotilität}

Zur Messung der Spermienmotilität wurden Spermien aus dem Nebenhodenschwanz isoliert, wie unter 2.2.13.1 beschrieben, jedoch erfolgte die Isolation nicht in M2, sondern in IVF-Medium. 10 $\mu l$ der Spermiensuspension wurden auf eine Analysekammer aufgebracht. Mittels des CASA (computer assisted semen analysis)-Systems (CEROS Version 10, Hamilton Thorne Research) wurde die Spermienmotilität bestimmt. Hierbei wurden jeweils ca. 6000 - 10000 Spermien von je 3 mutanten Mäusen und von Mäusen der Kontrollinie analysiert. Die Beurteilung erfolgte mittels folgender Parameter: Kurvenstreckengeschwindigkeit (VCL), durchschnittliche Streckengeschwindigkeit (VAP), Linearstreckengeschwindigkeit (VSL), Schwanzschlagfrequenz (BCF), Geradlinigkeit (STR) und die Amplitude des lateralen Kopfversatzes (ALH). Diese wurden jeweils nach 1,5 h, 3,5h und 5,5h nach Präparation gemessen.

\subsubsection{Akrosomenreaktion}

Spermien wurden isoliert und $1 \mathrm{~h}$ bei $37^{\circ} \mathrm{C}$, in $5 \% \mathrm{CO}_{2}$ inkubiert. Anschließend wurden diese in zwei Eppendorfgefäße überführt und 2 min bei 3000 x g zentrifugiert. Der Überstand wurde bis auf $50 \mu \mathrm{l}$ verworfen, 2,5 $\mu 1$ Ionophore A23187 (Endkonzentration $10 \mu \mathrm{m}$ in DMSO) und 2,5 $\mu 1$ Phosphorsäure ( $5 \mathrm{mM})$, als Negativkontrolle, hinzugefügt und $1 \mathrm{~h}$ bei $37{ }^{\circ} \mathrm{C}$ inkubiert. Die Spermien wurden dann 30 min bei $4{ }^{\circ} \mathrm{C}$ in $500 \mu \mathrm{PBS}+2 \%$ Formaldehyd fixiert und nach Abschluss bei $4000 \mathrm{xg}$ für 2 min zentrifugiert und $2 \mathrm{x}$ mit $0,15 \mathrm{mM}$ Ammoniumacetat 
gewaschen. Abschließend wurden die Spermien in $100 \mu 1$ PBS resuspendiert, $30 \mu 1$ dieser Lösung auf einem Objektträger ausgestrichen und mit Coomassie G-250 in $3.5 \% \mathrm{H}_{2} \mathrm{O}_{2}$ für 2,5 min gefärbt. Überreste wurden durch mehrmaliges Waschen mit Wasser entfernt. Unter dem Mikroskop wurden 200 Spermatozoen gezählt, wobei Spermien mit einem dunkelblauen Randsaum die Akrosomenreaktion nicht ausgeführt haben.

\subsubsection{Spermienmorphologie}

Spermien wurden wie unter 2.2.13.1 beschrieben aus dem Nebenhodenschwanz isoliert, auf einem Objektträger ausgestrichen und bei RT getrocknet. Fixiert wurden die Spermien in PBS + $5 \%$ Formaldehyd für 30 min. Der Ausstrich wurde entweder mit DAPI oder mit Hämatoxilin und Eosin gefärbt. Unter dem Mikroskop wurden 200 Spermien morphologisch begutachtet.

\subsubsection{Hypoosmotischer Schwelltest}

Diese Methode wurde von Jeyendran et al. (1984) entwickelt, um die funktionelle Integrität der Spermatozoenmembran zu beurteilen. Der Assay basiert auf dem osmotischen Prinzip, wobei Spermien in eine hypoosmolare Lösung eingebracht werden und man bei vitalen Spermien charakteristische Schwellungsphänömene, hauptsächlich im Bereich des Flagellums beobachten kann.

Hierfür wurden Spermien aus dem Nebenhodenschwanz isoliert, analog wie unter 2.2.13.5 beschrieben. Abweichend dann, wurden die Spermien in $500 \mu 1$ des hypoosmotischen Mediums eingebracht. Als Medium wurde hierfür eine Lösung, die zu 50\% aus D-Fruktose $(13,75 \mathrm{~g} / 500 \mathrm{ml}$ Aqua bidest., $150 \mathrm{mOsmol} / \mathrm{kg}$; reinst, Merck, Darmstadt) und $\mathrm{zu}$ weiteren 50\% aus triNatriumcitrat-Dihydrat (7,35g/500ml Aqua bidest., $150 \mathrm{mOsmol} / \mathrm{kg}$; Merck, Darmstadt) bestand, verwendet. Dieser Puffer wurde zu je 1,0 ml portioniert und die Aliquots bis zum weiteren Gebrauch bei $-20^{\circ} \mathrm{C}$ eingefroren. Nach der Spermienisolation wurden diese in ein Eppendorfgefäß überführt und weitere $1000 \mu 1$ des HOS-Mediums hinzugefügt und 30 min bei $37^{\circ} \mathrm{C}$ inkubiert. Im weiteren Verlauf wurde $10 \mathrm{~min}$ bei $400 \mathrm{xg}$ zentrifugiert, $750 \mu 1$ Überstand abgenommen und das Pellet im verbleibenden Medium resuspendiert. $20 \mu 1$ dieser Lösung wurden 
auf einem Objekträger ausgestrichen und 200 Spermatozoen unter dem Phasenkontrastmikroskop begutachtet.

\subsubsection{Versuch zur Spermien-Oozyten-Bindung (Bindungsassay)}

\subsubsection{Oozytenisolation und Entfernung der Zona pellucida}

Reife Oozyten wurden von superovulierten NMRI oder CD-1 weiblichen Mäusen gewonnen. Diesen wurden 5 IU PMSG (pregnant mare serum gonadotrophin) und nach 48h 5 IU HCG (human chorionic gonadotrophin) intraperitoneal injiziert. Um die Cumuluszellen zu entfernen, wurden die Eizellen unter Zugabe von Hyaluronidase $(3 \mathrm{mg} / \mathrm{ml}) 5-10 \mathrm{~min}$ bei $37{ }^{\circ} \mathrm{C}$ in $\mathrm{M} 16$ Medium inkubiert und $3 \mathrm{x}$ in $200 \mu \mathrm{l}$ M16 - Medium gewaschen. Die Entfernung der Zona pellucida wurde durch 15 - 30 s Behandlung mit saurer Tyrode's Lösung, pH 2.7, erreicht. Nach Überführung in IVF - Medium erfolgte die Überschichtung mit Mineralöl. Vor der weitern Verwendung wurden die Oozyten $1 \mathrm{~h}$ bei $37^{\circ} \mathrm{C}$ und in $5 \% \mathrm{CO}_{2}$ inkubiert.

\subsubsection{Bindungsassay}

Eizellen mit oder ohne Zona pellucida wurden in $50 \mu$ IVF-Medium überführt und ca. 500000 Spermien pro Reaktionsansatz zugegeben. Der Ansatz wurde $30 \mathrm{~min}-1 \mathrm{~h}$ bei $37{ }^{\circ} \mathrm{C}$ und in $5 \%$ $\mathrm{CO}_{2}$ inkubiert. Um unvollständig gebundene Spermien zu beseitigen, wurden die Oozyten $3 \mathrm{x}$ in neuem Medium gewaschen, alle Oozyten eines Versuches wurden in $10 \mu$ IVF - Medium gesammelt. Die Trennung von Spermien und Oozyten erfolgte durch Vortexen.

Die Spermienzahl wurde wie unter 2.2.13.1 beschrieben bestimmt und die Zahl der Spermien pro Eizelle errechnet, indem die Gesamtzahl der gezählten Spermien durch die Zahl der Oozyten dividiert wurde. 
Material und Methoden

\subsubsection{Computeranalyse}

Blast, Blast2, Megablast und andere Programme vom „National Center for Biotechnology Information" (NCBI www.ncbi.nlm.nih.gov) wurden zur Analyse von Genen und Proteinen benutzt. 


\section{Ergebnisse}

\subsection{Einführung zum Ergebnissteil ADAM 27}

Das $A D A M-27-G e n$ wurde erstmals von Zhu et al. (1999) beschrieben. Bei der Maus besteht es aus 20 unterschiedlich langen Exons, variierend von 70 - $200 \mathrm{bp}$, unterteilt von Introns unterschiedlicher Länge (Abb. 3.1a). Das humane Ortholog, ADAM 18, zeigt dieselbe genomische Struktur, bestehend aus 20 Exons ähnlicher Größe (Abb. 3.1b). Das Gen konnte auf Chromosom 8 A2 der Maus identifiziert werden (Bolcun-Filas, 2003). Das menschliche ADAM18-Gen liegt in einer synthenischen Region zur Maus auf Chromosom 8 p11.22.

Die meisten Angehörigen der $A D A M$-Familie befinden sich auf Chromosom 8 und ADAM 27 liegt am Ende eines Genclusters, welcher Gene für $A D A M$ 9, ADAM 32, ADAM 5 und ADAM 3 (Cyritestin) beinhaltet. 
Ergebnisse

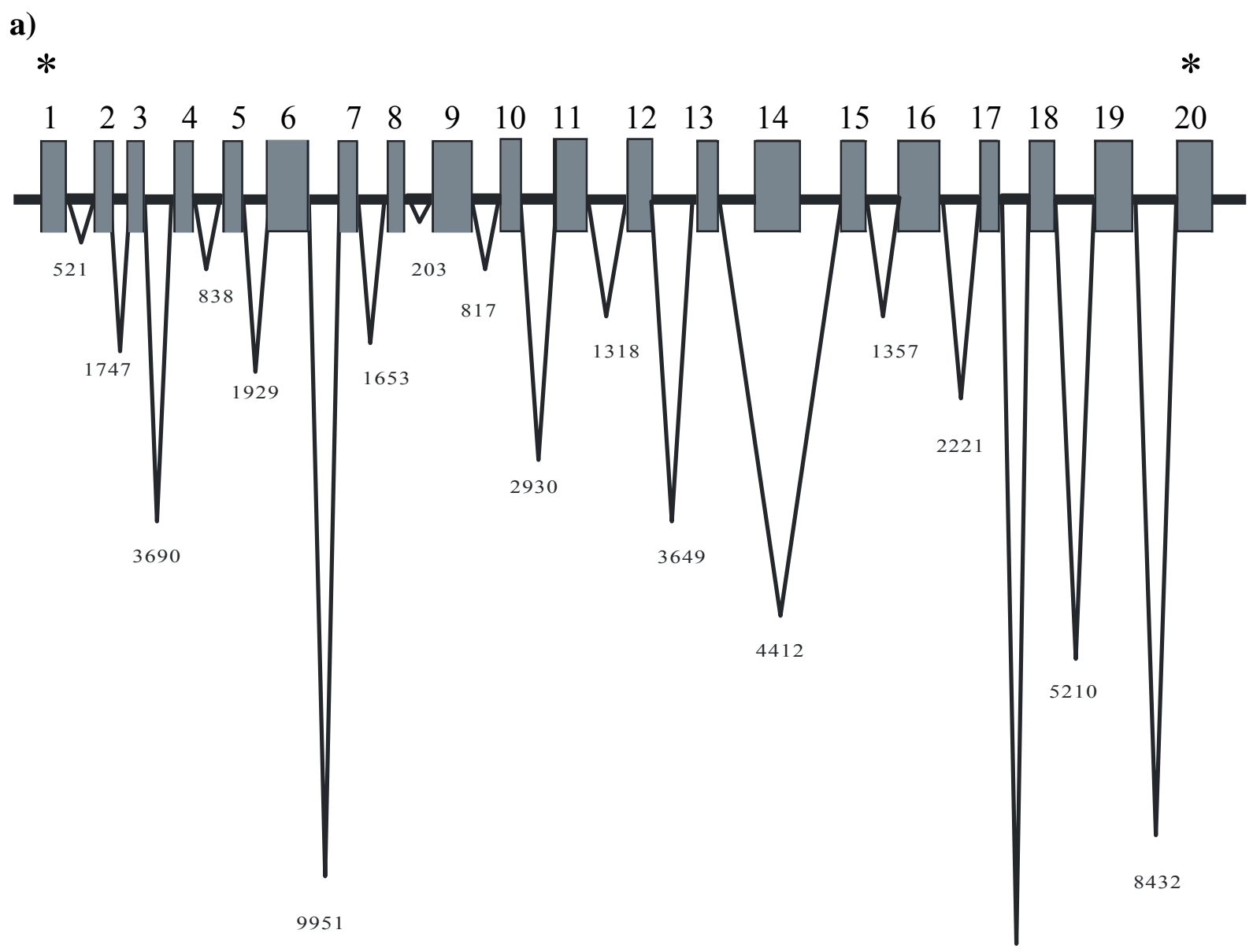

10671 
b)

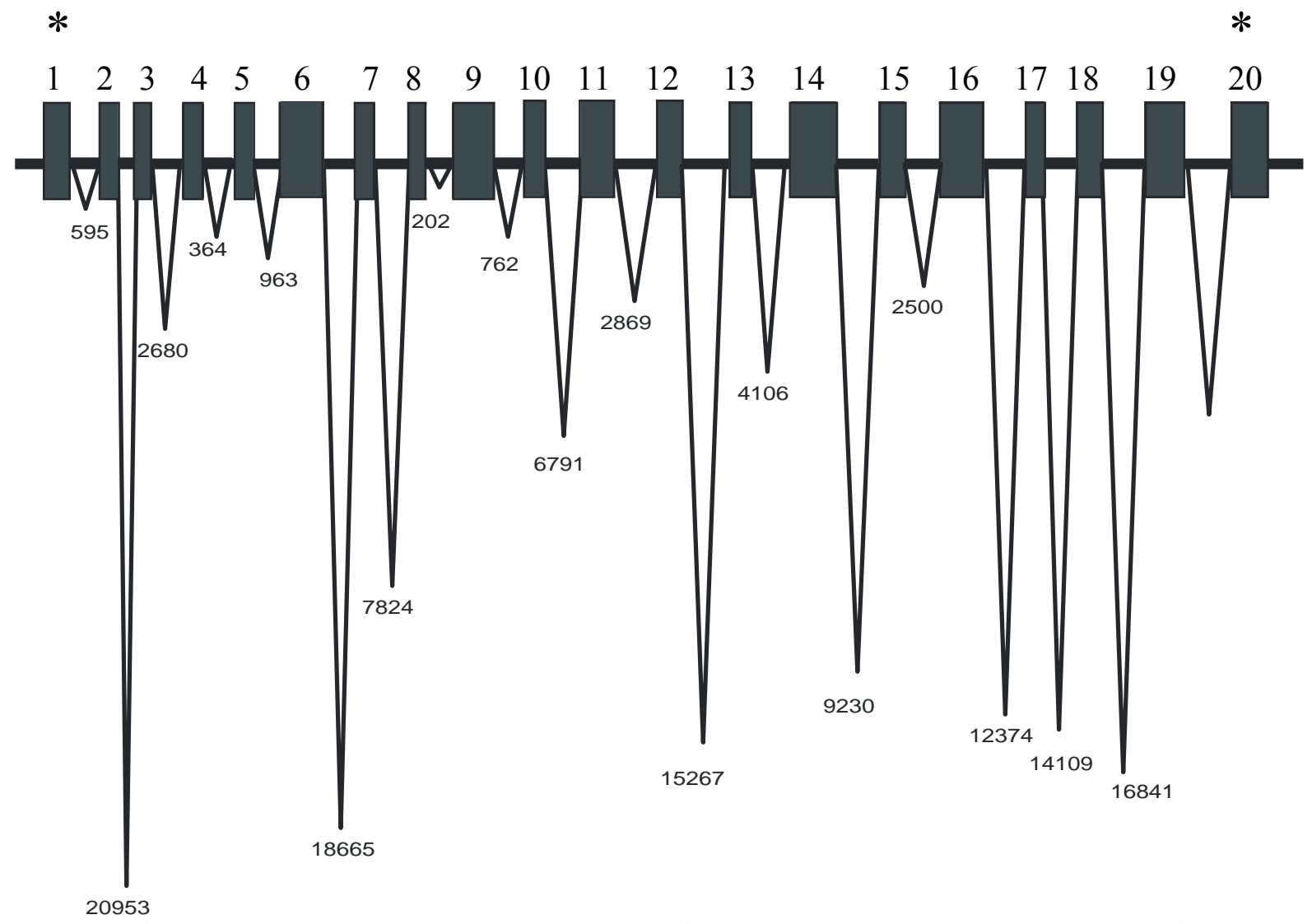

Abb. 3.1: Schematische Darstellung der Exon-Intron-Struktur des ADAM 27-Gens der Maus (a) und seinem humanen Ortholog ADAM 18 (b). Translationsstart und -ende sind mit Sternchen markiert. Die Ziffern oben bezeichnen die Exons, während untenstehende Zahlen die Länge der Introns darstellen (Bolcun-Filas, 2003, S 65f).

a) 1cccacggctgccaacggtcttgagctcggctgagcttcttgcacttggacccaacc

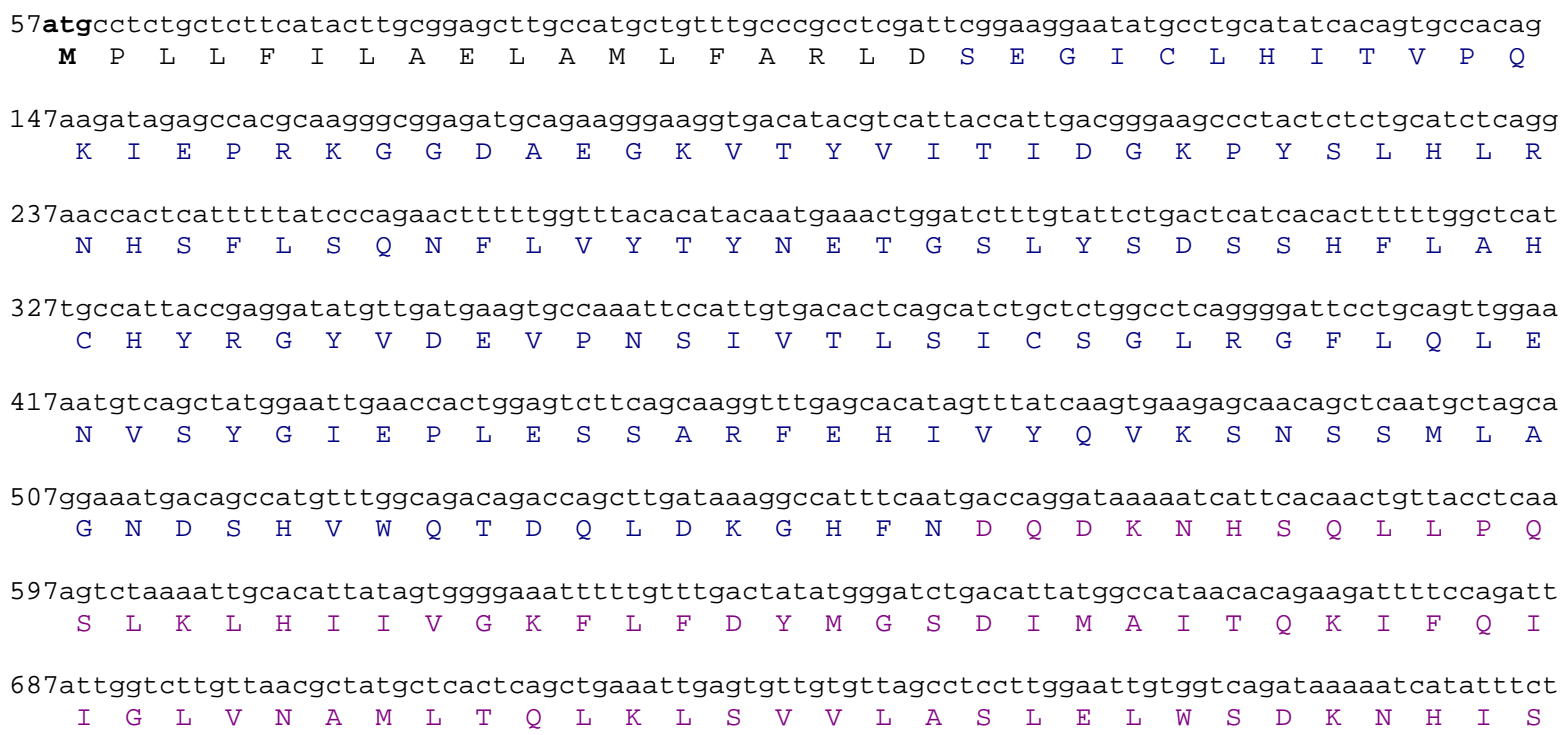




\section{Ergebnisse}

777actgatggaaatgctactgatattttacaaagacttttggactggaaacgagactatcttaccctgcagtccaatgaaataacacactta $\begin{array}{llllllllllllllllllllllllllllll}T & D & G & N & A & T & D & I & L & Q & R & L & L & D & W & K & R & D & Y & L & T & L & Q & S & N & E & I & T & H & L\end{array}$

867ctcatttacaggagacacccgaaatacatcggagcggcatcgccaggtgaaatatgcagtaaaagctatgttgcgggtgttggtatgtat

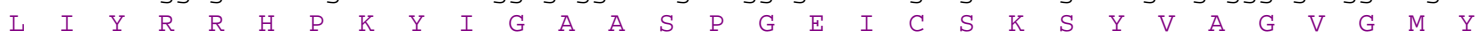

957ccagaagacataggtttggagggat tctcagtggttatcactcaactgattggccttcacataggattaacatacgacgacaatat taga $\begin{array}{llllllllllllllllllllllllllllll} & E & D & I & G & L & E & G & F & S & V & V & I & T & Q & L & I & G & L & H & I & G & L & T & Y & D & D & N & I & R\end{array}$

1047aattgttcctgtcccagcgctccatgcataatgcagcagggagcactgagttccagtgggaagaagacttttagcaactgtagcttgcat $\begin{array}{llllllllllllllllllllllllllllllll}N & C & S & C & P & S & A & P & C & I & M & Q & Q & G & A & L & S & S & S & G & K & K & T & F & S & N & C & S & L & H\end{array}$

1137gactacatgcactatgtttcaaattttgacacgcagtgtcttggtgacctgtcaaatgtgcatgtattgcaaccaaagcaagccgtgtgt

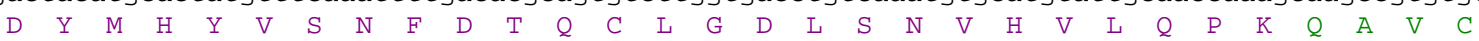

1227ggcaatggaatcatggaagctggtgaggaatgtgactgtggtaatgagacggaatgtcaatttaaagagtgctgcgaccatgaaacgtgc $\begin{array}{llllllllllllllllllllllllllllllll} & N & G & I & M & E & A & G & E & E & C & D & C & G & N & E & T & E & C & Q & F & K & E & C & C & D & H & E & T & C\end{array}$

1317aggctaaaaggctcagcacaatgtggatctggagcttgctgcatgcccacgtgtgagctgtcagcatcaggcacgccctgtaggaaagct

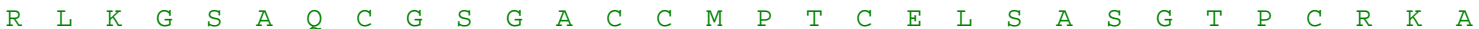

1407gttgacccagagtgtgacttcacagaatattgcgatggatcctctagccactgtgttcctgacacctttgcactgaacggccatttgtgc

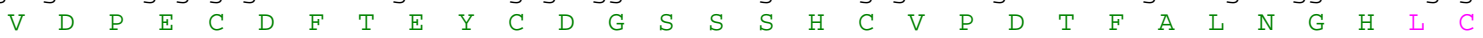

1497aggttgggatctgcatattgctacaatggaagatgccaggctctcaatgaccaatgtgtcagtttatttggaaaaggttctcaaggggct

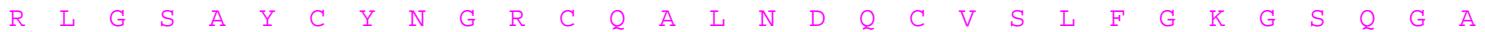

1587tcctatgcctgttttgaaaaagtgaat tcaccacgtgaaaatctggcaaactgtgattctaaagactcgtactcggtaccttgcggacag $\begin{array}{lllllllllllllllllllllllllllllllllll}S & Y & A & C & F & E & K & V & N & S & P & R & E & N & L & A & N & C & D & S & K & D & S & Y & S & V & P & C & G & Q\end{array}$

1677caggatgttctctgtgggaaattagcttgttttcggccgcccaagaattataagagccetagtcaatctgtggtctattcctatgtccac

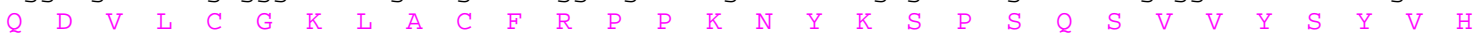

1767gacagcgtgtgtctgtccgtacttcctgggttgtctatgagatcagatggcagagacagcgcatacgtggctgacggcactgtgtgtgga

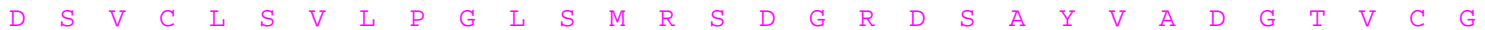

1857ccacaaatgtattgtataaacggaacctgcaaagaagttaatttcacaggaaatgactgcaacgccactaagaagtgcaaagggaatggg $\begin{array}{lllllllllllllllllllllllllllllll}P & Q & M & Y & C & I & N & G & T & C & K & E & V & N & F & T & G & N & D & C & N & A & T & K & K & C & K & G & N & G\end{array}$

1947atatgtaataactttggtaattgccaatgctttcctgactacaggcctccagattgtaacttacagattggatcaccggggggcagcatc $\begin{array}{llllllllllllllllllllllllllllll}I & C & N & N & F & G & N & C & Q & C & F & P & D & Y & R & P & P & D & C & N & L & Q & I & G & S & P & G & G & S & I\end{array}$

2037gacgacgggaacactctcagaactgagtcggcttttgctacaaagcgcctgagtaagaatgaggacagctgggtgatcctgggcttcttc

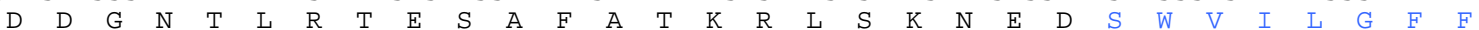

2127atcttctgccttcatcgtaactttccttgttgggatcatgaagagaaacgaaaggaaaatcgtgcctcagggagaacacaaaatatga

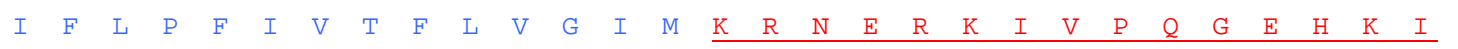
EP010133 synthetisches Peptid

2217gggccat tcat tgcaccagaaatcggccaaggaagctagcagttgatggacccaaggaggaagtgtgtgttctaactgctctgttaccgg tggatacactttaaatctcagacttttggaaaataaaactgatatatgcacgaaaaaaaaaaaaaaaaaaaaa

b)
$\mathbf{P}$
$\mathbf{M}$
D
C
$\mathbf{E}$
Tm
Ct

Prodomäne Metalloprotease Disintegrin Cysteinreiche EGF-ähnliche Transmembran Zytoplasmaschwanz

Abb. 3.2: a) Nukleotidsequenz und abgeleitete Aminosäurensequenz. Nummerierung der Nukleotide siehe linker Seitenrand, Translationsstart- und -endcodon sind fettgedruckt und mit Sternchen markiert. In der Aminosäurensequenz sind die verschiedenen Domänen (dazu siehe b) farblich markiert. Die 
Aminosäurensequenz, die zur Herstellung der Antikörper verwendet wurde, ist unterstrichen. Zur Bedeutung der Abkürzungen der Amino- und Nukleinsäuren siehe Abkürzungsverzeichnis (S. V).

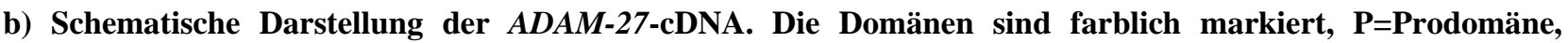
M=Metalloproteasedomäne, $D=$ Disintegrindomäne, C=Cysteinreiche Domäne, E=EGF-ähnliche Domäne, Tm=Transmembrandomäne, $\mathrm{Ct}=$ Zytoplasmaschwanz

\subsection{Strategien}

Um die Funktion des $A D A M-27-G e n s$ zu charakterisieren, wurden zwei Knockout-Strategien entwickelt, sowie eine transgene Mauslinie generiert. Die erste der Knockout-Strategien, ist die so genannte TM-Strategie, im Weiteren als AD27 bezeichnet (Abb. 3.3a). Bei dieser wurde die Transmembrandomäne des Proteins ausgeschaltet (Bolcun-Filas 2003). Bei der zweiten Strategie, der so genannten ATG-Strategie, im Weiteren $\boldsymbol{E} W 50$ genannt (Abb. 3.3b), wurde das ganze Gen ausgeschaltet, indem die ersten drei Exons des Gens entfernt wurden (Bolcun-Filas 2003). Für beide Strategien wurden Mäuse der genetischen Hintergründe 129/SVxC57BL/6J sowie 129/SV verwendet. Bei der als PAD bezeichneten transgenen Linie (Abb. 3.3c), wurde ein Genkonstrukt entworfen, bei welchem das $A D A M$-Gen unter den PGK-2-Promotor gestellt ist. Dieser Promotor ist Bestandteil des PGK-2-Gens, welches für eine Isoform der Phosphoglyceratkinase kodiert. Die PGK-2 wird hodenspezifisch ab dem Pachytänstadium in der Spermatogenese exprimiert. Unter diesem Promotor kann eine Überexpression des Genproduktes erreicht werden. Zusätzlich wurde das Fluoreszenzprotein EGFP (enhanced green fluorescence protein) eingebracht, welches ebenfalls mittels PGK-2 Promotor überexprimiert wird (Zawacka, 2004). Hierfür wurden Mäuse mit dem genetischen Hintergrund FVB verwendet. 


\section{Ergebnisse}

a)

AD27

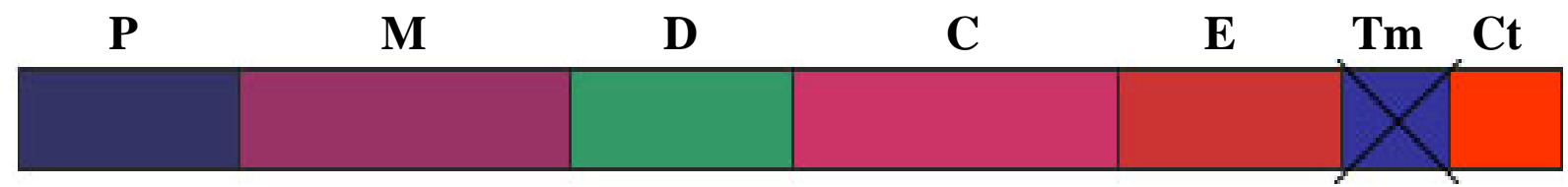

b)

EW50

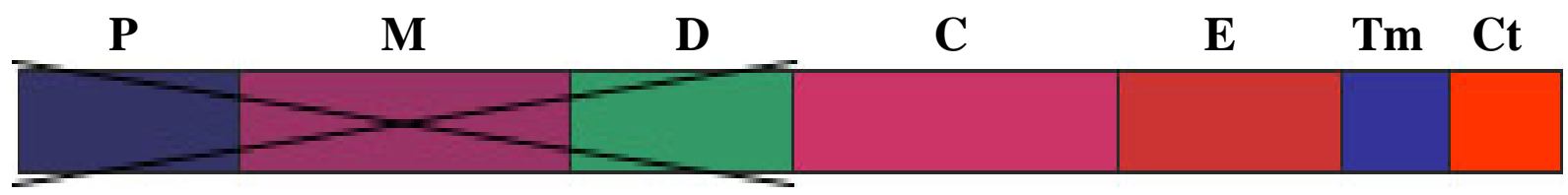

c)

PAD
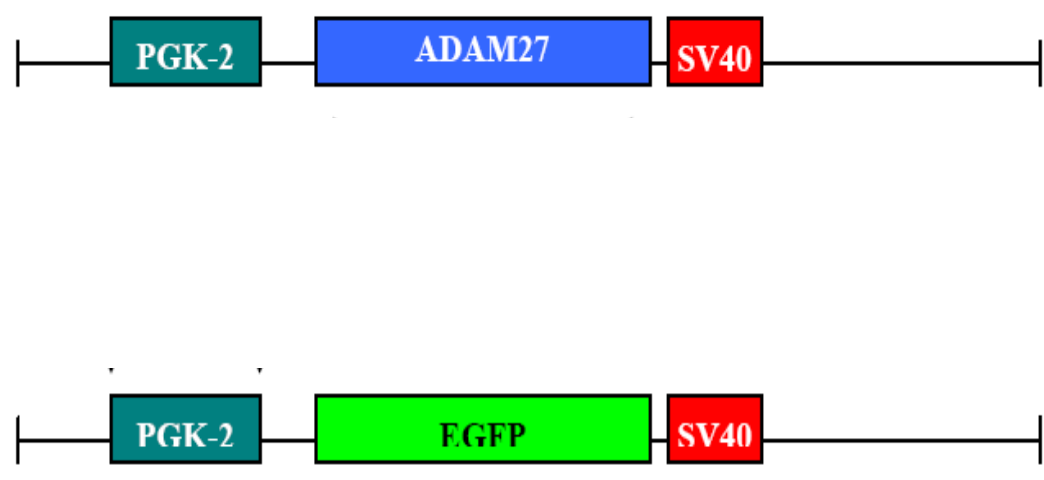

Abb. 3.3: Die verschiedenen Studienstrategien anhand schematischer Darstellungen der cDNA.

a) AD27: Ausschalten der Transmembrandomäne, b) EW50: Ausschalten der ersten drei Domänen, was zur kompletten Genausschaltung führt, c) PAD: Überexpression des ADAM-Gens mittels PGK-2 (Phosphoglyceratkinase 2)-Promotor, zusätzlich enthält das Konstrukt eine SV-40-Region. Weiterhin wurde ein Genkonstrukt mit dem enhanced green fluorescence protein (EGFP) eingebracht. 


\subsection{Analyse von AD27-Knockout-Mäusen}

\subsubsection{Wurfgrößenstatistik}

ADAM-27-Transmembran-Knockout-Mäuse sind phänotypisch unauffällig und haben keine makroskopisch sichtbaren Veränderungen oder Läsionen. Jedoch bei Verpaarung der heterozygoten F1-, sowie der homozygoten F2-Generation der Mäuse mit 129/SV-Hintergrund war eine Reduktion der Nachkommenzahl von durchschnittlich 4,2 Jungen pro Wurf der F1Generation, sowie 2,3 Jungen pro Wurf der F2-Generation zu beobachten. In Abb. 3.4 sind die Verpaarungen und deren durchschnittliche Nachkommenzahl (Mittelwert errechnet aus 9-10 Verpaarungen) dargestellt. Die Nachkommenzahl der Mäuse mit 129/SVxC57BL/6J HybridHintergrund war nicht beeinflusst, weshalb diese Mäuse nicht zur weiteren Forschung benutzt wurden.

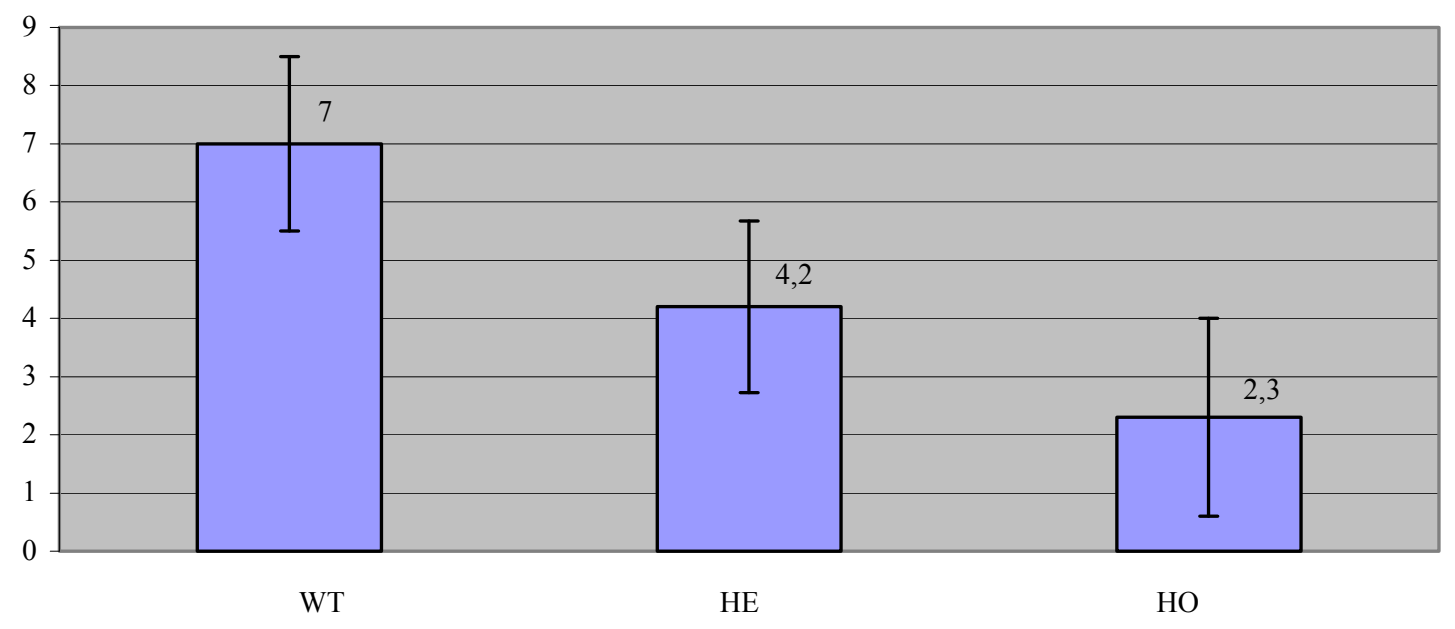

\footnotetext{
Abb. 3.4: Durchschnittliche Nachkommenzahl verschiedener Verpaarungen von AD27-Knockout-Mäusen. WT $=$ Wildtyp, $\mathrm{HE}=$ Heterozygotenverpaarung, $\mathrm{HO}=$ Homozygotenverpaarung. Es zeigte sich eine deutliche Reduktion der Nachkommenzahl in der Heterozygoten- und eine noch stärkere Reduktion in der Homozygotenverpaarung. Angaben mit Standardabweichung (dargestellt als Fehlerbalken).
} 


\section{Ergebnisse}

Weitere Untersuchungen ergaben einen deutlichen Unterschied der durchschnittlichen Nachkommenzahl zwischen jungen und alten $A D 27^{-/-}$-Männchen, verpaart mit Wildtypweibchen. Jüngere Männchen (bis zu einem Alter von 6 Monaten) erzeugten im Schnitt 4,6 Junge, während ältere Männchen ( $\mathrm{ab}$ einem Alter von 6 Monaten) lediglich 2,2 Jungen pro Wurf erzeugten.

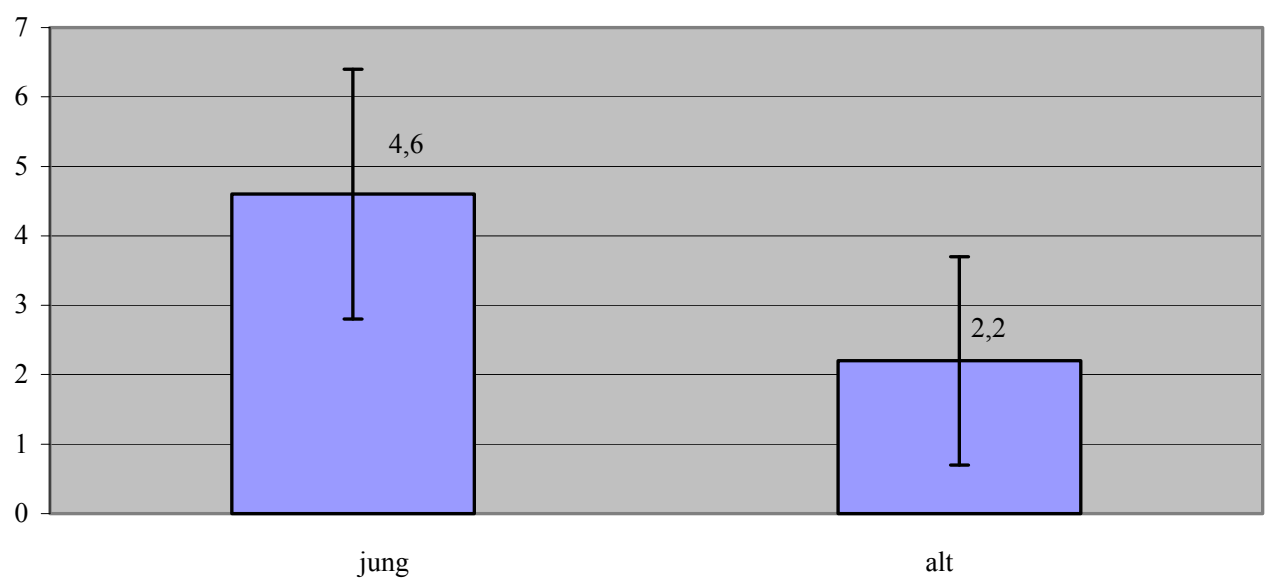

Abb. 3.5: Durchschnittliche Wurfgröße von $A D 27^{-/}$-Männchen verpaart mit Wildtypweibchen, getrennt nach Alter; jung $\leq$ sechs Monate, alt $\geq$ sechs Monate; Angaben mit Standardabweichung (dargestellt als Fehlerbalken). Zunehmende Reduktion der mittleren Nachkommenzahl mit zunehmendem Alter.

\subsubsection{Embryonalentwicklung}

Um die Embryonalentwicklung beurteilen zu können, wurden homozygote Knockout-Weibchen sowohl mit homozygot Knockout-, als auch mit Wildtypmännchen verpaart. Die Uteri der Vaginalpfropf-positiven Weibchen wurden am Tag 10,5 p.c. präpariert, die gefundenen Embryonen gezählt und hinsichtlich ihres makroskopischen Phänotyps beurteilt. Eine Reduktion der Embryonenzahl konnte bei den Verpaarungen beobachtet werden. Bei der HomozygotenVerpaarung betrug die mittlere Zahl gefundener Embryonen 2, bei der Verpaarung mit Wildtypmännchen betrug diese Zahl 3,4. Der Anteil fehlgebildeter Embryonen war nicht über das Normalmaß hinaus erhöht; Homozygoten-Verpaarung im Schnitt 0,75 fehlgebildete Embryonen, Verpaarung mit Wildtypmännchen 0,6 fehlgebildete Embryonen. 


\section{Ergebnisse}

a)

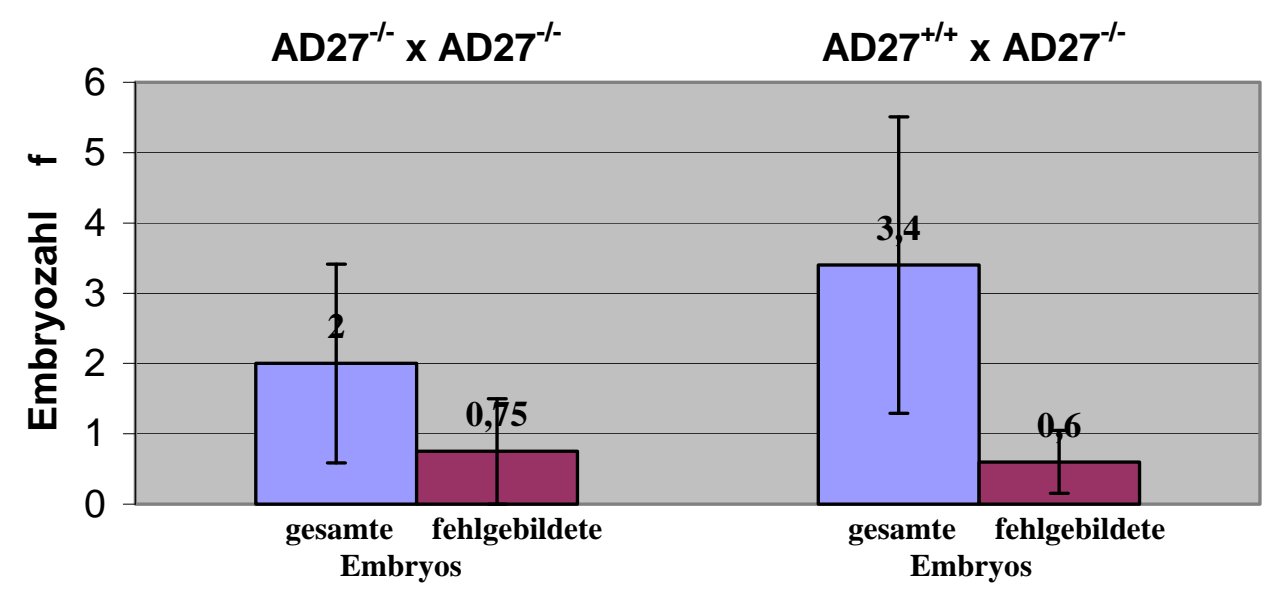

b)
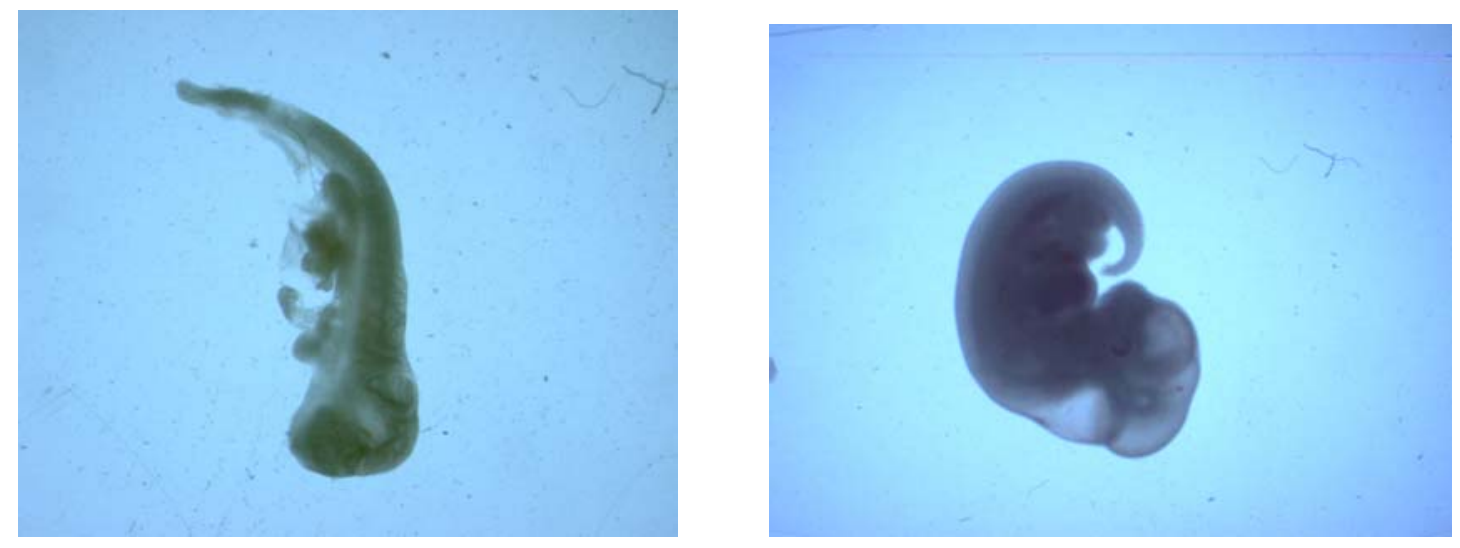

Abb. 3.6: a) Durchschnittliche Embryonenzahl und mittlere Zahl makroskopisch veränderter Embryonen. Angabe immer Männchen x Weibchen, Standardabweichungen als Fehlerbalken angegeben. Zu sehen ist eine verringerte Embryonenzahl am Tag 10,5 p.c., bei $A D 27^{\prime-}$ - und eine leicht verringerte Zahl bei $A D 27^{+/+}$ Männchen. b) Beispiel eines makroskopisch fehlgebildeten Embryos (linkes Bild), sowie eines normalen Embryos (rechtes Bild); beide präpariert 10,5Tage p.c.

Zum Ausschluss einer eventuellen Sterblichkeit während der Embryonalentwicklung wurden superovulierte Wildtyp- und $A D 27^{-/}$-Weibchen mit alten und jungen $A D 27^{-/-}$-Männchen verpaart und die Vaginalpfropf-positiven Mäuse am Tag 0,5, und 1,5 p.c. präpariert. Unter aseptischen Bedingungen wurden hierbei die Ovidukte entfernt und die Oozyten aus selbigen herausgespült. Befruchtete Eizellen sind am Tag 1,5 p.c. bereits im Zweizellstadium und sind somit von 


\section{Ergebnisse}

unbefruchteten Oozyten zu unterscheiden. Die Beurteilung von am Tag 0,5 p.c. präparierten Oozyten erfolgte anhand der sich bei befruchteten Eizellen bildenden Pronuklei. Befruchtete Oozyten wurden gezählt und in Relation zur Gesamtzahl von gezählten Eizellen gesetzt (siehe Abb. 3.7). Es zeigte sich mit 67\% befruchteter Eizellen am Tag 0,5 p.c. eine leichte Reduktion bei jungen $A D 27^{-/}$-Männchen im Vergleich zum Wildtyp. Eine deutlich geringere Fertilisierungsrate wiesen alte $A D 27^{-/}$-Männchen auf. Hier wurden lediglich 13,5\% der gezählten Eizellen befruchtet. Bei Wildtyptieren wurde kein signifikanter Unterschied zwischen jungen und alten Männchen hinsichtlich der Fertilisierungsrate gesehen (siehe Abb. 3.7a).

Ein ähnliches Ergebnis erhielt man bei der Präparation der Embryonen am Tag 1,5 p.c.. Hier wurde bei jungen $A D 27^{-/}$-Männchen ebenfalls eine nur leichte Reduktion der Befruchtungsrate gesehen, welche im Mittel 44\% betrug. Junge Wildtypmännchen wiesen eine mittlere Befruchtungsrate von $60 \%$ auf. Alte $A D 27^{-/-}$-Männchen zeigten ebenfalls eine deutlich geringere Fertilisierungsrate von lediglich 17\%, während die Fertilisierungsrate bei alten Wildtyptieren konstant auf dem Niveau der jungen Tiere blieb (siehe Abb. 3.7b).

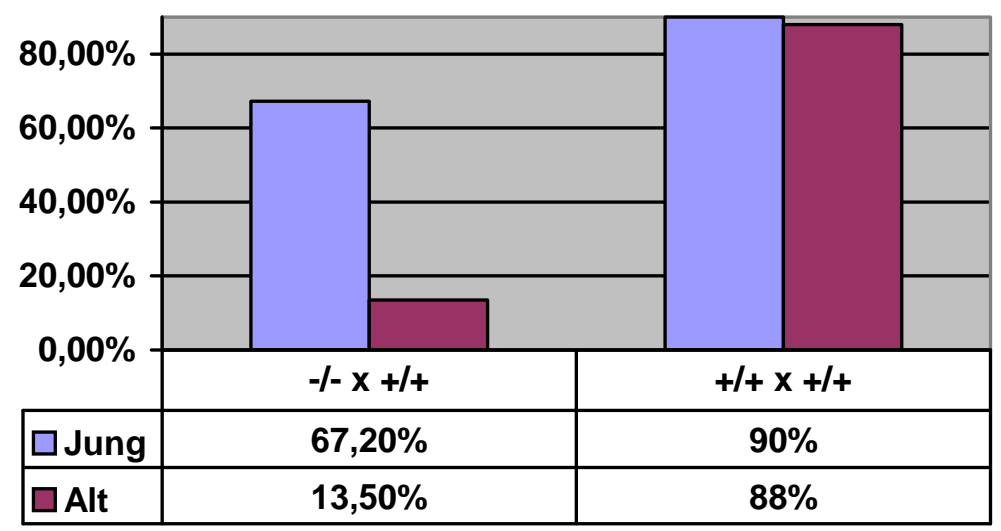

Abb. 3.7a: Prozentualer Anteil befruchteter Eizellen am Tag 0,5 p.c. Verpaart wurden junge ( $\leq 6$ Monate) und alte ( $\geq 6$ Monate) $A D 27^{-/-}$-Männchen mit Wildtypweibchen $(-/-\mathrm{x}+/+) . \quad+/+\mathrm{x}+/+=$ Wildtyp. Leichte Reduktion befruchteter Eizellen bei jungen $A D 27^{-/}$-Tieren im Vergleich zu Wildtypmäusen (67,2\% zu 90\%). Starke Reduktion befruchteter Eizellen bei alten $A D 27^{-\digamma}$-Tieren im Vergleich zu Wildtypmäusen (13,5\% zu 88\%). 


\section{Ergebnisse}

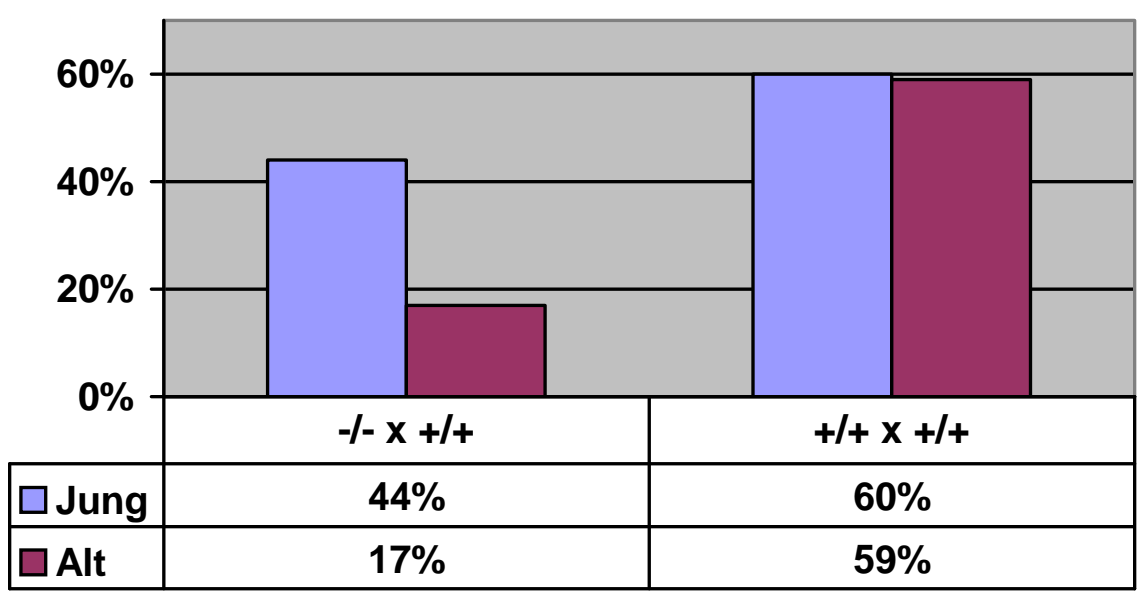

Abb. 3.7b: Prozentualer Anteil befruchteter Eizellen am Tag 1,5 p.c. Verpaart wurden junge ( $\leq 6$ Monate) und alte ( $\geq 6$ Monate) $A D 27^{/}-$-Männchen mit Wildtypweibchen $(-/-x+/+),+/+x+/+=$ Wildtyp. Leichte Reduktion befruchteter Eizellen bei jungen $A D 27^{\prime}$-Tieren im Vergleich zu Wildtypmäusen (44\% zu $\left.60 \%\right)$. Starke Reduktion befruchteter Eizellen bei alten $A D 27^{\prime}{ }^{-}$-Tieren im Vergleich zu Wildtypmäusen (17\% zu 59\%).

\subsubsection{Spermienparameter}

Zur Beurteilung der Spermienzahl in der Cauda epididymis wurden männliche $A D 27^{-/-}$- und $A D 27^{+/+}$-Mäuse unterschiedlichen Alters präpariert. Dabei wurden die Nebenhodenschwänze entfernt und die Spermien in M2-Medium aus diesen herausgepresst. Die Zählung erfolgte unter dem Phasenkontrastmikroskop mittels Neubauerzählkammer. Die Ergebnisse sind aus Abb. 3.8 ersichtlich, es zeigte sich kein signifikanter Unterschied der Spermienzahl im Nebenhodenschwanz zwischen $A D 27^{/-}$- und $A D 27^{+/+}$-Männchen im direkten Vergleich. Auch blieb mit zunehmendem Alter die Spermienzahl konstant. Lediglich bei den einjährigen Tieren konnte ein leichter Abfall der Spermienzahl um ca. eine Zehnerpotenz gesehen werden. Dies ist aber als physiologische Alterserscheinung zu werten 


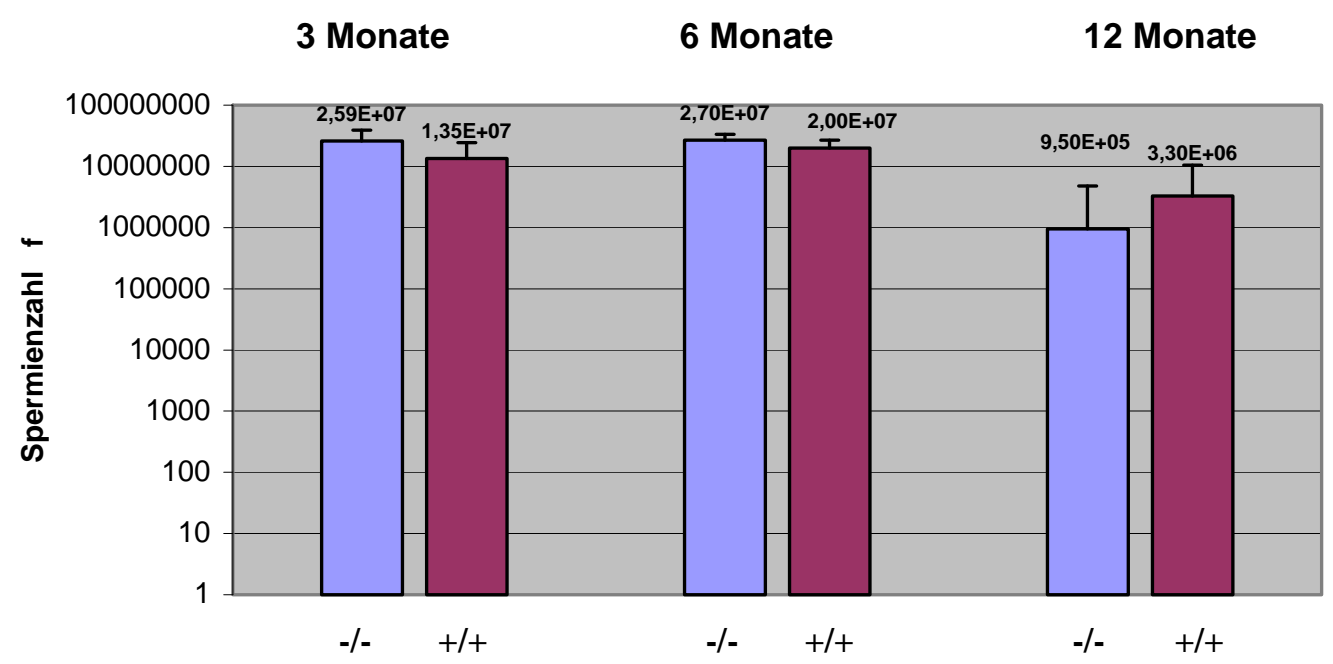

Abb. 3.8: Durchschnittliche Spermienzahl im Nebenhodenschwanz bei $A D 27^{-/}$- und $A D 27^{+/+}$-Mäusen im Alter von 3, 6 und 12 Monaten. Angegeben ist die mittlere Zahl von 4 bis 5 Tieren, sowie die dazugehörige Standardabweichung (als Fehlerbalken). Ein signifikanter Unterschied zwischen der Spermienzahl im Nebenhodenschwanz bei Wildtyp- und Knockout-Mäusen besteht nicht und bleibt auch weitgehend mit zunehmendem Alter konstant .

Da die Subfertilität der $A D 27^{-/}$-Mäuse nicht durch eine quantitativ verringerte Spermatogenese erklärt werden konnte, wurde die Zahl der Spermien im Uterus und Ovidukt nach Verpaarung bestimmt. Hierzu wurden Wildtypweibchen mit jungen und alten $A D 27^{-/}$-Männchen verpaart und die Uteri der Vaginalpfropf-positiven Weibchen präpariert. Die sich darin befindlichen Spermien wurden ausgepresst und unter dem Phasenkontrastmikroskop mittels Neubauerzählkammer gezählt. Die Spermienzahl im Uterus war bei den alten Tieren reduziert im Vergleich zu denen der jungen Tiere, wobei ältere Tiere im Mittel 1,6 x $10^{5}$ Spermien und die jüngeren Tiere durchschnittlich $2,4 \times 10^{6}$ Spermien im Uterus deponierten. Ebenso verhielt es sich mit der Anzahl von Spermien im Ovidukt. Hier konnten bei den alten Tieren keine Spermien gefunden werden, während bei den jungen Mäusen 448 Spermien im Mittel gezählt werden konnten. 


\section{Ergebnisse}

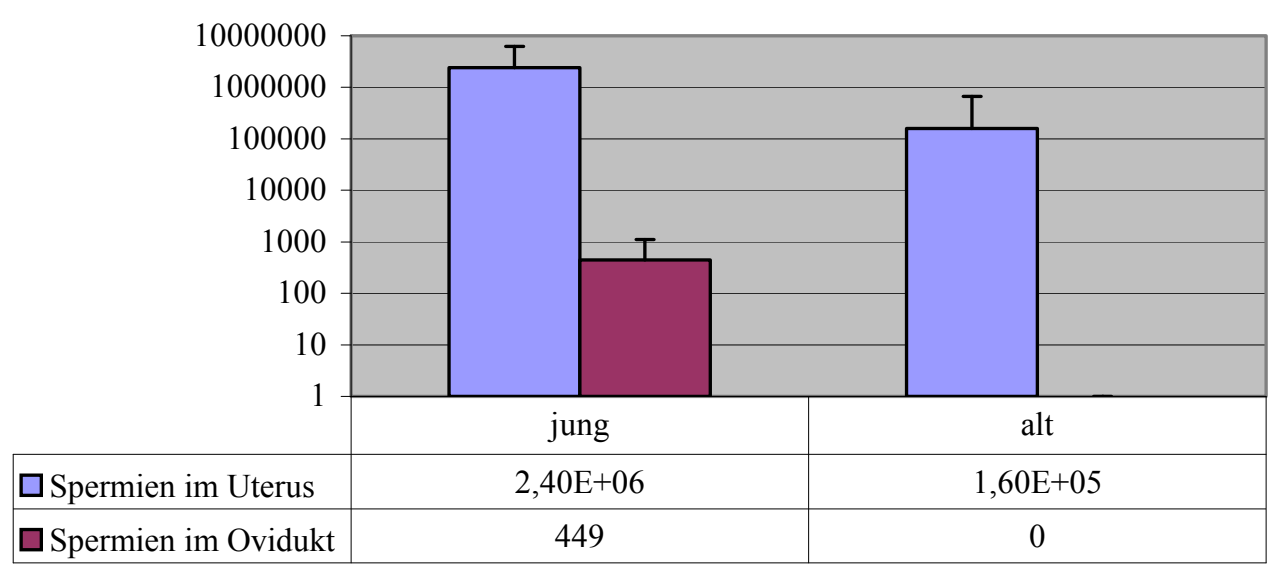

Abb. 3.9: Durchschnittliche Spermienzahl in Uterus und Ovidukt nach Verpaarung von ADAM-27-KnockoutMäusen mit Wildtypweibchen (Standardabweichung als Fehlerbalken). Die Durchschnittswerte wurden aus den Werten von 10-11 Tieren gebildet. Zu sehen ist eine Reduktion der Spermien alter $A D 27^{/-}$-Männchen im Uterus (2,40E+06 Spermien bei jungen vs. 1,60E+05 Spermien bei alten Tieren), sowie das Fehlen von Spermien dieser Tiere im Ovidukt.

Bei der morphologischen Begutachtung von $A D 27^{-/}$-Spermienausstrichen fiel eine erhöhte Rate an Fehlbildungen der Spermien auf, die sowohl Kopf als auch Schwanz betrafen. Die Köpfe waren jedoch deutlich stärker betroffen. Häufig waren die Spermienköpfe vakuolisiert, wobei allerdings mit lichtmikroskopischen Methoden nicht eindeutig bestimmt werden konnte, ob es sich um echte Vakuolen oder um Membraneinschlüsse handelt. Die Untersuchungen wurde an $A D 27^{--}$- sowie Wildtypmännchen unterschiedlichen Alters durchgeführt. Beurteilt wurden jeweils 200 Spermien nach den Kriterien: normal, fehlgebildet mit Vakuolenbildung, fehlgebildet ohne Vakuolenbildung. Die Gesamtzahl der fehlgebildeten Spermien wurde als Prozentangabe der insgesamt gezählten Spermien angegeben, die Zahl der Spermien mit Vakuolen wurde als Prozentangabe der gezählten fehlgebildeten Samenzellen angegeben. Festzustellen war neben der erhöhten Anzahl von Pathologien auch, daß dies mit zunehmenden Alter progredient zu sein schien. 40\% der Samenzellen von 3 Monate alten $A D 27^{-/}$-Tieren waren morphologisch verändert. Dieser Anteil stieg bei 12 Monate alten $A D 27^{-/}$-Tieren auf mehr als 80\%. Auch die Wildtypkontrollen zeigten eine solchen Anstieg, dieser ist jedoch, ebenso wie die Gesamtzahl veränderter Spermien, weniger stark ausgebildet als bei $A D 27^{-/}$-Mäusen. Interessanterweise verhält sich der Prozentsatz vakuolisierter Spermien weniger eindeutig. Bei jungen $A D 27^{-/}$- 


\section{Ergebnisse}

Männchen ist er am höchsten (>50\%), während er bei 9 Monate alten $A D 27^{-/}$-Tieren auf $20 \%$ fällt, um dann im fortschreitenden Alter wieder auf 30\% anzusteigen. (siehe Abb. 3.10)

a)

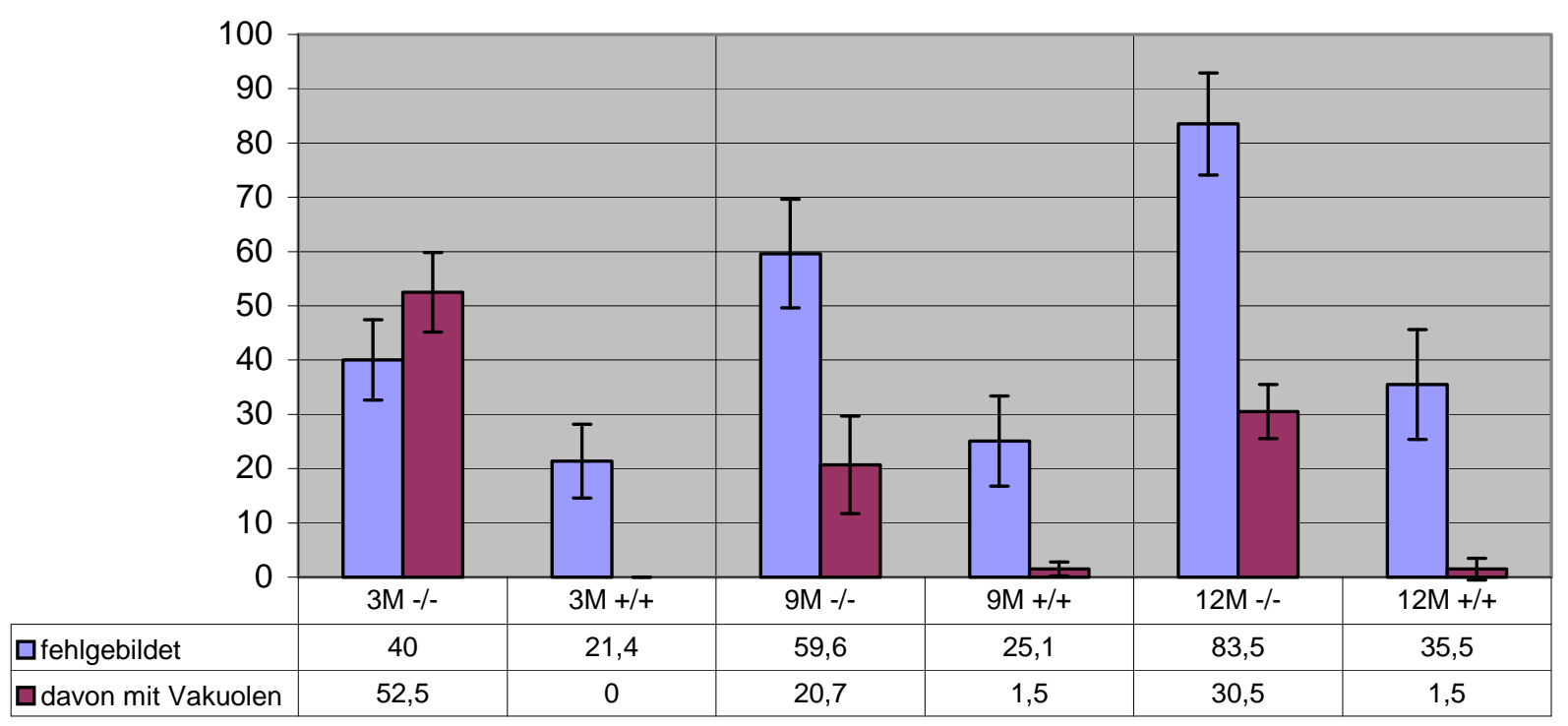

b)

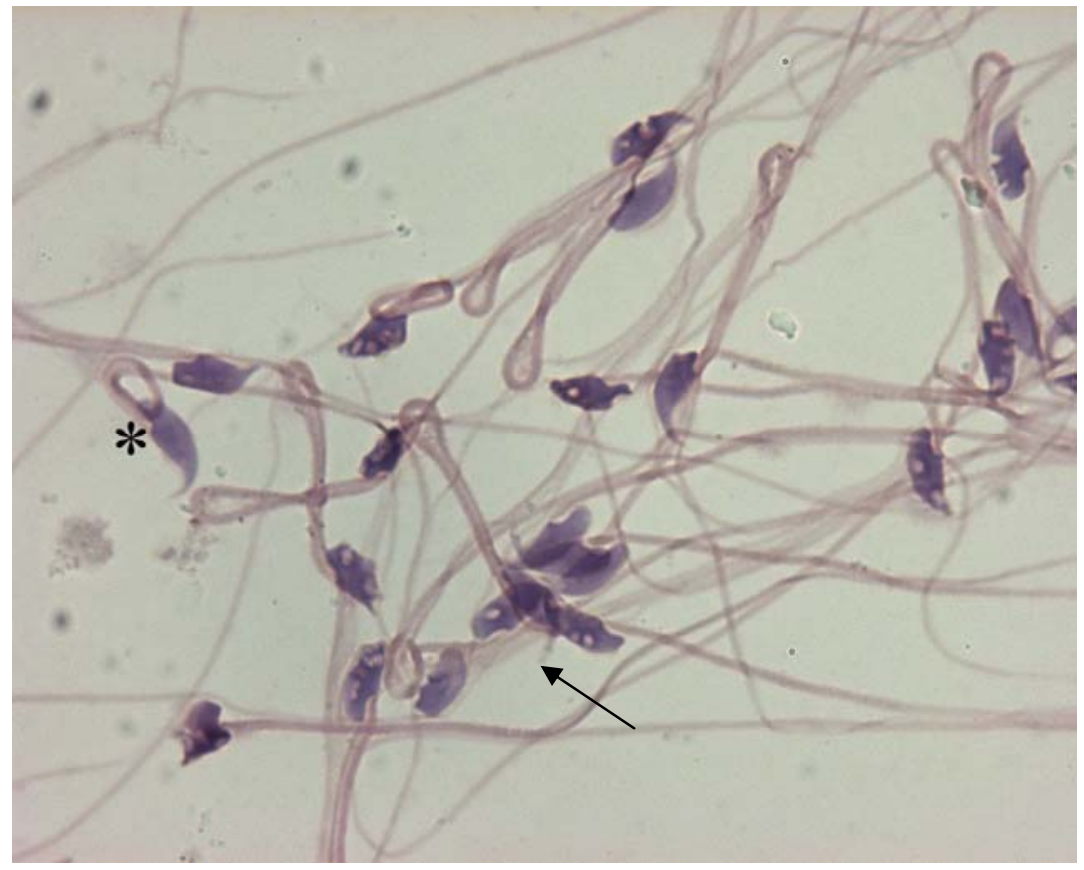


Ergebnisse

Abb. 3.10: a) Morphologie der Spermien von Mäusen unterschiedlichen Alters. Altersangabe in Monaten (z.B. $3 M=3$ Monate altes Männchen), Zahlenangaben in Prozent (Standardabweichung als Fehlerbalken) Erkennbar ist die deutliche Mehrzahl morphologisch veränderter Spermien bei $A D 27^{\prime-}$-Männchen im Vergleich zur Wildtypkontrolle, sowie der deutliche Anstieg fehlgebildeter Spermien mit zunehmendem Alter dieser Tiere. b) Mikroskopische Aufnahme von Spermien eines 16 Monate alten $A D 27^{-/}$-Männchens. Neben wenigen normalen Spermien (markiert mit Sternchen) sind die vielen fehlgebildeten Spermien mit und ohne Vakuolenbildung (siehe Pfeil) gut zu erkennen.

Um zu untersuchen, ob die morphologischen Veränderungen auf die Spermienmotilität Auswirkung haben, wurden Motilitätsmessungen nach 1,5, 3,5 und 5,5 Stunden Inkubation in vitro mit Spermien von $A D 2 T^{\circ-}$ - und Wildtyptieren verschiedenen Alters durchgeführt und jeweils gleiche Altersgruppen miteinander verglichen, sowie eine Gesamtstatistik aller gewonnen Daten erstellt. Vergleicht man den Prozentsatz motiler Spermien bei $A D 27^{-/}$-Tieren im Alter von 3, 6 und 12 Monaten, so fällt eine Abnahme motiler Spermien mit zunehmendem Alter auf. Diese ist jedoch wenig ausgeprägt und nicht eindeutig. Im Gegensatz dazu ist eine deutliche Abnahme des Anteils von Spermien mit progressiver Bewegung in zunehmenden Alter zu beobachten (siehe Abb. 3.11) Die erstellte Gesamtstatistik beinhaltet Daten analysierter Spermien der Linien AD27, sowie der beiden Wildtyplinien 129/SV und FVB als Kontrollen. Bestimmt und statistisch ausgewertet wurden die Parameter Kurven-Strecken-Geschwindigkeit (VCL), durchschnittliche Streckengeschwindigkeit (VAP), Linear-Strecken-Geschwindigkeit (VSL), Schwanzschlagfrequenz (BCF), Geradlinigkeit (STR) und die Amplitude des lateralen Kopfversatzes (ALH). Im Vergleich zur Wildtyplinie $A D 27^{+/+}$konnte keine eindeutige Abweichung der gemessenen Parameter bei $A D 27^{-/}$-Tieren festgestellt werden. 
Ergebnisse

a)

\begin{tabular}{|c|c|c|c|c|c|c|c|c|c|}
\hline$A D 27^{1-}$ & \multicolumn{3}{|c|}{3 Monate } & \multicolumn{3}{|c|}{6 Monate } & \multicolumn{3}{|c|}{12 Monate } \\
\hline Inkubationszeit & $1,5 \mathrm{~h}$ & $3,5 \mathrm{~h}$ & $5,5 \mathrm{~h}$ & $1,5 \mathrm{~h}$ & $3,5 \mathrm{~h}$ & $5,5 \mathrm{~h}$ & $1,5 \mathrm{~h}$ & $3,5 \mathrm{~h}$ & $5,5 \mathrm{~h}$ \\
\hline gemessene Spermien & 3048 & 3278 & 2770 & 3018 & 2806 & 3009 & 3120 & 2798 & 2687 \\
\hline motile Spermien (\%) & 72 & 65 & 56 & 65 & 52 & 56 & 37 & 58 & 44 \\
\hline progr. Spermien (\%) & 49 & 41 & 37 & 47 & 35 & 35 & 18 & 28 & 23 \\
\hline$A D 27^{+/+}$ & \multicolumn{3}{|c|}{3 Monate } & \multicolumn{3}{|c|}{6 Monate } & \multicolumn{3}{|c|}{12 Monate } \\
\hline Inkubationszeit & $1,5 \mathrm{~h}$ & $3,5 \mathrm{~h}$ & $5,5 \mathrm{~h}$ & $1,5 \mathrm{~h}$ & $3,5 \mathrm{~h}$ & $5,5 \mathrm{~h}$ & $1,5 \mathrm{~h}$ & $3,5 \mathrm{~h}$ & $5,5 \mathrm{~h}$ \\
\hline gemessene Spermien & 2135 & 2080 & 2145 & 2956 & 3083 & 2743 & 3235 & 3110 & 2907 \\
\hline motile Spermien (\%) & 48 & 34 & 26 & 71 & 58 & 45 & 61 & 63 & 53 \\
\hline progr. Spermien (\%) & 33 & 21 & 14 & 53 & 39 & 35 & 42 & 39 & 32 \\
\hline
\end{tabular}

b)

ALH
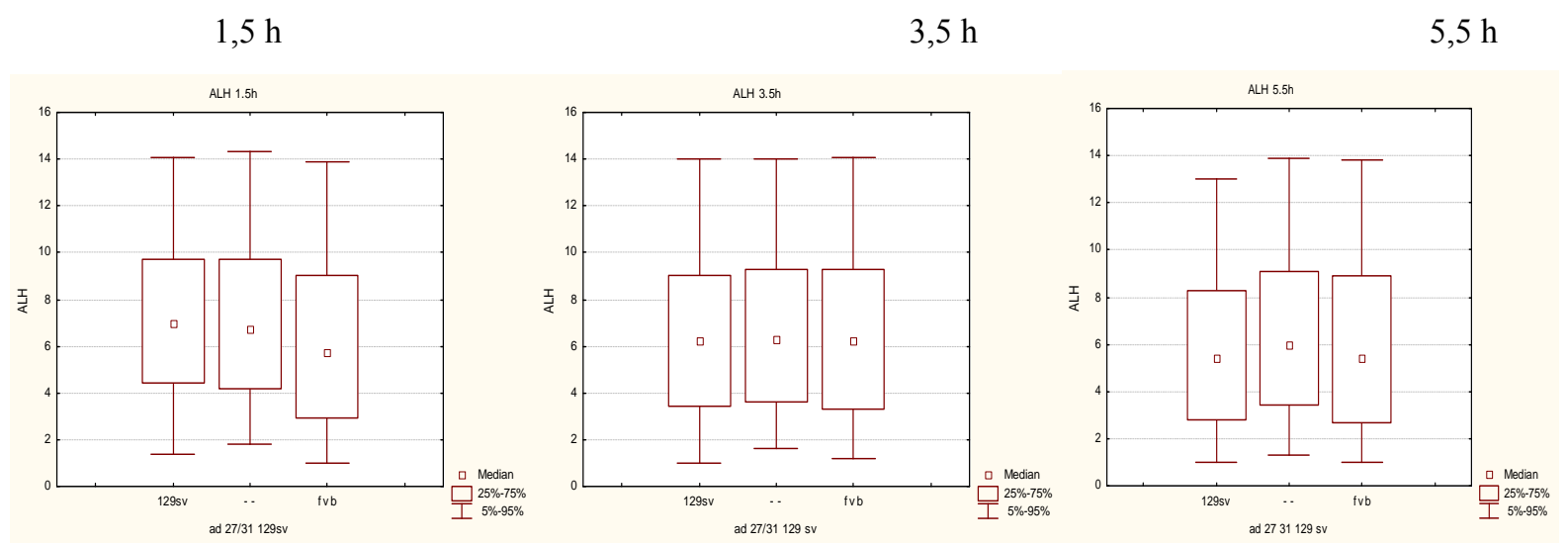

$\mathrm{BCF}$
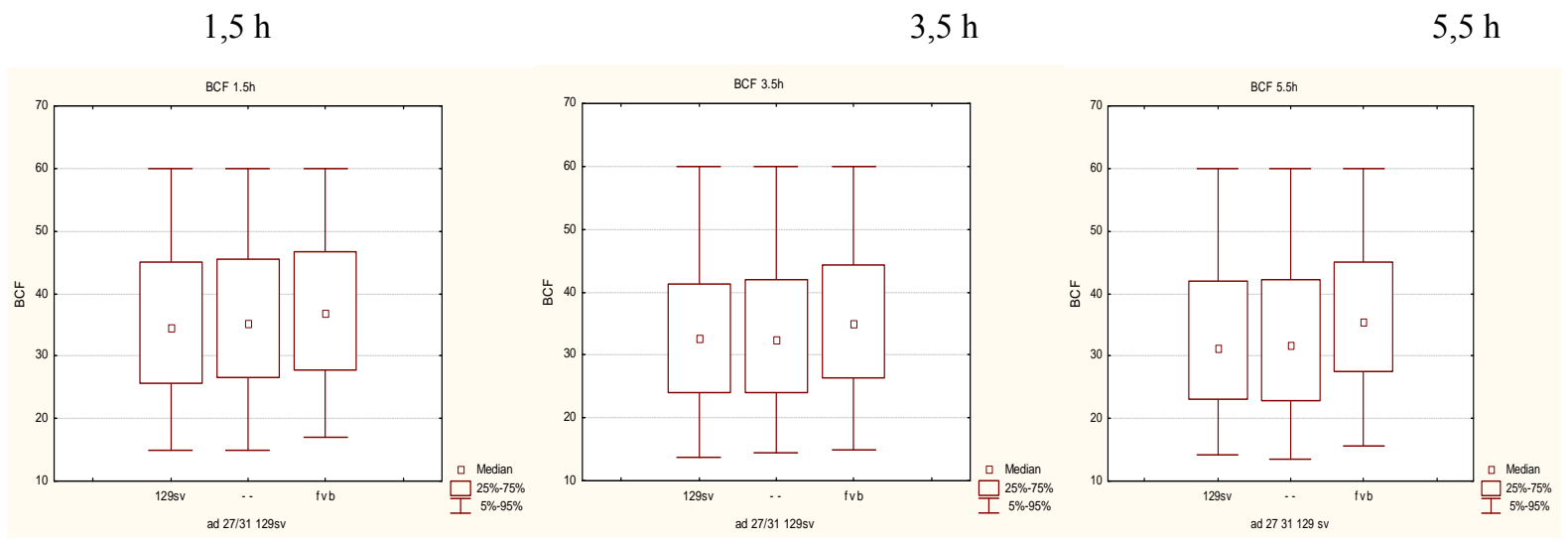
Ergebnisse
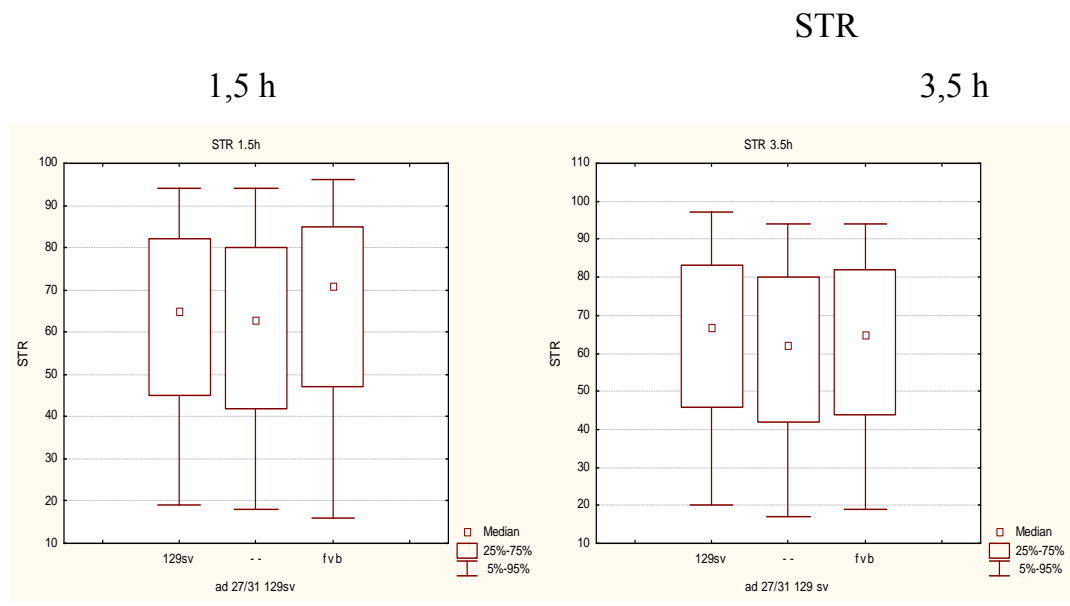

$5,5 \mathrm{~h}$
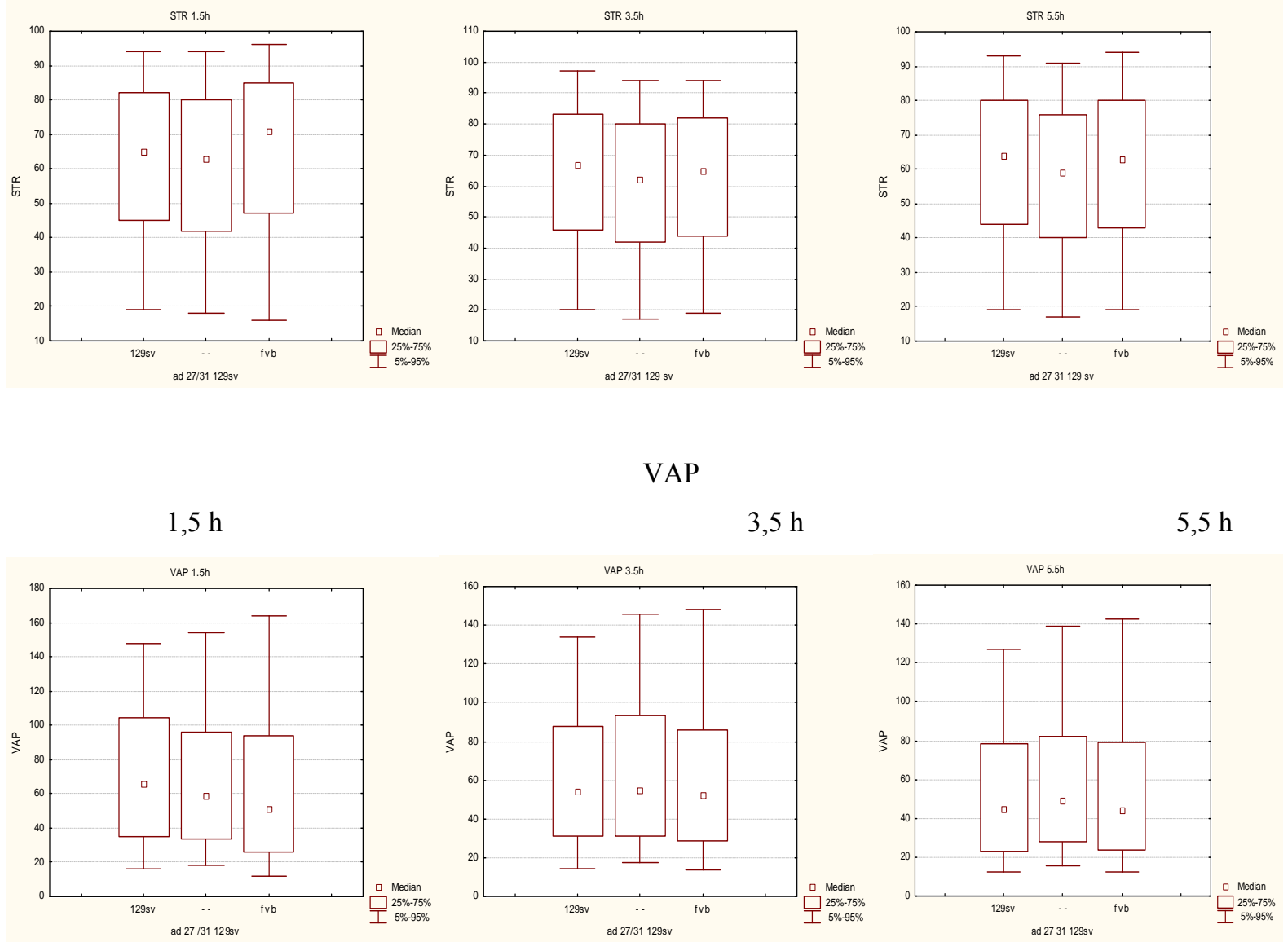

VCL
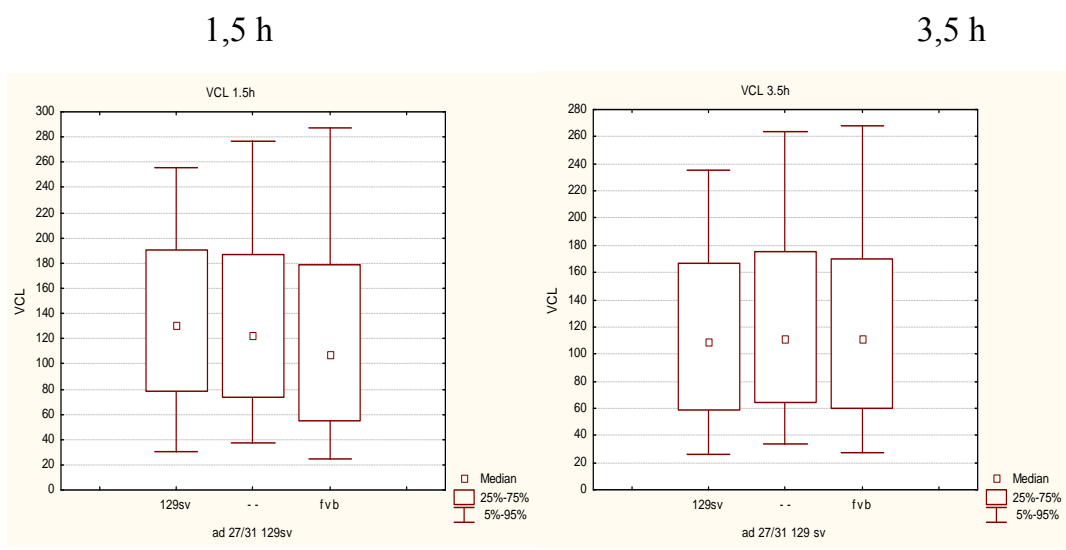

$5,5 \mathrm{~h}$

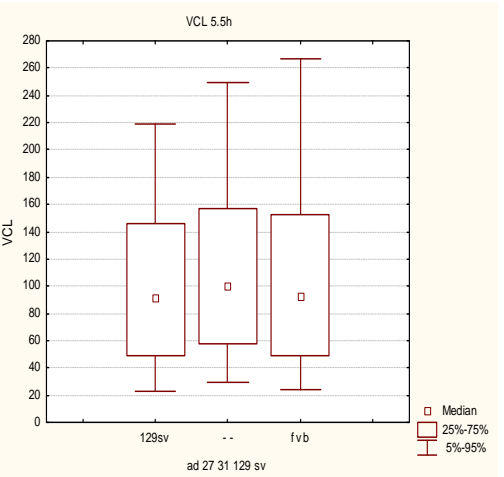




\section{Ergebnisse}

VSL
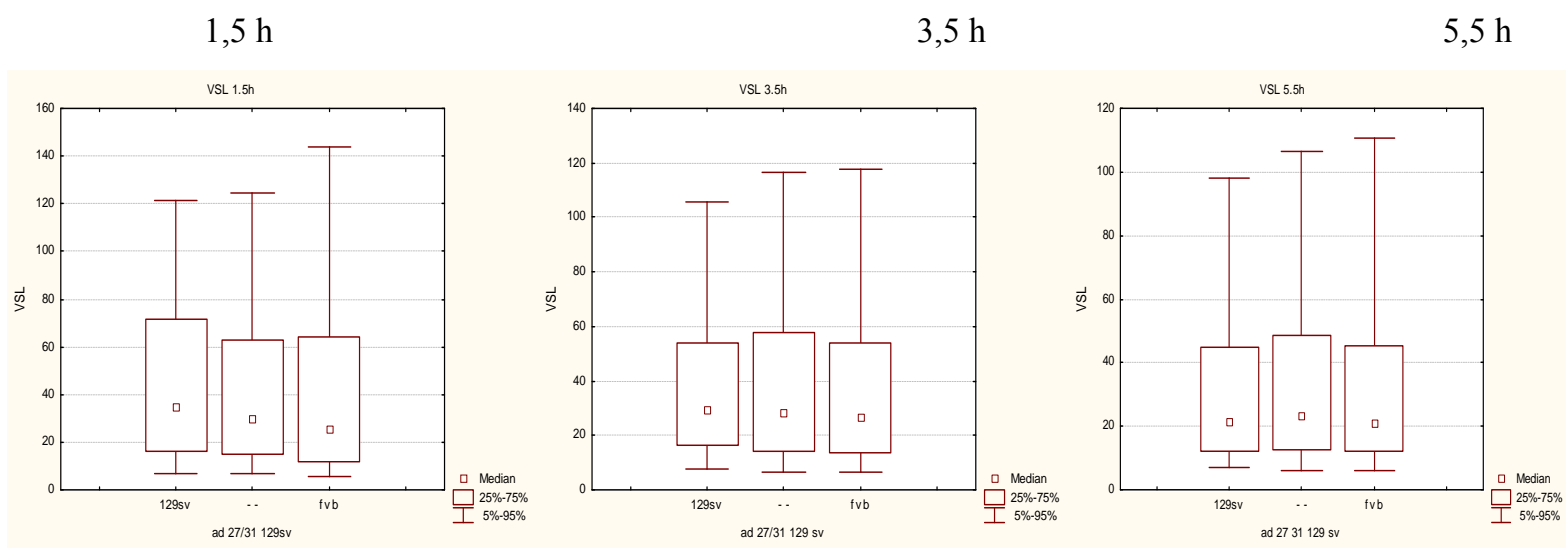

Abb. 3.11: a) Aufstellung der Gesamtmotilität und Progressivmotilität der Spermien von $A D 27^{\prime-}$ - und Wildtyptieren in Abhängigkeit vom Alter der Tiere. Vor allem die Progressivmotilität zeigt eine deutliche Tendenz zur Abnahme mit höherem Alter von $A D 27^{\prime}$-Männchen b) Computer gestützte Analyse der Motilität von Spermien der $A D 2 T^{\prime-}{ }_{-}$und Wildtyptiere. Spermiengeschwindigkeiten in $\mu \mathrm{m} / \mathrm{s}$, Vorwärtsbewegung in Prozent, lateraler Kopfversatz in $\mu \mathrm{m}$ und Schwanzschlagfrequenz in Hertz, jeweils gemessen nach 1,5, 3,5 und 5,5 Stunden Inkubationszeit. Für alle Parameter sind die Mediane und Perzentilen dargestellt. $\mathrm{VCL}=$ Kurven-Strecken-Geschwindigkeit, $\mathrm{VAP}=$ durchschnittliche Streckengeschwindigkeit, VSL $=$ Linear-Strecken-Geschwindigkeit, $\quad \mathbf{B C F}=$ Schwanzschlagfrequenz, STR $=$ Geradlinigkeit, ALH= Amplitude des lateralen Kopfversatzes. Eine eindeutige Veränderung der Motilität konnte nicht gesehen werden.

Die Fähigkeit der Spermien zur Akrosomenreaktion wurde nach Präparation, Fixation und Färbung (siehe 2.2.13.3) unter dem Lichtmikroskop geprüft. Spermien, die die Akrosomenreaktion nicht ausgeführt haben, zeigen einen deutlich sichtbaren, dunkelblau gefärbten Randsaum am Kopf, welches der Akrosomenregion entspricht. Dieser fehlt bei Spermien, welche die Akrosomenreaktion ausgeführt haben. Bei der Auswertung zeigte sich die Zahl von Spermien mit durchgeführter Akrosomenreaktion bei $A D 27^{-/}$-Tieren nicht reduziert im Vergleich zur Wildtypkontrolle (81,5\% zu 85\%). Fraglich bleibt jedoch, ob dies auf einer normalen Funktion des Akrosoms beruht oder die Ursache dafür ein fehlerhaft konfiguriertes Akrosom der fehlgebildeten Spermien ist, welches sich nicht anfärben lässt. (siehe Abb.3.12) 


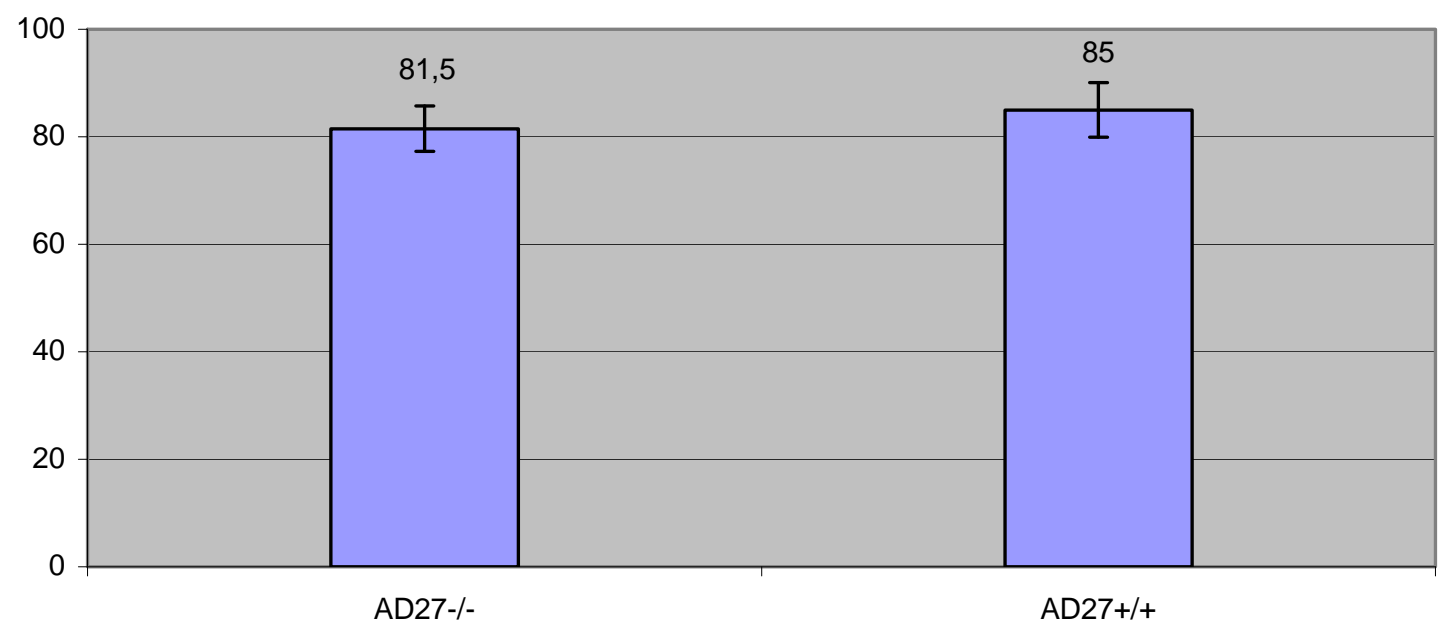

Abb. 3.12: Akrosomenreaktion von $A D 27^{\prime-}$ - und Wildtypmänchen. Angabe in Prozent, Standardabweichung als Fehlerbalken. Kein erkennbarer Unterschied zwischen Knockout- und Wildtyptieren.

Der im Weiteren durchgeführte Versuch, der hypoosmotische Schwelltest, welcher in der andrologischen Diagnostik zu den Standarduntersuchungen bei Infertilität des Mannes gehört, basiert auf dem osmotischen Prinzip und führt nach Einbringen der Spermien in ein hypoosmotisches Medium $\mathrm{zu}$ charakteristischen Schwellungen bei vitalen und befruchtungsfähigen Spermatozoen. Es konnte in verschiedenen Studien (z.B. Tartagni et al., 2004) gezeigt werden, daß schon bei subnormal ausfallendem Schwelltest eine Reduktion der Fertilität vorliegt. Somit steht mit diesem Test ein sehr sensitives Verfahren zur Beurteilung der männlichen Fertilität zur Verfügung. Die Beurteilung der Spermien erfolgte nach dem unten angegebenen Schema von Jeyendran et al. (1984), es zeigte sich ein signifikanter Unterschied zwischen Wildtyp- und $A D 27^{-/}$-Spermien, wobei letztere mit $36,5 \%$ deutlich weniger Schwellungsphänomene zeigten als Wildtypspermien, bei denen $42,5 \%$ der Spermien Schwellungsphänomene aufwiesen (siehe Abb. 3.13). 
a)

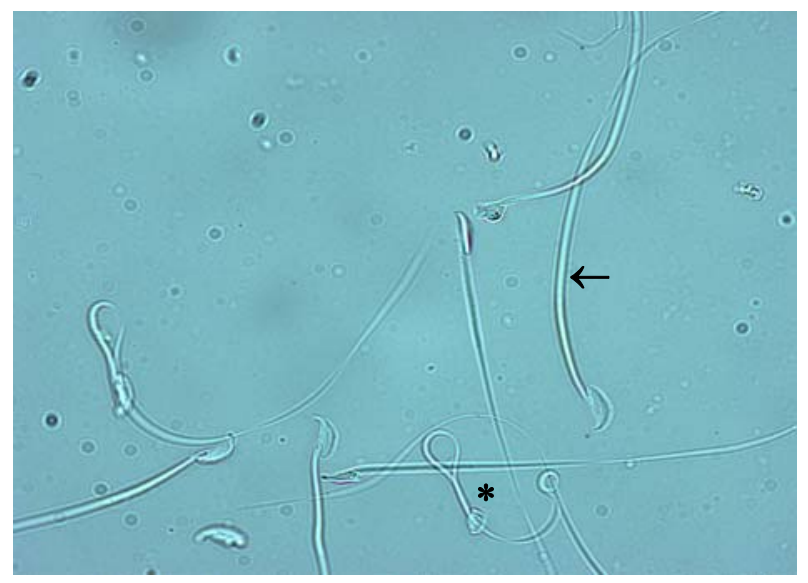

b)

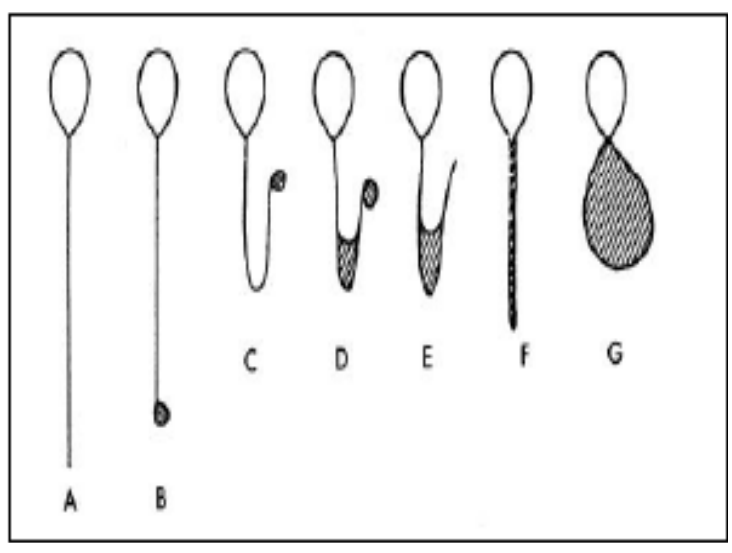

c)

\begin{tabular}{|c|c|c|}
\hline Schwellungstyp & $A D 27^{-/-}$ & $A D 27^{+/+}$ \\
\hline $\begin{array}{l}\mathrm{A}(=\text { nicht } \\
\text { geschwollen })\end{array}$ & $127+/-8$ & $106+/-7,6$ \\
\hline $\mathbf{B}$ & $8+/-7$ & $19+/-16,6$ \\
\hline $\mathrm{C}$ & $1+/-1,3$ & $5+/-2$ \\
\hline D & $17+/-6,4$ & $23+/-6,1$ \\
\hline $\mathbf{E}$ & $44+/-10,7$ & $30+/-11,6$ \\
\hline $\mathbf{F}$ & $1+/-1$ & $1+/-1,2$ \\
\hline G & $2+/-2$ & $16+/-13,6$ \\
\hline Gesamt geschwollen & $73(=36,5 \%)$ & $94(=47 \%)$ \\
\hline
\end{tabular}

Abb. 3.13: a) geschwollene (D-Typ, markiert mit Sternchen) und nicht geschwollene (markiert mit Pfeil) Spermien im mikroskopischen Bild b) Schema zur Einteilung und Beurteilung der geschwollenen bzw. nicht geschwollenen Spermien (Müller, 1998, S 31). c) Einteilung und Quantifizierung der Spermien nach Schwelltest bei $A D 2 T^{/-}$- und $A D 27^{+/+}$-Tieren. Zahlenangaben sind Mittelwerte von drei Tieren. Die Prozentangaben beziehen sich auf 200 Spermien. Angabe mit Standardabweichung. Geringerer Anteil geschwollener Spermien bei $A D 27^{\prime-}$-Männchen (36,5\%) im Vergleich zu Wildtyptieren (47\%). 


\section{Ergebnisse}

Die Bindungsfähigkeit von Spermien an Oozyten wurde mittels eines Binding Assay überprüft, wobei Spermien mit Wildtypoozyten mit Zon pellucida inkubiert und anschließend die gebundenen Spermien pro Oozyte ausgezählt wurden. Wie aus Abb. 3.14 ersichtlich, zeigte sich eine deutliche Reduktion der Zahl an gebundenen Spermien pro Oozyte bei homozygoten $A D 27^{-/}$ -Männchen. Während bei der Wildtypkontrolle im Mittel 154 Spermien pro Oozyte gebunden waren, reduzierte sich dieser Anteil bei $A D 27^{-/-}$-Männchen auf im Schnitt 22 Spermien. Dies zeigt eine deutliche Einschränkung der Bindungsfähigkeit von $A D 27^{-/}$-Spermien an Eizellen.

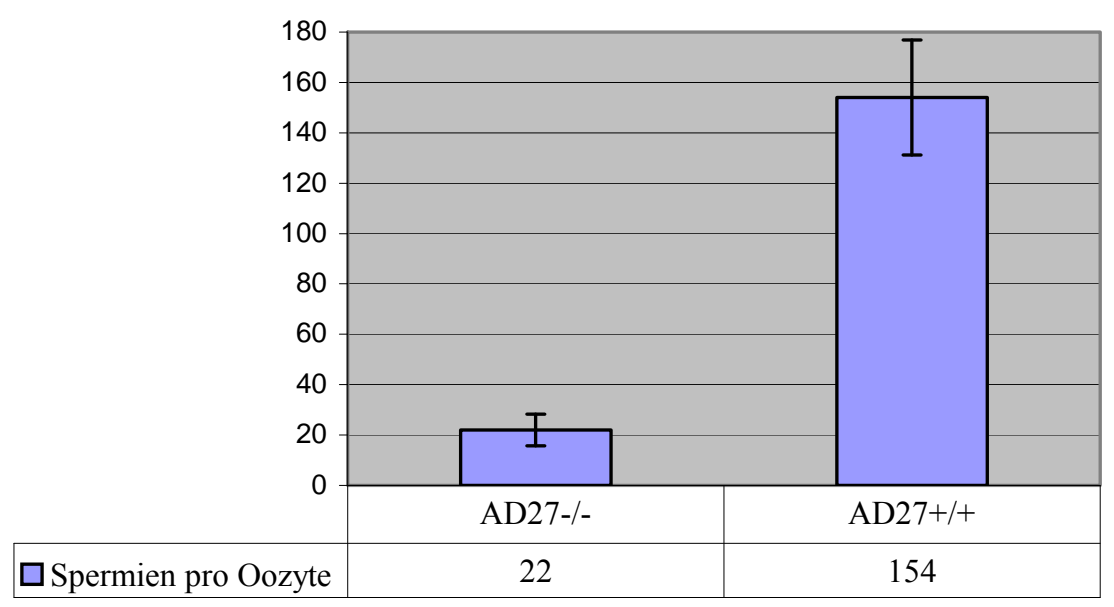

Abb. 3.14: Ergebnis des Binding-Assay-Test für Spermien von $A D 27^{\prime-}$ - und $A D 27^{+/+}$-Tieren. Angegeben ist die durchschnittliche Zahl gebundener Spermien pro Oozyte, sowie die jeweilige Standardabweichung. Zu sehen ist eine deutliche Reduktion gebundener Spermien bei $A D 27^{\prime}$-Tieren. Standardabweichung dargestellt als Fehlerbalken.

\subsubsection{Testishistologie}

Die morphologische Begutachtung von Testisschnitten erfolgte lichtmikroskopisch am HEgefärbten Präparat, sowie elektronenmikroskopisch am cacodylatfixierten Gewebe. Auffallend war die in der Regel in allen Tubuli bis zum Spermium ablaufende Spermatogenese, jedoch zeigten fast alle Tubuli eine geringere Spermatogeneseeffizienz (vorzeitige Ablösung der elongierten Spermatiden und Spermien). Auch zeigten sich zum Teil auffällige Kernkondensationsstörungen in elongierten Spermatiden, wobei es bei diesen bevorzugt zu einer vorzeitigen Ablösung vom Keimepithel kommt. Weiterhin sind auch mehrkernige Riesenzellen zu finden. Diese Veränderungen finden sich bei $A D 27^{-/}$- und zum Teil in ähnlicher Form auch 


\section{Ergebnisse}

bei $A D 27^{+/+}$-Männchen, jedoch sind die histomorphologischen Pathologien bei $A D 27^{-/}$-Tieren progredient, d.h. mit zunehmenden Alter der Tiere finden sich auch mehr Tubuli mit eingeschränkter Spermatogeneseeffizienz. Dies tritt bei $A D 27^{+/+}$-Männchen nicht auf. Zwar finden sich vereinzelt auch bei den Wildtyptieren veränderte Tubuli, jedoch ist deren Anzahl geringer und bleibt relativ konstant. Eventuell ist eine Zunahme von Pathologien in fortgeschrittenem Alter dieser Tiere zu verzeichnen. Dies alles scheint jedoch keinen Einfluß auf die Gesamtzahl gebildeter Samenzellen zu haben, weder bei $A D 27^{-/}$-, noch bei $A D 27^{+/+}$Männchen.
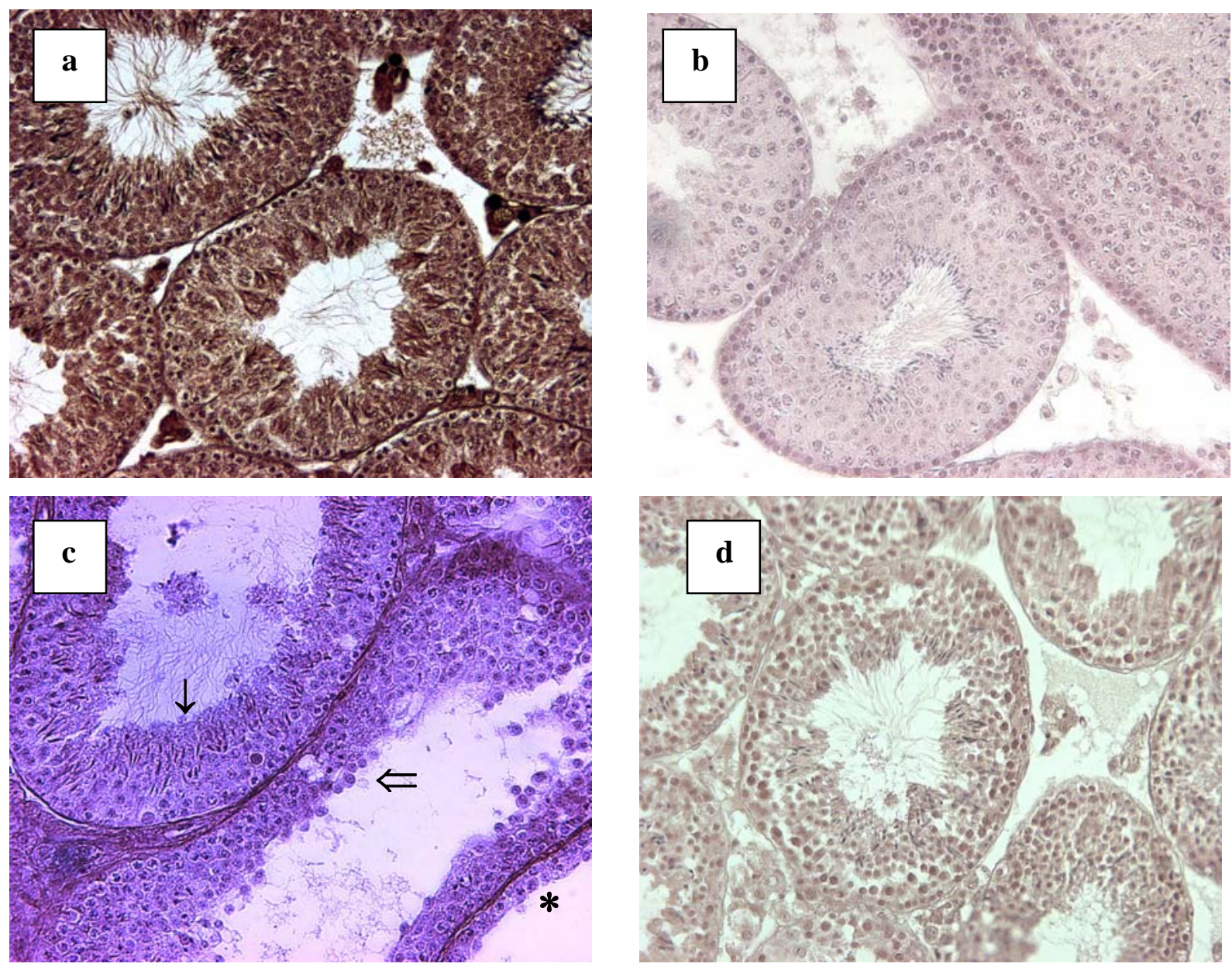

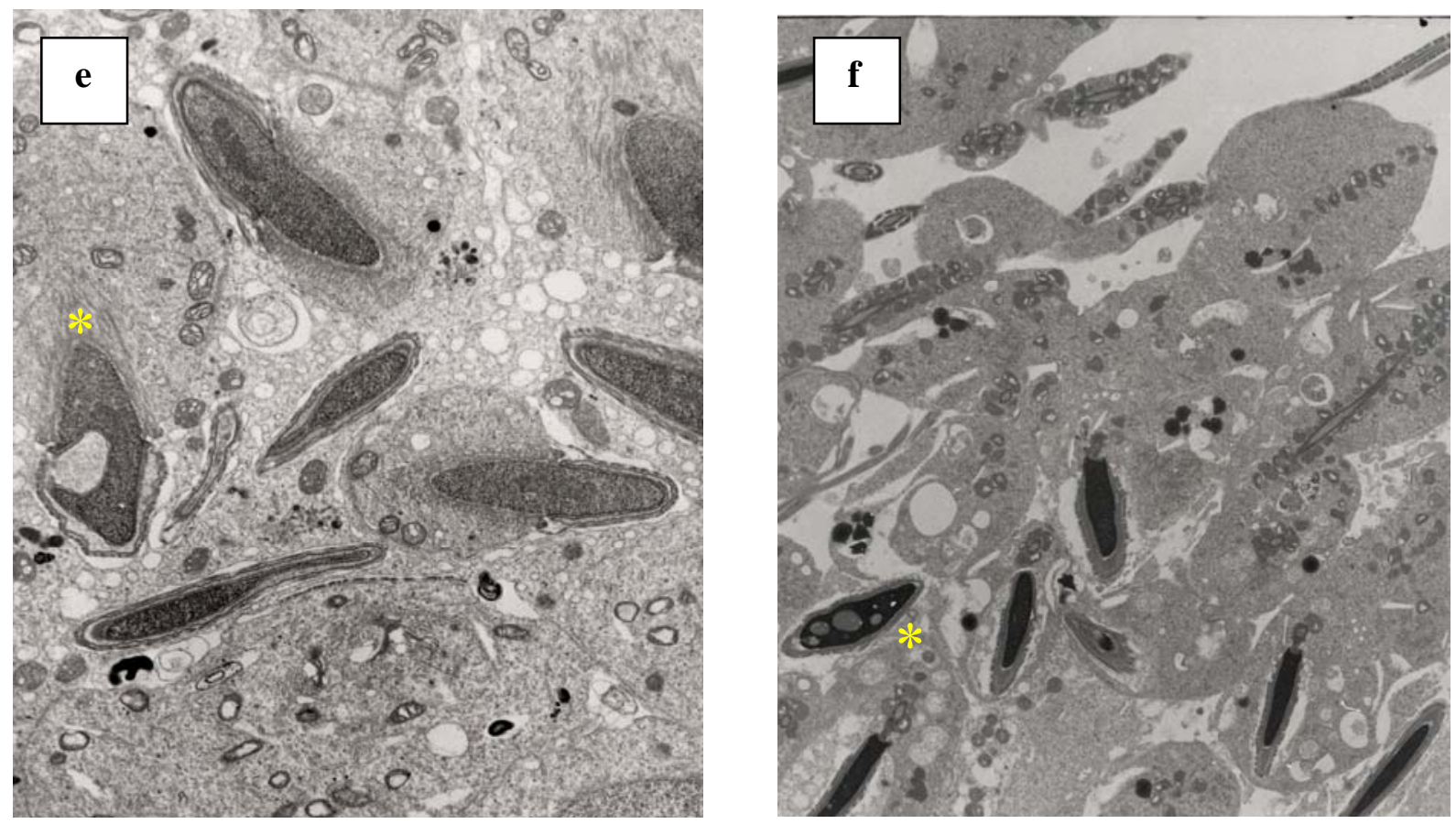

Abb. 3.14: a)+b) 3 Monate alte Männchen $A D 27^{/-}$(a) und $A D 27^{+/+}(b)$; normales Keimepithel in Tubuli nachweisbar. c) 12 Monate altes Männchen $A D 2 T^{\prime}$; Pfeil: Tubulus mit noch normalem Keimepithel, die Spermatogenese läuft noch weitgehend normal ab, Doppelpfeil: Tubulus mit strukturell verändertem Epithel, Sternchen: Tubulus mit komplettem Keimzellarrest. d) 12 Monate altes Männchen $A D 27^{+/+}$; noch weitgehend normales Keimepithel in Tubuli nachzuweisen. e)+f) Elektronenmikroskopische Aufnahme von Testisschnitten eines 11 Monate alten Tieres $A D 27^{/-}$; vor allem deutlich zu erkennen ist in einzelnen Zellen eine Störung der spermatogenen Kopfbildung im Sinne einer Vakuolisierung, was spermienmorphologisch einen der Hauptphänotypen darstellt (gelbe Sternchen).

\subsubsection{Immunhistochemie}

Die indirekte Immunhistochemie wurde an Hodenpräparaten von 8 Monate alten $A D 27^{-/}$- und $A D 27^{+/+}$- Mäusen durchgeführt und sollte eine eventuelle Kumulation des mutierten Genproduktes zeigen. Dieses wird, nach Ausschaltung der Transmembrandomäne, als nicht mehr membranverankertes Protein synthetisiert. Verwendet wurden 2 verschiedene Antikörper: antiMaus-ppADAM27, gerichtet gegen das in der zytoplasmatischen Domäne lokalisierte Peptid EPO10133 (Lage und Struktur des Peptids siehe Abb.3.2) und anti-Maus-fpADAM27, gerichtet gegen ein $A D A M-27-F u s i o n s p r o t e i n$, welches für die Herstellung rekombinanter Proteine im Rahmen einer anderen Studie (Bolcun-Filas, 2003) benötigt wurde. Da der ppADAM27- 


\section{Ergebnisse}

Antikörper die zytoplasmatische Domäne des mutierten Genproduktes nicht erkennt, erfolgte die immunhistochemische Färbung bei $A D 27^{-/}$-Mäusen mit dem anti-Maus-fpADAM27-Antikörper. Die Schnitte der Wildtypkontrollen wurden mit anti-Maus-ppADAM27-Antikörper inkubiert. Die

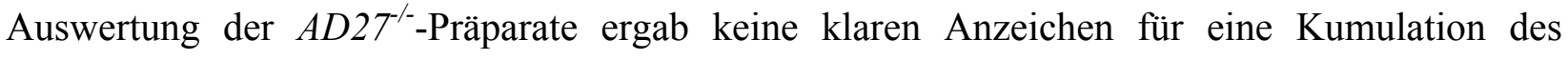
veränderten Genproduktes. Zwar konnte eine Signalvermehrung intraluminal zwischen den Zellen der Spermatogenese beobachtet werden, jedoch könnte es sich hierbei auch um unspezifische Signale handeln.

a)

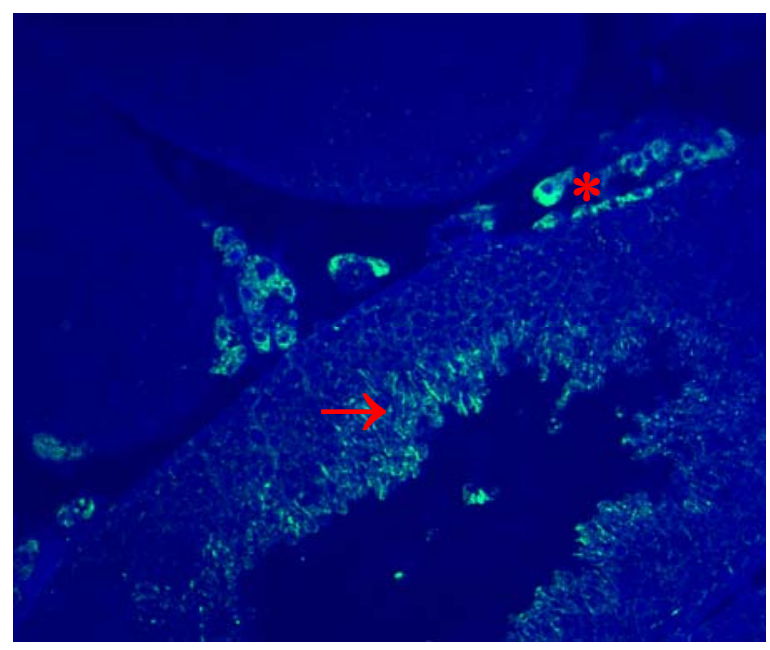

Abb. 3.15: Immunhistochemische Färbung von Testisschnitten. b)

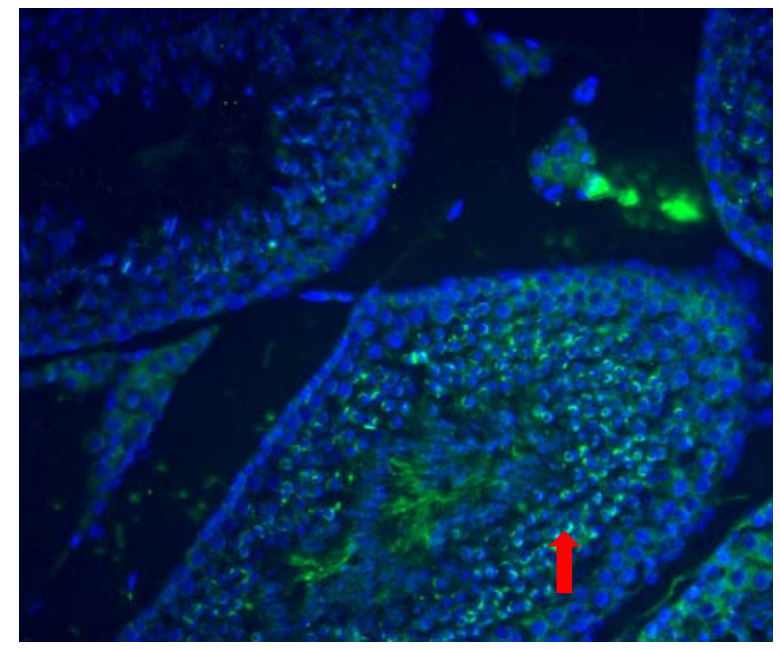

a) 8Monate altes $A D 2 T^{\prime}$-Männchen, Signalvermehrung intraduktal, zwischen Zellen in verschiedenen Spermatogenesestadien (Pfeil), unspezifische Signale in Leydigzellen (Sternchen). b) Wildtypkontrolle $A D 27^{+/+}$, Lokalisation der Signale in dem sich bildenden Akrosom (akrosomale Kappe) der Spermien (fettgedruckter Pfeil). 


\subsection{Analyse von EW50-Knockout-Mäusen}

\subsubsection{Transkriptionsanalyse}

Mittels RT-PCR und Northern Blot wurde die komplette Ausschaltung des ADAM-27-Gens überprüft. Für die RT-PCR wurde Gesamt-RNA aus den Hoden von homozygoten, heterozygoten und von Wildtypmäusen präpariert und anschließend mittels des SUPERSCRIPT ${ }^{\text {MM}_{-} \text {Kits von }}$ Invitrogen (Karlsruhe) in cDNA umgeschrieben. Anschließend wurde die Expression des $A D A M-$ 27-Gens mittels sequenzspezifischer Primer in einer PCR überprüft. Wie in Abbildung 3.16 ersichtlich, konnte keine Expression bei homozygoten Mäusen nachgewiesen werden.

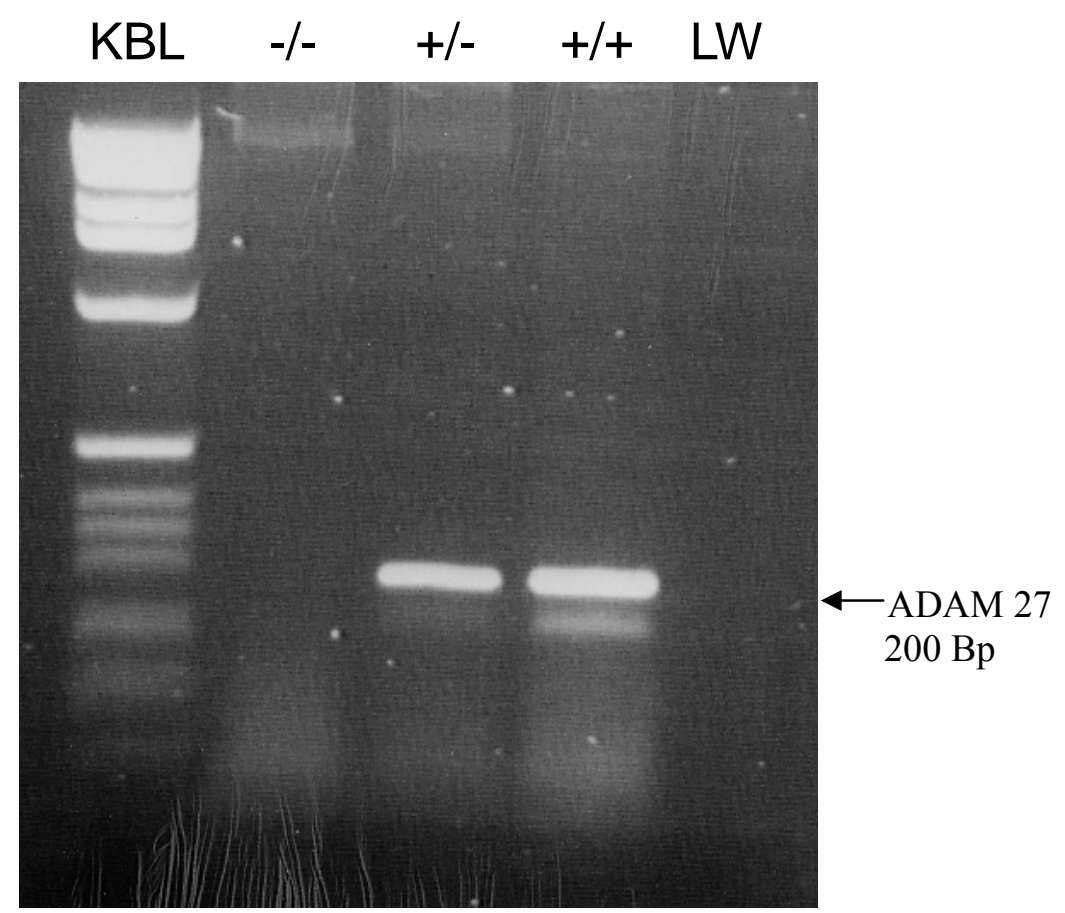

KBL LW -l- +/- +/+

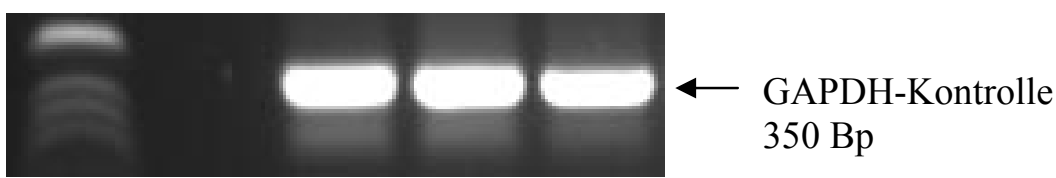

Abb. 3.16: RT-PCR von $E W 50^{+/+}-(+/+), E W 50^{+/-}$- (+/-) und EW50 $0^{-/}$-Tieren (-/-), Kein nachweisbares PCRProdukt wie erwartet bei $E W 50^{-/-}$-Männchen. Die Kontrolle mit dem ubiquitär exprimierten Gen GAPDH zeigt das Vorhandensein von cDNA in allen drei Proben. KBL=Standard, $L W=$ Leerwert 


\section{Ergebnisse}

Zur quantitativen Expressionsbestimmung wurde nun ein Northern Blot durchgeführt. Auch hierfür wurde Gesamt-RNA aus dem Hoden von homozygoten, heterozygoten und Wildtypmäusen benutzt und in zwei verschiedenen Gesamtmengen von $10 \mu \mathrm{g}$ und $20 \mu \mathrm{g}$ eingesetzt. Die RNA wurde in einer Gelelektrophorese aufgetrennt und anschließend mittels Kapillartransfertechnik auf eine Nitrozellulosemembran übertragen. Diese Filtermembran wurde mit der sequenzspezifischen, radioaktivmarkierten $A D A M-27-$ Sonde hybridisiert, welche mittels PCR von cDNA und anschließender Amplifikation durch kompetente Bakterienstämme, nach Einbringung in ein Plasmid (pGEM-T Easy, Promega, Mannheim), hergestellt wurde. Nach Entfernung überschüssiger Radioaktivität wurde die Membran unter einen Röntgenfilm gebracht und ü. N. bei $-80^{\circ} \mathrm{C}$ exponiert. Es konnte wiederum keine Expression des Gens bei homozygoten Knockout-Mäusen nachgewiesen werden. Die Genexpression heterozygoter Mäuse entspricht etwa der Hälfte derjenigen von Wildtypmäusen.
$\mathrm{EW}^{\mathrm{W} 0^{+/+}}$
$\mathrm{EW}^{+1 /-}$
$E \mathrm{~W}^{-/-}$.

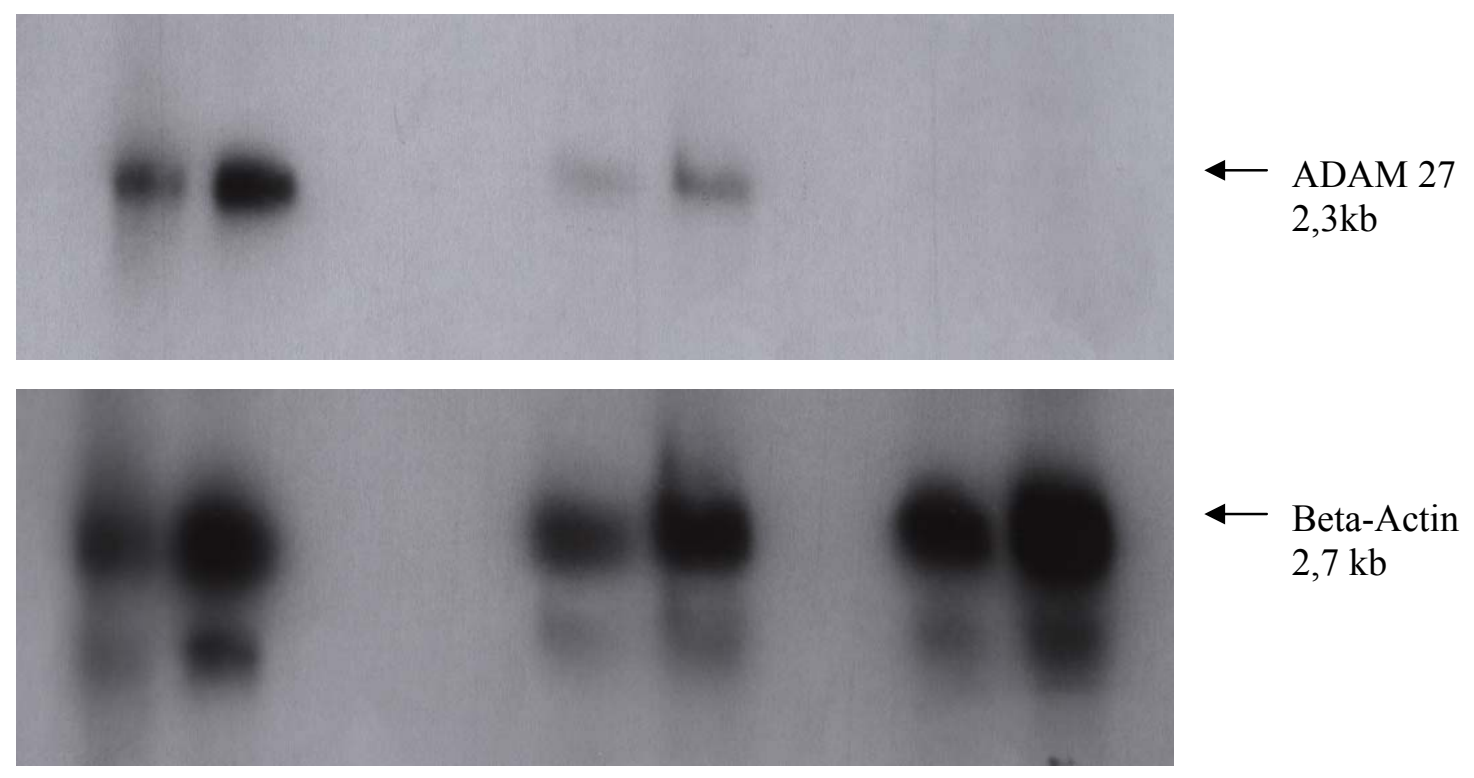

Abb. 3.17: Northern Blot von $E W 50^{+/+}-, E W 50^{+/-}$und $E W 50^{-/-}$-Tieren. Keine Expression von ADAM 27 in

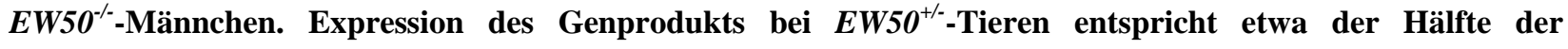
Wildtypkontrolle. Beta-Actin als Kontrolle ist überall nachweisbar. 


\section{Ergebnisse}

\subsubsection{Wurfgrößenstatistik}

Die EW50-Knockout-Mäuse sind phänotypisch unauffällig. Jedoch zeigen homozygote Knockout-Männchen eine ausgeprägte Subfertilität, was im Mittel 1,9 Nachkommen pro Wurf bedeutet. Auch eine Reduktion der Nachkommenzahl bei Heterozygotenverpaarungen konnte beobachtet werden, diese beträgt im Mittel 4,7 Nachkommen pro Wurf. Diese Reduktion ist nicht abhängig vom Alter der Mäuse. Der Phänotyp tritt bereits bei Eintritt in das fortpflanzungsfähige Alter auf. Nachfolgend sind die durchschnittlichen Wurfgrößen aufgeführt, die Angaben sind Mittelwerte aus mindestens zehn Würfen. (Abb. 3.18).

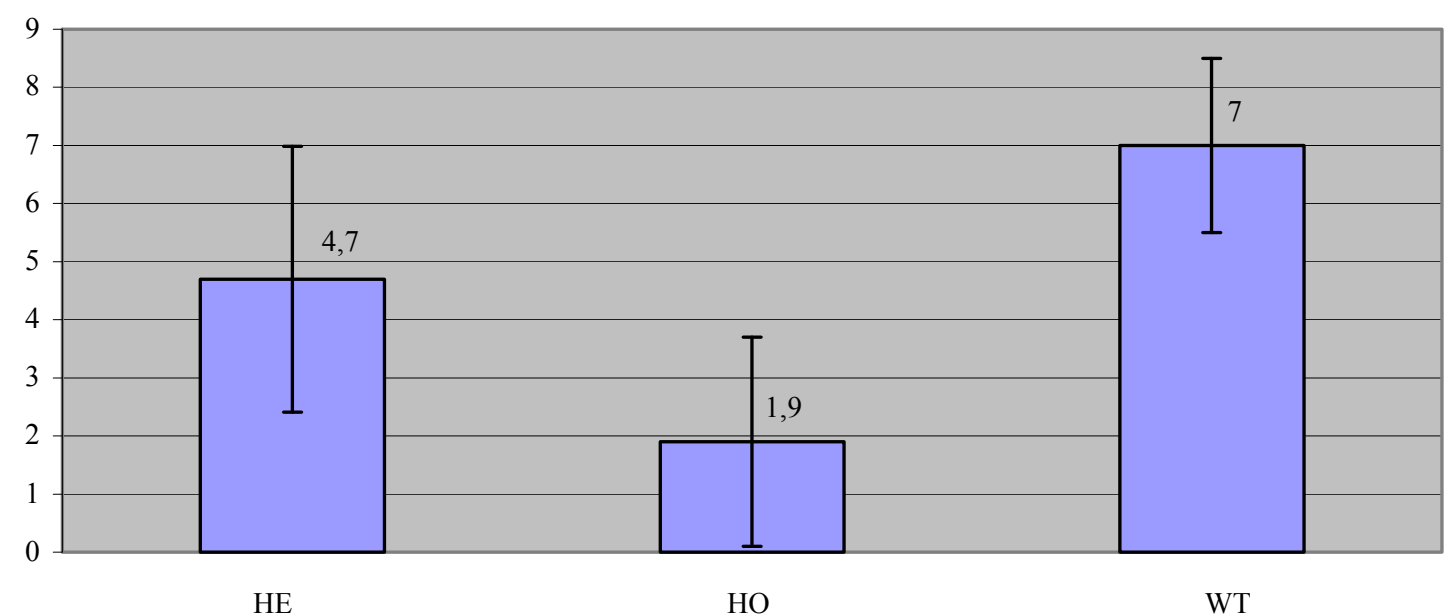

Abb. 3.18: Durchschnittliche Nachkommenzahl aus verschiedenen Verpaarungen von EW50-KnockoutMäusen. WT $=$ Wildtyp, $\mathrm{HE}=$ Heterozygotenverpaarung, $\mathrm{HO}=$ Homozygotenverpaarung. Erkennbare Reduktion der Nachkommenzahl der Heterozygotenverpaarung, im Mittel 4,7 Nachkommen pro Wurf, sowie deutlich eingeschränkte Nachkommenzahl der Homozygotenverpaarungen, im Mittel 1,9 Nachkommen pro Wurf. Angabe mit Standardabweichung, dargestellt als Fehlerbalken.

\subsubsection{Spermienparameter}

Zur Spermienzählung wurden die Nebenhodenschwänze aus präparierten $E W 50^{-/}$- sowie $E W 50^{+/+}$-Männchen in M2-Medium ausgepresst und die so gewonnenen Spermien in einer Neubauerzählkammer unter dem Phasenkontrastmikroskop ausgezählt. Es erfolgte eine Differenzierung nach dem Alter der Mäuse. Junge $E W 50^{-/}$-Tiere zeigten keine Reduktion der 
Spermienzahl. Die Spermienzahlen älterer $E W 50^{-/}$-Mäuse sind zwar im Durchschnitt um eine Zehnerpotenz niedriger die der Vergleichstiere, jedoch ist dies immer noch als normal zu werten. Die Ergebnisse sind aus nachfolgender Abbildung zu entnehmen.

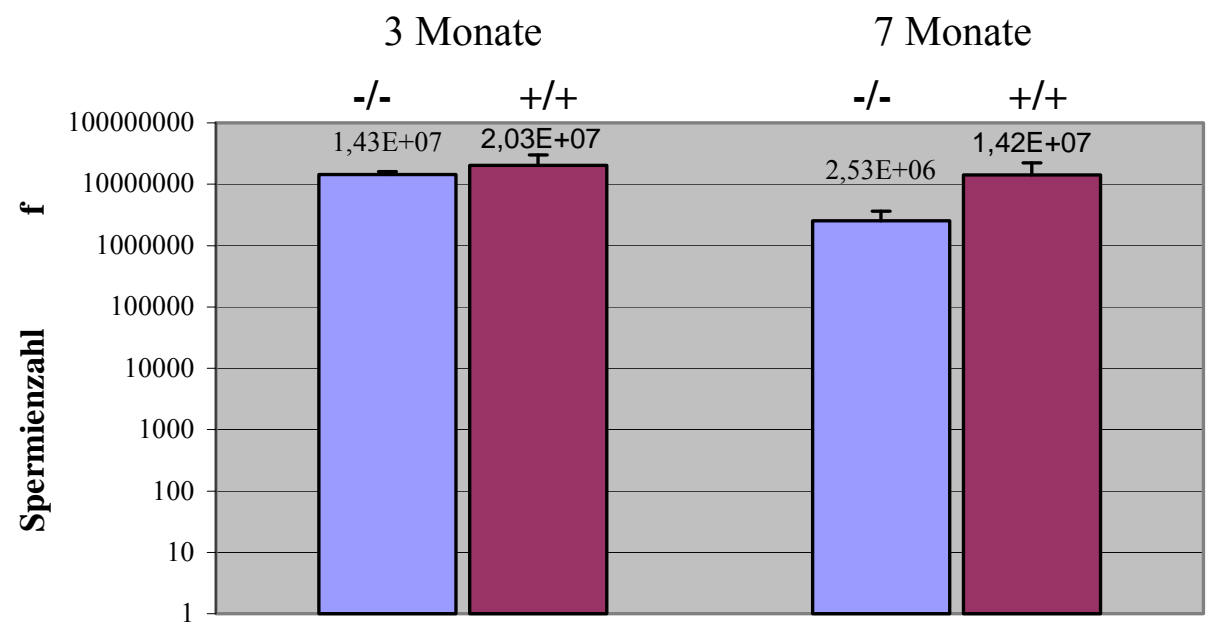

Abb. 3.19: Durchschnittliche Spermienzahl im Nebenhodenschwanz bei $E W 50^{-/}$- und Wildtypmäusen unterschiedlichen Alters. NHS= Nebenhodenschwanz, Standardabweichung dargestellt als Fehlerbalken. Erkennbar lediglich eine leichte Reduktion der mittleren Spermienzahl im Nebenhodenschwanz bei älteren EW50 $0^{-/}$-Männchen.

Die morphologische Untersuchung von EW50-Spermien ergab eine hochgradige Fehlbildungsrate von $68,5 \%$, die anders als bei $A D 27^{-/}$-Tieren bereits bei Tieren im Alter von 3 Monaten in vollem Umfang auftritt. Die morphologischen Veränderungen betreffen Kopf und Schwanz, die Köpfe sind aber hauptsächlich betroffen. Im Gegensatz zu den Spermien der AD27-Tiere, bei denen ein vermehrtes Auftreten von Vakuolen im Kopfbereich der Spermien einen sehr maßgeblichen Phänotyp darstellt, konnte dies bei den Spermien der $E W 50^{-/}$-Männchen nicht in diesem Maße beobachtet werden. Die Ergebnisse sind aus der nachfolgenden Abbildung ersichtlich. 


\section{Ergebnisse}

a)

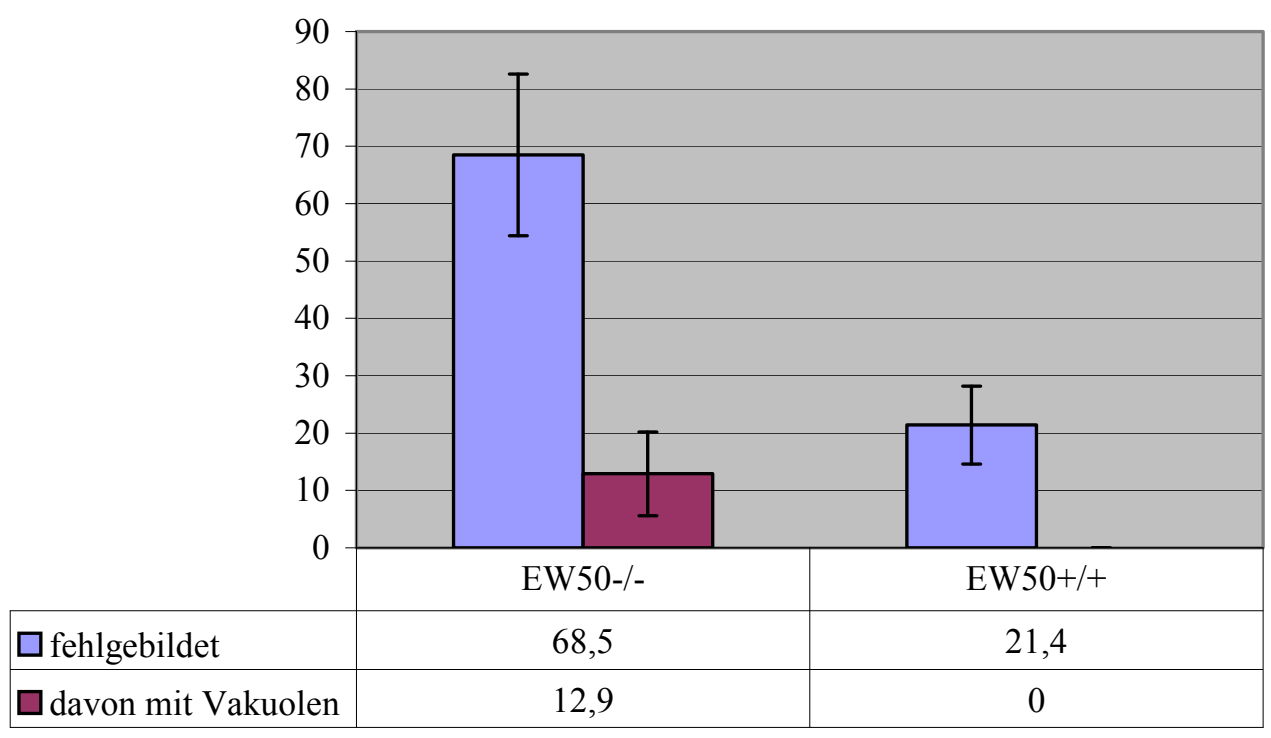

b)

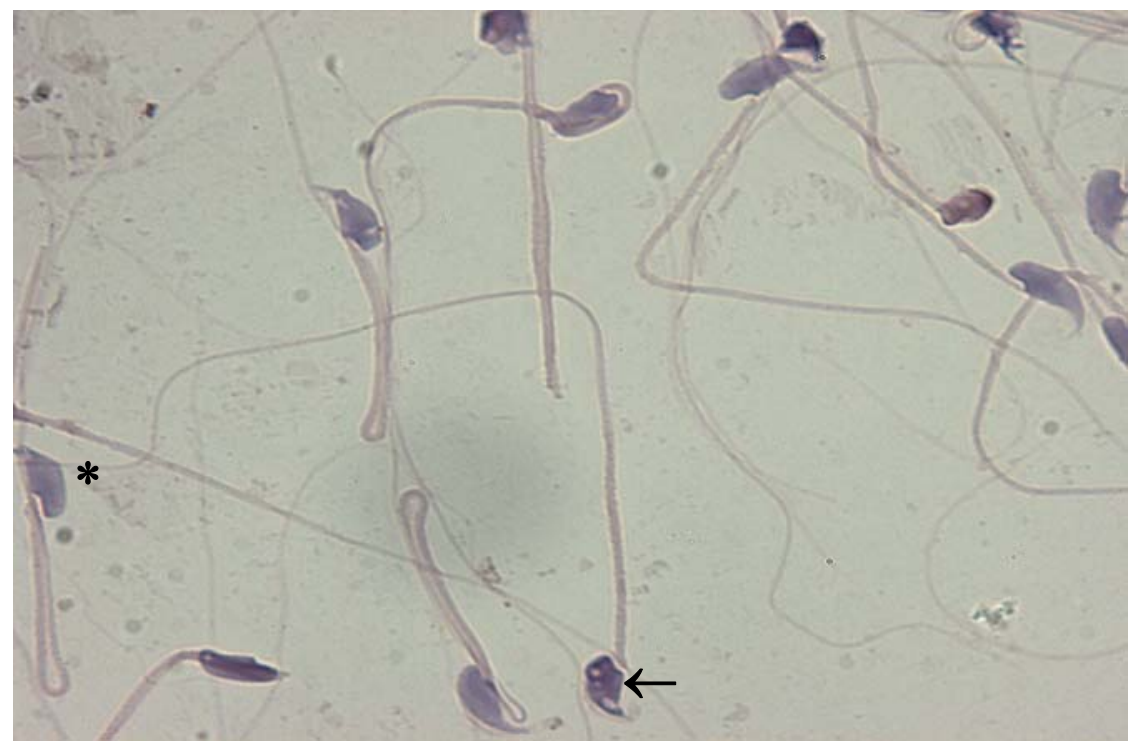

Abb. 3.20: a) Morphologie der Spermien von EW50 ${ }^{-/}$-Männchen. Zahlenangaben in Prozent, Standardabweichung als Fehlerbalken. Deutlich erhöhter Anteil makroskopisch fehlgebildeter Spermien bei $E W 50^{-/}$-Männchen im Vergleich zur Wildypkontrolle (68,5\% beim Knockout vs. 21,4\% beim Wildtyp). b) Mikroskopische Aufnahme von Spermien eines 3 Monate alten EW50 ${ }^{-/}$-Männchens mit verschiedenen sichtbaren Veränderungen, Spermium mit im Kopfteil vorhandenen Vakuolen markiert mit Pfeil, Spermium mit fehlgeformtem, jedoch nicht vakuolisiertem Kopf, markiert mit Sternchen. 


\section{Ergebnisse}

Die Fähigkeit der Spermien zur Akrosomenreaktion wurde nach Präparation, Fixation und Färbung (siehe 2.2.13.3) unter dem Lichtmikroskop geprüft. Spermien die die Akrosomenreaktion nicht ausgeführt haben, zeigen einen deutlich sichtbaren, dunkelblau gefärbten Randsaum am Kopf, welcher der Akrosomenregion entspricht. Dieser fehlt bei Spermien, welche die Akrosomenreaktion ausgeführt haben. Die Auswertung ergab keine Reduktion der Fähigkeit von EW50 $0^{--}$-Spermien zur Akrosomenreaktion. Bei 84\% der gezählten Spermien von homozygoten Tieren konnte kein sichtbarer blauer Randsaum entdeckt werden, damit ist der Anteil höher als bei den Wildtypkontrollen mit 75,5\%. Nicht festgestellt werden konnte allerdings, ob dies auf einer normalen Funktion des Akrosoms beruht oder die Ursache dafür ein fehlerhaft konfiguriertes Akrosom ist, welches sich nicht anfärben läßt.

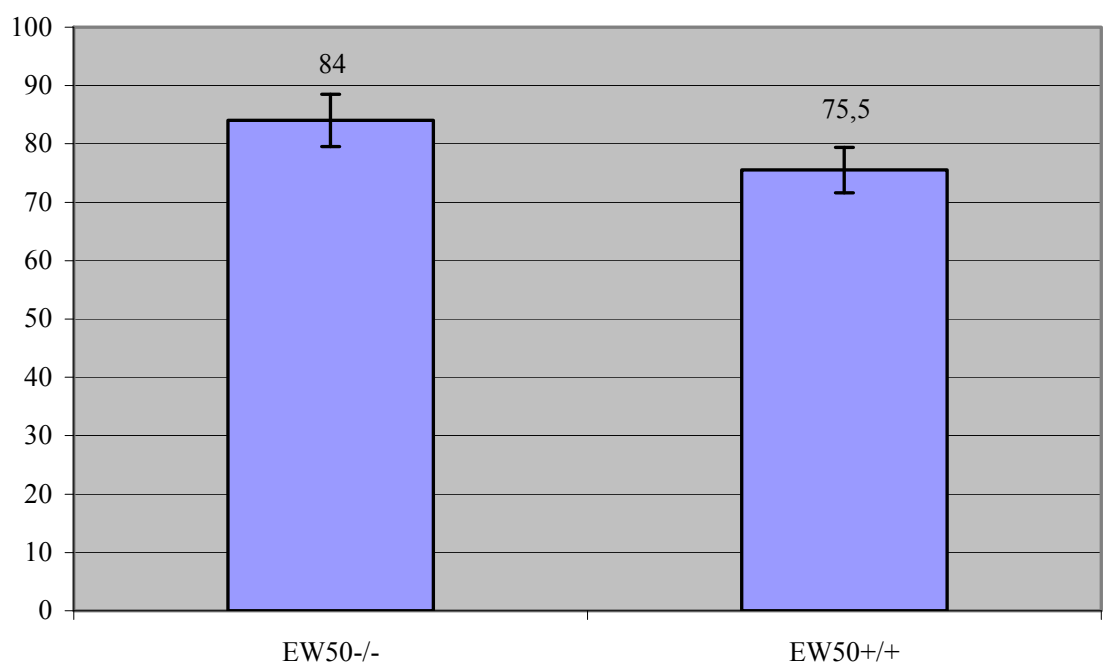

Abb. 3.21: Akrosomenreaktion von Wildtyp- und EW50 ${ }^{--}$-Spermien. Angabe in Prozent. Standardabweichung dargestellt als Fehlerbalken. Kein Unterschied in der Fähigeit zur Akrosomenreaktion zwischen diesen Tieren.

Ein weiterer, die Befruchtungsfähigkeit bewertender Versuch ist der hypoosmotische Schwelltest. Bei diesem Test wird die funktionelle Integrität der Spermatozoenmembran überprüft, indem die Spermien in ein hypoosmotisches Medium eingebracht werden. Dabei zeigen vitale Spermien unter dem Phasenkontrastmikroskop charakteristische Schwellphänomene, hauptsächlich im Bereich des Flagellums. Der Anteil geschwollener Spermatozoen kann als eine Art Fertilitätsindex gewertet werden, wobei ein niedriger Prozentsatz geschwollener Spermien als eher negativ zu bewerten ist. Der Test wurde mit je drei $E W 50^{-/}$- und $E W 50^{+/+}$-Männchen 


\section{Ergebnisse}

durchgeführt. Nach Einbringen der Spermien in das entsprechende Medium wurden 200 von diesen unter dem Phasenkontrastmikroskop beurteilt, entsprechend dem gezeigten Schwellungsphänomen nach Jeyendran et al. (1984) in unterschiedliche Typen eingeteilt und die Mittelwerte aus den Ergebnissen der Versuchstiere gebildet. Es konnte eine Reduktion der Gesamtzahl an geschwollenen $E W 50^{-/}$-Spermatozoen um die Hälfte des Wertes im Vergleich zu Wildtyptieren gezeigt werden, sowie eine Reduktion der einzelnen Schwellungstypen, wobei diese in unterschiedlichem Maße betroffen waren (Abb. 3.22).

a)

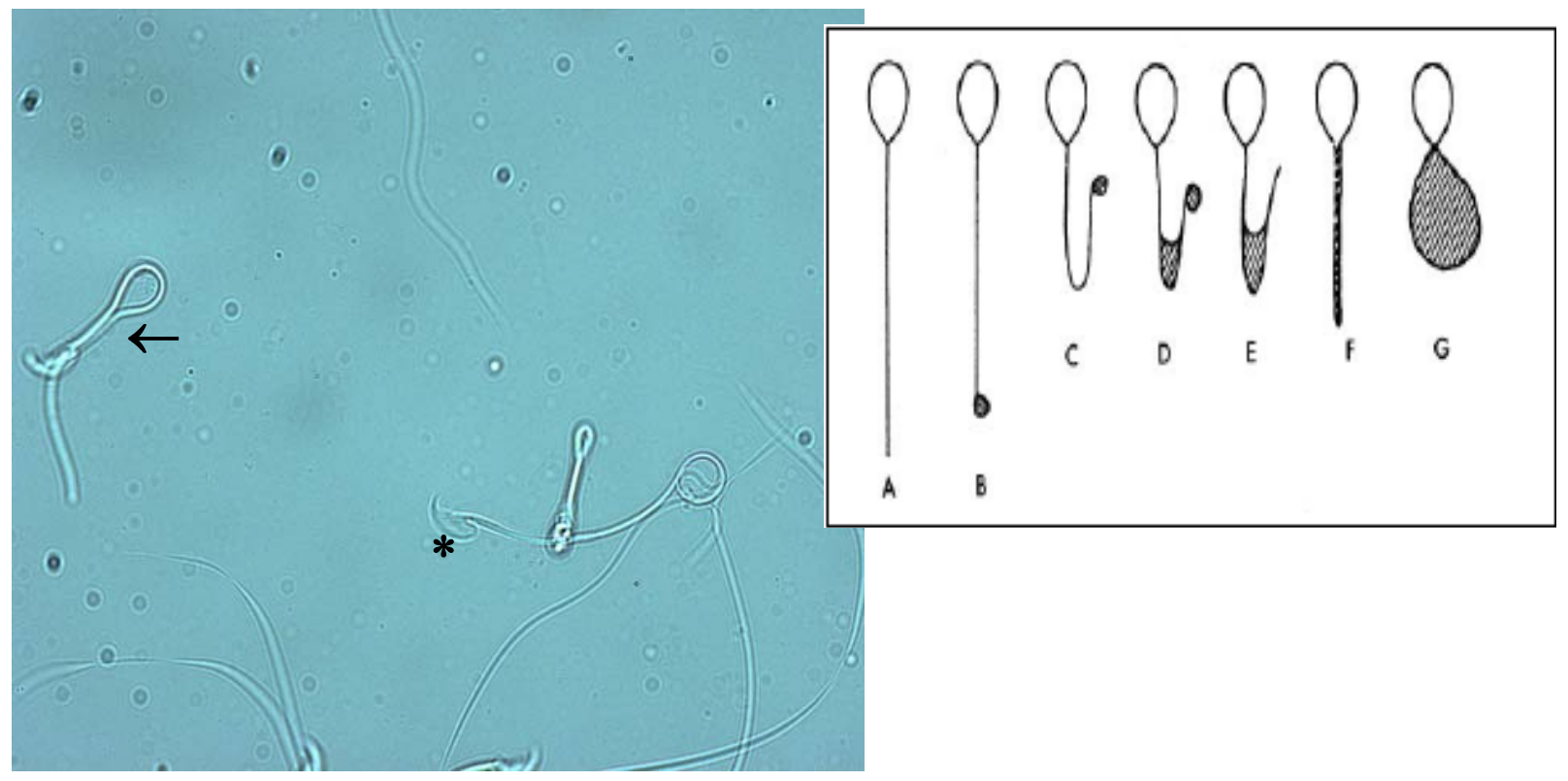


c)

\begin{tabular}{|c|c|c|}
\hline Schwellungstyp & $-/-$ & $+/+$ \\
\hline $\begin{array}{l}\mathrm{A}(=\text { nicht } \\
\text { geschwollen })\end{array}$ & $151+/-\mathbf{1 0 , 4}$ & $106+/-7,6$ \\
\hline $\mathbf{B}$ & $14+/-9,8$ & $19+/-16,6$ \\
\hline $\mathbf{C}$ & $2+/-1,5$ & $5+/-2$ \\
\hline $\mathbf{D}$ & $7+/-5,6$ & $23+/-6,1$ \\
\hline $\mathbf{E}$ & $20+/-12,5$ & $30+/-11,6$ \\
\hline $\mathbf{F}$ & $1+/-1$ & $1+/-1,2$ \\
\hline $\mathbf{G}$ & $6 \quad+/-7,8$ & $16+/-13,6$ \\
\hline Gesamt geschwollen & $50(=25 \%)$ & $94(=47 \%)$ \\
\hline
\end{tabular}

Abb. 3.22: a) Mikroskopische Aufnahme von geschwollenen Spermien (B-Typ, markiert mit Pfeil; E-Typ, markiert mit Sternchen) b)Schema zur Gruppeneinteilung der Spermien, je nach Schwellungstyp (Müller, 1998, S 31) c) Einteilung und Quantifizierung der Spermien nach Schwelltest bei $E W 50^{-/-}$und $E W 50^{+/+}$Tieren. Zahlenangaben sind Mittelwerte aller gezählten Spermien. Die Prozentangaben beziehen sich auf 200 Spermien. Angabe mit Standardabweichung. Reduktion der geschwollenen Spermien bei EW50 ${ }^{-/}$-Tieren (25\%) im Vergleich zur Wildtypkontrolle (47\%).

Motilitätsmessungen wurden mit Spermien von $6 \mathrm{EW}^{-0^{--}}$- und 5 Wildtyptieren nach $1.5,3.5$ und $5.5 \mathrm{~h}$ Inkubation in vitro durchgeführt. Nach $1.5 \mathrm{~h}$ Inkubation zeigte sich eine Reduktion des Anteils motiler $E W 50^{-/-}$-Spermien auf 22,5\%, zu 61\% beim Wildtyp. Auch der Anteil von Spermien mit progressiver Bewegung war bei $E W 50^{-/}$-Mäusen reduziert, $10 \% \mathrm{zu} 42 \%$ beim Wildtypen. Ebenso konnte nach 3.5 und 5.5 Stunden Inkubation eine ähnlich hohe Reduktion motiler und progressiv motiler Spermien bei $E W 50^{--}$-Tieren beobachtet werden. (Abb.3.23a). Die folgenden weiteren Parameter wurden untersucht und statistisch ausgewertet: Kurven-Strecken Geschwindigkeit (VCL), durchschnittliche Streckengeschwindigkeit (VAP), Linear-Strecken Geschwindigkeit (VSL), Schwanzschlagfrequenz (BCF), Geradlinigkeit (STR) und die Amplitude des lateralen Kopfversatzes (ALH). Für ALH, VCL, VAP, VSL konnte eine Reduktion bei Spermien von $E W 50^{--}$-Männchen im Vergleich zum Wildtyp nachgewiesen werden, welche nach 1.5 Stunden Inkubationszeit am größten, nach 3.5 und 5.5 Stunden zwar 


\section{Ergebnisse}

noch vorhanden, jedoch mit längerer Inkubationszeit abnahm. Für BCF und STR konnten nur leichte Abweichungen festgestellt werden, ein Trend ist nicht erkennbar (Abb.3.23).

a)

\begin{tabular}{|l|l|l|l|l|}
\hline Tier & Inkubationszeit & $\begin{array}{l}\text { Gemessene } \\
\text { Spermien }\end{array}$ & $\begin{array}{l}\text { Motile Spermien } \\
(\%)\end{array}$ & $\begin{array}{l}\text { Progressive } \\
\text { Spermien (\%) }\end{array}$ \\
\hline EW50 & & 3348 & $\mathbf{2 2 , 5}$ & $\mathbf{1 0}$ \\
\hline & 1.5 & 2378 & $\mathbf{1 9 , 5}$ & $\mathbf{9 , 5}$ \\
\hline & 3.5 & 2570 & $\mathbf{1 7}$ & $\mathbf{8}$ \\
\hline$E W 50^{+/+}$ & 5.5 & 2935 & $\mathbf{6 1}$ & $\mathbf{4 2}$ \\
\hline & 1.5 & 2017 & $\mathbf{6 3}$ & $\mathbf{3 9}$ \\
\hline & 3.5 & 2113 & $\mathbf{5 3}$ & $\mathbf{3 2}$ \\
\hline
\end{tabular}

Abb 3.23a: Motilitätsmessung für EW50 ${ }^{--}$- und Wildtypmäuse. Erkennbare Reduktion von motilen und progressiv motilen Spermien bei $E W 50^{-/}$-Mäusen (22,5\% und 10\% nach 1,5 h Inkubationszeit) im Vergleich zu $\mathrm{EW}_{50^{+/+}}$-Mäusen (61\% und $42 \%$ nach 1,5 h Inkubationszeit).

b)

ALH

$1,5 \mathrm{~h}$

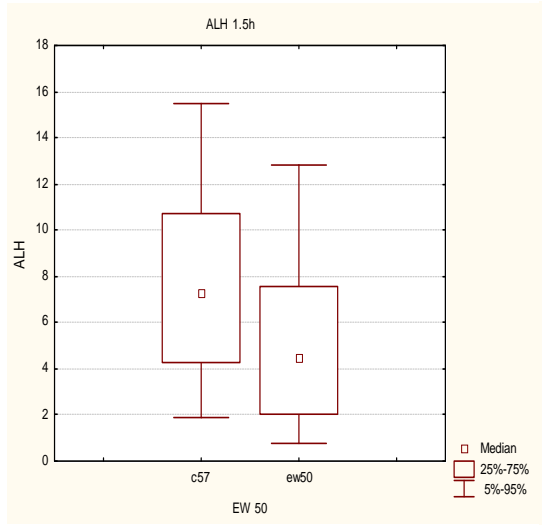

$3,5 \mathrm{~h}$

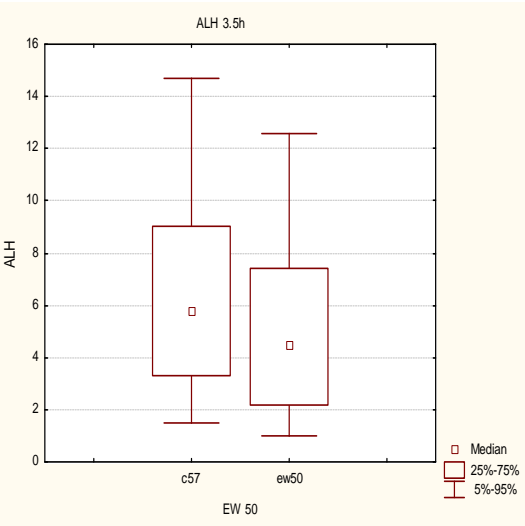

$5,5 \mathrm{~h}$

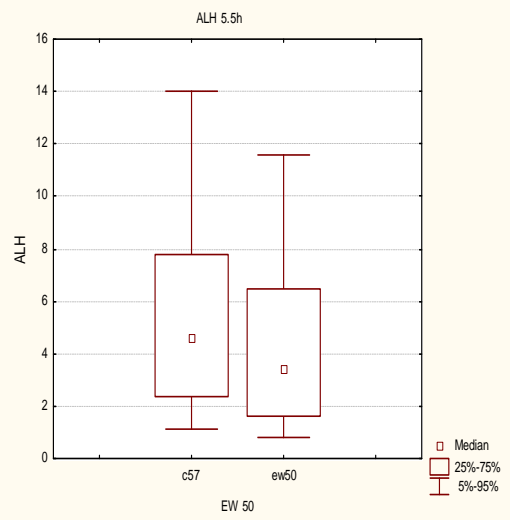


Ergebnisse

BCF

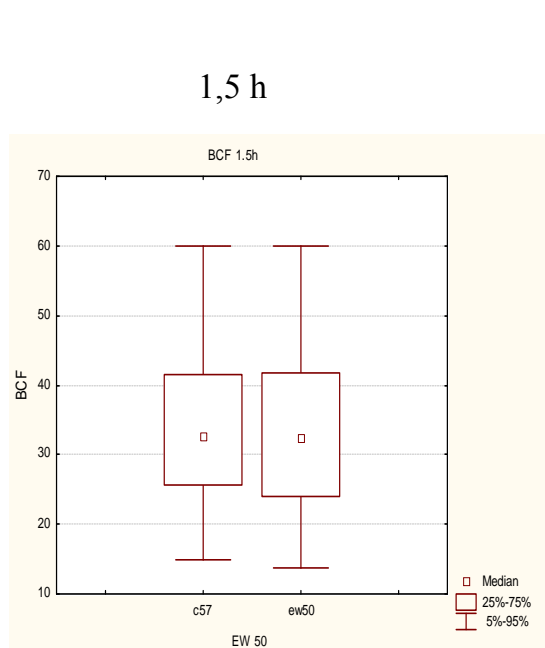

$3,5 \mathrm{~h}$

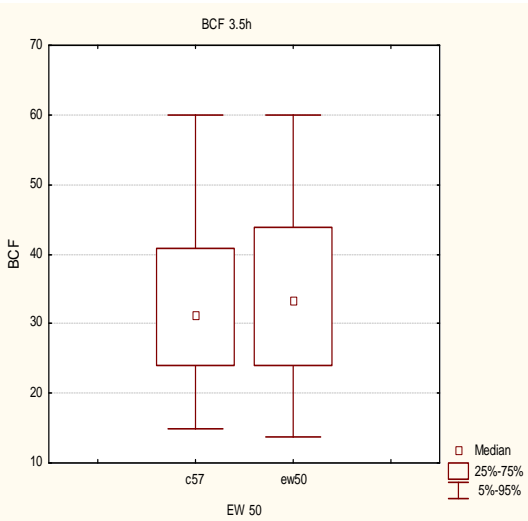

STR
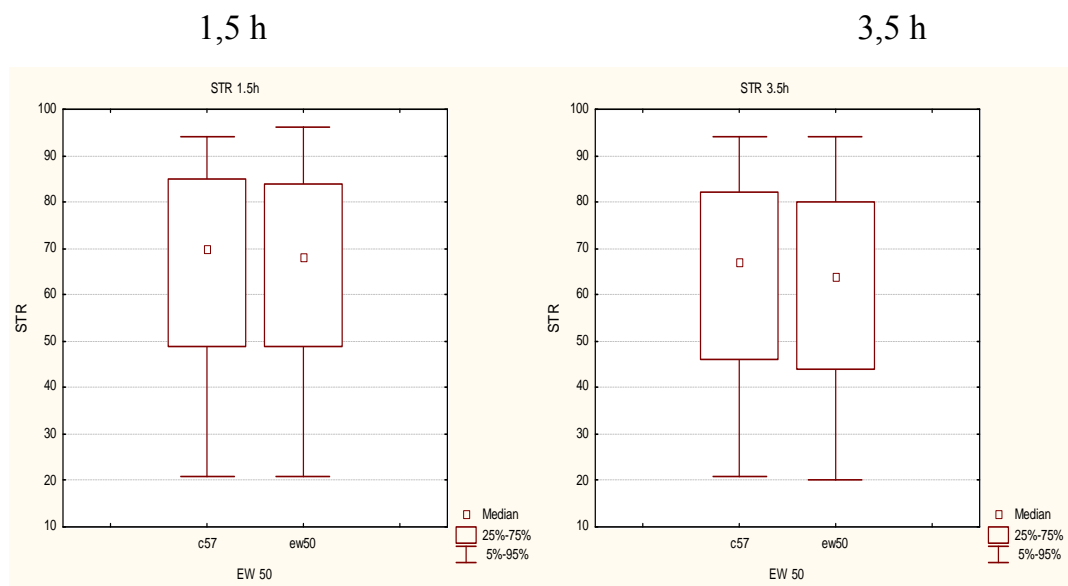

VAP

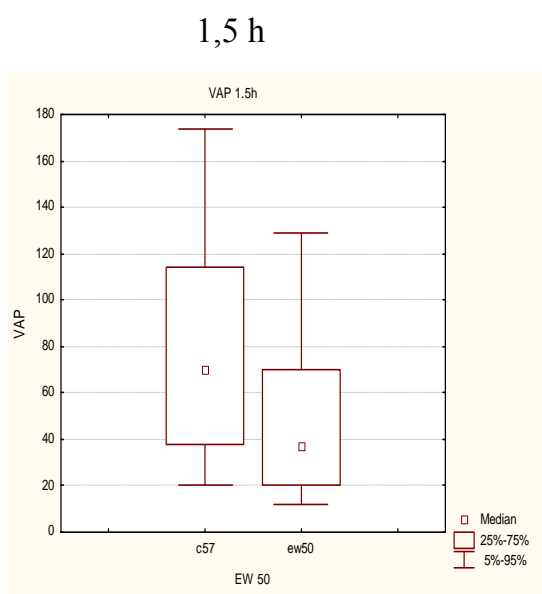

$3,5 \mathrm{~h}$

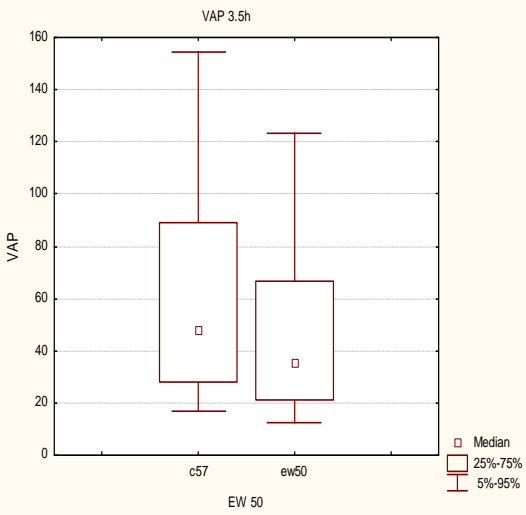

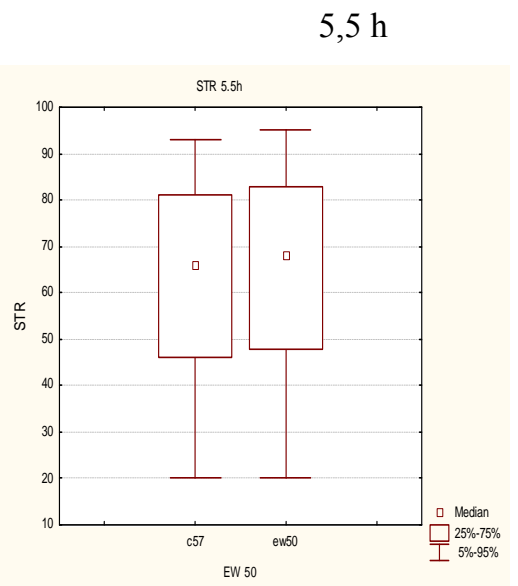

$5,5 \mathrm{~h}$

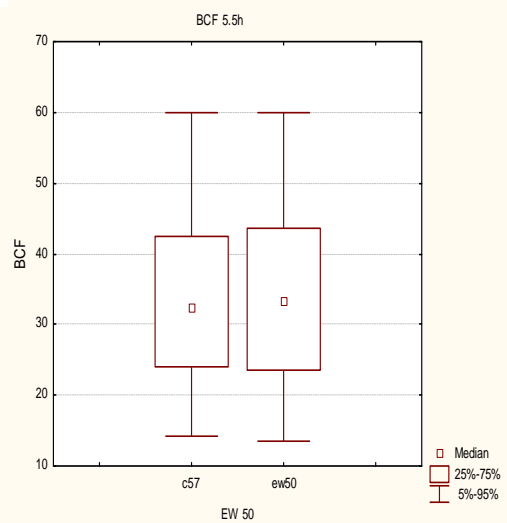

$5,5 \mathrm{~h}$

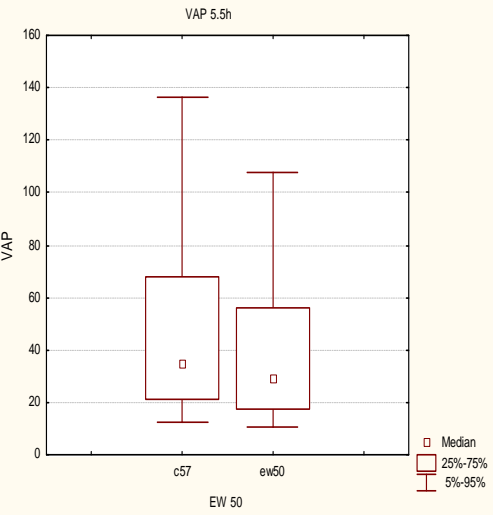


VCL

$1,5 \mathrm{~h}$

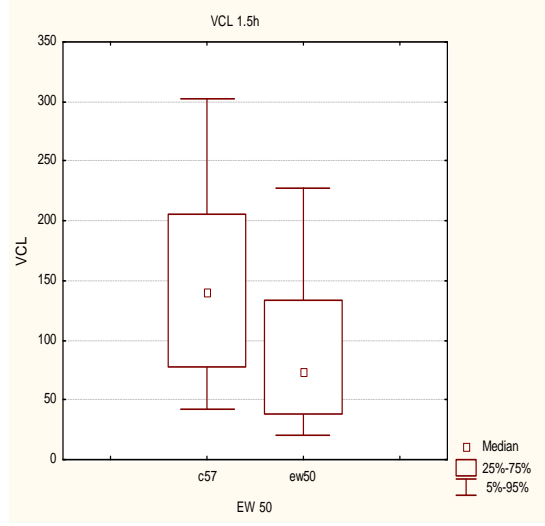

$3,5 \mathrm{~h}$

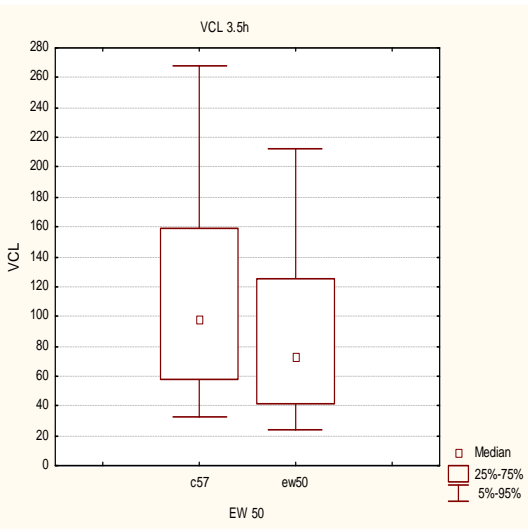

$5,5 \mathrm{~h}$

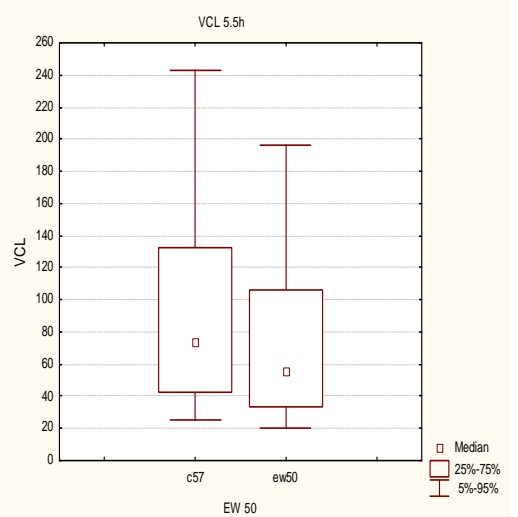

VSL

$1,5 \mathrm{~h}$

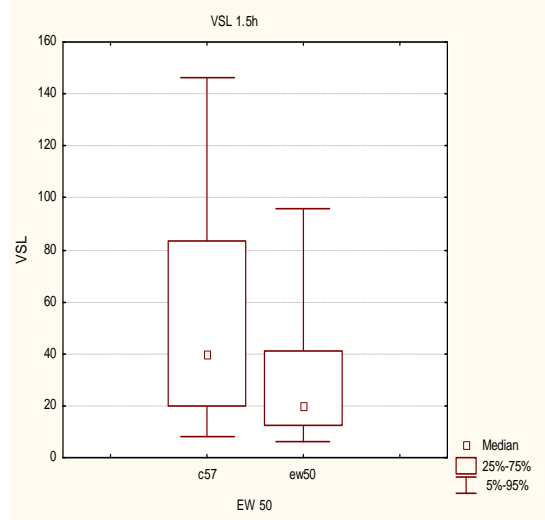

$3,5 \mathrm{~h}$

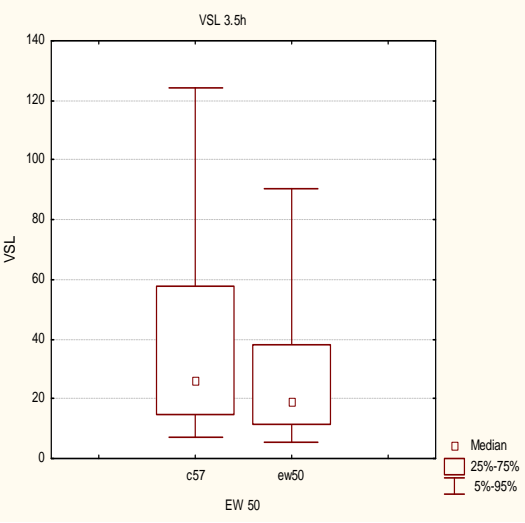

$5,5 \mathrm{~h}$

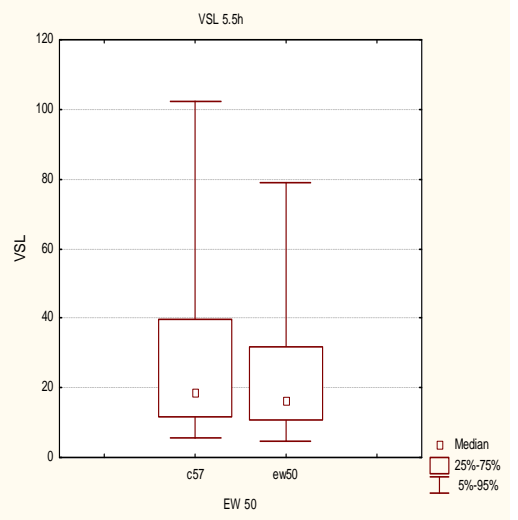

Abb.3.23b: Computer gestützte Analyse der Motilität von Spermien der EW50 ${ }^{-/}$- und Wildtyptiere. Sp, Spermiengeschwindigkeiten in $\mu \mathrm{m} / \mathrm{s}$, Vorwärtsbewegung in Prozent, lateraler Kopfversatz in $\mu \mathrm{m}$ und Schwanzschlagfrequenz in Hertz, jeweils gemessen nach 1,5, 3,5 und 5,5 Stunden Inkubationszeit. Für alle Parameter sind die Mediane und Perzentilen dargestellt. VCL= Kurven-Strecken-Geschwindigkeit, VAP= durchschnittliche Streckengeschwindigkeit, VSL= Linear-Strecken-Geschwindigkeit, BCF= Schwanzschlagfrequenz, STR= Geradlinigkeit, ALH= Amplitude des lateralen Kopfversatzes. Die ADAM 27 defizienten Spermatozoen zeigten signifikant erniedrigte Geschwindigkeiten und lateralen Kopfversatz verglichen mit denen der Wildtypkontrollen ( $P<0,001$ im Mann-Whitney U-Test).

Zur weiteren Beurteilung der Befruchtungsfähigkeit von Spermien der Knockout-Mäuse wurde ein Bindungsassay durchgeführt. Hierbei wird die Fähigkeit der Spermien zur Bindung an die Oozytenmembran getestet, indem Spermien mit Oozyten inkubiert werden, die nichtgebundenen Spermien abgewaschen und anschließend die gebundenen Spermien pro Oozyte ausgezählt 


\section{Ergebnisse}

werden. Der Test wurde zweimal durchgeführt. Einmal wurde nur die Anzahl der gebunden Spermien von $E W 50^{-/-}$-Männchen pro Oozyte im Vergleich zur Wildtypkontrolle überprüft. Im zweiten Test wurde als weiteres Kriterium die Bindungsfähigkeit an Oozyten mit und ohne Zona pellucida überprüft. Test eins ergab für die homozygoten Männchen nur durchschnittlich 8,6 gebundene Spermien pro Oozyte. Die Wildtypkontrollen zeigten im Mittel 154 gebundene Spermien pro Oozyte. Dieses Ergebnis konnte in Test zwei bestätigt werden. Hier konnten durchschnittlich lediglich 1,7 Spermien von EW50/--Tieren an eine Oozyte mit Zona pellucida binden. Bei den Kontrollen waren es im Mittel 13,3 Spermien pro Oozyte. Mehr Spermien konnten an Zona-freie Oozyten binden, jedoch auch hier war eine Reduktion bei den homozygoten Knockout-Mäusen zu zeigen (Abb.3.24 und 3.25).

a)

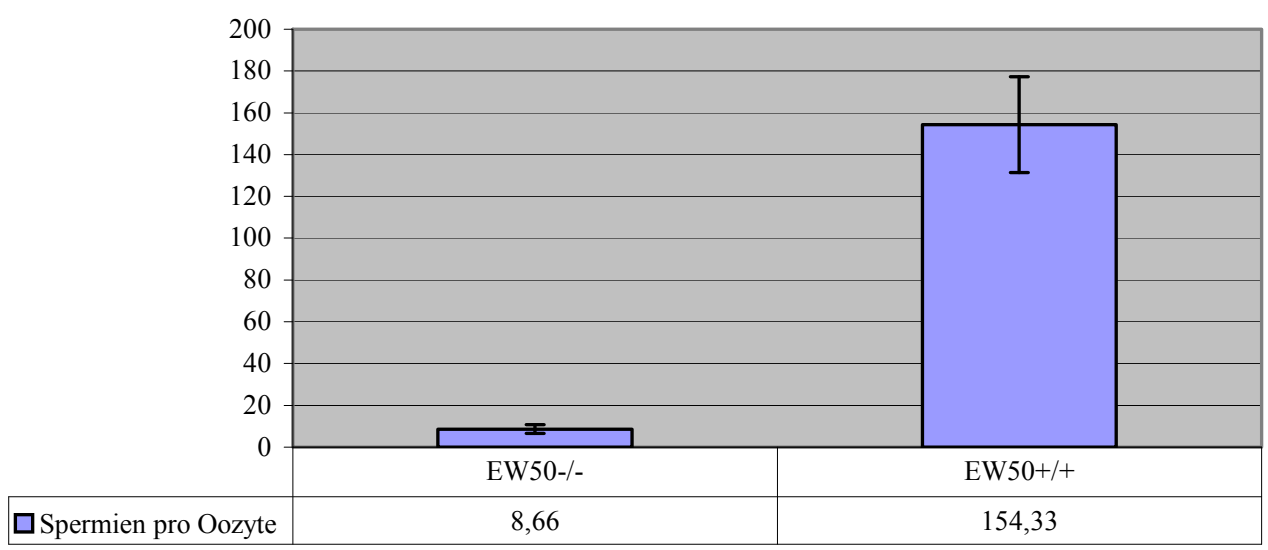




\section{Ergebnisse}

b)

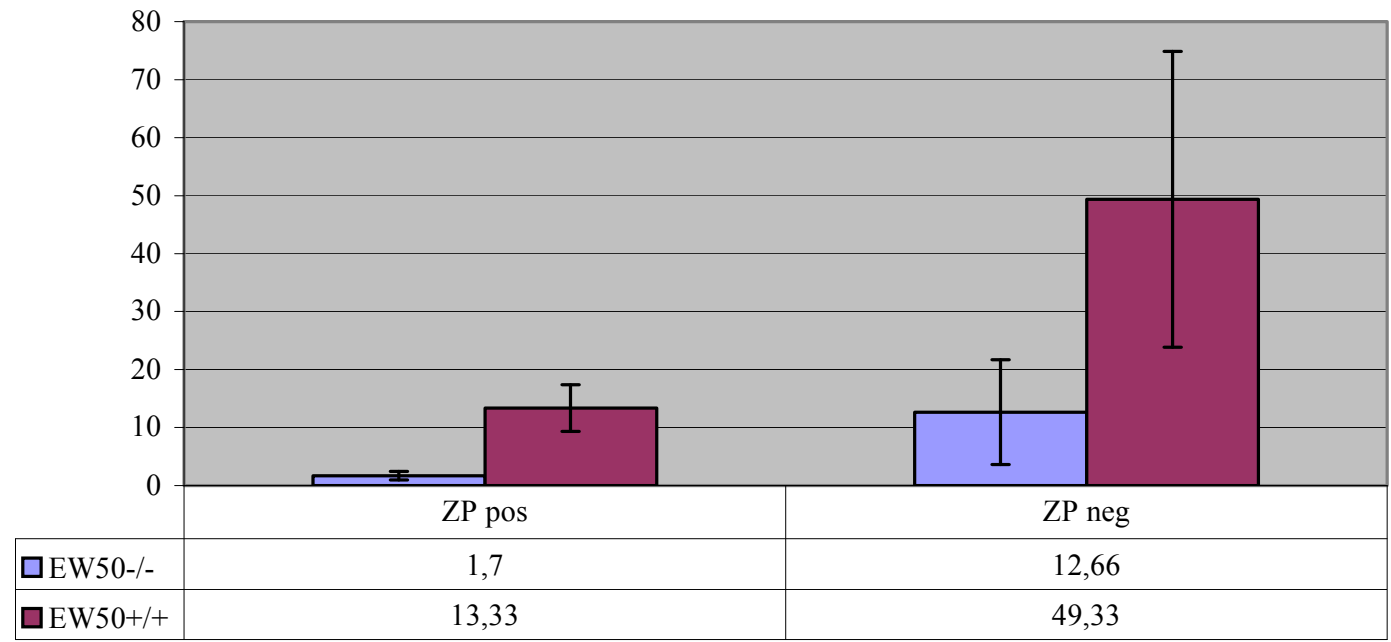

Abb. 3.24: a) Bindungsassay von Spermien der $E W 50^{-/}$- und $E W 50^{+/+}$-Mäuse im Vergleich. Untersuchung von gebundenen Spermien nur an Oozyten mit Zona. Starke Reduktion der gebundenen Spermien pro Oozyte bei $E W 50^{-/-}$-Tieren: 8,66/Oozyte; 154,33 Spermien/Oozyte beim Wildtyp. b) Bindungsassay von $E W 50^{-/-}$- und $E W_{50}{ }^{+/+}$-Mäusen, vergleichend zwischen Oozyten mit und ohne Zona pellucida. Reduktion der gebundenen Spermien von $E W_{50}^{-/-}$-Männchen bei Oozyten mit und ohne Zona pellucida. Angegeben ist jeweils die durchschnittliche Zahl Spermien pro Oozyte, Standardabweichung als Fehlerbalken.
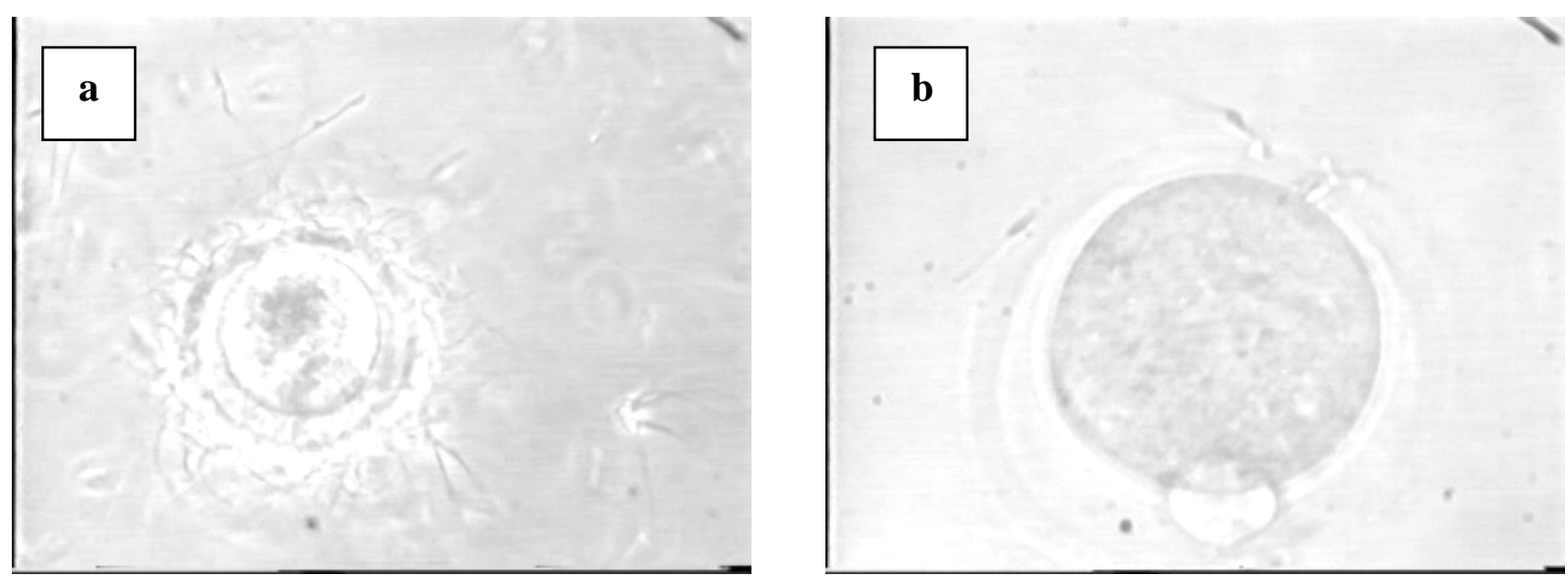


\section{Ergebnisse}
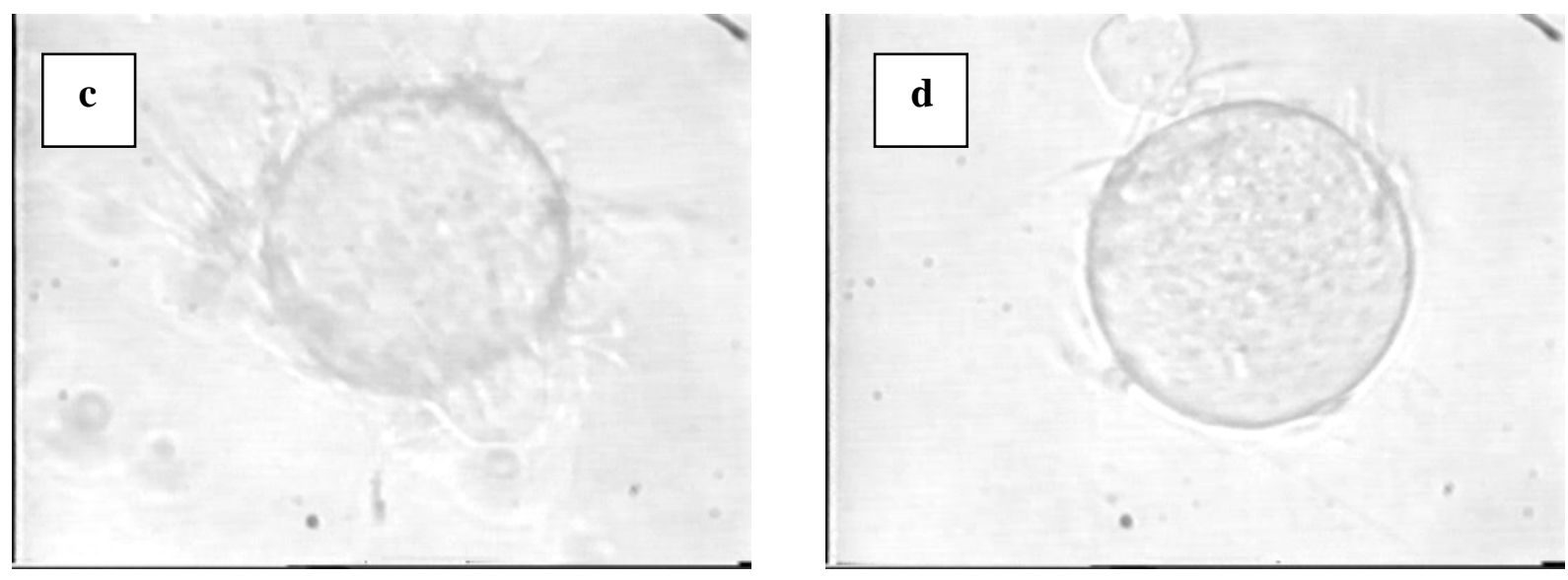

Abb. 3.25: Abbildungen des Bindingsassay a) an Oozyte gebundene Wildtypspermien b) an Oozyte gebundene Spermien von $E W 50^{-/}$-Männchen, im Vergleich zwischen a) und b) fällt die deutliche Reduktion der gebundenen Spermien von $E W 50^{-/}$-Tieren auf. c) an Zona-freier Oozyte gebundene Wildtypspermien d) an Zona-freier Oozyte gebundene Spermien von $E W 50^{-/-}$-Männchen, auch hier ist eine Reduktion gebundener Spermien von $E W 50^{-/}$-Männchen im Vergleich zum Wildtyp ersichtlich.

\subsubsection{Testishistologie}

Die morphologische Begutachtung von Testisschnitten von $E W 50^{-/}$- und $E W 50^{+/+}$-Tieren erfolgte lichtmikroskopisch am HE-gefärbten Präparat, sowie elektronenmikroskopisch am cacodylatfixierten Gewebe. Histomorphologisch konnte außer einer vermehrten Bildung großer Vakuolen im Keimepithel kein Unterschied zu den bei $A D 27^{-/}$-Tieren gewonnenen Ergebnissen festgestellt werden. Es kommen die gleichen Pathologien vor, jedoch sind diese, im Unterschied zu $A D 27-T i e r e n$, nicht mit zunehmenden Alter progredient, sondern bereits im Alter von ca. 3 Monaten in ähnlicher Ausprägung vorhanden wie bei weitaus älteren Mäusen der Linie $A D 27^{-\alpha}$. Ebenfalls scheinen auch hier die morphologischen Veränderungen keinen Einfluss auf die Gesamtzahl gebildeter Samenzellen zu haben. 

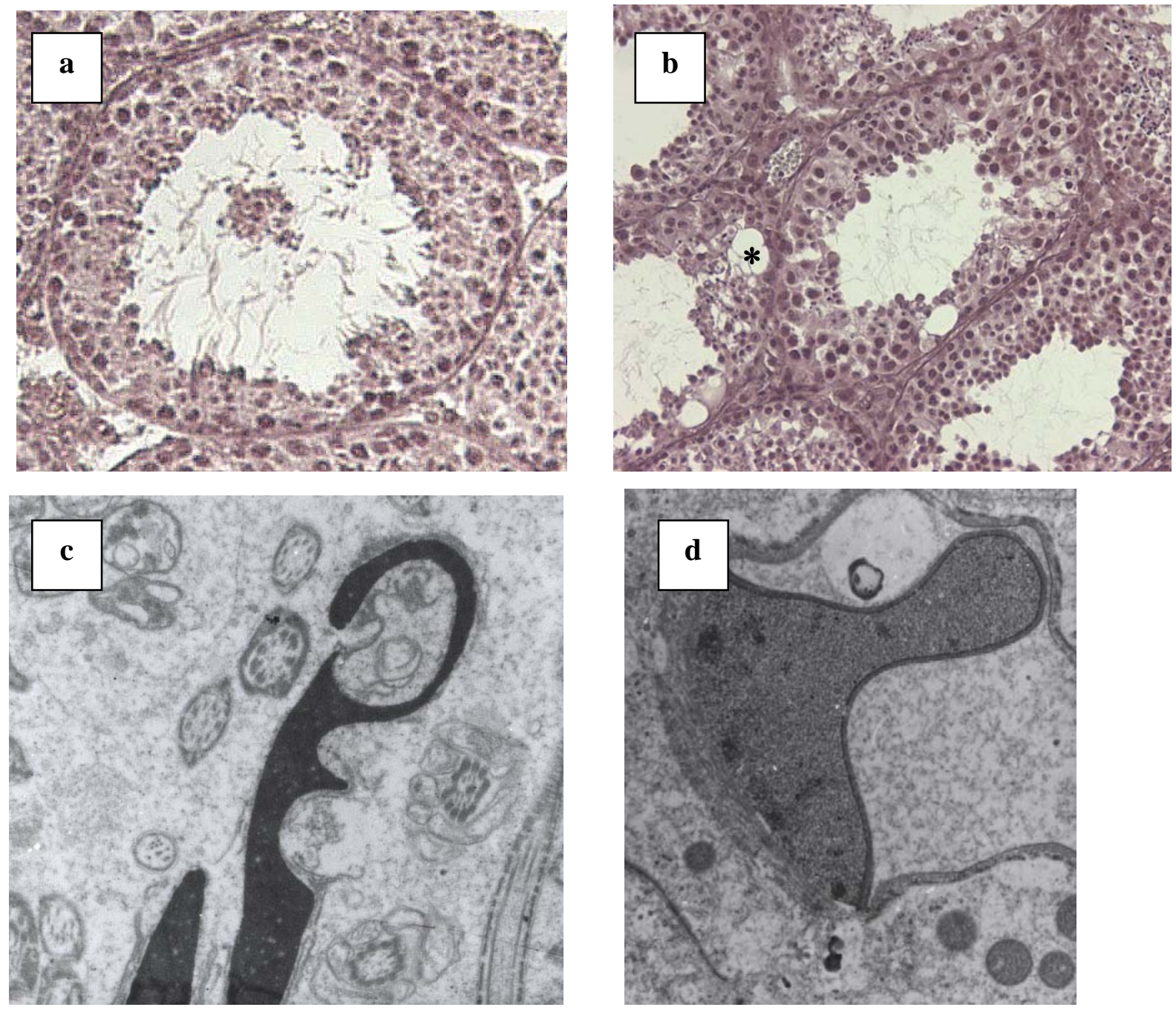

Abb. 26: a)+b) 3 Monate altes Männchen $E W 50^{-/}$; a) Tubulus mit noch weitgehend normalem Keimepithel und Spermatogenese b) Tubuli mit verändertem Keimepithel, noch Zellen in Stadien der Spermatogenese vorhanden, Vakuolenbildung (Sternchen)

c) elektronenmikroskopische Aufnahme eines fehlgeformten Spermienkopfes, spermienmorpholgisch stellt dies eine sehr häufig anzutreffende Pathologie dar d) auffällige Bildungsstörung des Akrosoms 


\subsection{Analyse von transgenen PAD-Mäusen}

In einer bei Studienbeginn diskutierten Hypothese bestand die Annahme, daß die Speziesspezifität in der Interaktion zwischen Spermium und Oozyte nicht durch einzelne Liganden und Rezeptoren, sondern durch eine artindividuelle Oberflächenstruktur von Spermaund Eizelle gewährleistet wird. Somit könnte eine Überexpression von $A D A M$ 27, als potentielles Glied in dieser Kette, zu einer Veränderung der Spermiumoberflächenstruktur führen und in der Folge Auswirkungen auf die Fruchtbarkeit der Versuchstiere haben. Founder-Tiere dieser transgenen Linie waren bei Studienbeginn bereits im Labor vorhanden, so daß mit der Etablierung einer homozygoten (T/T) Linie begonnen werden konnte.

Die Founder-Tiere wurden mit Wildtypmäusen des genetischen Hintergrundes 129/SVxC57BL6 verpaart und deren Nachkommen durch PCR an genomischer DNA genotypisiert. Als Primer kamen PGK-2seq/FP und AD27 5'seq/RP zur Verwendung (Abb. 3.27).

a)

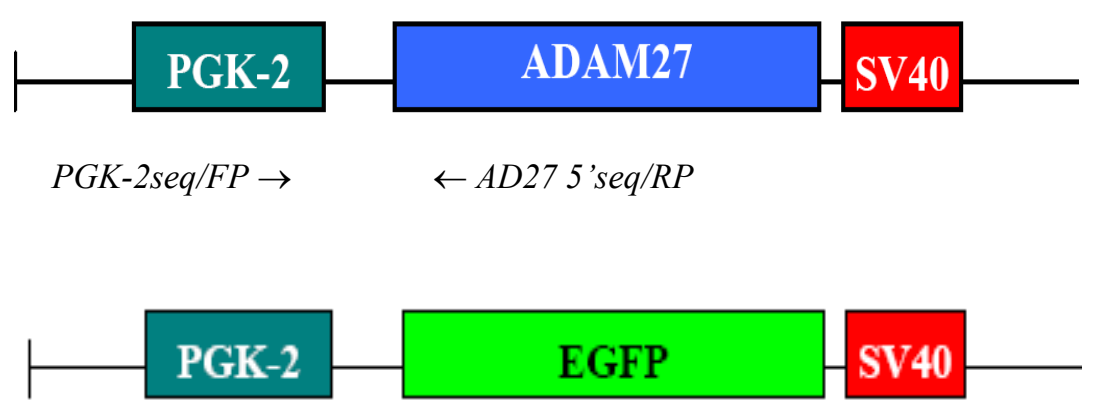

b)

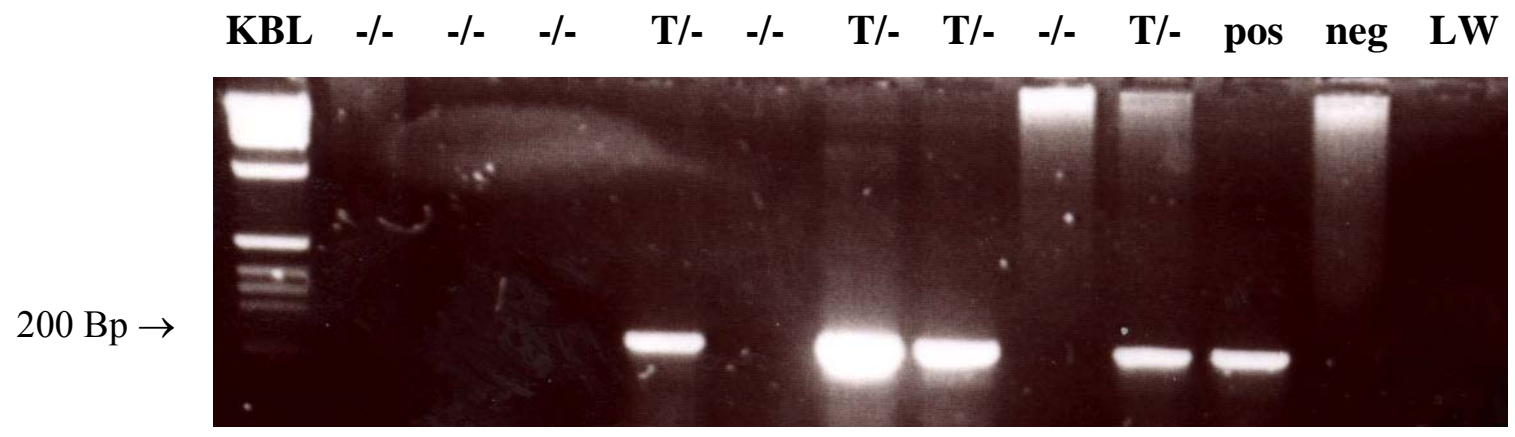

Abb. 3.27: a) Genkonstrukte PAD und EGFP, Position der Genotypisierungsprimer PGK-2seq/FP als Forward-Primer im PGK-Promotor und AD27 5'seq/RP als Revers-Primer im ADAM 27-Gen bei PAD (nach Bolcun-Filas, 2003, S. 108) b) Genotypisierungs-PCR mit o. g. Primern, das PCR-Produkt hat eine Größe von ca. $200 \mathrm{Bp}$; -/- = Wildtyp, T/- = heterozygot transgen, pos = Positivkontrolle, neg $=$ Negativkontrolle, $\mathrm{LW}=$ Leerwert 


\subsubsection{Expressionsanalyse}

Da mehrere transgene Linien vorhanden waren, wurde eine Northern-Blot Analyse durchgeführt, um die Linie mit der stärksten Expression des $A D A M$-Genkonstruktes sowie des EGFP-Gens zu finden. Die dafür verwendete $A D A M-27-S o n d e$ wurde wie oben erwähnt hergestellt, die verwendete EGFP-Sonde war bereits im Labor vorhanden.

Es wurde Gesamt-RNA aus Hoden und Niere von heterozygot transgenen Männchen aus den verschiedenen Linien isoliert, diese durch Gelelektrophorese aufgetrennt und anschließend mittels Kapillartransfertechnik auf eine Nitrozellulosemembran aufgebracht und fixiert. Diese wurde zunächst mit der radioaktiv markierten EGFP-Sonde hybridisiert und anschließend mit einem Röntgenfilm entwickelt. Nach dem Stripping des Nitrozellulosefilters, wurde dieser mit der radioaktiv markierten $A D A M-27-$ Sonde erneut hybridisiert und damit ebenfalls ein Röntgenfilm entwickelt. Dabei zeigte sich, daß ein spezifisches Signal in beiden Linien nur bei RNA aus Hodengewebe, nicht jedoch aus Nierengewebe, zu detektieren war. Auch zeigte die Linie PAD \#4 eine stärkere Expression für EGFP und $A D A M 27$ als Linie PAD \#5, sodaß daraufhin die Linie $P A D \# 5$ beseitigt und die nachfolgenden Experimente mit Linie PAD \#4 durchgeführt wurden. (Abb. 3.28)

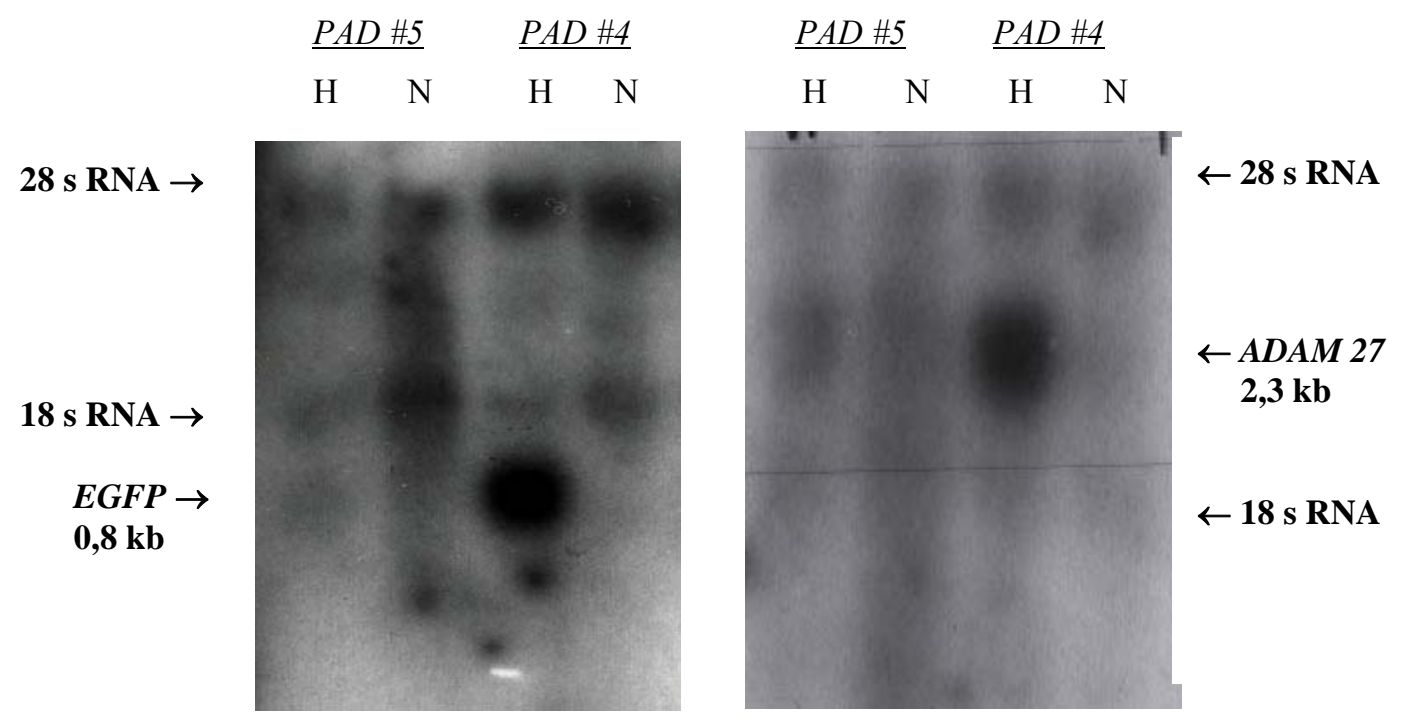

Abb. 3.28: Northern Blot Linien PAD \#4/PAD \#5 mit Gesamt-RNA aus Hoden $(\mathrm{H})$ und Niere $(\mathrm{N})$. Stärkere Expression von ADAM 27 und EGFP bei PAD \#4 als bei PAD \#5. Expression beider Genkonstrukte nur in Hoden-RNA nachweisbar. 


\section{Ergebnisse}

Die heterozygoten Tiere der F1-Generation wurden untereinander weiter verpaart und die Nachkommen ebenfalls mittels PCR genotypisiert. Die für das Konstrukt positiv getesteten Tiere der F2-Generation wurden anschließend mittels quantitativer Real-Time-PCR auf Hetero- bzw. Homozygotie getestet. Die Ergebnisse wurden in ein Diagramm übertragen und graphisch ausgewertet. Anhand dieser Grafik (Abb. 3.29) wurden 1:1 Verpaarungen mit homozygoten Männchen und Weibchen angesetzt.

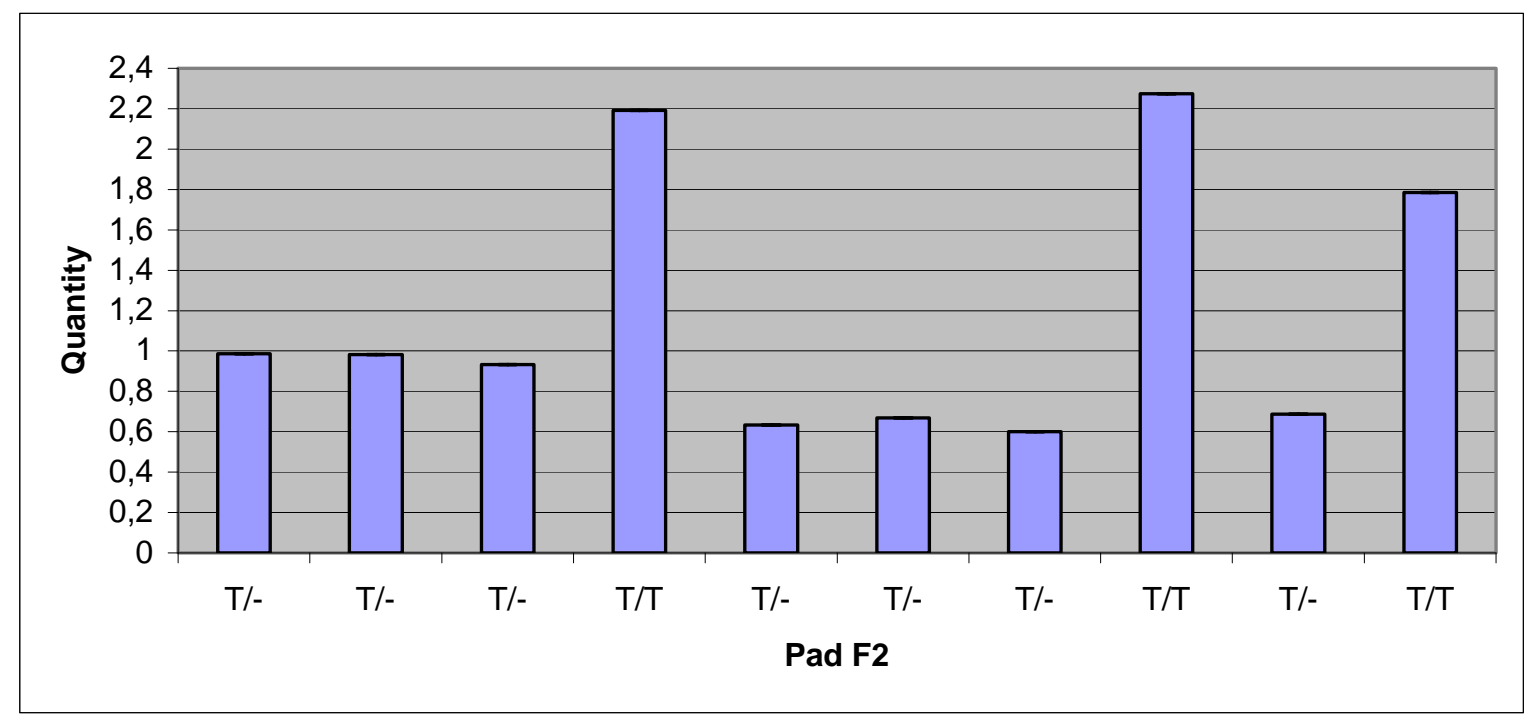

Abb. 3.29: Graphische Auswertung der Genotypisierung der F2-Generation mittels quantitativer Real-TimePCR. Nach Übertragung der Daten in ein Diagramm und Vergleich der RNA-Quantitäten mit einem bekannten heterozygoten Tier als Standardkontrolle kann zwischen T/- (heterozygot) und T/T (homozygot) Tieren differenziert werden.

\subsubsection{Wurfgrößenstatistik}

Die homozygoten transgenen $A D A M-27-T i e r e(\mathrm{~T} / \mathrm{T})$ sind phänotypisch unauffällig. Die Fertilität wurde anhand der Nachkommenzahl überprüft, wobei die Nachkommenzahl aus mindestens 5 Würfen berücksichtigt wurde. Es zeigte sich keine signifikante Reduktion der Nachkommenzahl bei hetero- oder homozygoten Verpaarungen gegenüber dem Wildtyp. Die mittlere Wurfgröße 


\title{
Ergebnisse
}

der heterozygoten Verpaarungen betrug 8,3 Nachkommen pro Wurf, während die der homozygoten Verpaarungen im Durchschnitt 8 Nachkommen pro Wurf betrug.

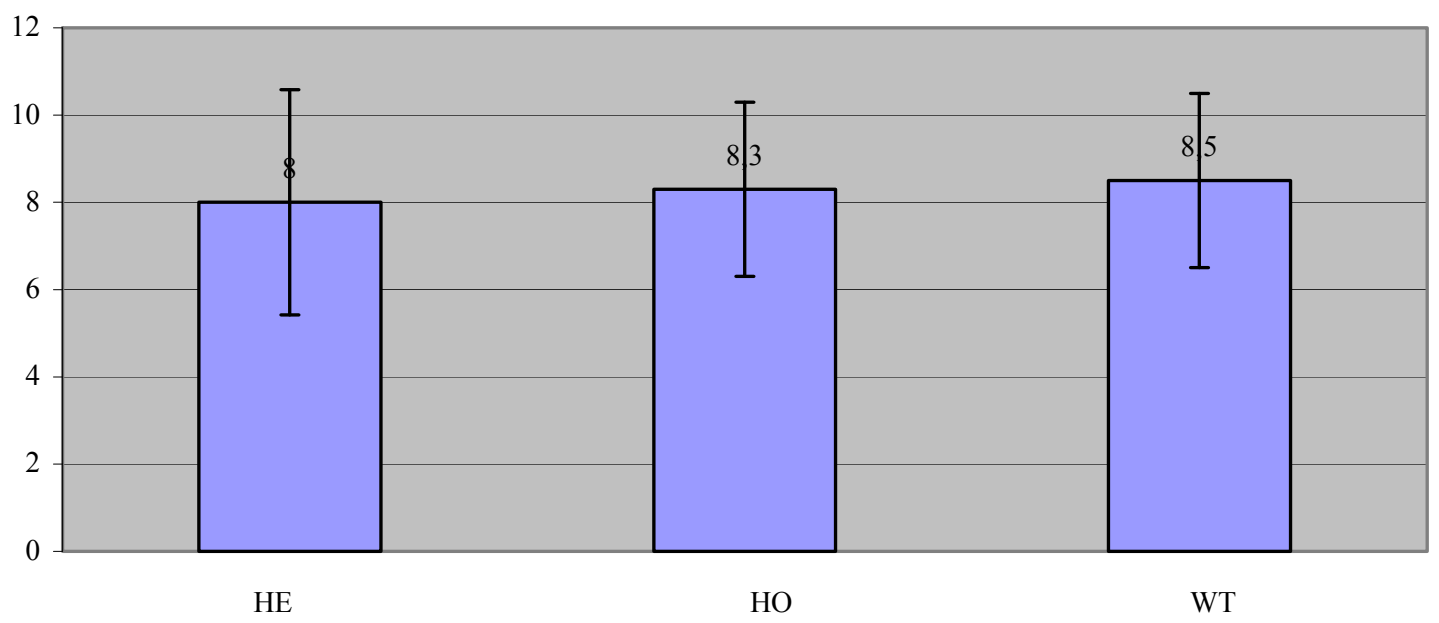

\begin{abstract}
Abb. 3.30: Durchschnittliche Wurfgrößen bei transgenen PAD-Mäusen. Normale Wurfgrößen bei Hetero(HE) (8 Nachkommen pro Wurf), sowie Homozygotenverpaarungen (HO) (8,3 Nachkommen pro Wurf). Angabe mit Standardabweichung, dargestellt als Fehlerbalken.
\end{abstract}

Da die Fertilität der transgenen Mäuse nicht beeinträchtigt war und die Tiere auch sonst keine Abweichungen im Phänotyp, verglichen mit dem Wildtyp zeigten, kann davon ausgegangen werden, daß eine Überexpression des $A D A M-27-G e n s$ ohne weitreichende Konsequenzen für Phänotyp und Morphologie bleibt. Deshalb wurden weitere Experimente mit den Tieren dieser Linie nicht durchgeführt. 


\section{Ergebnisse}

\subsection{Analyse von EW50/PAD-Mäusen}

Dieses Experiment, bei dem Mäuse der Linien PAD und EW50 miteinander verpaart wurden, wurde gemacht, um zu sehen, ob eine Normalisierung des Phänotyps der EW50-Tiere möglich ist. Theoretischer Hintergrund ist, das ausgeschaltete $A D A M-27-G e n$ der EW50-Tiere durch das überexprimierte $A D A M-27-G e n$ der $P A D$-Mäuse zu kompensieren.

\subsubsection{Expressionsanalyse}

Verpaart wurden $E W 50^{-/}$-Weibchen mit $P A D$ T/T-Männchen. Die aus diesen Verpaarungen stammenden Tiere der F1-Generation wurden untereinander verpaart und die daraus stammenden Mäuse der F2-Generation mittels PCR genotypisiert. Dabei wurde genomische DNA aus Mausschwanzbiopsaten isoliert und mit den genspezifischen Primerpaaren amplifiziert. Für die weiteren Experimente wurden die Tiere mit dem $E W 50^{-/} ; P A D p o s-G e n o t y p$ gewählt. Um die Expression des $A D A M-27-G e n s$ in den $E W 50^{-/} ; P A D p o s-M a ̈ u s e n$ nachzuweisen, wurde ein Northern Blot durchgeführt. RNA von Wildtyp-, EW50-- -und EW50 $0^{-/} ; P A D p o s$-Mäusen wurde nach dem Blotten mit der spezifischen $A D A M-27-$ Sonde hybridisiert und anschließend die radioaktiven Signale mittels Röntgenfilm aufgezeichnet.

Eine Expression des $A D A M$-Gens war nur bei Wildtyp- und EW50 $0^{-/} ;$PADpos-Tieren, nicht jedoch bei $E W 50^{-/}$-Männchen zu sehen (Abb. 3.31). 


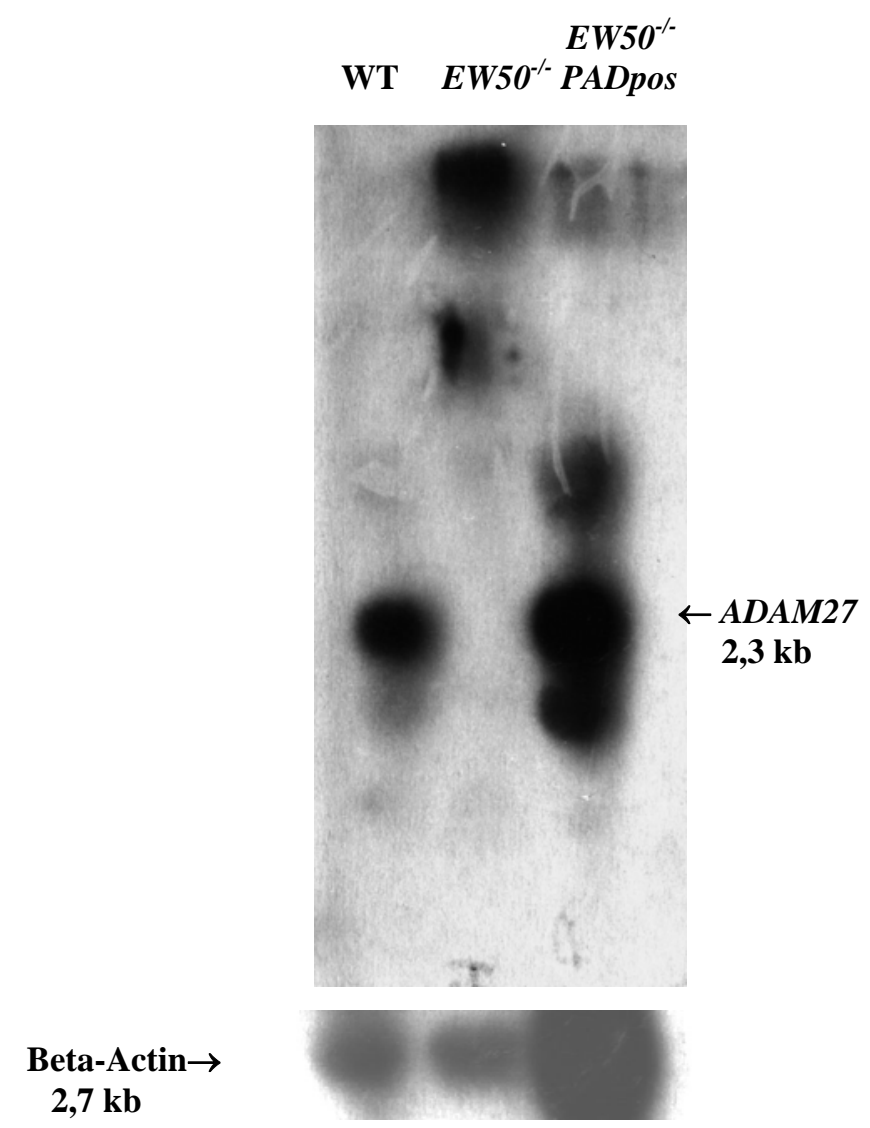

Abb. 3.31: Northern Blot mit Testis-RNA von $E W 50^{-/-}-E W 50^{-/} ; P A D p o s-$ und Wildtyptieren. Expression des ADAM-Gens bei WT- und EW50;PADpos-Mäusen, nicht bei $E W 50^{-/-}$-Tieren, Beta-Actin als RNA-Kontrolle

\subsubsection{Wurfgrößenstatistik}

In Inzuchtverpaarungen wurden die $E W 50^{-/} ; P A D p o s$-Tiere der F2-Generation auf ihre Fertilität hin untersucht und eine Wurfgrößenanalyse durchgeführt. Aus mindestens fünf Würfen wurde die mittlere Wurfgröße bestimmt, die bei durchschnittlich 8 Jungen pro Wurf lag. Da die mittlere Nachkommenanzahl 7 Jungen pro Wurf bei der Wildtyplinie (129sv) betrug, ist eine Wurfgrößenreduktion somit nicht gegeben (Abb. 3.32). Man kann diesbezüglich von einer normalen Fertilität dieser Mäuse ausgehen, was auf eine Normalisierung des Phänotyps der $E W 50^{--}$-Mäuse deutet, da die durchschnittliche Nachkommenanzahl dieser Linie, wie oben erwähnt, lediglich 1,9 Jungen beträgt. 


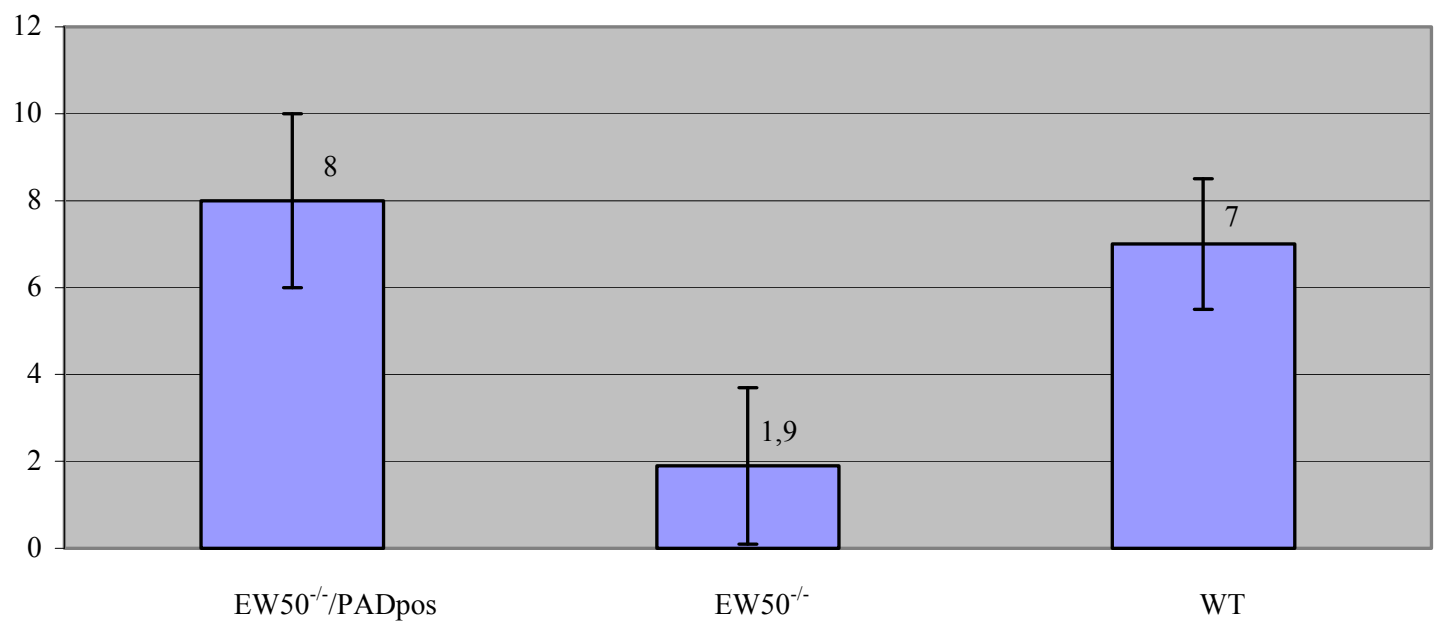

Abb. 3.32: Durchschnittliche Wurfgröße der verschieden Linien im Vergleich. Normale Wurfgröße bei EW50 ${ }^{-/}$/PADpos-Tieren (8 Nachkommen pro Wurf), stark reduzierte Nachkommenzahl bei $E$ W50 ${ }^{-/}$-Tieren (1,9 Nachkommen pro Wurf). Standardabweichung als Fehlerbalken.

Um zu prüfen, inwieweit es zu einer Normalisierung der pathologischen Befunde der $E W 50^{-/}$Tiere gekommen ist, wurden noch weitere Versuche durchgeführt und verschiedene Parameter bestimmt, die einen Überblick über die Fertilität und den Phänotyp der Rescuemäuse geben sollten.

\subsubsection{Spermienparameter}

Es wurde bei den Rescuetieren die Anzahl der Spermien im Nebenhodenschwanz bestimmt. Zwar war diese bei $E W 50^{-/}$-Tieren nicht reduziert, trotzdem sollte geklärt werden, ob sich eventuelle Veränderungen hier ergeben haben. Auch hier zeigte sich keine signifikante Reduktion der

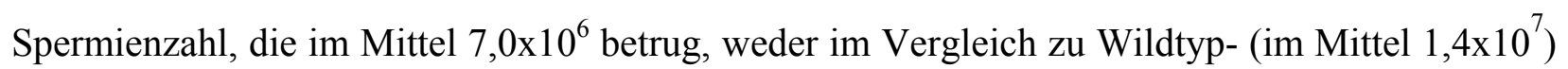

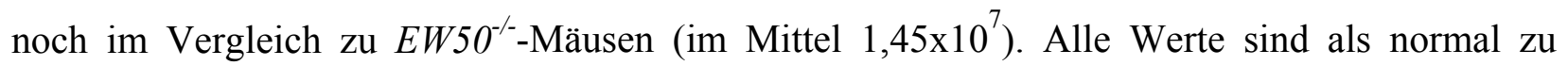
betrachten. Die Ergebnisse sind nochmals in der untenstehenden Übersicht aufgeführt (Abb. $3.33)$. 


\section{Ergebnisse}

Anzahl Spermien im Nebenhodenschwanz

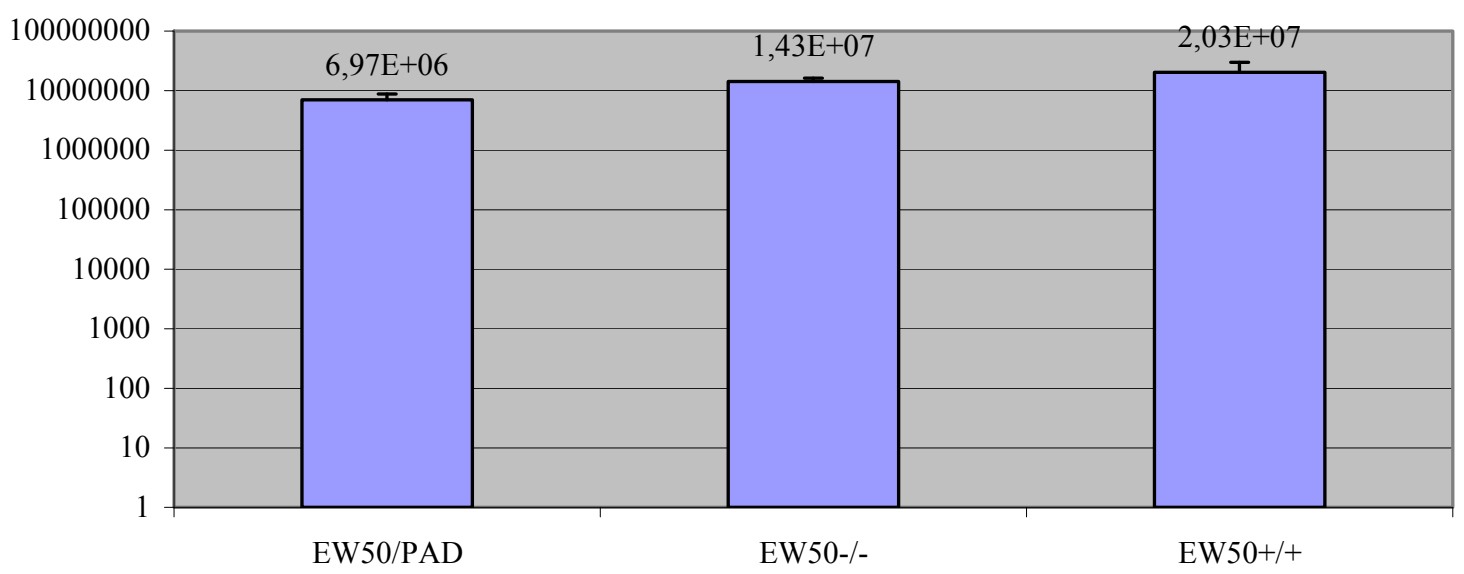

Abb. 3.33: Durchschnittliche Spermienzahl im Nebenhodenschwanz bei mutanten Mäusen und Wildtypmäusen. Aus den Werten ist keine signifikante Reduktion der Spermienzahl bei EW50/PAD-Tieren im Vergleich zu denen der anderen Mutanten- und denen der Wildtyplinie ersichtlich. Standardabweichung dargestellt als Fehlerbalken.

Da die $E W 50^{-/}$-Tiere erhebliche Veränderungen bei der Spermienmorphologie zeigten, war dieser Parameter sehr geeignet, um die Auswirkungen des Rescueexperimentes auf den Phänotyp zu untersuchen. 200 Spermien von jeweils drei $E W 50^{-/} ; P A D p o s-M a ̈ n n c h e n$ im Alter von 3 Monaten wurden nach ihrer Morphologie begutachtet und ausgewertet, sowie ein Mittelwert gebildet. Die Anzahl fehlgebildeter Spermien betrug im Mittel ca. 15,83\%, womit die EW5 $50^{--} ;$PADpos-Tiere einen deutlich geringeren Anteil fehlgeformter Spermien haben als die Tiere der Linie $E W 50^{--}$, deren Anteil felgebildeter Spermien beträgt im Durchschnitt 68\% (siehe Abb. 3.34). 


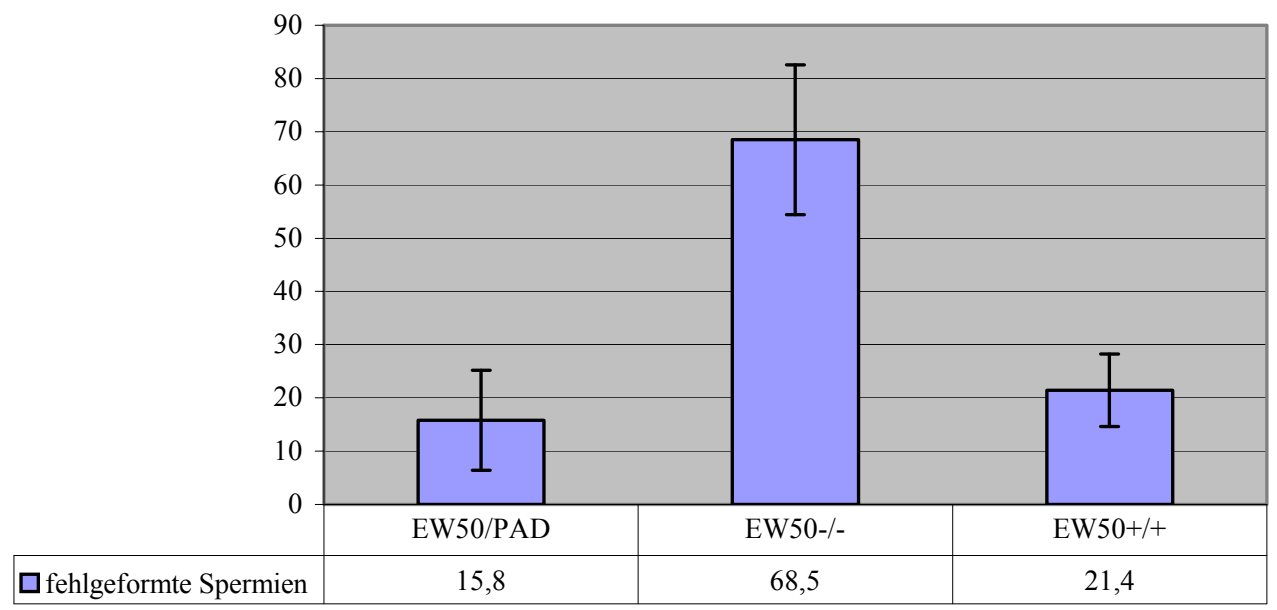

Abb. 3.34: Anteil fehlgebildeter Spermien bei $E W 50^{-/} ; P A D p o s-, E W 50^{-/}$- sowie WT-Männchen. Angaben in Prozent, Standardabweichung dargestellt als Fehlerbalken. $\mathrm{Zu}$ sehen ist ein deutlich geringerer Anteil fehlgebildeter Spermien bei EW50/PAD-Tieren (15,8\%) im Vergleich zu EW50 ${ }^{-/}$-Mäusen (68,5\%), Wildtypkontrolle: $21,4 \%$.

Da mit dem hypoosmotischen Schwelltest ein sehr sensitiver Test zur Beurteilung der Fertilität von Spermien zur Verfügung steht, wurde dieser Test ebenso zur Beurteilung der Spermien der EW5 $0^{--} ;$PADpos-Mäuse herangezogen. Durchgeführt wurde er mit den Spermien von jeweils drei Tieren der Linie $E W 50^{-/} ;$PADpos und der Wildtyplinie 129/SV. Zum Vergleich wurden auch die Ergebnisse des Schwelltests mit Spermien von EW50--Männchen herangezogen. Diese Spermien zeigten eine stark reduzierte Schwellneigung (Abb. 3.22), was auf eine verminderte Fertilisationsfähigkeit schließen läßt. Das Ergebnis dieser Untersuchung zeigt ein normales Schwellvermögen der Spermien von $E W 50^{-/} ; P A D p o s-M a ̈ n n c h e n$. Es konnte kein Unterschied zwischen diesen Spermien und denen der Wildtyptiere beobachtet werden. Unterschiede im Sinne einer nicht reduzierten Zahl geschwollener Spermien zeigten sich im Vergleich zu Spermien der $E W 50^{-/}$-Tiere. Deren Spermien zeigten lediglich zu 25\% Schwellungsphänomene. (Abb.3.22). 
a)

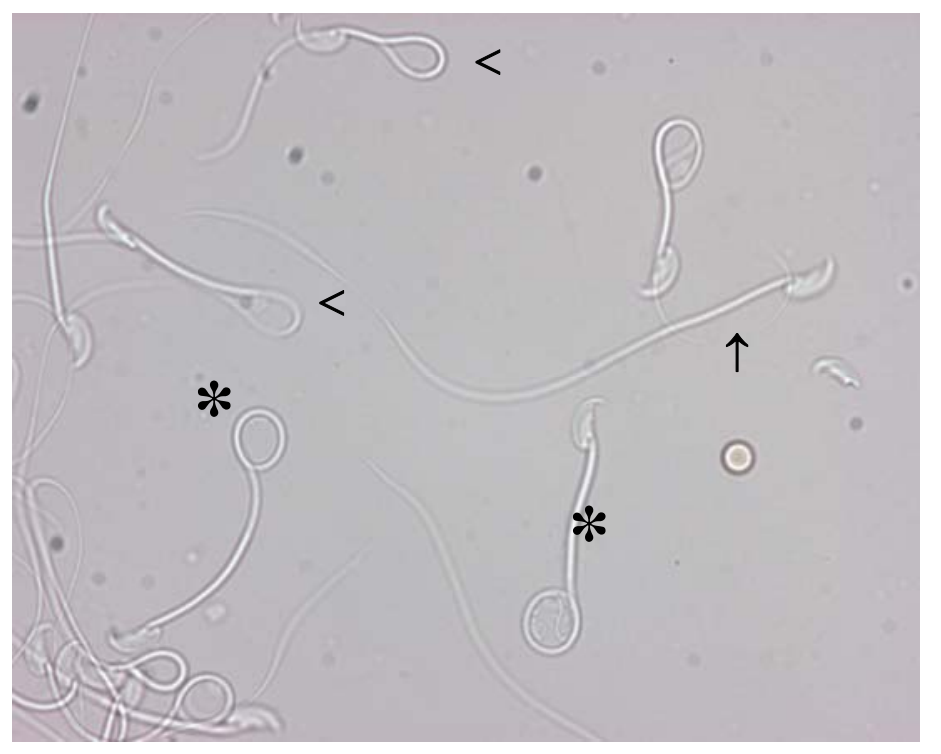

b)

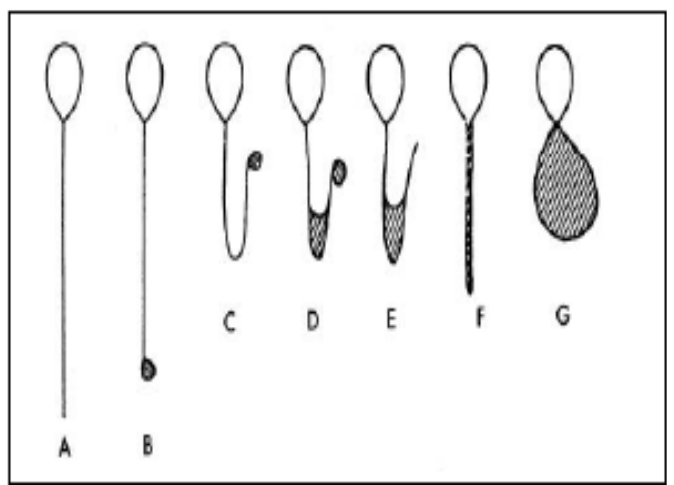

c)

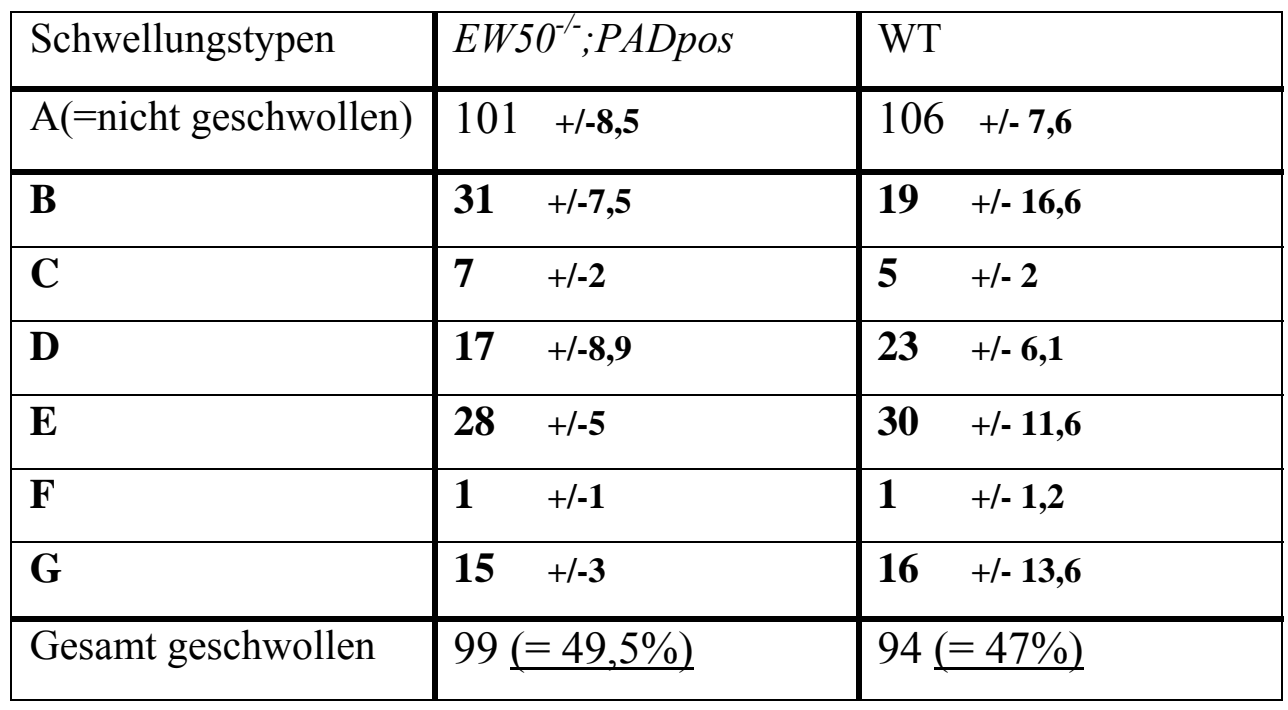

Abb. 3.35: a) geschwollene (B-Typ, markiert mit Sternchen; E-Typ, markiert mit Pfeilköpfen) und nicht geschwollene (markiert mit Pfeil) Spermien im mikroskopischen Bild b) Schema zur Spermieneinteilung nach Schwelltyp (Müller, 1998, S. 31) c) Einteilung und Quantifizierung der Spermien nach Schwelltest bei EW50 ${ }^{-/}$ ;PADpos- und WT-Tieren. Zahlenangaben sind Mittelwerte aller gezählten Spermien. Die Prozentangaben beziehen sich auf 200 Spermien. Angabe mit Standardabweichung. Der Anteil geschwollener Spermien bei EW50 $^{-/}$;PADpos- Männchen (49,5\%) entspricht der Wildtypkontrolle (47\%). 


\section{Diskussion}

\section{Diskussion}

Die Familie der $A D A M$-Gene ist eine heterogene Gruppe von Genen, die für Proteine mit Proteolyse- und Zelladhäsionsaktivität kodieren. Viele dieser Gene werden im Hoden exprimiert, was hinweisend auf ihre potentielle Funktion in Spermatogenese oder Befruchtung ist. Für einige Gene dieser Gruppe, wie z.B. das Gen Cyritestin, konnte die funktionelle Bedeutung bei der Bindung von Spermien an Oozyten bereits gezeigt werden (Shamsadin et al., 1999). In dieser Studie wurde mittels in-vitro- und in-vivo-Experimenten das Gen ADAM 27 auf seine Funktion hin untersucht.

Zuerst soll eine kurze Zusammenfassung gegeben werden über die im Rahmen dieser Studie erhaltenen wichtigsten Ergebnisse. Im Weiteren soll ein aktueller Überblick gegeben werden über die $A D A M$-Genfamilie bezüglich deren potentieller Funktion und vorhandener KnockoutModelle. In einem dritten Teil erfolgt eine Beschreibung von $A D A M$ 27, wie auch eine Gegenüberstellung und Diskussion wichtiger Ergebnisse der Versuchsreihen AD27 und EW50, sowie der transgenen Versuchsreihe $P A D$ und des Rescueexperiments.

\subsection{Ergebniszusammenfassung}

Die Ausschaltung des $A D A M-27-G e n s$ bewirkt eine hochgradige Subfertilität der männlichen Mäuse, welche bei $A D 27^{-/}$-Tieren (ADAM-27-Knockout-Modell mit ausgeschalteter Transmembrandomäne) zu Beginn der Geschlechtsreife noch nicht vorhanden ist, jedoch mit fortschreitendem Alter zunimmt. EW50---Tiere (ADAM-27-Knockout-Modell mit komplett ausgeschaltetem Gen) weisen hingegen bereits kurz nach Eintritt in das geschlechtsreife Alter eine hochgradige Subfertilität auf (siehe Abb. 3.4, 3.5 und 3.18). Ursächlich hierfür kann die hochgradige Zahl morphologisch veränderter Spermien sein, welche sowohl bei Mäusen der Linie AD27 (hier ebenfalls progredient mit dem Alter) wie auch bei der Linie EW50 auftritt (siehe Abb. 3.10a, 3.20a). Die Integrität der Spermazellmembran scheint gestört, da diese Spermien eine verminderte Schwellung in einem hypoosmotischen Medium aufweisen (Abb.

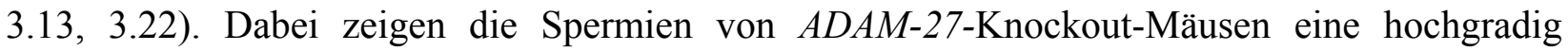


verminderte Bindung an die Zona pellucida und an das Oolemm (Abb. 3.14, 3.24, 3.25). Als weiterer morphologischer Phänotyp konnten in Testisschnitten Störungen innerhalb des Keimepithels gefunden werden. Es kommt $\mathrm{zu}$ einer vorzeitigen Ablösung von elongierten Spermatiden und Spermien aus dem Gewebeverband. Diese Veränderungen sind bei $A D 27^{-{ }^{-}}$Männchen progredient und erreichen den Gipfel im Alter, während $E W 50^{-/-}$-Tiere diese Veränderungen bereits als Jungtiere aufweisen (Abb. 3.14, 3.26). Keinen Einfluß hat das Ausschalten von ADAM 27 auf Spermienzahl (Abb3.8, 3.19), -motilität (Abb3.11, 3.23), Ausführen der Akrosomenreaktion (Abb3.12, 3.21) und die weitere Entwicklung des Embryos nach Befruchtung (Abb3.6, 3.7). Keinen Einfluß auf die Fertilität hat die Überexpression von ADAM 27 (Abb3.30).

\subsection{ADAM-Gene und ihre möglichen Funktionen}

(nach Edwards et al., 2008)

Wie bereits erwähnt, ist die Gruppe der $A D A M$-Gene eine große Gruppe von Genen mit verschiedenen Funktionen im Bereich von Zelladhäsion und proteolytischer Prozessierung der Ektodomänen von Zellrezeptoren und Signalmolekülen. Ein Überblick über die möglichen Funktionen anhand der bislang verfügbaren Knockout-Modelle zeigt Abb. 4.1.

\begin{tabular}{|l|l|l|}
\hline $\begin{array}{l}\text { KDAM- } \\
\text { Knockout }\end{array}$ & Phänotyp & Autor \\
\hline ADAM 1a & $\begin{array}{l}\text { männliche Infertilität, Störungen in Spermien- } \\
\text { migration und -adhäsion }\end{array}$ & Nishimura et al., 2004 \\
\hline ADAM 1b & keine Störung der Fertilität & Kim E et al., 2006 \\
\hline ADAM 2 & $\begin{array}{l}\text { männliche Infertilität, Störungen in Spermien- } \\
\text { migration und -adhäsion, Störung der } \\
\text { Neuroblastenmigration in den Bulbus olfactorius }\end{array}$ & $\begin{array}{l}\text { Cho et al., 1998 } \\
\text { Nishimura et al., 2004 } \\
\text { Murase et al., 2008 }\end{array}$ \\
\hline ADAM 3 & $\begin{array}{l}\text { männliche Infertilität, Störung in } \\
\text { Spermienadhäsion }\end{array}$ & $\begin{array}{l}\text { Shamsadin et al. 1999 } \\
\text { Nishimura et al., 2007 }\end{array}$ \\
\hline ADAM 8 & $\begin{array}{l}\text { keine Pathologien, reduziertes ,shedding“ von } \\
\text { CHL-1 im Gehirn }\end{array}$ & Kelly et al., 2005 \\
\hline ADAM 9 & keine Pathologien & Sahin et al., 2004 \\
\hline
\end{tabular}


Diskussion

\begin{tabular}{|c|c|c|}
\hline$A D A M 10$ & $\begin{array}{l}\text { Frühsterblichkeit E9,5p.c., gestörte ZNS- und } \\
\text { Herzentwicklung }\end{array}$ & Hartmann et al., 2002 \\
\hline$A D A M 11$ & $\begin{array}{l}\text { Hippokampus-bedingte Beeinträchtigung des } \\
\text { räumlichen Lernens, veränderte Antwort auf } \\
\text { Nozizeption }\end{array}$ & $\begin{array}{l}\text { Takahashi et al., 2006a } \\
\text { Takahashi et al., 2006b }\end{array}$ \\
\hline$A D A M 12$ & $\begin{array}{l}\text { Embryonalsterblichkeit 30\%, Störung im braunen } \\
\text { Fettgewebe }\end{array}$ & $\begin{array}{l}\text { Kurisaki et al., 2003; Sahin et al., } \\
\text { 2004; Masaki et al., } 2005\end{array}$ \\
\hline$A D A M 15$ & $\begin{array}{l}\text { reduzierte Tumorneovaskularisation, } \\
\text { Osteoarthritis }\end{array}$ & $\begin{array}{l}\text { Horiuchi et al., 2003; Sahin et al., } \\
\text { 2004; Bohm et al., } 2005\end{array}$ \\
\hline$A D A M 17$ & $\begin{array}{l}\text { perinatale Sterblichkeit, wahrscheinlich durch } \\
\text { Herzfehler, hypoplastische Lungen, Störung mit } \\
\text { der Reifung epithelialer Gewebe }\end{array}$ & $\begin{array}{l}\text { Peschon et al., 1998; ; Zhao et al., } \\
\text { 2001; Shi et al., 2003; Jackson et } \\
\text { al., } 2003\end{array}$ \\
\hline$A D A M 19$ & $\begin{array}{l}\text { postnatale Sterblickeit } 80 \% \text {, multiple } \\
\text { kardiovaskuläre Defekte }\end{array}$ & $\begin{array}{l}\text { Kurohara et al., 2004; Sahin et al., } \\
\text { 2004; Horiuchi et al., } 2005\end{array}$ \\
\hline$A D A M 22$ & $\begin{array}{l}\text { postnatale Sterblichkeit, Ataxie, } \\
\text { Hypomyelinisation peripherer Nerven }\end{array}$ & Sagane et al., 2005 \\
\hline$A D A M 33$ & keine Pathologien & Chen et al., 2006 \\
\hline
\end{tabular}

Abb. 4.1: Übersicht über Knockout-Modelle für verschiedene $A D A M$-Gene in Mäusen mit jeweiligem Phänotyp und Autor (nach Edwards et al., 2008, S. 267)

$A D A M 8$ wird primär in hämatopoetischen Zellen exprimiert. Eine gewisse Rolle für $A D A M 8$ in der Pathogenese neurodegenerativer Erkrankungen und im Rahmen der Leukozyteninfiltration wurde von Horiuchi et al. (2005) vermutet. $A D A M 8$ ist die Sheddase für $C H L 1$, einem neuronalen Adhäsionsmolekül und die Prozessierung dessen wird in Zusammenhang gebracht mit neuronalem Überleben und Neuronenwachstum. Obwohl $A D A M-8^{-/-}$-Mäuse keinen offensichtlichen Phänotyp besitzen, zeigen sie jedoch ein deutlich vermindertes Shedding von CHL 1 im Gehirn (Naus et al., 2004; Kelly et al., 2005).

$A D A M 10$ ist das Beispiel einer $A D A M$-Sheddase und ist beteiligt in der Intramembranproteolyse mit regulierender Funktion im Rahmen des Notch/Delta-Signalweges und der APP-Prozessierung (Saftig und Hartmann, 2005). Notch ist ein Membranprotein welches die Expression unterschiedlicher Gene reguliert. Dieses Protein unterliegt drei proteolytischen Prozessierungen in seinem Lebenszyklus und $A D A M 10$ ist die Protease, welche hauptsächlich für die zweite Prozessierung verantwortlich scheint. Der Verlust von $A D A M 10$ führt zu einem Absterben der Embryonen am Tag 9.5 p.c. Die Analyse dieser Embryonen ergab multiple Defekte im Bereich 


\section{Diskussion}

des ZNS und des kardiovaskulären Systems. Dieses findet Übereinstimmung mit Mäusen, in denen der Notch/Delta-Signalweg ausgeschaltete wurde (Hartmann et al., 2002). Auch ADAM 17 wurde im Rahmen des Notch-Shedding in in-vitro-Versuchen eine Rolle zugeschrieben, jedoch zeigen $A D A M-17-K n o c k o u t-M a ̈ u s e ~ k e i n e r l e i ~ D e f e k t e$, die mit diesem Signalweg in Verbindung stehen.

Obwohl $A D A M-11^{-/-}$-Mäuse normal erscheinen, zeigen sie jedoch Störungen im Lernen und in der motorischen Koordination (Takahashi et al., 2006). Obwohl der genaue Pathomechanismus hier weiterer Forschung bedarf, stimmt dies überein mit der hauptsächlichen Expression von ADAM 11 im Hippocampus und im Cerebellum.

Einige $A D A M$-Knockout-Mäuse ( $\left.A D A M 9^{--}, A D A M 12^{-/}, A D A M 15^{-/}\right)$zeigen keinerlei sichtbare Pathologien. Eine Frühsterblichkeit von 30\% der Nachkommen wenige Wochen nach Geburt bei $A D A M 12^{-/-}$-Tieren wurde in einer Studie berichtet (Kurisaki et al., 2003), wobei TripelKnockout-Mäuse für $A D A M 9 / 12 / 15^{-/-}$keinerlei Auffälligkeiten in diese Richtung zeigten und auch sonst keine sichtbaren Pathologien oder Einschränkungen der Fertilität zeigten (Sahin et al., 2004), sodaß die Frühsterblichkeit am ehesten auf den genetischen Hintergrund zurückzuführen ist. ADAM 12 (Meltrin $\alpha$ ) wurde ursprünglich, auf Grund seiner Expression in Myoblasten, zusammen mit ADAM 19 (Meltrin $\beta$ ) und ADAM 9 (Meltrin $\gamma$ ), eine Rolle in der Myoblastenfusion im Rahmen der Muskelentwicklung zugeschrieben (Yagami-Hiromasa et al., 1995). Jedoch zeigen $A D A M-12^{-/-}$-Mäuse keine Defekte in der Muskelentwicklung. Interessanterweise konnte die Überexpression von $A D A M 12$ die Muskeldystrophie von $m d x$ Mäusen abmildern, jedoch nur kurzfristig. Mit zunehmendem Alter der Tiere verliert sich dieser Effekt wieder (Moghadaszadeh et al., 2003; Jorgensen et al., 2007). Somit bleibt die Rolle von $A D A M 12$ in der Muskelentwicklung weiter unklar. Weiterhin zeigten $A D A M-12^{-/}$-Mäuse geringe Defekte in der Bildung des braunen Fettgewebes (Kurisaki et al., 2003) und Tiere mit transgener Überexpression vermehrt Adipositas (Kawaguchi et al.,2002). Somit könnte $A D A M 12$ eine Rolle in der Proliferation und Differenzierung von Fettgewebszellen haben.

Mäuse, in denen $A D A M 15$ ausgeschaltet wurde, zeigen ebenfalls keinen deutlichen Phänotyp. Lediglich ältere Tiere neigen zur Entwicklung von Osteoarthritis, was assoziiert sein könnte mit der Fähigkeit von $A D A M$ 15, die Kollagene Typ II und VI und Chondrozyten zu verbinden (Bohm et al., 2005). Auch wurde eine verminderte Neovaskularisation von Tumoren und vermindertes Tumorwachstum beschrieben (Horiuchi et al., 2003). 


\section{Diskussion}

$A D A M 17$ ist die Sheddase für $T N F \alpha$ und wird benötigt für den $E G F$-Rezeptorsignalweg (Peschon et al., 1998). ADAM-17/--Mäuse sterben kurz vor der Geburt (ca. Tag 17,5 p.c.) mit offenen Augenlidern, Haut- und Haarfehlbildungen und Reifungsstörungen multipler Organe. Diese Defekte zeigen sich analog in Mäusen, in denen der $E G F$-Rezeptor oder einer der Liganden (HB-EGF, Amphiregulin, TGF $\alpha$ ) ausgeschaltet wurde (Blobel, 2005; Horiuchi et al., 2005). $A D A M-22^{-/}$-Mäuse sterben kurz vor der Entwöhnung. Dies wird assoziiert mit einer Hypomyelinisation peripherer Nerven und Ataxie (Sagane et al., 2005). Es wurde gezeigt, daß $A D A M 22$ der Rezeptor für das sezernierte neuronale Protein LGI 1 ist. Eine Mutation im LG1Gen führt zu einer hereditären Form der Epilepsie, die autosomal dominante, laterotemporale Epilepsie (Fukata et al., 2006). LGI 1 wird vom präsynaptischen Neuron exprimiert und bindet an ADAM 22 am postsynaptischen Neuron. Im Modelversuch konnte gezeigt werden, daß die Zytoplasmadomäe von $A D A M 22$ mit dem Protein PSD-95 interagiert, welches wiederum mit dem $A M P A$-Rezeptor, verantwortlich für den glutaminergen Signalweg, interagiert (Snyder, 2006). Eine Störung in diesem Signalweg könnte für die Entstehung der Epilepsie verantwortlich sein. In Patienten mit diesem Epilepsietyp konnte jedoch keine Mutation im ADAM-22-Gen gefunden werden (Chabrol et al. 2007), sodaß die Funktion von ADAM 22 weiterer Forschung bedarf.

\subsection{ADAM 27}

Das $A D A M-27-G e n$ hat eine Größe von $72,5 \mathrm{~kb}$ und liegt auf dem kurzen Arm des Mauschromosoms 8 A2. Mit 20 Exons zeigt es den typischen genomischen Aufbau anderer ADAM-Gene (Bolcun-Filas, 2003). Das Transkript hat eine Größe von ca. 2,37 kb (Zhu et al., 1999) und wird in ein ca. 98 kDa großes Protein translatiert (Kim T et al., 2006). Dieses Protein wird im Verlauf der Spermienreifung innerhalb des Nebenhodens zu einer Größe von ca. 42 kDa prozessiert (Bolcun-Filas, 2003; Kim T et al., 2006). Exprimiert wird es ausschließlich im Hoden (Zhu et al., 1999) und dort spezifisch in Keimzellen (Bolcun-Filas, 2003). Im Verlauf der postnatalen Hodenentwicklung ist $A D A M 27$ erstmalig am Tag 15 post natum nachweisbar, wobei hier sowohl das Transskript wie auch das Protein nachweisbar sind (Bolcun-Filas, 2003). Dies entspricht dem frühen Pachytänstadium der Spermatogenese. Mittels Western Blot konnte 


\section{Diskussion}

gezeigt werden, daß $A D A M 27$ während der gesamten Spermatogenese bis zum reifen Spermium nachweisbar ist (Bolcun-Filas, 2003; Kim T et al., 2006).

Das $A D A M-27-P r o t e i n ~ z e i g t$ den typischen Domänenaufbau der $A D A M$-Proteine und gehört zu der $A D A M$-Gruppe ohne Proteinaseaktivität, da ihm dafür das notwendige Zinkbindungsmotiv fehlt (Zhu et al., 1999). Somit ist für ADAM 27 nur die Funktion als Adhäsionspartner anzunehmen.

Es handelt sich bei $A D A M 27$ um ein Transmembranprotein, dessen subzelluläre Lokalisation während der Spermatogenese dem sich bildenden Golgi-Apparat entspricht (Bolcun-Filas, 2003), wobei sich $A D A M 27$ in der weiteren Spermiogenese auch in der akrosomalen Kappe nachweisen läßt. Die weitere subzelluläre Lokalisation an reifen Spermien ist bislang noch nicht bekannt, Versuche mittels Immunhistochemie konnten $A D A M 27$ nicht in reifen Spermien darstellen. Diese Situation fand sich sowohl an Spermien von Mäusen als auch an menschlichen (Frayne et al., 2002; Bolcun-Filas, 2003; Kim T et al., 2006). Experimente zeigten jedoch, daß es sich bei $A D A M 27$ nicht um ein Oberflächenprotein des Spermiums handelt (Kim $\mathrm{T}$ et al., 2006). Knockout-Mäuse für $A D A M 2$ oder 3 zeigten keine verminderte Konzentration von $A D A M 27$, weder in Spermatiden noch in reifen Spermien (Kim T et al., 2006).

\subsubsection{ADAM-27-Knockout}

Untersuchungen zur Fertilität von $A D 27^{-/}$- und $E W 50^{-/-}$-Mäusen ergaben erniedrigte Nachkommenzahlen für beide Knockout-Modelle (siehe Abb. 3.4, 3.5 und 3.18). Während die mittlere Nachkommenzahl bei $E W 50^{-/-}$-Tieren mit dem Eintritt ins geschlechtsreife Alter (ab ca. 3 Monate) hochgradig reduziert ist und bis ins Alter der Tiere stabil bei ca. 2 Jungtieren pro Wurf bleibt, zeigt sich bei $A D 27^{-/}$-Mäusen eine mit dem Alter zunehmende Reduktion der mittleren Nachkommenzahl. Diese liegt bei 3 Monate alten Tieren mit ca. 4 Jungtieren pro Wurf auf dem Niveau der Heterozygotenverpaarung von AD27- und EW50-Tieren. Mit zunehmenden Alter reduziert sich die durchschnittliche Nachkommenzahl auf ebenfalls ca. 2 Nachkommen pro Wurf und liegt somit in etwa auf dem Niveau von $E W 50^{-/}$-Tieren. Eine Funktion für $A D A M 27 \mathrm{im}$ Rahmen der Reproduktion, wie schon durch das Expressionsmuster vermutet, ist somit anzunehmen. 


\section{Diskussion}

Die Befruchtung der Oozyten erfolgt bei der Maus, wie auch bei den meisten Säugetieren, innerhalb des Ovidukts (Wassarman et al., 2001). Die Migration der Spermien in die Ampulle ist ein Zusammenspiel aus aktiven und passiven Transportvorgängen. Hier findet eine erste Selektion von Spermien statt, da nur intakte Spermien bis in den Ovidukt gelangen (Suarez und Pacey, 2006). Die Befruchtung einer Eizelle ist ein auf molekularer Ebene sehr komplexes Geschehen. Spermien treten in Interaktion mit Oozyten auf 3 verschiedenen Ebenen: 1. mit der die Oozyte umgebenden Cumuluszellschicht, 2. mit der Zona Pellucida und 3. mit der Oozytenmembran (Evans, 2002). Der eigentliche Vorgang der Befruchtung beginnt mit der Bindung des Spermiums an die Zona pellucida und endet mit der Verschmelzung von Ei- und Samenzelle. Dieser Vorgang kann in 5 Phasen eingeteilt werden: Spermien mit intaktem Akrosom binden in einer Spezies-spezifischen Art an die Zona Pellucida (1). Dies induziert die zelluläre Exozytose, die Akrosomenreaktion der Spermien (2), ohne die eine Penetration der Zona Pellucida nicht möglich ist (3). Des Weiteren bindet nun das Spermium an das Oolemm (4) und verschmilzt schließlich mit diesem (5). Die Fusion von Ei und Spermium verhindert ein weiteres Verschmelzen mit anderen Spermien, die die Zona Pellucida bereits durchdrungen haben. Kein weiteres frei schwimmendes Spermium kann mehr an die Zona binden. An diesem Punkt ist die Oozyte befruchtet und wird zur Zygote (Wassarman et al., 2001). Eine Störung auf jeder dieser Ebenen und Vorgänge kann zu einer reduzierten Fruchtbarkeit führen.

Auf Grund dieses komplexen Geschehens ist verständlich, daß nur morphologisch intakte Spermien in der Lage sind, eine Eizelle zu befruchten. Die morphologische Beurteilung der Spermien von $A D 27^{-/-}$- und $E W 50^{-/-}$-Männchen zeigte eine sehr große Zahl fehlgebildeter Spermien. Nahezu 70\% der Spermien von $E W 50^{-/-}$-Männchen waren fehlgebildet. Auch die Spermien von $A D 27^{-/}$-Tieren zeigten Deformitäten, jedoch konnte hier, analog zur Reduktion der Nachkommenzahl, ein altersabhängiger Effekt beobachtet werden. Mit zunehmendem Alter erhöhte sich der Anteil deformierter Spermien von 40\% (mit Eintritt ins geschlechtsreife Alter), auf bis zu 83\% (im Alter von 12 Monaten). Der Anteil fehlgebildeter Spermien blieb bei der Wildtypkontrolle konstant. Die morphologischen Veränderungen betreffen überwiegend den Spermienkopf, welcher in unterschiedlichstem Maße fehlgebildet war. Insbesondere bei $A D 27^{-{ }^{-}}$Spermien fiel eine ausgeprägte Vakuolisierung des Spermienkopfes auf (Abb. 3.10b). Der Anteil der Spermien mit Vakuolen machte bei jungen $A D 27^{-/}$-Tieren über $50 \%$ der veränderten Spermien aus, während dieser Anteil bei älteren Tieren interessanterweise wieder abfiel. Bei EW50-/-Tieren machten Spermien mit Vakuolen nur 12\% der Veränderungen aus. Ein sehr 


\section{Diskussion}

geringer Prozentsatz von Wildtypspermien (1,5\%) zeigte ebenfalls solche Vakuolisierungen. Diese Ergebnisse stimmen überein mit der gesehenen Sub-/Infertilität, welche bei $E W 50^{-/}$Männchen direkt auftritt, während diese bei $A D 27^{--}$-Männchen progredient ist. Offensichtlich scheint es bei den Spermien zu einer schweren Störung im Bereich des Zellzytoskelettes zu kommen, welche mit den gesehenen Veränderungen einhergeht. Eine Funktion innerhalb des Zellzytoskelettes wurde im Vorfeld für ein anderes Mitglied der ADAM-Familie noch nicht beschrieben und würde eine neue mögliche Funktion der $A D A M$-Gene darstellen.

Histologische Schnitte von $E W 50^{--}$-Hoden zeigten eine gestörte Interaktion von Keim- und Sertolizelle, was sich in einer vorzeitigen Ablösung der elongierten Spermatiden in den Tubuli seminiferi ausdrückt. Die Spermatogenese läuft zwar in der Regel bis zum Spermium ab, jedoch mit geringerer Effizienz (vorzeitige Ablösung der elongierten Spermatiden). Die Spermatiden weisen zum Teil auffällige Kernkondensationsstörungen auf, wobei sich gerade diese Spermatiden vorzeitig ablösen. Die Verbindung/Interaktion zwischen Keim- und Sertolizelle scheint hier somit gestört.

Auch die Spermatogenese stellt ein auf molekularer Ebene sehr komplexes Geschehen dar und ist unter anderem direkt von der Interaktion zwischen Keim- und Sertolizelle abhängig. Störungen der Verbindung zwischen Keim- und Sertolizelle können zu Störungen der Spermatogenese führen (Griswold, 1998).

Wie bereits erwähnt, scheint es während der Spermatogenese der Knockout-Mäuse zu einer massiven Störung im Bereich des Zellzytoskelettes zu kommen. Dies könnte direkt durch das Ausschalten von $A D A M 27$ hervorgerufen sein oder indirekt, als Folge z.B. einer gestörten Interaktion innerhalb des Keimepithels oder beides. Die Verbindung zwischen Keim- und Sertolizelle ist sehr komplex und wird über eine Vielzahl an Zellverbindungselementen hergestellt. Auf Grund der subzellulären Lokalisation ist die Funktion in der direkten Interaktion zwischen diesen beiden Zelltypen für $A D A M 27$ eher unwahrscheinlich, da es sich nicht um ein Oberflächenprotein handelt.

Ein Beispiel für eine Störung im Bereich des Zellzytoskelettes mit nachfolgend gestörter Interaktion innerhalb des Keimepithels ist für die Knockout-Mäuse für Hrb bekannt. Die Verbindungsplatte zwischen Akrosom und Zellkern, das sogenannte Akroplexom, ist ein wichtiges Stabilisierungselement, welches das Akrosom im Rahmen der Spermiogenese an seinem Platz fixiert und mechanischen Zug, ausgeübt von der Sertolizelle über die sog. ektoplasmatischen Spezialisierungen, auf den Zellkern während der Elongation überträgt 


\section{Diskussion}

(Kierszenbaum und Tres, 2004). Knockout-Mäuse für Hrb, einem Protein, welches sich an der zytosolwärts gerichteten Seite von Proakrosom-Vesikeln befindet und für die Verschmelzung dieser Vesikel zum Akrosom verantwortlich ist, waren infertil auf Grund reduzierter Spermienmotilität, Unfähigkeit der Spermien an Oozyten zu binden und auf Grund strukturell fehlgebildeter Spermien (Kang-Decker et al., 2001). Spermien dieser Tiere waren alle ohne Akrosom und die Spermienköpfe waren alle nicht elongiert. Als Ursache wird hierfür das Nichtverschmelzen der Proakrosom-Vesikel zum Akrosom und das Nichtausbilden des Akroplexoms diskutiert, in dessen Folge die mechanische Elongation des Spermienkopfes nicht stattfinden kann (Kang-Decker et al., 2001, Kierszenbaum und Tres, 2004). Ähnliches könnte man für $A D A M 27$ diskutieren. Hierbei ist jedoch zu berücksichtigen, daß für keines der bislang erforschten $A D A M$-Gene die Funktion bei der Membranfusion nachgewiesen ist (Edwards et al., 2008). Eine direkte Funktion bei der Verschmelzung der Proakrosomvesikel ist also eher unwahrscheinlich, vielmehr könnte es durch Störung im Bereich des Akrosom-AkroplexomKomplexes und eine sich daraus ergebende Destabilisierung zu den gesehenen Fehlbildungen im Bereich des Spermienkopfes kommen. Bemerkenswert ist, daß nicht alle Spermien morphologische Veränderungen aufwiesen, ca. 30\% der Spermien von $E W 50^{-/}$-Männchen waren normal geformt. Spermien von Hrb-Knockout-Mäusen zeigten jedoch zu 100\% morphologische Veränderungen. Vielleicht könnte dies dadurch erklärt werden, daß $A D A M$ 27, wie bereits erwähnt, keine direkte Rolle in diesen Vorgängen aufweist, sondern eher im Komplex mit anderen Proteinen vorliegt und eher stabilisierende Funktion hat. Ein Ausschalten des Gens bewirkt somit keinen kompletten Funktionsverlust, sondern führt zu einem Komplex mit geringerer Effizienz. Daß das Ausschalten eines Teils eine Proteinkomplexes nicht automatisch zu einem Funktionsverlust führen muß, zeigt die Knockout-Maus für $A D A M 1 b$, welches als Fertilin-Komplex mit $A D A M 2$ vorliegt. Diese Maus zeigt keine Einschränkungen der Fertilität (Kim E et al., 2006).

Als Beispiele für eine direkte Störung der Interaktion innerhalb des Keimepithels mit nachfolgenden Störungen bei der Spermienmorphologie und Fertilität seien hier die KnockoutMäuse für Nectin 2 und 3 genannt. Diese Gene kodieren für Calcium unabhängige, immunoglobulinähnliche Zelladhäsionsmoleküle und sind im Rahmen der Interzellularverbindung assoziiert mit F-Actinflamenten. Diese Gene werden in einer Vielzahl von Zellen exprimiert, unter anderem im Hoden, wobei Nectin 2 in den Sertolizellen (Bouchard et al., 2000; Mueller et al., 2003) und Nectin 3 in den Keimzellen gebildet wird (Inagaki et al., 
2006). Diese beiden Proteine bilden im Rahmen der Sertoli-Keimzellverbindung, als Teil der ektoplasmatischen Spezialisierung, ein hetero-trans-Dimer und sind direkter Bestandteil dieser Verbindung. Knockout-Mäuse für Nectin 2 oder 3 gleichen sich in ihrem Phänotyp, was die direkte Verbindung dieser beiden Proteine widerspiegelt. Nectin-2 ${ }^{-/}$-Männchen sind auf Grund morphologisch fehlgeformter Spermien unfruchtbar. Interessanterweise zeigen die Spermien dieser Tiere einen Phänotyp, welcher dem der Spermien von ADAM-27-Knockout-Mäusen sehr ähnelt (Abb. 4.2). Die morphologischen Veränderungen betreffen den Spermienkopf und die Flagelle, wobei sich kein vorherrschender Phänotyp im Kopfbereich herauskristallisiert, sondern vielmehr ein breites Muster an morphologischen Veränderungen vorliegt (Mueller et al., 2003). Die Nuklei zeigen sich alle fehlgeformt, ebenso die Akrosomen, wobei es im Spermienkopfbereich auch zum Auftreten von Vakuolen kommt. Im Bereich der Spermienmittelstücke zeigen sich die Mitochondrien desorganisiert, die normalerweise dicht gepackte mitochondriale Scheide fehlt.
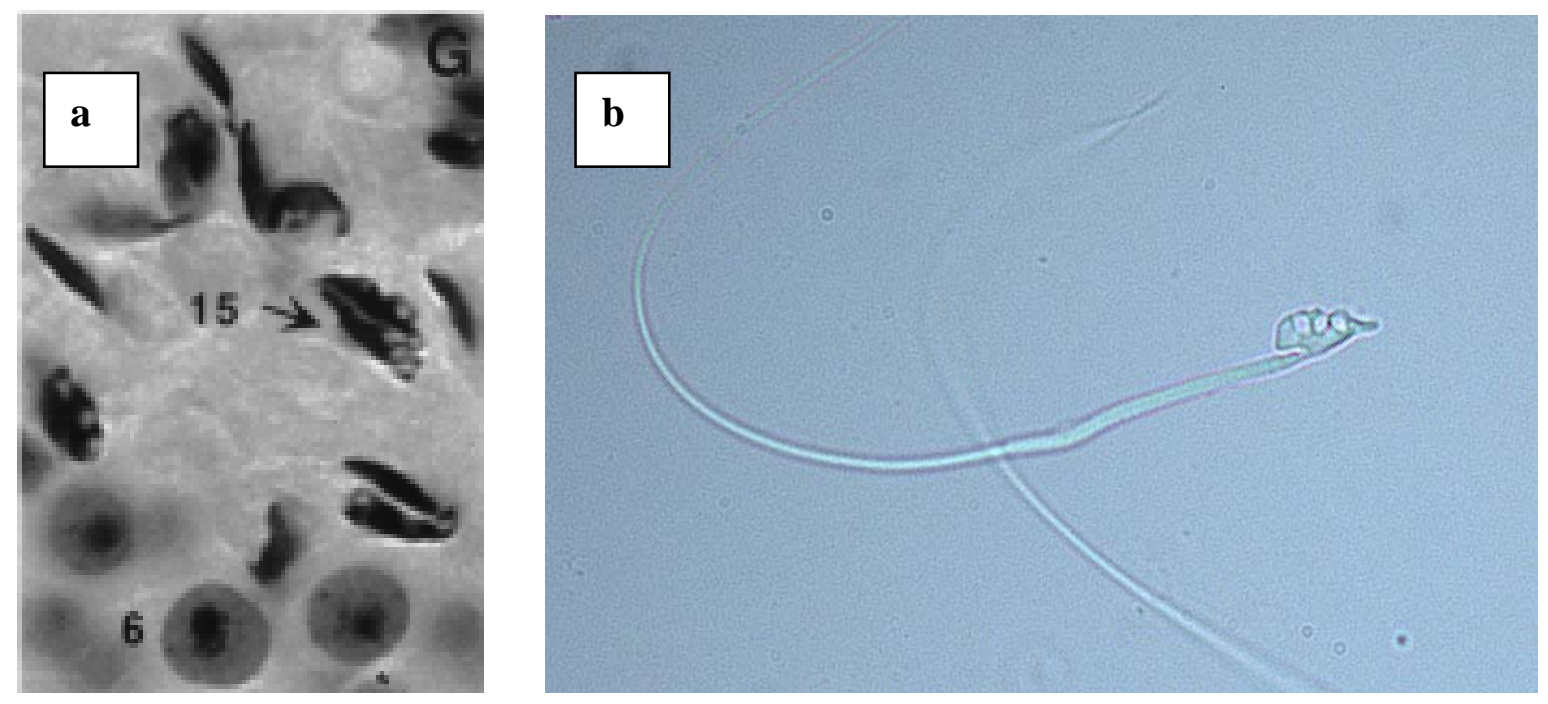

Abb. 4.2: a) Eine histologischer Testisschnitt von Nectin-2 ${ }^{-/}$-Mäusen aus Bouchard et al., 2000, S. 2868. Gut zu sehen hier die Vakuolisierung im Bereich der Spermienköpfe. b) Zum Vergleich ein Spermium von EW50 ${ }^{-/}$. Erkennbare Ähnlichkeit des Phänotyps der Spermien beider Linien.

Diese Veränderungen wirkten sich weder auf die Zahl von Spermien im Nebenhodenschwanz noch auf die Spermienmotilität aus. Im Weiteren bestanden keine Fehlbildungen in Bezug auf Testisgröße, ein Arrest im Keimepithel wurde nicht beschrieben, auch nicht, ob es zu einer vorzeitigen Ablösung der elongierten Spermatiden kommt. Das es nach Ausschalten von Nectin 2 oder 3 doch zu einer Störung der Spermium-Sertolizellen-Interaktion kommt, zeigten Versuche, in denen jeweils eines dieser Gene mittels spezifischer Antikörper geblockt wurde. Hierauf kam 


\section{Diskussion}

es $\mathrm{zu}$ einem Verschwinden von Actinfilamenten im Bereich der ektoplasmatischen Spezialisierung zwischen Keim- und Sertolizelle und die Spermatiden zeigten eine Ablösung vom Keimepithel (Toyama et al., 2008).

Ursächlich für die morphologischen Veränderungen könnte hier zum einen die gestörte Verbindung zwischen Spermatide und Sertolizelle sein. In Folge dessen verläuft, analog zu dem vermuteten Mechanismus bei Hrb-Knockout-Mäusen, die Gestaltung des Spermienkopfes fehlerhaft und die Ausbildung des Zellzytoskelettes wird schwer gestört. Von den Nectinen ist bekannt, daß sie, z.B. über Afadin, direkten Einfluß auf das Zellzytoskelett haben (Rikitakea und Takaia, 2008), sodaß man nach Ausschalten von Nectin 3 einen direkten Effekt auf das Zellzytoskelett diskutieren könnte. Hier muß aber berücksichtigt werden, daß der Phänotyp von Nectin-2 $2^{--}$- und $3^{-/-}$-Mäusen identisch ist und das Nectin 2 nur in Sertolizellen gebildet wird (Toyama et al., 2008). Eine indirekte Störung des Zellzytoskeletts, bedingt durch die gestörte Interzellularverbindung, scheint somit eher wahrscheinlich.

Auf Grund der verblüffenden Ähnlichkeit der Spermienmorphologie von z.B. Nectin-2/- und $A D A M-27^{-/}$- Mäusen kann eine Interaktion dieser beiden Proteine vermutet werden. Die Proteine der Nectin-Familie interagieren mit einer Vielzahl weiterer Proteine, welche u.a. direkten Einfluß auf das Zellzytoskelett haben (Rikitakea und Takaia, 2008). Zu denken wäre hier, daß es durch das Ausschalten von $A D A M 27 \mathrm{zu}$ einer Störung im Bereich des Zellzytoskelettes kommt, was indirekt zu einer Beeinflussung der Nectin-2/3-Verbindung führt und damit zu einer Störung der Keimzell-Sertolizellinteraktion.

Im Unterschied zu Tieren der Linie EW50 ist der Phänotyp bei AD27-Tieren mit fortschreitendem Alter progredient. Während junge $A D 27^{-/}$-Mäuse $40 \%$ veränderte Spermien aufweisen, liegt dieser Wert bei älteren Tieren bei über $80 \%$. Im Weiteren gleichen sich die Phänotypen beider Knockout-Modelle, sodaß ein Ausschalten der Transmembrandomäne einem Funktionsverlust gleichkommt. Beim Ausschalten der Transmembrandomäne eines Transmembranproteins wie $A D A M$ 27, sollte es theoretisch zu einer Umverteilung des Proteins kommen, mit z.B. einer stattfindenden Exozytose und Akkumulation des Proteins im umgebenden Gewebe oder z.B. mit Akkumulation im Zytosol, mit dann zunehmenden störenden Effekten auf z. B. die Spermatogenese. Die Ausschaltung der Transmembrandomäne nimmt dem $A D A M$-27-Protein nicht komplett seine hydrophoben Eigenschaften und ist mittels Western Blot weiterhin in der Membranfraktion von isolierten Proteinen aus $A D 27^{-/}$-Maustestis nachweisbar (Bolcun-Filas, 


\section{Diskussion}

2003). Immunhistochemisch gelang leider kein sicherer Nachweis des veränderten $A D A M 27$ bei $A D 27^{-/}$-Tieren (Abb. 3.15a). Eine Akkumulation von $A D A M 27$ innerhalb des Spermiums führt

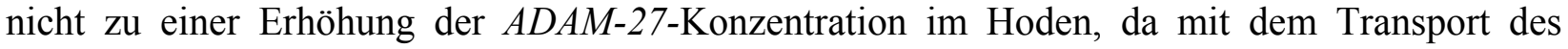
Spermiums aus dem Hoden auch ADAM 27 wegtransportiert wird und so die Gesamtkonzentration von $A D A M 27$ im Hoden unverändert bleibt. Eine Akkumulation im Hoden, verursacht z.B. durch Exozytose, würde zumindest zu einer Konzentrationserhöhung von $A D A M$ 27 innerhalb des Hodens führen. Diese würde mit zunehmenden Alter des Tieres weiter steigen und würde zumindest dynamisch mit der altersprogredienten Infertilität übereinstimmen. Jedoch muß hierbei berücksichtigt werden, das eine Überexpression von $A D A M 27$ keinen Einfluß auf die Fertilität ausübt, so gesehen bei PAD (Abb. 3.30).

Eine abschließende Erklärung zum altersabhängigen Phänotyp kann zur Zeit nicht gegeben werden, die Durchführung weiterer Untersuchungen ist zur Klärung erforderlich.

Die Überprüfung der Fähigkeit von $E W 50^{-/}$-Spermien zur Akrosomenreaktion zeigte im Vergleich zur Wildtypkontrolle keine Einschränkung in dieser Hinsicht (Abb.3.21). Hier muß jedoch berücksichtigt werden, daß die Anfärbung des Akrosoms erst nach Inkubation mit Ionophor und damit nach vermeintlicher Akrosomenreaktion stattfindet. Eine Unterscheidung zwischen bereits reagiertem bzw. auf Grund der Malformation nicht angefärbtem Akrosom ist so nicht möglich. Somit ist eine exakte Angabe über die Funktionalität des Akrosoms dieser Spermien nicht möglich.

Die weitere funktionelle Analyse für $E W 50^{-/-}$-Spermien ergab unter anderem eine verminderte Schwellung der Spermien nach dem Einbringen in ein hypoosmotisches Medium. Dieser klassische hypoosmotische Schwelltest nach Jeyendran et al. (1984) ist ein sehr sensitiver Test zur Überprüfung der Fertilität und wird in der humanen andrologischen Praxis angewendet. Überprüft wird hierbei die funktionelle Integrität der Spermienmembran, wobei zugrunde gelegt wird, daß nur Zellen mit intakter und biochemisch aktiver Membran die Fähigkeit besitzen, in hypotoner Lösung anzuschwellen (Curry und Watson, 1994). Somit läst sich vom Anschwellen eines Spermiums in hypoosmotischer Lösung auf die Funktionstüchtigkeit und chemische Aktivität schließen, wobei sich die Antwort membranintakter Spermien dabei in morphologischen Veränderungen des Spermienschwanzes und -hauptstückes ausdrückt. Diese 
Veränderungen können mehrgestaltig sein, ein Überblick über mögliche Schwellphänomene gibt Abb. 3.22b.

Spermien von $E W 50^{-/-}$- und $A D 27^{-/-}$-Tieren zeigten eine verminderte Tendenz zu solchen Schwellungsphänomenen. Störungen der Zellmembranintegrität dieser Spermien könnten somit vorliegen. Somit sind die Spermien in ihrer Befruchtungsfähigkeit eingeschränkt.

Inwieweit diese Störung der Membranintegrität direkt von $A D A M 27$ abhängt oder als eher sekundärer Effekt im Rahmen der gestörten Spermatogenese zu sehen ist, bedarf weiterer Klärung, nichtsdestotrotz ist eine Störung der Membranintegrität im Rahmen der vermuteten Funktion von $A D A M$ 27, nämlich im Bereich des Zellzytoskelettes, sehr wahrscheinlich.

Auch die weiteren Störungen, wie verminderte Zahl von Spermien im Uterus/Ovidukt bei $A D 27^{-/-}$ -Mäusen oder verminderte Zahl an an Oozyten gebundenen Spermien im Rahmen des Binding Assays, sind als Folge der gestörten Spermatogenese zu werten. Ähnliches wurde z.B. bei Nectin$2^{-/-}$-Mäusen beschrieben (Mueller et al., 2003). Spermien dieser Tiere wurden ebenfalls in geringerer Zahl durch Uterus und Ovidukt transportiert und zeigten Fehlbildungen im Binding Assay. Dies steht im Einklang mit der bereits von Griswold (1998) beschriebenen Theorie, daß Störungen im Rahmen der Interaktion innerhalb des Keimepithels eine gestörte Fertilität bedingen. Es kann abgeleitet werden, daß ADAM 27 in Interaktion mit dem Nectin-Komplex und mit dem Zellzytoskelett steht.

\subsubsection{Transgene $P A D$-Mäuse und Rescueexperiment}

Transgene Mäuse für $A D A M 27$ wurden unter der Annahme etabliert, daß $A D A M 27$ als mögliches Oberflächenprotein in die Interaktion zwischen Spermium und Oozyte involviert ist. Eine Überexpression des Gens würde so zu einer gestörten Spermienoberflächenstruktur führen und somit die Interaktion zwischen Spermium und Oozyte stören. Da es sich bei $A D A M$ 27, wie nach Studienbeginn von Kim T et al. (2006) gezeigt, nicht um ein Oberflächenprotein handelt, scheint die direkte Störung der Spermienoberfläche durch Überexpression unwahrscheinlich. Nichtsdestotrotz ist Infertilität bei transgenen Mäusen beschrieben, wie zum Beispiel bei Tieren, welche das RPGR-Gen überexprimieren (Brunner et al., 2008). RPGR, für retinitis pigmentosa GTPase regulator gen, ist bei $20 \%$ aller Patienten mit Retinitis pigmentosa mutiert und ist 


\section{Diskussion}

assoziiert mit Transportvorgängen entlang primärer Zilien (Khanna et al., 2005). Mäuse, die dieses Gen überexprimieren, sind infertil auf Grund verschiedener struktureller Störungen der Spermienmorphologie, welche mit der Kopienzahl des überexprimierten Gens korrelieren. Bei Männchen mit gering erhöhter Kopienzahl kam es zum Beispiel zu strukturellen Störungen im Mittelstück. Spermien von Männchen mit stark erhöhter Kopienzahl hingegen zeigten einen kompletten Verlust des Spermienschwanzes.

Vor diesem Hintergrund wurde die Fertilität von transgenen $A D A M-27-M a ̈ u s e n ~ u n t e r s u c h t$. Nach Etablierung einer homozygoten transgenen Mauslinie $P A D$, zeigte sich, das die Fertilität dieser Tiere nicht eingeschränkt war. Die durchschnittliche Wurfgröße von $P A D$-Tieren lag auf dem Niveau der Wildtypkontrolle (siehe Abb. 3.30). Eine Überexpression von ADAM 27 scheint sich somit nicht auf die Spermatogenese bzw. auf Zellzytoskelett und Spermien-Sertolizell-Interaktion auszuwirken, auf eine weitere Analyse dieser Tiere wurde in diesem Rahmen verzichtet.

Im Weiteren wurden Tiere der Linien $E W 50$ und $P A D$ verpaart, um zu überprüfen inwieweit sich der Phänotyp von $E W 50^{-/}$-Tieren normalisieren lässt. Somit kann weiterhin differenziert werden, inwieweit der Phänotyp direkt von dem ausgeschalteten Gen abhängt oder ob zum Beispiel durch das Ausschalten des Gens weitere Gene beeinflusst werden.

Knockout-Mäuse für Ppplcc, einer von 4 hochkonservierten Typ-1-Serin/ThreoninProteinphosphatasen, sind unfruchtbar auf Grund induzierter Apoptose in Spermatiden und dysfunktionaler Spermiogenese (Varmuza et al., 1999) Dieses Gen wird in 2 Isoformen exprimiert (PPP1CC1 und 2), wobei sich diese beiden Isoformen im C-terminalen Ende in einer einzigartigen 21-Aminosäure-carboxy-terminalen Verlängerung bei PPP1CC2, unterscheiden (Solerac et al., 2009). Weiterhin wird PPP1CC1 nahezu ubiquitär exprimiert, während PPP1CC2 hodenspezifisch ist. Mäuse, bei denen PPP1CC2 durch PPP1C-Hemmer geblockt wurde, zeigten eine Aktivierung und Stimulation der Spermienmotilität (Smith et al., 1996). Dementsprechend wurde dieser Isoform eine wichtige Rolle in der Steuerung der Spermienmotilität zugeschrieben. Wie erwähnt sind Knockout-Mäuse für Ppplcc unfruchtbar. Es erfolgte ein Rescueexperiment dieser Mäuse mit PPP1CC2. Rescuemäuse mit einer Überexpression von PPP1CC2 sind jedoch weiterhin infertil, eine komplette Normalisierung des Phänotyps fand nicht statt. Obwohl die Ursache hierfür letztlich noch nicht geklärt ist, wurden mehrere Theorien hier diskutiert. Zum einen, da nur eine Isoform überexprimiert wird, könnte das alleinige Fehlen der anderen Isoform für den inkompletten Rescue verantwortlich sein. Auf Grund einer strukturellen Ähnlichkeit dieser Spermien mit Knockout-Mäusen für das Serum-Selenoprotein Pl wurde weiterhin eine 


\section{Diskussion}

Störung im Seleniumtransport der Rescuemäuse diskutiert. Zumindest ließ sich der Phänotyp hier nicht normalisieren, sodass das Ausschalten von PPPIC weitergehende, komplexere Störungen nach sich zieht, die alleine durch die Überexpression einer Isoform von PPPICC nicht zu kompensieren sind (Solerac et al., 2009).

In dieser Studie wurden $P A D-\mathrm{T} / \mathrm{T}-$ Männchen mit $E W 50^{-/-}-$Weibchen verpaart und eine Inzuchtlinie $E W 50^{-/} ; P A D p o s$ etabliert. Diese Tiere wurden hinsichtlich Fertilität und einiger Spermienparameter untersucht. Tiere dieser Linie zeigten eine normale Fertilität mit einer durchschnittlichen Nachkommenzahl entsprechend der Wildtypkontrolle (Abb. 3.32). Auch die überprüften Spermienparameter zeigten keinen Unterschied im Vergleich zur Wildtypkontrolle. Insbesondere der Anteil fehlgeformter Spermien blieb auf dem Niveau der Wildtypkontrolle (Abb. 3.34). Unter Berücksichtigung dieser Ergebnisse scheint es zu einem komplettem Rescue des Phänotyps von $E W 50^{-/-}$-Männchen gekommen zu sein, das transgene $A D A M-27-K o n s t r u k t$ ersetzt komplett die Funktion des nativen $A D A M$ 27. Die Einführung des transgenen Genkonstruktes substituiert nur die direkte Funktion des exprimierten Proteins. Eine regulatorische Funktion auf andere Gene, bedingt durch eine zeitlich festgelegte Expression wird hierdurch nicht beeinflusst, da das Gen unter der transkriptionalen Kontrolle eines anderen Promotors steht und sich damit der originären transkriptionalen Kontrolle entzieht. Im Umkehrschluß bedeutet dies, daß der Phänotyp von $E W 50^{-/-}$-Tieren auf der direkten Funktion von ADAM 27 beruht und nicht das Ergebnis einer komplexen Störung mehrerer Gene ist. ADAM 27 hat somit eine wichtige Funktion in der Spermatogenese inne und stellt mit der möglichen Funktion im Rahmen des Zellzytoskelettes ein weiteres Funktionsspektrum der ADAMGenfamilie dar. 


\section{Ausblick und weiterführende Experimente}

Die Spermatogenese stellt ein sehr komplexes Geschehen dar und ADAM 27 scheint eine wichtige Rolle hierbei zu spielen. Für die weitere Charakterisierung von $A D A M 27$ wäre zunächst die weitere ultrastrukturelle Lokalisation des nativen Proteins mittels z.B. Elektronenmikroskopie interessant. Auf Grund der oben beschriebenen Ähnlichkeit von Spermien von Nectin-2-- - und $E W 50^{-/-}$-Mäusen und die mögliche Interaktion mit den Nectinen, sollte eine Expressionsbestimmung von Nectin 2 und 3 bei ADAM-27-Knockout-Mäusen durchgeführt werden. Wie bereits beschrieben, ist bei Fertilin- $\alpha$-Knockout-Mäusen Fertilin $\beta$ ebenfalls nicht mehr nachweisbar. Dies ist Ausdruck der funktionellen Interaktion der beiden FertilinUntereinheiten. Ähnliches wurde für Nectin 2 und 3 beschrieben. Somit könnte bei einer Interaktion von $A D A M 27$ mit Nectin 3 dieses bei $E W 50^{-/-}$-Mäusen ebenfalls nicht mehr nachweisbar sein. Der Nachweis einer Interaktion zwischen diesen Genen würde weitere wichtige Anhaltspunkte geben über die Funktion von $A D A M 27$.

Diese Untersuchungen sind weitere wichtige Schritte auf dem Weg, die Vorgänge der Spermatogenese $\mathrm{zu}$ beleuchten und $\mathrm{zu}$ verstehen und so letztlich neue Wege in der Therapie der männlichen Sterilität zu finden. $A D A M 27$ könnte auf diesem Weg ein wichtiger Baustein sein. 


\section{Zusammenfassung}

Das in dieser Studie auf seine Funktion hin untersuchte $A D A M-27-G e n$, angehörend der Gruppe der $A D A M$-Gene ohne Proteasefunktion, wird ausschließlich im Hoden exprimiert und ist dort mutmaßlich in die Vorgänge der Spermatogenese involviert.

Die funktionelle Analyse dieses Genes erfolgte an 2 Knockout-Mausmodellen, wobei bei ersterem die Transmembrandomäne und bei dem zweiten Modell das komplette Gen ausgeschaltet wurde. Weiterhin erfolgte die funktionelle Analyse an einem transgenen Mausmodell und einem Rescueexperiment.

Das $A D A M-27-G e n$ liegt auf dem kurzen Arm des Mauschromosoms 8 A2 und hat eine Größe von 72,5 kb. Das Transkript hat eine Größe von ca. 2,37 kb (Zhu et al., 1999), welches in ein ca. $98 \mathrm{kDa}$ großes Protein translatiert wird (Kim T et al., 2006). Die Expression ist hoden- und dort keimzellspezifisch (Zhu et al., 1999; Bolcun-Filas, 2003). Bei ADAM 27 handelt es sich um ein Transmembranprotein, welches innerhalb der Spermatogenese in dem sich bildenden GolgiApparat lokalisiert ist (Bolcun-Filas, 2003). Die subzelluläre Lokalisation an reifen Spermien ist bislang noch unbekannt, jedoch erscheint $A D A M 27$ nicht an der Spermienoberfläche (Kim T et al., 2006). Auf Grund des fehlenden, für die Proteasefunktion essentiellen, Zinkbindungsmotivs wird für $A D A M 27$ die Funktion als Adhäsionspartner angenommen.

Nach dem Ausschalten des $A D A M-27-G e n s$ zeigt sich phänoypisch eine hochgradige Subfertilität der männlichen Mäuse, welche bei $A D 27^{-/}$-Tieren ( $A D A M-27-$ Knockout-Modell mit ausgeschalteter Transmembrandomäne) progredient mit dem Alter der Tiere ist, während $E W 50^{-/-}$ -Tiere (ADAM-27-Knockout-Modell mit komplett ausgeschaltetem Gen) bereits kurz nach Eintritt in das geschlechtsreife Alter eine hochgradige Subfertilität aufweisen. Ursache scheint die hochgradige Zahl morphologisch veränderter Spermien zu sein, welche bei beiden Mauslinien auftritt, bei Tieren der Linie AD27 allerdings ebenfalls progredient mit dem Alter ist. Diese Spermien zeigten eine verminderte Bindung an die Zona pellucida und an das Oolemm, ebenfalls scheint die Spermienmembranintegrität, auf Grund verminderter Schwellung der Spermien in einem hypoosmotischen Medium, gestört. Weiterhin bestanden bei diesen Tieren Störungen innerhalb des Keimepithels. In Testisschnitten zeigte sich eine vorzeitige Ablösung von elongierten Spermatiden und Spermien aus dem Gewebeverband. Diese Veränderungen sind bei $A D 27^{-/}$-Männchen progredient und erreichen den Gipfel im Alter, während $E W 50^{-/-}$-Tiere diese 
Veränderungen bereits als Jungtiere aufweisen. Eine abschließende Erklärung für diesen altersprogredienten Phänotyp kann jedoch derzeit nicht gegeben werden. Keinen Einfluß auf die Fertilität hat die Überexpression von $A D A M 27$ (Mauslinie $P A D$ ). Das durchgeführte Rescueexperiment, in dem $E W 50^{-/}$-Weibchen mit transgenen $P A D$-Männchen verpaart wurden, zeigte bei den $E W 50^{-/} ; P A D p o s$-Tieren eine komplette Normalisierung des Phänotyps.

Die Ursache für die Subfertilität scheint die hohe Zahl von morphologisch veränderten Spermien zu sein, was auf einer Störung innerhalb des Zellzytoskelettes der Spermien zu beruhen scheint. Diese könnte entweder direkt durch das Ausschalten von $A D A M 27$ oder indirekt durch das vorzeitige Ablösen der Spermatiden aus dem Gewebeverband, als Ausdruck einer gestörten Spermatozyten-Sertolizellinteraktion, bedingt sein. Eine mögliche Erklärung hierfür könnte die mutmaßliche Interaktion von ADAM 27 mit Nectin 3 sein. Nectin 3 ist ein Spermienprotein und interagiert mit Nectin 2, welches in den Sertolizellen gebildet wird. Hierüber wird die direkte Verbindung wischen Keim- und Sertolizelle gebildet und ein Ausschalten von Nectin 2 oder 3, bewirkt eine Störung dieser Verbindung. Der beobachtete Phänotyp dieser Tiere ähnelt stark

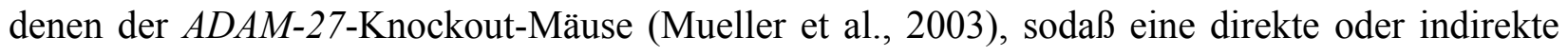
Interaktion von $A D A M 27$ mit Nectin 3 denkbar wäre.

Da Infertilität auch bei transgenen Mäusen beschrieben wurde, wurde die transgene Mauslinie $P A D$ etabliert. Die Überexpression von $A D A M 27$ zeigte hier allerdings keine Störung der Fertilität. Durch die Verpaarung von $E W 50^{-/}$-Weibchen mit transgenen $P A D$-Männchen konnte eine komplette Normalisierung des Phänotyps erreicht werden. Die Spermien dieser Tiere unterschieden sich weder in der durchschnittlichen Wurfgröße noch in der Zahl morphologisch veränderter Spermien von der Wildtypkontrolle. Somit scheint der Phänotyp der ADAM-27Knockout-Mäuse auf der direkten Funktion von ADAM 27 zu beruhen und ist nicht zum Beispiel Folge einer komplexen Störung mehrerer Gene.

Hiermit kann für $A D A M 27$ eine wichtige Funktion in der Spermatogenese angenommen werden und mit der möglichen Funktion im Rahmen des Zellzytoskelettes stellt dies ein weiteres Funktionsspektrum der $A D A M$-Genfamilie dar. 


\section{Literaturverzeichnis}

\section{Literaturverzeichnis}

Al-Fakhri N, Wilhelm J, Hahn M, Heidt M, Hehrlein F W, Endisch A M, Hupp T, Cherian S M, Bobryshev Y V, Lord R S, Katz N (2003): Increased expression of disintegrin-metalloproteinases ADAM-15 and ADAM-9 following upregulation of integrins alpha5beta1 and alphavbeta3 in atherosclerosis. J. Cell Biochem. $\underline{89}$ 808-823.

Birnboim H C (1983): A rapid alkaline extraction method for the isolation of plasmid DNA. Methods Enzymol. 100 243-255.

Birnboim H C and Doly J (1979): A rapid alkaline extraction procedure for screening recombinant plasmid DNA. Nucleic Acids Res. 7 (6) 1513-1523.

Blobel C P (2005): ADAMs: key components in EGFR signalling and development. Nat. Rev. Mol. Cell Biol. $\underline{6(1)}$ 32-43

Boehm D, Herold S, Kuechler A, Liehr T, Laccone F (2004): Rapid Detection of Subtelomeric Deletion/Duplication by Novel Real-Time Quantitative PCR Using SYBR-Green Dye. Hum. Mutat. 23 (4) 368-378

Bohm B B, Aigner T, Gehrsitz A, Blobel C P, Kalden J R, Burkhardt H (1999): Upregulation of MDC15 (metargidin) messenger RNA in human osteoarthritic cartilage. Arthritis Rheum. $\underline{42}$ 1946-1950

Bohm B B, Aigner T, Roy B, Brodie T A, Blobel C P, Burkhardt H (2005): Homeostatic effects of the mmetaloproteinase disintegrin ADAM 15 in degenerative cartilage remodeling. Arthritis Rheum. 52 (4) 1100-1109

Bolcun-Filas E: Expression and functional analysis of the testis expressed genes ADAM 27 and testase 2. Biol. Diss. Göttingen 2003 


\section{Literaturverzeichnis}

Bosse F, Petzold G, Greiner-Petter R, Pippirs U, Gillen C, Muller H W (2000): Cellular localization of the disintegrin CRII-7/rMDC15 mRNA in rat PNS and CNS and regulated expression in postnatal development and after nerve injury. Glia. $\underline{32}$ 313-327.

Bouchard M J, Dong Y, McDermott B M Jr, Lam D H, Brown K R, Shelanski M, Bellve A R, Racaniello V R (2000): Defects in nuclear and cytoskeletal morphology and mitochondrial localization in spermatozoa of mice lacking nectin-2, a component of cell-cell adherens junctions. Mol. Cell Biol. 20 2865-2873

Brunner S, Colman D, Travis A J, Luhmann U F, Shi W, Feil S, Imsand C, Nelson J, Grimm C, Rülicke T, Fundele R, Neidhardt J, Berger W (2008): Overexpression of RPGR leads to male infertility in mice due to defects in flagellar assembly. Biol. Reprod. 79 (4) 608-617

Chabrol E, Gourfinkel-An I, Scheffer I E, Picard F, Couarch P, Berkovic S F, McMahon J M, Baja N, Mota-Vieira L, Mota R, Trouillard O, Depienne C, Baulac M, LeGuern E, Baulac S (2007): Absence of mutations in the LGI1 receptor ADAM 22 gene in autosomal dominant lateral temporal epilepsy. Epilepsy Res. 76 (1) 41-48

Chen C, Huang X, Sheppard D (2006): ADAM 33 is not essential for growth and development and does not modulate allergic asthma in mice. Mol. Cell Biol. 26 (18) 6950-6956

Chien A, Edgar D B, Trela J M (1976): Deoxyribonucleic acid polymerase from the extreme thermophile Thermus aquaticus. J. Bacteriol. 127 (3) 1550-1557.

Cho C, Bunch D O, Faure J E, Goulding E H, Eddy E M, Primakoff P, Myles D G (1998): Fertilization defects in sperm from mice lacking fertilin beta. Science 281 (5384) 1857-1859.

Chomczynski P, Sacchi N (1987): Single-step method of RNA isolation by acid guanidinium thiocyanate-phenol-chloroform extraction. Anal. Biochem. 162 156-159.

Clark J M (1988): Novel non-templated nucleotide addition reactions catalyzed by procaryotic and eucaryotic DNA polymerases. Nucleic Acids Res. 16 9677-9686. 


\section{Literaturverzeichnis}

Curry M R, Watson P F (1994): Osmotic effects on ram and human sperm membranes in relation to thawing injury. Cryobiology $\underline{31} 39-46$

Denhardt DT (1966): A membrane-filter technique for the detection of complementary DNA. Biochem. Biophys. Res. Commun. 23 641-646

Dev A: Expression and functional analysis of murine Brunoll and Brunol4, members of Elav/Bruno family. Biol. Diss. Göttingen 2006

Edwards D R, Hansley M M, Pennington C J (2008): The ADAM Metalloproteinases Mol. Aspects Med. 29 258-289

Evans J P (2002): The molecular basis of sperm-oocyte membrane interactions during mammalian fertilization. Hum. Reprod. Update $\underline{8(4)}$ 297-311

Feinberg A P, Vogelstein B (1989): A technique for radiolabeling DNA restriction endonuclease fragments to high specific activity. Anal. Biochem. 123 6-13

Frayne J, Hurd E A, Hall L (2002): Human tMDC III: a sperm protein with a potential role in oocyte recognition. Mol. Hum. Reprod. $\underline{8(9)}$ 817-822.

Fukata Y, Adesnik H, Iwanaga T, Bredt D S, Nicoll R A, Fukata M (2006): Epilepsy-related ligand/receptor complex LGI1 and ADAM22 regulate synaptic transmission. Science 313 (5794) 1792-1795

Griswold M D (1998): The central role of Sertoli cells in spermatogenesis. Semin. Cell Dev. Biol. $\underline{9} 411-416$

Hanes J, Freudenstein J, Rapp G, Scheit K H (1992): Construction of a plasmid containing the complete coding region of human elongation factor 2. Biol. Chem. Hoppe-Seyler 373 (4) 201204 


\section{Literaturverzeichnis}

Hartmann D, de Strooper B, Serneels L, Craessaerts K, Herreman A, Annaert W, Umans L, Lubke T, Lena Illert A, von Figura K, Saftig K (2002): The disintegrin/metalloprotease ADAM 10 is essential for Notch signalling but not for alpha-secretase activity in fibroblasts. Hum. Mol. Genet. 11 (21) 2615-2624

Hodge R (1994): Preparation of RNA gel blots. Methods Mol. Biol. 28 49-54

Horiuchi K, Weskamp G, Lum L, Hammes H P, Cai H, Brodie T A, Ludwig T, Chiusaroli R, Baron R, Preissner K T, Manova K, Blobel C P (2003): Potential role for ADAM 15 in pathological neovascularization in mice. Mol. Cell Biol. 23 (16) 5614-5624

Horiuchi K, Zhou H M, Kelly K, Manova K, Blobel C P (2005): Evaluation of the contributions of ADAMs 9, 12, 15, 17 and 19 to heart development and ectodomain shedding of neuroregulins beta1 and beta2. Dev. Biol. 283 (2) 459-471

Inagaki M, Irie K, Ishizaki H, Tanaka-Okamoto M, Miyoshi J, Takai Y (2006): Role of cell adhesion molecule nectin-3 in spermatid development. Genes Cells 11 1125-1132

Jackson L F, Qiu T H, Sunnarborg S W, Chang A, Zhang C, Patterson C, Lee D C (2003): Defective valvulogenesis in HB-EGF and TACE-null mice is associated with aberrant BMP signaling. EMBO J. 22 (11) 2704-2716

Jeyendran R S, Van der Ven H H, Perez-Pelaez M, Grabo B G, Zaneveld L J D (1984): Development of an assay to assess the functional integrity of the human sperm membrane and ist relationship to other semen characteristics. J. Reprod. Fertil. 70 219-225.

Jia L G, Shimokawa K, Bjarnason J B, Fox J W (1996): Snake venom metalloproteinases: structure, function and relationship to the ADAMs family of proteins. Toxicon $\underline{34} 1269-1276$.

Jorgensen L H, Jensen C H, Wewer U M, Schroder H D (2007): Transgenic overexpression of ADAM12 suppresses muscle regeneration and aggravates dystrophy in aged mdx mice. Am. J. Pathol. 171 (5) 1599-1607 
Kang-Decker N, Mantchev G T, Juneja S C, McNiven M A, van Deursen J M A (2001): Lack of Acrosome Formation in Hrb-Deficient Mice. Science 294 1531-1533

Kawaguchi N, Xu X, Tajima R, Kronqvist P, Sundberg C, Loechel F, Albrechtsen R, Wewer U M (2002): ADAM 12 protease induces adipogenesis in transgenic mice. Am. J. Pathol. 160 (5) 1895-1903

Kelly K, Hutchinson G, Nebenius-Oosthuizen D, Smith A J, Bartsch J W,Horiuchi K, Rittger A, Manova K, Docherty A J, Blobel C P (2005): Metalloprotease-disintegrin ADAM 8: expression analysis and targeted deletion in mice. Dev. Dyn. 232 (1) 221-231

Khanna H, Hurd T W, Lillo C, Shu X, Parapuram S K, He S, Akimoto M, Wright A F, Margolis B, Williams D S, Swaroop A (2005): RPGR-ORF15, which is isutated in retinitis pigmentosa, associates with SMC1, SMC3, and microtubule transport proteins. J. Biol. Chem. 280 (29) $33580-33587$

Kheradmand F, Werb Z (2002): Shedding light on sheddases: role in growth and development. Bioessays 24 8-12.

Kierszenbaum A L, Tres L L (2004): The acrosome-acroplaxome-manchette complex and the shapig of the spermatid head. Arch. Histol. Cytol. $\underline{67}$ 271-284

Kim E, Nishimura H, Baba T (2003): Differential localization of ADAM1a and ADAM1b in the endoplasmic reticulum of testicular germ cells and on the surface of epididymal sperm. Biochem. Biophys. Res. Commun. 304 (2) 313-319

Kim E, Yamashita M, Naknishi T, Park K-E, Kimura M, Kashiwabara S-i, Baba T (2006): Mouse Sperm lacking ADAM1b/ADAM2 Fertilin can fuse with the egg plasma membrane and effect fertilization. J. Biol. Chem. 281 (9) 5634-5639 


\section{Literaturverzeichnis}

Kim T, Oh J, Woo J-M, Choi E, Im S H, Yoo Y Y J, Kim D H, Nishimura H, Cho C (2006): Expression and relationship of male reproductive Adams in mouse. Biol. Reprod. $\underline{74}$ 744-750

Kurisaki T, Masuda A, Sudo K, Sakagmi J, Higashiyama S, Matsuda Y, Nagabukuro A, Tsuji A, Nabeshima Y, Asano M, Iwakura Y, Sehara- Fujisawa A (2003): Phenotypic analysis of Meltrin alpha (ADAM 12)-deficient mice: involvment of Meltrin alpha in adipogenesis and myogenesis. Mol. Cell Biol. 23 (1) 55-61

Kurohara K, Komatsu K, Kurisaki T, Masuda A, Irie N, Asano M, Sudo K, Nabeshima Y, Iwakura Y, Sehara-Fujisawa A (2004): Essential roles of Meltrin beta (ADAM 19) in heart development. Dev. Biol. 267 (1) 14-28

Laird P W, Zijderveld A,Linders K, Rudnicki M A, Jaenisch R, Berns A (1991): Simplified mammalian DNA isolation procedure. Nucleic Acids Res. 19 (15) 4293.

Masaki M, Kurisaki T, Shirakawa K, Sehara-Fujisawa A (2005): Role of meltrin [alpha] (ADAM 12 ) in obesity induced by high-fat diet. Endocrinology 146 (4) 1752-1763

McCulloch D R, Harvey M, Herington A C (2000): The expression of the ADAMs proteases in prostate cancer cell lines and their regulation by dihydrotestosterone. Mol. Cell. Endocrinol. 167 $11-21$

Moghadaszadeh B, Albrechtsen R Guo L T, Zaik M, Kawaguchi N, Borup R H, Kronqvist P, Schroder H D, Davis K E, Voit T, Nielsen F C, Engvall E, Wewer U M (2003): Compensation for dystrophin-deficiency: ADAM12 overexpression in skeletal muscle results in increased alpha 7 integrin, utrophin and associated glycoproteins. Hum. Mol. Genet. 12 (19) 2467-2479

Moro M A, Hurtado O, Cardenas A, Romera C, Madrigal J L, Fernandez-Tome P, Leza J C, Lorenzo P, Lizasoain I (2003): Expression and function of tumour necrosis factor-alphaconverting enzyme in the central nervous system. Neurosignals 12 (2) 53-58. 


\section{Literaturverzeichnis}

Müller H C: Klinische Relevanz unterschiedlicher Spermatozoenparameter für die Fertilisation in vitro. Med. Diss. Gießen 1998

Mueller S, Rosenquist T A, Takai Y, Bronson RA, Wimmer E (2003): Loss of nectin-2 at Sertolispermatid junctions leads to male infertility and correlates with severe spermatozoan head and midpiece malformation, impaired binding to the zona pellucida and oocyte penetration. Biol. Reprod. 69, 1330-1340.

Murase S, Cho C, White J M, Horwitz A F (2008): ADAM 2 promotes migration of neuroblasts in the rostral migratory stream to the olfactory bulb. Eur. J. Neurosci. 27 (7) 1585-1598

Naus S, Richter M, Wildeboer D, Moss M, Schachner M, Bartsch J W (2004): Ectodomain shedding of the neural recognition molecule CHL1 by the metalloprotease-disintegrin ADAM8 promotes neurite outgrowth and supresses neuronal cell deat. J. Biol. Chem. 279 (16) 1608316090

Nishimura H, Kim E, Fujimori T, Kashiwabara S, Kuroiwa A, Matsuda Y, Baba T (2002): The Adam1a and ADAM1b genes, instead of the ADAM1 (fertilin a) gene, are localized on mouse chomosome 5. Gene $\underline{291(1-2)}$ 67-76

Nishimura H, Kim E, Nakanishi T, Baba T (2004): Possible Function of the ADAM1a/ADAM2 Fertilin Complex in the Appearance of ADAM3 on the Sperm Surface. J. Biol. Chem. 279 (33) 34957-34962

Nishimura H, Myles D G, Primakoff P (2007): Identification of an ADAM2-ADAM3 Complex on the Surface of Mouse Testicular Germ Cells and Cauda Epididymal Sperm. J. Biol. Chem. $282(24)$ 17900-17907 


\section{Literaturverzeichnis}

Peschon J J, Slack J L, Reddy P, Stocking K L, Sunnarborg S W, Lee D C, Russell W E, Castner B J, Johnson R S, Fitzner J N, Boyce R W, Nelson N, Kozlosky C J, Wolfson M F, Rauch C T, Cerretti D P, Paxton R J, March C J, Black R A (1998): An essential role for ectodomain shedding in mammalian development. Science 282 (5392) 1281-1284

Rikitakea Y, Takaia Y (2008): Interactions of the cell adhesion molecule nectin with transmembrane and peripheral membrane proteins for pleiotropic functions. Cell. Mol. Life Sci. $\underline{65} 253-263$

Saftig P, Hartmann D: ADAM10 a major membrane protein ectodomain sheddase involved in regulated intramembrane proteolysis. In: Hooper N M, Lendeckel U (Hrsg.): The ADAM Family of Proteases. Springer, Berlin 2005, 85-121

Sagane K, Hayakawa K, Kai J, Hirohashi T, Takahashi E, Miyamoto N, Ino M, Oki T, Yamazaki K, Nagasu T (2005): Ataxia and peripheral nerve hypomyelination in ADAM22-deficient mice. BMC Neurosci $\underline{6(1)} 33$

Sahin U, Weskamp G, Kelly K, Zhou H M, Higashiyama S, Peschon J, Hartmann D, Saftig P, Bloel C P (2004): Distinct roles for ADAM 10 and ADAM 17 in ectodomain shedding of six EGFR ligands. J. Cell Biol. 164 (5) 769-779

Saiki R K, Gelfand D H, Stoffel S, Scharf S J, Higuchi R, Horn G T, Mullis K B, Erlich H A (1988): Primer-directed enzymatic amplification of DNA with a thermostable DNA polymerase. Science. 239 (4839) 487-491

Sambrook J, Fritsch E F, Maniatis T: Molecular cloning: A Laboratorial manual. Cold Spring Harbor, New York 1989

Shamsadin R, Adham I M, Nayernia K, Heinlein U A, Oberwinkler H, Engel W (1999): Male mice deficient for germ-cell cyritestin are infertile. Biol. Reprod. $\underline{61}$ 1445-1451 


\section{Literaturverzeichnis}

Shi W, Chen H, Sun J, Buckley S, Zhao J, Anderson K D, Williams R G, Warburton D (2003): TACE is required for fetal murine cardiac development and modeling. Dev. Biol. 261 (2) 371380

Smith G D, Wolf D P, Trautman K C, da Cruz e Silva E F, Greengard P, Vijayaraghavan S (1996): Primate sperm contain protein phosphatase 1, a biochemical mediator of motility. Biol. Reprod. 54 (3) 719-727

Snyder S H (2006): Neuroscience. ADAM finds an exciting mate. Science 313 (5794) 1744-1745

Solerac D C, Kadunganattila S, Ramdasa S, Myersa K, Rocac J, Slaughterb T, Pilderb S H, Vijayaraghavan S (2009): Expression of transgenic PPP1CC2 in the testis of Ppp1cc-null mice rescues spermatid viability and spermiation but does not restore normal sperm tail ultrastructure,

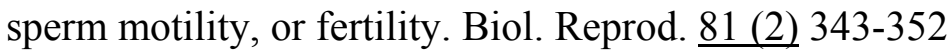

Stein K K, Go J C, Primakoff P, Myles D G: (2005): Defects in the secretory pathway traffickig durig spermdevelopmet in ADAM 2 knockout mice. Biol. Reprod. 73 (5) 1032-1038

Suarez S S, Pacey A A (2006): Sperm transport in the female reproductive tract. Hum. Reprod. Update 12 (1) 23-37

Takashi E, Sagane K, Oki T, Yamazaki K, Nagasu T, Kuromitsu J (2006a): Deficits in spatial learning and motor coordination in ADAM 11-deficient mice. BMC Neuroscience 719

Takashi E, Sagane K, Nagasu T, Kuromitsu J (2006b): Altered nociceptive response in ADAM 11-deficient mice. Brain Res. 1097 (1) 39-42

Tartagni M, Cicinelli E, Schonauer M M, Causio F, Petruzzelli F, Loverro G (2004): Males with subnormla hypo-osmotic swelling test scores have lower pregnancy rates than those with normal scores when ovulation induction and timed intercourse is used as a treatment for mild problems with sperm count, motility, or morphology. J. Androl. $\underline{25}$ 781-783 


\section{Literaturverzeichnis}

Toyama Y, Suzuki-Toyota F, Maekawa M, Ito C, Toshimori K (2008): Disruption of ectoplasmic specializations between Sertoli cells and maturing spermatids by anti-nectin-2 and anti-nectin-3 antibodies. Asian J. Androl. 10 (4) 577-584

Varmuza S, Jurisicova A, Okano K, Hudson J, Boekelheide K, Shipp E B (1999): Spermiogenesis is impaired in mice bearing a targeted mutation in the protein phosphatase 1c gamma gene. Dev. Biol. 205 98-110.

Wassarman P M, Jovine L, Litscher E S (2001): A profile of fertilization in mammals. Nat. Cell Biol. $\underline{3}$ 59-64

Yagami-Hiromasa T, Sato T, Kurisaki T, Kamijo K, Nabeshima Y, Fujisawa-Sehara A (1995): A metalloprotease-disintegrin participating in myoblast fusion. Nature $\underline{377 \text { (6550) } 652-656}$

Zawacka A: Analysis of ADAM 27 protein function during fertilization. M.Sc.-Arbeit Torun 2004

Zhao J, Chen H, Peschon J J, Shi W, Zhang Y, Frank S J, Warburton D (2001): Pulmonary hypoplasia in mice lacking tumor necrosis factor-alpha converting enzyme indicates a indispensable role for cell surface protei shedding during embryonic lung branching morphogenesis. Dev. Biol. 232 (1) 204-218

Zhu G Z, Lin Y, Myles D G, Primakoff P (1999): Identification of four novel four novel ADAMs with potential roles in spermatogenesis and fertilization. Gene $\underline{234}$ 227-237

Zuther K: Molekulargenetische Analysen bei Patienten mit Deletionssyndrom 2q-. Biol. Diplomarbeit Göttingen 2004 


\section{Lebenslauf}

Ich, Christian Baldauf, derzeit wohnhaft Knochenbachstraße 35, 37671 Höxter, wurde am 25.08.1982 in Schmalkalden geboren.

Ich besuchte die staatliche Grundschule Brotterode von September 1989 bis Juni 1993, sowie das Werratalgymnasium Schwallungen von September 1993 bis Juni 2001. Die allgemeine Hochschulreife erwarb ich im Juni 2001.

Meinen Grundwehrdienst leistete ich von Juli 2001 bis März 2002 als Waffeninstandsetzer beim Transportbataillon 10 in Ellwangen.

Hiernach begann ich das Studium der Humanmedizin im April 2002 an der Georg-AugustUniversität Göttingen. Nach dem ersten Abschnitt der ärztlichen Prüfung im März 2004, konnte ich das Medizinstudium erfolgreich mit dem 2. Abschnitt der ärztlichen Prüfung im Juni 2008 abschließen.

Nach Erhalt der Approbation als Arzt arbeite ich seit August 2008 als Assistenzarzt in der urologischen Klinik des St. Ansgar Krankenhauses Höxter.

Meine Dissertationsarbeit begann ich während des Studiums nach dem ersten Abschnitt der ärztlichen Prüfung im Fachbereich Humangenetik. 